\title{
Panic disorder and agoraphobia in daily life
}

Citation for published version (APA):

Dijkman-Caes, C. I. M. (1993). Panic disorder and agoraphobia in daily life. [Doctoral Thesis, Maastricht University]. Rijksuniversiteit Limburg. https://doi.org/10.26481/dis.19931015cd

Document status and date:

Published: 01/01/1993

DOI:

$10.26481 /$ dis. $19931015 \mathrm{~cd}$

Document Version:

Publisher's PDF, also known as Version of record

\section{Please check the document version of this publication:}

- A submitted manuscript is the version of the article upon submission and before peer-review. There can be important differences between the submitted version and the official published version of record.

People interested in the research are advised to contact the author for the final version of the publication, or visit the DOI to the publisher's website.

- The final author version and the galley proof are versions of the publication after peer review.

- The final published version features the final layout of the paper including the volume, issue and page numbers.

Link to publication

\footnotetext{
General rights rights.

- You may freely distribute the URL identifying the publication in the public portal. please follow below link for the End User Agreement:

www.umlib.nl/taverne-license

Take down policy

If you believe that this document breaches copyright please contact us at:

repository@maastrichtuniversity.nl

providing details and we will investigate your claim.
}

Copyright and moral rights for the publications made accessible in the public portal are retained by the authors and/or other copyright owners and it is a condition of accessing publications that users recognise and abide by the legal requirements associated with these

- Users may download and print one copy of any publication from the public portal for the purpose of private study or research.

- You may not further distribute the material or use it for any profit-making activity or commercial gain

If the publication is distributed under the terms of Article $25 \mathrm{fa}$ of the Dutch Copyright Act, indicated by the "Taverne" license above, 
PANIC DISORDER AND AGORAPHOBIA IN DAILY LIFE

PANIEKSTOORNIS EN AGORAFOBIE IN HET DAGELIJKS LEVEN 



\section{PANIC DISORDER AND AGORAPHOBIA IN DAILY LIFE}

\section{PROEFSCHRIFT}

ter verkrijging van de graad van doctor aan de Rijksuniversiteit Limburg te Maastricht, op gezag van de Rector Magnificus, Prof. Mr. M.J. Cohen, volgens het besluit van het College van Dekanen, in het openbaar te verdedigen op vrijdag 15 oktober 1993 om 16.00 uur door

Chantal Irma Mauricette Dijkman-Caes 
promotor: $\quad$ Prof. Dr. M.W. de Vries

co-promotor: Dr. H.F. Kraan

beoordelingscommissie: Prof. Dr. H.M. van Praag (voorzitter)

Prof. Dr. J.J.C.B. Bremer

Prof. Dr. A. Ehlers (Philips Universität Marburg)

Prof. Dr. M.A. van den Hout

Dr. F.J. van Zuuren (Universiteit van Amsterdam)

ISBN: $90-9006338-2$

Technische realisatie: Perion Computer \& Buro Service

met sponsoring van: Ciba-Geigy B.V. 
1.1. Panic Disorder and Agoraphobia

1.2. Epidemiological Significance of Panic Disorder and Agoraphobia 3

1.3. Diagnostic Reliability of Panic Disorder and Agoraphobia 4

1.4. The Relationship between Panic Disorder and Agoraphobia 5

1.5. Agoraphobia Without a History of Panic Disorder 6

1.6. Comorbidity with other disorders 7

1.7. Course, Outcome and Psychosocial Impairment 8

CHAPTER 2 KEY ISSUES IN RESEARCH ON PANIC DISORDER AND AGORAPHOBIA

2.1. Biological Factors 11

2.1.1. genetic and familial factors 11

2.1.2. hyperventilation, hypocapnia and alkalosis $\quad 12$

2.1.3. drug specificity and serotonin deficiency 13

$\begin{array}{ll}\text { 2.1.4. premenstrual anxiety } & 13\end{array}$

2.2. Psychological Factors 15

2.2.1. psychodynamic approaches 15

2.2.2. personality traits and personality disorders 16

2.2.3. conditioning models 17

2.2.4. cognitive models 19

2.3. Microsocial Factors 21.

2.3.1. attachment and early life events 21

2.3.2. life events prior to illness 23

2.3.3. marital relationships 24

2.4. Macrosocial Factors 25

2.4.1. socioeconomic factors 26

2.4.2. stereotypes about femininity 27

2.4.3. the social and cultural meaning of public places 28

2.4.4. the social and cultural meaning of being alone 29

2.4.5. acknowledgement by significant others 32

2.5. Key Issues in Research on Panic Disorder and Agoraphobia 33

2.5.1. individual variation 35

2.5.2. demographic characteristics and associated social roles 35

2.5.3. social anxiety and severity of psychopathology 36

2.5.4. the role of acknowledgement by significant others in agoraphobia 36

2.6. Research Questions 37 
CHAPTER 3 RESEARCH ON PANIC DISORDER AND AGORAPHOBIA IN DAILY LIFE

3.1. Essential Features of Daily Life Research 39

3.1.1. ecological validity 39

3.1.2. prospective data 40

3.2. Methods of Research in Daily Life 41

3.2.1. ambulatory monitoring during behavioral avoidance tests $\quad 41$

3.2.2. self-monitoring in daily diaries $\quad 42$

3.2.3. combinations of diaries and behavioral avoidance tests $\quad 43$

3.2.4. event sampling techniques 43

3.2.5. combinations of event sampling techniques and continuous recordings of psychophysiological responses 44

3.2.6. time sampling techniques 45

3.2.7. combinations of time sampling techniques and continuous recordings of psychophysiological responses 45

3.2.8. combinations of event sampling and time sampling techniques 46

3.3. Responses associated with panic disorder and agoraphobia 46

3.3.1. psychophysiological responses $\quad 47$

3.3.2. cognitive responses 48

3.3.3. behavioral responses 49

3.3.4. desynchrony between response systems 49

3.4. Individual, Situational and Temporal Factors related to Panic 50

3.4.1. characteristics of the individual 50

3.4.2. characteristics of the situational context 51

3.4.3. temporal factors 52

3.5. Discussion 52

CHAPTER 4 EXPERIENCE SAMPLING RESEARCH ON PANIC DISORDER AND AGORAPHOBIA $\quad 57$

4.1. Subjects 57

4.1.1. demographic differences between panic patients with and without agoraphobia, neurotic and normal controls 58

4.1.2. cross-sectional data of panic patients with and without agoraphobia and neurotic controls

4.2. The Experience Sampling Method (ESM) 62

4.3. Instruments and Procedures 63

4.4. Codings for Situations 64

4.5. Data Analysis 65

4.6. Compliance and Reactivity Issues 66

4.6.1. the compliance of psychiatric patients 66

4.6.2. reasons for missing responses 69

4.6.3. deviations from normal daily routine 71

4.6.4. experimental effects 72

4.6.5. task difficulty and impedement 73 
5.1. Measurement and Validity Issues 76

5.1.1. the measurement of symptoms of panic 76

5.1.2. the construction of the ESM panic scale 78

5.1.3. scalability of items related to panic and anxiety 79

5.1.4. aspects of construct validity $\quad 81$

5.2. Panic Experiences in Panic Patients with and without Agoraphobia 84

5.3. Individual Variation 87

5.4. Severity of Psychopathology 88

$\begin{array}{ll}\text { 5.5. Discussion } & 90\end{array}$

CHAPTER 6 TIME ALLOCATION AND AVOIDANCE IN DAILY LIFE 93

6.1. Statistical Analysis of Time Allocation Data 94

6.2. Time Allocation to Different Types of Situations 95

6.2.1. differences in time allocation to different types of situations 95

6.2.2. time allocation to different types of situations after the adjustment for demographic characteristics and missing responses $\quad 96$

6.2.3. discussion 97

6.3. Time Allocation and Acknowledgement by Significant Others 98

6.3.1. differences in acknowledgement by significant others 98

6.3.2. differences in acknowledgement by significant others after the adjustment for demographic characteristics and missing responses

6.3.3. discussion 100

6.4. Time Allocation and Acknowledgement by the Environment 101

6.4.1. differences in acknowledgement by the environment 101

6.4.2. differences in acknowledgement by the environment after the adjustment for demographic characteristics and missing responses

6.5. Time Allocation and Acknowledgement by Activities 103

6.5.1. differences in acknowledgement by activities 103

6.5.2. differences in acknowledgement by activities after the adjustment for demographic characteristics and missing responses 105

6.5.3. discussion 105

6.6. Time Allocation and Severity of Psychopathology 106

6.7. Individual Variations in Time Allocation 108

6.8. General Discussion 108 
CHAPTER 7 THE PREDICTABILITY OF PANIC EXPERIENCES

7.1. Introduction

7.1.1. characteristics of daily life situations

7.1.2. demographic characteristics

7.1.3. panic disorder with and without agoraphobia

7.1.4. temporal factors

7.2. Statistical Analysis

7.3. Results

7.4. Discussion

CHAPTER 8 PANIC DISORDER AND AGORAPHOBIA IN DAILY LIFE: OVERVIEW, CONCLUSIONS AND IMPLICATIONS

8.1. Overview 125

8.2. Conclusions 128

8.2.1. individual variation 128

8.2.2. demographic characteristics and associated social roles $\quad 129$

8.2.3. severity of psychopathology 130

8.2.4. acknowledgement by significant others 131

8.3. Diagnostic, Therapeutic and Research Implications 132

8.3.1. diagnostic implications 132

8.3.2. implications for therapy and prevention 134

8.3.3. research implications 135

$\begin{array}{ll}\text { Summary } & 139\end{array}$

$\begin{array}{ll}\text { Samenvatting } & 141\end{array}$

References 143

$\begin{array}{lll}\text { Appendix } 1 & \text { DSM III(R) diagnostic criteria } & 169\end{array}$

$\begin{array}{lll}\text { Appendix } 2 & \text { ESM report } & 170\end{array}$

$\begin{array}{lll}\text { Appendix } 3 \text { Coding system } & 172\end{array}$

Appendix 4 Interrater agreement on codings for situations 174

$\begin{array}{lll}\text { Appendix } 5 \text { Individualized complaints } & 175\end{array}$

Appendix 6 The predictability of panic experiences: Statistical analysis 177

Dankwoord 182

$\begin{array}{ll}\text { Curriculum vitae } & 179\end{array}$ 


\section{PREFACE}

Research about panic disorder and agoraphobia is important, because a lot of people are suffering from these disorders and the psychosocial impairments that accompany them. A large number of studies have already been carried out on this subject, all concentrating on different isolated aspects of it. Traditional research about panic disorder and agoraphobia failed to take into account the natural physical, social and temporal context in which the behavior occurs. Moreover, these studies described panic disorder and agoraphobia as if they were clear-cut diagnostic entities. In fact, panic disorder and agoraphobia are complex phenomena, and relatively little is known about behavioral aspects of these disorders. After reading the results of many studies, we wondered: 'Where are the people behind this?', 'When do they experience panic symptoms?, 'How do they feel after the panic attack faded away?' and 'How do they actually behave?'.

The aim of the present study was not to solve diagnostic problems about the interrelationship of panic disorder and agoraphobia, neither to identify causes of panic disorder and agoraphobia. Instead, we wanted to describe the daily life experiences of panic patients with and without agoraphobia in all its complexity. The study is an attempt to describe individual variations, variability over time and variability according to the situational context in a systematic way without forgetting the patient, the person behind the disorder. We wanted to investigate the entire individual with all its subjective states in various situations by gathering personalized descriptions of experiences at various randomly choosen moments in daily life.

Experiences of panic patients with and without agoraphobia have been registered by means of a random time sampling technique, called the Experience Sampling Method (ESM). The subjects carried a terminal watch that signaled them on randomly chosen moments during the course of the day. At each signal, the subjects reported where and with whom they were, what they were doing and whether they experienced feelings of anxiety and symptoms of paric.

This dissertation is the result of a first interface between this new sampling technique and old problems. The study avoids reductionism and is based on a more flexible, but also a more complex data set. Puzzling, intruiging and challenging findings will be presented, but more research will be needed to test the generalizability and replicability of the results. Who is hoping for clear cut answers and definite conclusions will be disappointed. Who is able to face complex relationships, incertainties and unanswered questions may learn from it. Much of the work in this volume has to be seen as pioneering in order to find out whether ESM can be applied in research on panic disorder and agoraphobia, what information ESM can add to traditional research, but also what the difficulties and footangles are in this type of research.

These footangles soon became clear. To be honest, gathering data in daily life was found to be troublesome, sometimes impractical, and constantly a potential source of indecipherable noise. Daily life is complex and complex information is difficult to get. Reactivity, compliance and the willingness of patients to report private aspects of daily life are crucial factors in the phase of data gathering. Important choices have to be made about the frequency and timing of measurements. Choosing the right time of measurement, not too often, but often enough to catch important events and fluctuations in symptomatology is 
important. Describing situations by adequate codings is difficult. Many codes are needed for fine-grain analyses of specific events and to study interconnections between symptoms and situations in individual patients. But, these codings have to be collapsed in broader categories in order to describe more general trends at the group level. By doing so, loss of information is inevitable. Of course, statistical analysis was difficult. We were confronted with many variables and a relatively low number of subjects, as a consequence of the effort needed to collect the data. The statistical analyses presented in this volume are therefore by no means definite solutions to important statistical problems. Instead, the statistical models provide a summary of multiple explorative analyses. The method ensures high ecological validity, but in the natural context it is hard to keep potential confounding factors under control: much of the variance can not be explained, because things constantly change. In laboratory settings, many factors can be kept under control. The study of psychological and behavioral responses in the natural environment will always include 'noise', since we cannot experimentally manipulate the natural environment without interrupting normal daily routine.

In chapter 1, we will provide a clear description of the diagnostic features of panic disorder and agoraphobia, their epidemiological significance, their intertelationship, the natural course and outcome, as well as psychosocial impairments and other disorders associated with it. In chapter 2 , we will give an overview of studies on biological, psychological and social factors that are related to panic disorder and agoraphobia. Based on this review, 4 main research issues will be selected:

(1) individual variations in the experience of panic and in the amount of time spent in different types of situations;

(2) the influence of demographic characteristics and associated social roles on daily life variables;

(3) the relationship between daily life measures and the severity of psychopathology;

(4) the role of acknowledgement by significant others in agoraphobia.

Chapter 3 will provide a comprehensive overview of daily life studies on panic disorder and agoraphobia. Advantages and disadvantages of different sampling techniques will be highlighted and the choice of the ESM method will be motivated. Chapter 4 will introduce the method in further detail. Subjects will be described in terms of demographic, diagnostic and cross-sectional data. Data about compliance with ESM and a coding system for describing different types of daily life situations will be presented.

The results of the study will be reported in chapter 5 through 7. The aim of chapter 5 is to describe the experience of panic in daily life. Differences between panic patients with and without agoraphobia in the frequency and severity of panic experiences in daily life will be investigated. In chapter 6 , agoraphobic patients will be compared to panic patients without agoraphobia, neurotic and normal controls in terms of the time they spent in different types of daily life situations. In chapter 7, we will focus on fluctuations in the occurrence of panic experiences in relationship to situational, demographic, diagnostic and temporal factors.

Finally, chapter 8 will provide an overview of the most important issues presented in the previous chapters. General conclusions will be formulated. Diagnostic and therapeutic implications (including preventive measures) as well as implications for future research will be discussed. 
The aim of this introductory chapter is to provide a clear picture of the relationship between panic disorder and agoraphobia. First, a brief introduction to the DSM III(R) definitions of panic disorder and agoraphobia will be given. Next, data about the epidemiological and clinical significance of panic disorder and agoraphobia will be presented. Then some diagnostic problems will be discussed. Data about the reliability of DSM III(R) diagnoses will illustrate that reasons for disagreements between raters often concern the frequency of panic attacks and the severity of agoraphobic avoidance. Evidence will be reviewed in favor of the view that agoraphobia is a secondary stage in the development of paric disorder. Nevertheless, the high prevalence of agoraphobia without (a history of) panic disorder in the general population will urge us to question this perspective. Data about individual variations in the patterning of symptoms, as well as the comorbidity with other disorders will show that the clinical picture of panic disorder and agoraphobia is more complex than the descriptions based on DSM III(R) presented above. Finally, a closer look at longitudinal data about the course and outcome of panic disorder and agoraphobia will complete the picture. Panic disorder and agoraphobia will then be presented as disorders with a chronic and persistent course, that are often associated with marked psychosocial impairments.

\subsection{Panic Disorder and Agoraphobia}

In the 19th century, psychiatry began to focus on anxiety symptoms and disorders. During the American Civil War Da Costa (1871) reported a syndrome in soldiers, the 'irritable heart', referring to a series of symptoms similar to what we now call a panic attack. The same syndrome was later described by other authors as 'soldiers heart', 'effort syndrome' or 'Da Costa syndrome'. Almost at the same time, Westphal (1872) described intense fear of open spaces as 'Agoraphobia'. Benedikt (1870) and Legrand du Saulle (1878) depicted the same phenomenon as 'Platzschwindel' and 'peur des espaces' respectively.

In 1895 Freud suggested to separate 'anxiety neuroses' from neurasthenia and hysteria. At the same time, he classified anxiety disorders in three main categories, namely' anxiety attacks, chronic anxiety and phobias. The psychiatric diagnostic classification system DSM III (A.P.A., 1980) added obsessive compulsive disorders and post-traumatic stress disorders to these categories and regrouped them into three classes of anxiety disorders: (1) Phobic Disorders, including Agoraphobia (with/without panic attacks), Social Phobia and Simple Phobia; (2) Anxiety States, including Panic Disorder, Generalized Anxiety Disorder and Obsessive Compulsive Disorder; and (3) Post-traumatic Stress Disorders. In the revised version, DSM III(R), different degrees of agoraphobic avoidance are classified as subtypes of Panic Disorder. A separate category of agoraphobia without a history of panic disorder is maintained in DSM III(R), although those patients may experience limited symptom attacks. DSM III(R) criteria (APA, 1987) for panic disorder and agoraphobia are given in appendix 1 .

According to DSM III(R), panic disorders are characterized either by repeatedly occurring panic attacks, at least 4 in a 4 week period or by one or more panic attacks followed by a 
period of at least a month of persisting fear of having another attack. Panic attacks are discrete periods of intense apprehension, fear or terror. In a few cases, the attack is not experienced as anxiety, but as an intense feeling of discomfort. The attacks are accompanied by characteristic symptoms, such as shortness of breath or smothering sensations, palpitations or accelerated heart rate, chest pain or discomfort, dizziness, unsteady feelings or faintness, depersonalization or derealization and fear of dying, going crazy or loosing control. Usually, the attacks have a sudden onset and last only a few minutes. Panic disorder can be accompanied by different levels of agoraphobic avoidance.

Agoraphobic situations are described in DSM III(R) as places or situations from which escape might be difficult or embarrassing or in which help might not be available in the event of a panic attack. As a result of this fear, the person either restricts travel or needs a companion when away from home, or else endures agoraphobic situations despite intense anxiety. Common agoraphobic situations include: being alone outside the home, being in a crowd or standing in a line, traveling by bus, train or car, passing tunnels or bridges. An inventory of the most frequently mentioned fears by a group of 35 patients with panic disorder and agoraphobia (table 1.1.) shows that different types of situations are feared and that fear of open spaces is certainly not the most prominent fear in agoraphobia.

\section{table 1.1 .}

The most frequently mentioned fears reported by patients with panic disorder and agoraphobia $(n=35)$. from: Boulenger and Uhde, 1987, p. 123.

$\begin{array}{lc}\text { driving a car } & 54 \% \\ \text { shops, shopping-centres } & 43 \% \\ \text { being alone } & 37 \% \\ \text { being in a crowd, queueing } & 34 \% \\ \text { leaving home } & 34 \% \\ \text { restaurants, escalators } & 29 \% \\ \text { doctors, dentists } & 29 \% \\ \text { being locked up } & 23 \% \\ \text { bridges, tunnels } & 20 \% \\ \text { meetings, coming across strangers } & 20 \% \\ \text { public transport } & 17 \% \\ \text { traveling by plane } & 14 \% \\ \text { heights } & 14 \% \\ \text { open or empty spaces } & 6 \%\end{array}$

Most agoraphobic patients feel better in the presence of a trusted companion. For some individuals comfort may be experienced in the presence of a pet or with certain objects, like the grip of an umbrella, shopping baskets on wheels, a bicycle to push rather than to ride or a telephone close by to call a trusted person (Marks, 1970). Agoraphobia can put a heavy burden on the family. Sometimes, the affected person may be unable to go out unaccompanied and may become housebound. In severe cases, patients may not be able to stay at home alone and a constant companion is required. Some authors (e.g., Chambless, 
1982), therefore, describe agoraphobia as fear of being away from home and away from familiarity instead of fear of being alone or being in public places.

\subsection{Epidemiological Significance of Panic Disorder and Agoraphobia}

Epidemiological studies indicate that anxiety disorders are among the most prevalent mental disorders in the general population. Both the NIMH Epidemiological Catchment Area Program (ECA; Regier et al., 1984; Eaton and Kessler, 1985) and the Munich Follow-up Study (Wittchen and von Zerssen, 1988) used the NIMH Diagnostic Interview Schedule (DIS, Robins et al., 1981) to estimate the prevalence of anxiety disorders in the general population. Lifetime prevalences of DSM III anxiety disorders between 10.3 and $13.9 \%$ and six month prevalence rates of 7.6 through $8.1 \%$ have been reported (Wittchen, 1986). According to these studies, simple phobia and agoraphobia had the highest lifetime and 6 months prevalence rates. The prevalence of agoraphobia varied between 3.5 and $5.7 \%$ lifetime and the six month prevalence between 2.7 and $3.6 \%$. The prevalence of panic disorder appeared to be significantly lower, the lifetime prevalence ranged from 1.4 to $2.4 \%$ and the six month prevalence from 0.6 to $1.1 \%$. Similar prevalence rates were reported in several studies (for an overview, see: Humble, 1987).

Both agoraphobia and panic disorder occur more frequently in women. In the Munich Follow-up Study, the lifetime prevalence of panic disorder was $1.7 \%$ in men and $2.9 \%$ in women and that of agoraphobia $2.9 \%$ in men and $8.3 \%$ in women (Wittchen, 1986). According to DSM III(R) (A.P.A., 1987), in clinical samples panic disorder without agoraphobia is about equally common in males and females, while panic disorder with agoraphobia is about twice as common in females than in males. Theories about sex differences in the prevalence of panic disorder and agoraphobia will be discussed in chapter 2 .

Panic disorder and agoraphobia often require treatment. Past panic disorders (patients meeting DSM III criteria for panic disorder but not having panic attacks for at lcast one month) have been found in $7.3 \%$ of the primary care patients, while current panic disorders were found in 13.3\% (Katon, 1986; Katon et al., 1986, 1987). Moreover, another $9.7 \%$ of these patients reported less frequent panic attacks (less than 3 times in a three week period) in the past and $8.7 \%$ currently. Panic patients were further found to have significantly elevated numbers of medical and emergy room visits (Markowitz et al., 1989; Siegel et al., 1990). In the Munich Follow-up Study, a majority of cases with panic disorder and/or agoraphobia had a significantly elevated number of visits to general health services (Wittchen, 1988). In the ECA study, panic disordered subjects were among the most heavy users of mental health services (Boyd, 1986).

Panic altacks seem to be an important reason to seek treatment, since persons with other disorders and panic attacks were more likely to use mental health services than persons with other disorders without panic attacks. Agoraphobic subjects, on the other hand, were significantly more likely to use mental health services than subjects with other phobias and agoraphobic subjects with panic attacks were found to seek more often mental health treatment than agoraphobic subjects without panic attacks (Thompson et al., 1988). Nevertheless, agoraphobia and panic do not always lead to health care visits. A large percentage (73\%) of the agoraphobic persons in the ECA study did not seek treatment for a mental health reason in the past 6 months, and $29 \%$ of the agoraphobic cases did not use any 
health service for any reason during this period. Even from the cases with agoraphobia and panic attacks, only half of the patients sought treatment for a mental heaith care reason, and $18 \%$ of the subjects did not use any health service for any reason during a 6 month period (Thompson et al., 1988).

Panic disorder and agoraphobia are thus epidemiologically significant disorders that often require treatment, although not all patients will mention mental health problems. Patients may seek treatment for a variety of physical or psychiatric symptoms. Differences between epidemiological data from mental health care settings and data gathered in the general population will be addressed further in section 1.5. The comorbidity of panic disorder and agoraphobia with other psychiatric disorders and symptoms will be discussed in section 1.6 .

\subsection{Diagnostic Reliability of Panic Disorder and Agoraphobia}

Research about the diagnostic reliability mainly concerns the DSM III classification system. Although the classification of agoraphobia as a subtype of panic disorder is probably an improvement, the critiques of DSM III remain for the revised DSM III(R). The comorbidity of DSM III disorders is generally high: the presence of a DIS disorder increases the odds of having almost any other DIS disorder (Boyd et al., 1984). One or more additional diagnoses could be assigned to $89 \%$ of the patients with panic disorder and to $52 \%$ of the agoraphobic patients (Barlow, 1985). Barlow (1985) compared the current DSM III diagnoses assigned by 2 experienced clinicians using a structured interview schedule (ADIS; diNardo et al., 1983) in a sample of patients admitted to an anxiety clinic. In this study, the interrater agreement about the primary diagnosis was found to be higher in agoraphobia (kappa $=.85)$ than in panic disorder $(\mathrm{kappa}=.65)$. In a more heterogeneous sample, the interrater agreement between lay interviewers and psychiatrists using the DIS was computed and much lower kappas of lifetime DSM III diagnoses were found: .67 for agoraphobia and only .40 for panic disorder (Robins et al., 1981).

In a recent study about the reliability of DSM III(R) anxiety disorders, lifetime diagnoses were included (Mannuza et al., 1989). The interrater kappa for a lifetime diagnosis of agoraphobia was .81 and for panic disorder .67. When panic and agoraphobia were conceptualized as a continuum ranging from panic disorder without agoraphobia to panic disorder with extensive agoraphobic avoidance, the two extremes could be diagnosed more reliably than the midrange with limited avoidance. Here again, reliability may be overestimated since the sample consisted of former and present patients of an anxiety clinic, and consequently the range of possible symptoms is smaller than in the general population. Mannuza et al. (1989) also investigated the reasons for disagreement between raters. Variance in subject reports accounted for about half of the discrepancies. In these cases, information about symptoms, the frequency and duration of panic altacks, the nature of agoraphobic avoidance and the onset of the disorder was either minimized, denied or distorted. All disagreements about a diagnosis of agoraphobia resulted from variance in reporting on the extent of avoidance. Some subjects reported extensive avoidance of multiple situations to one rater and mentioned only one or two situations to the other. Disagreements between raters about the frequency of panic attacks and the severity of agoraphobic avoidance pose an important diagnostic problem, since they may interfere with our ability to evaluate the relationship between panic disorder and agoraphobia. 


\subsection{The Relationship between Panic Disorder and Agoraphobia}

The idea that panic disorder can be regarded as the first stage of a multistage disorder culminating in agoraphobia was offered by Klein (KJein, 1980, Klein \& Gorham, 1987). According to Klein's model, the illness starts with the sudden appearance of spontaneous panic attacks without any specific phobic stimuli. Spontaneous panic attacks at first lead to help-seeking behavior. After recurrent panic attacks, the patients develop anticipatory anxiety, chronic tension and increasing autonomic distress. Then, after developing high levels of chronic anxiety in between panic attacks, the patients begin to display avoidant and dependent behaviors. They reduce their activities outside the home and ask for companionship, because they believe that this will decrease the likelihood of a new panic attack. They not only start to avoid situations in which panic occurred previously, but also situations in which help might not be available in case of panic. Yet, Klein and Gorham (1987) do point out that the course of illness is variable: some patients have panic attacks but never develop high levels of chronic anxiety, some avoid only airplanes or elevators, while others develop agoraphobic behavior but never seem to have full-blown panic attacks.

Research evidence pointing at the similarity between panic disorder and agoraphobia with panic attacks supports Klein's assumptions. Tumer et al. (1986a) studied the covariation of panic symptoms and agoraphobic fear in both panic disorder and agoraphobia with panic attacks by means of a panic index and an agoraphobia index based on the Fear Survey Schedule and the SCL-90. High correlations between panic and agoraphobic fear were found irrespective of diagnoses. The panic patients indeed tended to report more panic and milder agoraphobic fears, but there was a large overlap between both groups. No significant differences were found between panic patients with and without agoraphobia in the severity and frequency of panic attacks (Ganellen et al., 1986; Craske et al., 1987a; Rapee \& Murrell, 1988; Fleming \& Faulk, 1989). In general, few differences were found on multiple psychometric variables and on indices of clinical illness between panic disordered and agoraphobic patients (Garvey \& Tuason, 1984, Thyer et al., 1985; Cameron et al., 1986a; Noyes et al., 1987; Faravelli et al., 1988; Fleming \& Faulk, 1989).

Further evidence for Klein's assumptions is found in studies about the course of illness in panic disorder and agoraphobia. Agoraphobic avoidance was found to be preceded by at least one panic attack in more than $90 \%$ of the patients with panic disorder and agoraphobia (Boulenger \& Uhde, 1987). Uhde et al. (1985) reported that $97 \%$ of the agoraphobic patients developed avoidance behaviors within six months after their first panic attack. Aronson and Logue (1987) registered a gradual onset of agoraphobia after the onset of panic attacks in $69 \%$ of the panic patients, while in $25 \%$ of the patients panic and agoraphobia almost started simultaneously. In another study, $58 \%$ of the agoraphobic patients reported a simultaneous onset of panic and agoraphobia, in $11 \%$ of the cases agoraphobia developed within 4 weeks after the onset of panic and in $27 \%$ a longer period of time (between 20 weeks and 9 years) was recorded (de Ruiter et al., 1987). On the other hand, there are also studies indicating that agoraphobic avoidance may precede the onset of panic. Lelliott \& Marks (1988) registered a simultaneous onset of panic attacks and agoraphobic avoidance in $33 \%$ and panic preceding agoraphobia in $49 \%$ of the patients, but they also identified cases with avoidance of agoraphobic situations before the onset of panic (18\%). In a study by Fava et al. (1988), 18 out of 20 agoraphobic patients reported at least one symptom of agoraphobia before the onset of panic. In a recent study about the 
course of panic disorder and agoraphobia in the general population, the onset of panic disorder preceded the onset of agoraphobia in only $20 \%$ of the subjects with panic disorder and agoraphobia; $33 \%$ of the cases developed panic disorder and agoraphobia within the same year; and agoraphobia preceded the onset of panic disorder in $47 \%$ of the cases (Thompson et al., 1989).

Panic disorder and agoraphobia are clearly interrelated disorders. Data from clinical settings indicate that agoraphobia is in most cases a secondary though not necessary stage of panic disorder. In clinical samples, agoraphobic avoidance was reported by 60 to $85 \%$ of the panic patients (Uhde et al., 1985b; Aronson \& Logue, 1987; Mellman \& Uhde, 1987). When we take a closer look at the prevalence of agoraphobia without (a history of) panic disorder in the general population, a different picture emerges.

\subsection{Agoraphobia Without a History of Panic Disorder}

Studies about panic disorder and agoraphobia in clinical settings often suggest that all patients with agoraphobia also have panic attacks. Low incidence rates of agoraphobia without a history of panic disorder in mental health care settings have been reported in several studies (diNardo et al., 1983; Garvey \& Tuason, 1984; Tumer et al., 1986a). According to DSM III(R), most agoraphobics without a history of panic disorder do experience limited symptom attacks. In the few cases of agoraphobia without panic attacks identified in mental health care settings either limited symptom attacks or other physical complaints with an unpredictable or spasmodic nature as a functional equivalent of panic attacks have been noted (Thyer et al., 1985).

Epidemiological studies in the general population provide a totally different picture. Since some studies were based on DSM III classifications and combined agoraphobia with and without panic attacks into a single category, it is often not possible to estimate the prevalence of agoraphobia without a history of panic disorder. It is, however, a consistent finding that prevalence rates of panic disorder are much lower than prevalence rates of agoraphobia in the general population (section 1.2). These findings can be explained in two ways. Most of the studies rely on retrospective information and sometimes suffer from serious methodological drawbacks (for a discussion on methodological problems in epidemiological research, see: Wittchen, 1988). The reliability of retrospective information (sometimes collected by non-clinicians) about the possible occurrence of panic attacks in the past can be questioned (see also section 1.3). Another reason for discrepancies between data from clinical settings and data gathered in the general population might be that agoraphobic subjects without (a history of) panic disorder less often seek treatment. The cooccurrence of paric attacks with a lot of physical symptoms may be a more urgent reason to ask for medical treatment (Boyd, 1986; Thompson et al., 1988; section 1.2).

Recent findings denote that agoraphobia without panic attacks or panic disorder are much more prevalent in the general population than clinical impressions may suggest. In the Munich Follow-up Study, the comorbidity of panic disorder and agoraphobia was investigated in subjects with untreated anxiety disorders and more cases of agoraphobia without panic attacks or without panic disorder were identified than cases with panic attacks or panic disorder (Wittchen, 1988). According to Wittchen (1986), only $16 \%$ of the agoraphobic subjects met DSM III criteria for panic disorder and another $25 \%$ reported infrequent 
panic attacks (less than 3 in a 3 week period). In the Zurich study, the prevalence of anxiety disorders was estimated in a population of young adults. Here again, cases of agoraphobia without panic disorder occurred more frequently than cases with panic disorder (Angst \& Dobler-Mikola, 1986). The current prevalence rate was 0.7 for agoraphobia with panic attacks and 1.5 for agoraphobia without panic attacks (Angst \& Dobler-Mikola, 1985). In the New Haven ECA site, the six month prevalence rate was $2.9 \%$ for agoraphobia with no history of panic disorder and $0.3 \%$ for agoraphobia with panic disorder. Yet, 47\% of the agoraphobic subjects without a history of panic disorder did experience some panic symptoms, mostly infrequent or minor attacks (Weissman \& Merinkagas, 1986). The group of agoraphobic subjects with panic disorder included the smallest percentages of agoraphobics in all ECA sites. The range of subjects with agoraphobia and panic disorder varied between 6 and 13\%, with pure agoraphobia between 23 and 53\%, with agoraphobia and panic symptoms between 17 and $50 \%$ and with agoraphobia and other disorders between 17 and 28\% (Weissman et al., 1986). In a community study in Canada, a majority of cases with a lifetime diagnosis of agoraphobia ( $85 \%$ ) occurred in the: absence of panic disorder. Moreover, all the cases with agoraphobia and panic disorder also had a lifetime diagnosis of depression (Thompson et al., 1989).

Agoraphobia is thus not always a secondary stage of panic disorder. Data gathered in the general population demonstrate that agoraphobia without (a history of) panic disorder is much more prevalent than panic disorder with agoraphobia. Furthermore, these data indicate that agoraphobia often co-exists with minor or infrequent panic attacks and with other disorders. Therefore, comorbidity issues will be adressed in the following section.

\subsection{Comorbidity with other disorders}

Symptoms of panic not only occur in patients meeting DSM III(R) criteria of panic disorder. Infrequent panic attacks were found to be rather common in normals (Norton et al., 1985, 1986; Margraf \& Ehlers, 1988; Brown \& Cash, 1989) and to occur in a high percentage of all anxiety patients (Boyd, 1986; Barlow et al., 1985). Only when the frequency criterion was included, differences between panic patients and other anxiety patients emerged (Barlow et al., 1985).

On the other hand, panic patients with and without agoraphobia often display a variety of symptoms and/or comorbid disorders. Aronson \& Logue (1987), for instance, registered persistent generalized anxiety in $70 \%$, current or past major depression in $52 \%$, alcohol abuse in $17 \%$ and substance abuse in $10 \%$ of the panic patients. In another study, obsessive compulsive symptoms were reported in $27 \%$ of the cases with panic disorder (Mellman \& Uhde, 1987). Furthermore, panic patients and especially panic patients with agoraphobia often reported symptoms of somatization disorder, hypochondriasis, blood injury and fears of illness and death (Buglass et al., 1977; Arrindell, 1980; King et al., 1986; Fava et al., 1988).

Comorbidity with social fears was also found to be common in panic disorder and agoraphobia. Patients with panic disorder and/or agoraphobia received relatively often (estimates range from 9 to $35 \%$ of the cases) an additional diagnosis of social phobia (Barlow et al., 1986; di Nardo \& Barlow, 1990). Panic patients and agoraphobic patients reported fears of being observed in $49 \%$, concerns about humiliation in $31 \%$ and avoidance in $28 \%$ 
of the cases (Rapee et al., 1988). Similar findings were reported in other studies. In a Dutch sample of anxiety patients, an additional diagnosis of social phobia was assigned to $11 \%$ of the panic patients with agoraphobia (de Ruiter et al., 1989a). Stein et al. (1989a), on the other hand, found that $46 \%$ of a sample of panic disordered patients met DSM III criteria for social phobia. According to psychiatrists ratings, 55\% of a sample of agoraphobic patients suffered from clinically significant social phobias and $30 \%$ of the social phobics from clinically significant agoraphobic symptoms (Solyom et al., 1986).

High comorbidity rates were further demonstrated in the general population. In the $\mathrm{Mu}$ nich Follow-up Study (Wittchen, 1988), large proportions of cases with panic disorder and agoraphobia met the criteria for affective disorders (major depression or dysthymia; $71 \%$ in panic disorder, $65 \%$ in agoraphobia), for medication abuse $(28 \%$ in panic disorder, $23 \%$ in agoraphobia) and for alcohol abuse (50\% in panic disorder, $23 \%$ in agoraphobia).

In general, comorbidity refers to the co-existence of different disorders (or at least of different types of symptoms) in an individual at a specific point in time. Nevertheless, different symptoms and disorders are not necessarily simultaneously present, but may also follow each other in time. Retrospective studies about the longitudinal course of panic disorder demonstrated large individual variations in patterns and sequences of symptoms. Breier et al. (1986) found generalized anxiety disorders in $80 \%$, major depression in $70 \%$, alcoholism in $17 \%$ and obsessive compulsive syndromes in $17 \%$ of the symptom histories of agoraphobic patients.

These findings point at a particularly important diagnostic problem: after years of illness panic patients can be classified into different diagnostic calegories, such as agoraphobia without panic attacks, generalized anxiety disorders, affective disorders, obsessive compulsive disorders, somatoform disorders, social phobias or substance abuse. Large individual variations in the patterning and sequence of symptoms can be expected. In the following section, evidence about the severity of illness and the amount of impairment in daily life will be presented.

\subsection{Course, Outcome and Psychosocial Impairment}

Clinical descriptions often suggest that the severity of agoraphobia fluctuates over time (Marks, 1970; Chambless, 1982). Buglass et al. (1977) found marked variability in agoraphobic complaints within one month. In a large survey of agoraphobic subjects, $90 \%$ of the respondents said their agoraphobic complaints fluctuated on a day-to-day basis (Thorpe \& Bums, 1983). Similar variations in the occurrence of panic attacks in panic patients have been described (Barlow, 1988). Nevertheless, complete remissions without treatment seem to be rare. In the study by Breier et al. (1986), symptoms of panic, agoraphobia, anticipatory and generalized anxiety were found to be chronic and unremitting in agoraphobic patients in contrast to the episodic nature of symptoms of depression. In another survey of 1200 agoraphobics, $80 \%$ of the subjects reported that they never had symptom-free periods (Marks \& Herst, 1970). Longitudinal data from the Munich Follow-up Study about the course and outcome of anxiety disorders indicated that the most frequent pattern of symptom course in panic disorder and agoraphobia is chronic and persistent (Krieg et al., 1987; Wittchen, 1988). In this study, only a few cases with anxiety disorders had an episodic course with almost symptom-free intervals over a period of more than 6 months. 
Impairment of work is common in panic disorder and particularly in agoraphobia. In a survey of subjects with panic attacks, 38\% reported that they lost or had quit a job after the onset of panic, and $7 \%$ of the subjects reported that this was caused by the panic attacks (Siegel et al., 1990). In this study, full time workers with panic attacks reported twice as many work days lost than full time workers in the general population. In the survey by Thorpe and Bums (1983), the inability to work was significantly more often reported by male $(75 \%)$ than by female agoraphobics $(41 \%)$. In a community study of young adults (the Zurich study), $18 \%$ of the agoraphobic subjects reported absence from work and/or loss of job as a consequence of agoraphobia (Angst \& Dobler-Mikola, 1985). Panic disorder was further found to be associated with an increased risk of being financially dependent (Markowitz et al., 1989).

The severity of illness is further reflected in a higher risk for suicidal ideation and suicide attempts. In a large sample drawn from the ECA study, $20 \%$ of the subjects with panic disorder and $12 \%$ of the cases with panic attacks made suicide attempts at some time in their life (Markowitz et al., 1989; Weissman et al., 1989). Although the risk of suicide attempts was much higher in panic patients with comorbid disorders (26\%) than in patients with uncomplicated panic disorder (7\%), the risk was significantly higher in patients with uncomplicated panic disorder than in subjects with no disorder and comparable to the risk observed in patients with uncomplicated major depression (Johnson et al., 1990).

Impairments of leisure activities, social contacts and marital relationships were also often reported by subjects with panic disorder (Markowitz et al., 1989) and agoraphobia (Thorpe and Bums, 1983; Angst \& Dobler-Mikola, 1985). Cross-sectional evaluations of social role behaviors in the Munich Follow-up Study demonstrated marked impairment in different social role areas, such as work, the interaction with the partner and restrictions in leisure time. Cases with panic disorder and agoraphobia were rated by clinicians as more severely impaired than other anxiety disorders (Wittchen, 1988). Buglass et al. (1977), on the other hand, found few differences between agoraphobic women and normal controls in domestic activities: Agoraphobic women only did less shopping than the normal controls. Neither were there any differences between agoraphobics and normals in the number of social contacts with family or friends, but the agoraphobic patients scored lower on measures of social range and social integration, including participation in large groups.

In summary, panic disorder and agoraphobia are epidemiologically significant disorders that are closely interrelated. Agoraphobia often develops after the onset of panic disonder. but agoraphobia is certainly not an inevitable consequence of panic disorder. Different patterns and sequences of symptoms are evident. Studies about the comorbidity of anxiety disorders, depression and substance abuse provide a totally different picture than the pure types described in DSM MI(R). Like Perugi et al. (1988a), we can conclude that panic patients display 'various clinical manifestations with variations of acute anxiety, diffuse anxiety, phobic anxiety, social phobia, agoraphobia, hypochondriasis and depressive symptomatology in various mixed pattems'. Moreover, panic disorder and agoraphobia are associated with varying degrees of constrictions in life style. DSM IHI(N) diagnoses tell us little about how disorders and symptoms are experienced and lived in their natural context. Daily life studies assessing experiences, symptoms and behavior in the natural environment then may be a better way to uncover variations between and within subjects. 


\section{CHAPTER 2 KEY ISSUES IN RESEARCH ON PANIC DISORDER AND AGORA-}

PHOBIA

In chapter 1, the relationship between panic disorder and agoraphobia has been described. Almost all agoraphobic patients in health care settings experience panic attacks and the first panic attack often preceeds the onset of agoraphobia. Still, it is clear that not every panic patient will become agoraphobic in the long run. In spite of a massive body of research, relatively little is known about factors related to the onset and maintenance of agoraphobia in panic patients. In the present chapter, we will provide an overview of studies on biological, psychological and social factors that have been related to the onset and maintenance of panic disorder and agoraphobia. To give an exhaustive review of the literature lies beyond the purpose of this discourse. Instead, the most important findings will be summarized. The major goal of this review is to demonstrate that several factors have been identified that are related to panic disorder, but also that only few differences were found between panic patients with and without agoraphobia. Based on this review, a number of key issues will be selected that will be explored further in the present study.

\subsection{Biological Factors}

The search for biological mechanisms underlying anxiety and particularly panic has been strongly stimulated by the work of Donald Klein and his group. Klein (1980) stated that spontaneous panic attacks are qualitatively different from other types of anxicty in that they are due to biological dysfunctions. Since then, a whole range of biological ex planations of paric have been offered.

\subsection{1. genetic and familial factors}

Some family and twin studies suggested the existence of a genetic factor for panic anxiety, that is independent from other (anxiety) disorders (Crowe et al., 1983; Torgersen, 1983). The morbidity risk for panic disorder was found to be increased among the relatives of both agoraphobic and panic patients; but the morbidity risk for agoraphobia was. only increased among the relatives of agoraphobics and not among the relatives of panic patients (Noyes et al., 1986; Gruppo Italiano Disturbi d'Ansia, 1989). Other findings indicated that the comorbidity of major depression and anxiety disorders increases the risk for major depression and anxiety disorders in relatives (Leckman et a.l., 1983a). Particularly the comorbidity of major depression and panic disorder should increase the risk for a variety of disorders in relatives: panic disorder and major depression, but also phobias and alcoholism (Leckman et al., 1983b). In a recent twin study, however, a relationship was found between major depression and mixed anxiety depression (with or without panic attacks), but not between pure anxiety disorders and (mixed) major depression (Torgersen, 1990). In relatives of agoraphobic patients, high prevalence rates of affective disorders and alcoholism have been reported (Munjack \& Moss, 1981). Moreover, the increased risk seems to affect male and female relatives in different ways. The risk of having an anxiety disorder was found to be $34 \%$ in female siblings of agoraphobic patients, while $31 \%$ of the male relatives developed alcohol dependence or abuse (Noyes et al., 1986). 
Sex differences in the prevalence of agoraphobia and alcoholism can be related to cultural factors. D. Chambless (1982) suggested that a large number of male agoraphobics are to be found not in phobia wards, but in bars, Alcoholics Anonymous and alcoholism treatment centres. Evidence about the prevalence of panic attacks and agoraphobic fears in alcoholics and the prevalence of alcohol abuse in panic disordered and agoraphobic patients indicated that panic and agoraphobia inceed may be frequently masked by alcohol abuse and that alcohol is often used as self-medication (for a review, see: Cox et al., 1990).

In summary, some evidence for familial risks of panic disorder and agoraphobia was found. But the interrelationship with risks for other anxiety disorders, major depression and alcoholism is not clear yet. Neither is it evident that familial links in panic disorder are due to genetic factors, since adoption studies are lacking. At the microsocial level, concurrent explanations about patterns of familial interaction will be offered (section 2.3.1.). Differences in response style between men and women with agoraphobic fears may further reflect cultural influences (section 2.4.).

\subsection{2. hyperventilation, hypocapnia and alkalosis}

Panic attacks can be provoked by the infusion of sodium lactate (Pitts \& McClure, 1967; Liebowitz et al., 1984, 1985) and the inhalation of 35\% carbon dioxide (Griez \& van den Hout, 1984). A majority of panic patients react with panic to the infusion of sodium lactate and the inhalation of carbon dioxide, while only a minority of normal subjects and non-panic patients do so (for an overview: Ehlers et al., 1986a; van den Hout, 1988). Inhalation of carbon dioxide provokes somatic sensations that are similar to DSM III symptoms of panic attacks not only in panic patients, but also in normal subjects (van den Hout \& Griez, 1984). Panic patients experience a significant increase in subjective anxiety after the inhalation of carbon dioxide. Normal subjects and non-panic patients, on the other hand, did not report the same increase in subjective anxiety (Griez \& van den Hout, 1982; van den Hout \& Griez, 1982a; Griez et al., 1987; van den Hout et al., 1987a; Griez et al., 1990). The specific effect of panic induction procedures in panic patients led to the assumption that panic patients suffer from physiological abnormalities in the acid-base balance.

Other evidence for acid-base changes underlying panic is found in the similarity between panic disorder and the hyperventilation syndrome. Panic disorders (with and without agoraphobia) and hyperventilation syndromes often co-exist (Garssen et al., 1983; Hoes et al., 1987; de Ruiter et al., 1989b). Sodium lactate infusions and hyperventilation both result in hypocapnia and alkalosis (Garssen et al., 1983; Liebowitz et al., 1985). Carbon dioxide inhalation at first results in hypercapnia, but then through a violent stimulation of the chemoregulatory system leads to increased ventilation and a rapid fall in alveolar $\mathrm{CO}_{2}$ resulting in a hypocapnic 'overshoot' (van den Hout \& Griez, 1985). Physiological changes, however, do not sufficiently explain the results of panic induction studies. Hyperventilation, lactate and carbon dioxide all produce hypocapnia and alkalosis. Still, hyperventilation has been found to produce physical discomfort, but only little subjective anxiety (Gorman et al., 1984; Rapee, 1986). Moreover, panic symptoms induced by carbon dioxide inhalation occur before the hypocapnic overshoot (van den Hout \& Griez, 1985). And finally, subjective anxiety occurs also after $5 \%$ carbon dioxide inhalation, which does not induce hypocapnia and alkalosis (Gorman et al., 1984; Woods et al., 1986). 
Furthermore, it is important to note that panic patients with and without agoraphobia react in the same way to the experimental induction of panic. Most of the panic induction studies included both panic patients with and without agoraphobia. No differences between panic patients with and without agoraphobia have been reported. Liebowitz et al. (1984) explicitly stated that they found no differences between panic patients with and without agoraphobia in the number of patients who panicked after lactate infusion, neither in the mean duration between lactate administration and panic. Therefore, it seems unlikely that different physiological abnormalities are involved in panic disorder with and without agoraphobia.

In summary, panic induction studies demonstrated that lactate infusion and carbon dioxide inhalation provoke panic in panic patients, but not in normals and non-panic controls. $\mathrm{Pa}$ nic induction results in symptoms that are similar to those occurring during natural panic, both in panic patients and in controls, but panic patients report more subjective anxiety. Until now no specific biological mechanisms have been identified that sufficiently explain the results of panic induction studies. Concurrent cognitive explanations have to be taken into account (section 2.2.4.).

\subsection{3. drug specificity and serotonin deficiency}

Drug therapy studies showed that panic patients react favorably to tricyclic antidepressants (for an overview: Lydiard \& Ballenger, 1988). Imipramine was found to be effective in the treatment of panic disorder, even in the absence of depression (Sheehan et al., 1980; Zitrin et al., 1980; Mavissakalian, 1987a). Tricyclic antidepressants not only reduce panic symptoms, but are also effective in the treatment of agoraphobia. Several studies demonstrated that a combined treatment of imipramine and exposure is superior to exposure only (Zitrin et al., 1980, 1983; Telch et al., 1985; Klein et al., 1987). Most studies indicated that imipramine and exposure have a mutually potentiating effect in the treatment of panic disorder with agoraphobia (for a discussion on this topic: Mavissakalian, 1988).

The assumption that antidepressants specifically treat panic and that benzodiazepines are better suited to treat other types of anxiety has not been supported by empirical evidence. Imipramine was indeed more effective in the treatment of phobic patients with panic attacks than in non-panicking (simple) phobics (Sheehan et al., 1980; Zitrin et al., 1983). Yet, tricyclic antidepressants also reduce generalized anxiety and obsessive compulsive symptoms in non-panic patients (for a review, see: Modigh, 1987; den Boer, 1988). Moreover, benzodiazepines, particularly alprazolam, are also effective in the treatment of panic anxiety (for a review, see: Pollack \& Rosenbaum, 1988; Ballenger, 1990). And finally, the fact that both depressed and panic patients respond to tricyclic antidepressants has raised many questions about the relationship between panic disorder and major depression (for a review, see: Lesser, 1988).

Drug treatment studies indicated that neurotransmittors play an important role in panic disorder. Tricyclic antidepressants and MAO inhibitors are effective in the treatment of panic and have an effect both on the serotonergic and the noradrenergic system. Most evidence suggests that serotonergic neurotransmission is involved in panic. Tricyclic antidepressants and MAO inhibitors enhance the activity in serotonin synapsis in the brain, either by increasing the responsiveness of post-synaptic serotonin receptors or by decreasing the sensi- 
tivity of serotonin autoreceptors, that normally exert an inhibitory influence on the presynaptic serotonin neuron (Eriksson, 1987; den Boer, 1988). Fluvoxamine, a specific inhibitor of the presynaptic uptake of serotonin having little effect on noradrenergic receptors, reduces anxiety symptoms and panic attacks in anxiety patients (den Boer et al., 1987). On the other hand, maprotiline, a specific noradrenaline uptake inhibitor was ineffective in the treatment of panic patients (den Boer \& Westenberg, 1988). There is also evidence that the administration of the serotonin precursor 5-HTP prevents panic attacks (Kahn \& Westenberg, 1985). And finally, it has been argued that benzodiazepines, such as alprazolam also affect serotonergic neurotransmission (for a discussion about the mode of action of alprazolam; see: Erickson, 1987).

In summary, drug treatment studies indicated that serotonergic pathways are implicated in the pathophysiology of panic disorder, but the exact nature of the dysfunction at the receptor level is not clear yet. Biological differences between panic patients with and without agoraphobia seem unlikely. Neither is it legitimate to conclude that biological abnormalities cause panic disorder. Research evidence about conditioning and cognitive factors (section 2.2.3. and 2.2.4.) indicate that both biological and psychological factors play an important role in panic disorder.

\subsection{4. premenstrual anxiety}

Most of the theories about biological factors in panic disorder and agoraphobia do not explain sex differences in the prevalence of agoraphobia. The only hypothesis accounting for specific biological vulnerabilities in women relates anxiety to the menstrual cycle. Women often. report anxiety and negative moods in the premenstrual phase (Asso, 1986). Moreover, panic symptoms appear to get worse during the premenstrual phase. About half of a female agoraphobic sample reported more anxiety premenstrually, and $30 \%$ reported an increase in the number of panic attacks (Breier et al., 1986). In another study, 39\% of the agoraphobic women having a menstrual cycle experienced exacerbations of agoraphobic complaints premenstrually, yet there was no difference in the magnitude of these premenstrual variations and those occurring at other times during the menstrual cycle (Buglass et al., 1977). Furthermore, it was hypothesized that women are more readily conditioned in the premenstrual phase. Van der Molen et al. (1988) found that premenstrual women tended to have an enhanced susceptibility to the acquisition of fear. In a study using a clear definition of menstrual phases and controls for expectancy effects and oral contraception use, however, no differences in conditionability were found between premenstrual and intermenstrual women, although there was a trend for women to be more responsive than men (Hedlund \& Chambless, 1990).

Nor the nature neither the etiology of menstrually related syndromes is clear. Most studies suffer from serious methodological drawbacks (Rubinow \& Roy-Byme, 1984). Prospective studies showed that premenstrual negative moods may be overrepresented in retrospective reports (Rubinow et al., 1984, Cameron et al., 1987, 1988; Stein et al., 1989b). Ratings of mood in daily life challenge previous findings about premenstrual mood changes. Daily self-reports of symptoms and mood indicated that normal women experience more physical symptoms, but no significant changes in mood during the premenstrual and menstrual phases (Wilcoxon et al., 1976; Slade, 1984). Moreover, large interindividual differences were evident and stressful events were found to affect mood to a greater extent than the phase 
of the menstrual cycle (Wilcoxon et al., 1976). Prospective studies further failed to show a consistent pattern of fluctuations in panic attacks and generalized anxiety in women with panic disorder (Cameron et al., 1987, 1988; Stein et al. 1989b; see also chapter 3). Premenstrually occurring bad moods seem to be more easily recalled in retrospective reports than other 'terrible days', thus pointing at the influence of culturally held beliefs about the menstrual cycle (Alagna \& Hamilton, 1987; Johnson, 1987).

Biological changes during the menstrual cycle may further interact with cognitive factors, especially the fear of bodily sensations (section 2.2.4.). Kuczmierczyk \& Adams (1986) found that women with a premenstrual syndrome had higher heart rates during the premenstrual phase than women without this syndrome. And Asso (1986) demonstrated that the self-reported perception of autonomic activity during the premenstrual phase was significantly related to negative mood. Yet, the autonomic electrodermal reactivity was not significantly related to mood. The perception of bodily sensations during the premenstrual phase, therefore, may have an important influence on anxiety complaints.

In summary, retrospective data suggest that sex differences in anxiety complaints are related to the menstrual cycle. Prospective studies provided little evidence for an increase in anxiety complaints and panic attacks during the premenstrual phase. Retrospective exaggerations of premenstrual complaints may reflect culturally held beliefs about the menstrual cycle. Biological factors do not sufficiently explain sex differences in anxiety complaints. Hypotheses about the enhanced susceptibility to the acquisition of fear in the premenstrual phase reflect at least an interaction between biological factors and conditioning (section 2.2.3.).

\subsection{Psychological Factors}

At the psychological level, the influence of characteristics of the individual will be evaluated. Psychoanalysis and learning theory are the most prominent frames of reference at this level. Psychodynamic theories about panic disorder and agoraphobia will be summarized. Evidence about personality traits and disorders that are thought to be predisposing to the development of agoraphobia will be discussed. Finally, conditioning and cognitive models of panic disorder and agoraphobia will be presented.

\subsection{1. psychodynamic approaches}

In the psychoanalytic view, anxiety is conceptualized as a universal human experience, bridging pathological and nomal anxieties. Freud developed several models of anxiety (for a review, see: Michels et al., 1985). In his psychodynamic model, Freud (1926) recognized the function of anxiety as an alarm signal helping the ego to defend itself against real or internal danger. Internal dangers are inner drives or affects that are threatening to the ego. These drives are related to threats that were experienced during childhood: separation, loss of love, castration and guilt. Reactivation of these drives elicites anxiety. Anxiety acts as a signal to the ego to defend itself. Neurotic anxiety may have an apparent immediate situational cause, yet it is always related to drives and threats from early childhood. Neurotic symptoms are defensive responses in order to avoid anxiety about unconscious conflicts (Freud, 1926). Agoraphobia then originates from an outburst of anxiety, resulting from psychological conflicts over internal drives. Agoraphobic patients try to 
protect themselves against their own erotic desires and the danger of punishment after erotic contacts. The fact that an agoraphobic patient feels safer when he stays within a limited distance from the house or in the company of a relative, is explained by Freud through the mechanism of regression. Regression to infancy is used by the ego to avoid the dangers and temptations that threaten it now.

The idea that agoraphobic anxiety may be related to anxiety of separation and loss of love was further elaborated by later psychoanalysts. The focus of attention shifted from the fear of the street and public places to the fear of leaving home and family. According to Deutsch (1929), agoraphobic anxiety and the fear to leave a loved person is an overcompensation for unconscious hostile wishes directed against this person. Frances and Dunn (1975) conceptualized agoraphobia as a re-enactment of the childhood attachment-autonomy conflict with the present partner. In this view, different symptoms may accur according to the level of self-other differentiation. Depersonalization, for instance, occurs when leaving the partner is experienced as losing a part of the self, as a threat to self-constancy.

In summary, Freud conceptualized neurotic symptoms and avoidance as defensive responses to anxiety elicited by drives that are threatening to the ego. Other psychoanalysts focused on separation anxiety and attachment-autonomy conflicts in agoraphobia. The role of separation anxiety, the fear of abandonment and proximity seeking in agoraphobia is further stressed in attachment theory (Bowlby, 1973). This viewpoint culminated in a description of interactions within the parental family, and therefore will be reviewed at the microsocial level (section 2.3.1.). Freud's conceptualization of agoraphobia as fear of erotic encounters in the streets further points at the cultural meaning of 'the street', which will be addressed at the macrosocial level (section 2.4.3.).

\subsection{2. personality traits and personality disorders}

In clinical descriptions, agoraphobia has often been related to personality traits and disorders. Questionnaire data indicated that agoraphobic patients are less assertive and more anxious, depressed and helpless than normal controls (Fisher \& Wilson, 1985). Chambless (1985) demonstrated that the severity of agoraphobic fears was significantly related to higher levels of social anxiety, depression and chronic anxiety. Panic patients with increasing levels of avoidance reported more social phobic fears (Pollard and Cox, 1988; Rapee \& Murrell, 1988; Stein et al., 1989a). Therefore, it has been suggested that the hypersensitivity to the opinions of others predisposes to the development of agoraphobia. Van Zuuren (1987) demonstrated an effect of gender: Agoraphobic women, but not agoraphobic men differed from other types of phobics of the same sex in terms of personality traits, such as field dependence, self-sufficiency, neurosomatism and rigidity. In other studies, however, male and female agoraphobic patients did not differ significantly on measures of psychopathology and personality traits (Dei et al., 1990; Rijken et al., 1990).

A higher prevalence of dependent personality disorders in agoraphobic patients than in panic patients has been used as an argument to legitimate the distinction between panic disorder with and without agoraphobia in DSM III(R) (Reich et al., 1987). There is little agreement, however, about the prevalence of Axis II diagnoses in agoraphobia. Some authors reported $40 \%$ dependent personality disorders in agoraphobics (Reich et al., 1987); while others found that only $27 \%$ met the diagnostic criteria for any personality disorder (Mavis- 
sakalian \& Hamann, 1986). Neither is it clear whether certain personality traits or disorders are specific to agoraphobia. Reich et al. (1987) found higher prevalence rates of dependent and avoidant personality disorders in panic patients with agoraphobia than in uncomplicated panic disorder. Others demonstrated that dependent, avoidant and histrionic personality disorders or traits are more likely to occur in agoraphobic patients than other types of personality traits (Mavissakalian \& Hamman, 1986). Yet, they failed to find significant differences in personality traits and disorders between panic patients with and without agoraphobia (Mavissakalian \& Hamann, 1988). Arrindell \& Emmelkamp (1987a) further found that dependent personality traits are equally prevalent in agoraphobic women as in female non-phobic patients and normal controls.

Even when agoraphobics are more dependent, it is not clear whether dependency is primary or secundary to agoraphobia: a dependent personality disorder may predispose to agoraphobia, but dependency can also be due to the restricted life style of agoraphobics. In retrospect, no premorbid differences in dependency between agoraphobics and matched controls were found (Buglass et al., 1977). Also in favor of the hypothesis that personality disorders are secondary to panic disorder or agoraphobia is the finding that pharmacological treatment combined with self-exposure instructions reduced the number of pathological personality traits in agoraphobic patients with panic attacks (Mavissakalian \& Hamann, 1987).

In summary, agoraphobic patients experience more social anxiety, chronic anxiety and depression than panic patients without agoraphobia. The role of social anxiety in panic disorder and agoraphobia will be further evaluated in section 2.2.4. Nevertheless, there is little evidence in favor of the view that specific personality traits or disorders predispose to the development of panic disorder or agoraphobia. Dependency and avoidance may be the consequences of agoraphobia as well. Finally, the relationship between gender and personality traits is not clear yet. In section 2.4.2., agoraphobic behavior will be further related to feminine role behavior.

\subsection{3. conditioning models}

Classical conditioning experiments showed that animals learn to escape from aversive stimuli and that they continue to avoid even when these stimuli are no longer given. A two factor model was postulated: anxiety is acquired through classical conditioning and avoidance is maintained through operant learning (Mowrer, 1960; a comprehensive overview of conditioning models is given by Mineka, 1985).

According to the classical conditioning model, phobias result from the simultaneous presentation of an anxiety eliciting unconditioned stimulus and a conditioned stimulus. In this view, agoraphobia is conditioned after a traumatic experience in a specific situation. Sheehan (1982), for instance, advocated that the onset of phobias is conditioned in situations in which the first spontaneous panic attacks occurred. Multiple phobias are subsequently developed through stimulus generalization. The principle of classical conditioning is illustrated with case descriptions of the single trial conditioning of fear (Wolpe, 1981). Still, there is conflicting evidence about the number of agoraphobias developing after a conditioning event. Goldstein and Chambless (1978) identified a clear conditioning event in only 4 out of 32 agoraphobic patients. Öst and Hugdahl (1983), on the other hand, found that 
$81 \%$ of a sample of 80 agoraphobic patients ascribed the origin of their phobias to a direct conditioning experience. In a Dutch sample of 91 phobic outpatients (mainly agoraphobic), $78 \%$ reported conditioning experiences, but conditioning was the single pathway to fear in only $29 \%$ of the patients (Merckelbach et al., 1989a). Combinations of conditioning, vicarious and/or informational learning were observed in 53\% of the patients. Conditioning experiences in the pure conditioning group consisted of frightful interoceptive sensations, mostly DSM III defined panic attacks. Moreover, in $73 \%$ of the cases the conditioning event occurred outside the home, and in another $19 \%$ when alone at home. The first panic attack seems to occur relatively often when the subject is alone or in a public place. In a sample of panic patients with agoraphobia, $95 \%$ retrospeclively reported that their first panic attack occurred in a public place (Lelliot and Marks, 1988). Barlow and Craske (1988) found that $49 \%$ of the agoraphobic patients reported that their first panic attack occurred when alone, compared to $27 \%$ of the panic patients. Other studies failed to find significant differences between panic patients with different levels of agoraphobia in terms of the places and social contexts in which they experienced their first attack (Rapee \& Murrell, 1988; Craske et al., 1990). Although classical conditioning may play some role in the acquisition of phobias, the reliability of retrospective reports of the first panic attack can be questioned. Furthermore, this model does not explain where the first panic attack comes from. Therefore, biological and social factors have to be taken into account. A majority of patients experienced periods of psychological or physical stress before the conditioning event (Lelliot \& Marks, 1988; Merckelbach et al., 1989a; Craske et al., 1990), thus pointing at the influence of life events prior to illness (section 2.3.2).

Another shortcoming of the classical conditioning model is that it does not explain why the first panic attack might occur more often in public places and why fear of public places seems to be more readily acquired than fear of other situations. Seligman (1971), therefore, introduced the concept of 'preparedness': evolution 'prepared' species to acquire fear of stimuli that can possibly threaten their survival. An individual who is alone in a public domain far away from his own territory is a vulnerable one. As a result, fear of public places should be easier to acquire than fear of candy. Agoraphobia relevant situations should refer to open landscapes without a safe refuge, to closed-in spaces with the risk of being trapped and to be without the proximity of kin at the risk of being attacked by animals or strangers. The high prevalence of agoraphobia in women is linked to the following factors: women are less able to defend themselves, child care makes flight more difficult, women represent a potential reproductive resource to other groups, and food gathering requires shorter excursions than hunting (Nesse, 1987). Experimental studies in the laboratory compared psychophysiological reactions to phobia relevant stimuli and to neutral stimuli. Little empirical support was provided for the hypothesis that psychophysiological responses to fear relevant stimuli are more easily acquired, although there is some support for an enhanced resistance to extinction (for a critical review, see: Merckelbach et al., 1989b; McNally, 1987). In agoraphobia, the role of prepared leaming is difficult to investigate. A naturalistic study provided some evidence for the role of preparedness in the conditioning of fear in agoraphobia relevant situations (van den Hout et al., unpublished manuscript). In this study, normal subjects were sent to a big department store and to a non-agoraphobic situation, which was chosen for each subject separately. The subjects wore a heart rate monitor and a walkman playing Muzak, that would be interrupted several times by a piercing blood-curdling human scream. After each scream subjects reported how distressing the present scream was and how unpleasant they expected the next to be. 
The preparedness theory predicts that the agoraphobia relevant situation would be characterized by a larger increase in heart rate after each scream, by slower habituation and by a larger leaming effect demonstrated in a stronger reaction at a later test with a more quiet scream. These hypotheses were confirmed to a large extent. The differences between the experimental and the control condition were not significant at the first scream, but slower habituation and a learning effect did occur in the agoraphobia-relevant condition.

According to the two factor model, avoidance is the escape from (classically conditioned) aversive stimuli and the anxiety reduction reinforces avoidance behavior. Yet, several observations are not sufficiently explained by this model: avoidance behavior is sometimes extremely persistent, fear and avoidance may vary independently and the first panic attack is not always preceded by a fear provoking aversive experience in the places patients subsequently avoid (Rachman, 1984a). Animal studies showed that some stimuli have an inhibitory effect, while they reduce the expectation of punishment. Therefore, Gray (1971) postulated that the omission of anticipated punishment is a reinforcing event and that some stimuli subsequently receive conditioned rewarding properties and become 'safety signals'. The reinforcement of avoidance behavior by safety signals should occur independently from the fear aroused by warning signals, and consequently avoidance behavior continues even after the diminishment of fear. Rachman $(1983,1984 \mathrm{a} / \mathrm{b})$ further elaborated this sifety signal perspective in relation to agoraphobia. Clinical observations pointed out that the presence of safety signals (either trusted companions or talismen) in feared situations encourage agoraphobics to enter these settings (e.g., Marks, 1970). Central to the theory is that worrying about seeking and finding momentarily unavailable safe places is a basic process in the distress agoraphobics experience. Agoraphobia then is no longer seen as a fear of specific places, but rather as anxiety in the absence of familiarity and safety (Hallam, 1978). Unfortunately, there is little empirical evidence from studies in men to support these propositions (for a critical review on safety signals, see: Himadi, 1987). Moreover, Rachman (1984a) stated that a history of overprotection, dependency and a personal loss can reduce the sense of safety. Accordingly, the role of developmental factors (section 2.3.1) and life events (section 2.3.2) has to be evaluated. At the macrosocial level, characteristics of situations that potentially increase or reduce the sense of safety will be explored further (section 2.4.5.).

In summary, according to the two factor model, phobias are acquired through classical conditioning and maintained through operant conditioning. The classical conditioning model states that agoraphobia is conditioned after the occurrence of a traumatic event in a specific situation. The preparedness theory postulates that the fear of public places is more readily acquired, since being alone in a public place was potentially threatening to survival during evolution. And finally, the safety signal perspective conceptualizes agoraphobia as anxiety in the absence of familiarity and safety.

\subsection{4. cognitive models}

Cognitive models relate panic to maladaptive thoughts and images. According to Clark (1988), panic results from the catastrophic misinterpretation of bodily sensations. In this view, panic attacks can be triggered either by internal stimuli (e.g., thoughts or images) or by external stimuli (e.g., agoraphobic situations). The threat perceived in these stimuli produces bodily sensations. These bodily sensations are perceived as dangerous and inter- 
preted as an indication of an impending catastrophy, e.g., a heart attack. Finally, a vicious circle of increasing apprehension eliciting an increase in bodily sensations culminates in panic. In a similar way, Beck (1988) stated that panic patients are particularly sensitive to internal sensations and tend to fix their attention on bodily or mental experiences that can be interpreted as a sign of danger.

Studies using standardized interviews provided clear phenomenological descriptions of thoughts and images concerning physical, psychological or a social disaster that may occur during a panic attack (Hibbert, 1984; Ley, 1985; Ottaviani \& Beck, 1987). Questionnaire data indicated that panic patients report significantly more fear of bodily sensations than non-panic patients and normal controls (van den Hout et al., 1987b; Clark et al., 1988). Further evidence for selective information processing of physical threat cues in panic disorder was found in experiments using cognitive tasks. In comparison to normal controls, panic patients displayed an attentional bias: panic patients selectively attended to words about bodily sensations, fear and catastrophes (Clark et al., 1988; Ehlers et al., 1988a; McNally et al., 1990). The same effect was, however, not found for words related to social threat conditions (Ehlers et al., 1988a; Hope et al., 1990). Finally, assessments of symptoms and cognitions during exposure tasks demonstrated a significant association between negative cognitions and experiences of anxiety and panic (Last et al., 1985a; Rachman et al., 1987; Kenardy et al., 1988, 1989; see also chapter 3).

The interaction between bodily sensations and appraisal further provides an explanation for experimentally induced panic. Biological theories of panic disorder based on panic induction studies have been critisized on methodological grounds (Margraf et al., 1986) and on their failure to evaluate concurrent cognitive explanations (van den Hout \& Griez, 1986; van den Hout, 1988; Ehlers \& Margraf, 1989). Several studies demonstrated that responses to carbon dioxide and lactate can be manipulated by giving different instructions about the effects to expect (van den Hout \& Griez, 1982b; van der Molen et al., 1986; Rapee et al., 1986; van der Molen \& van den Hout, 1988). High anxiety and even panic could be experimentally induced in panic patients by giving false heart rate feedback (Margraf et al., 1987a; Ehlers et al., 1988b). Furthermore, the anxiogenic effect of carbon dioxide inhalation in panic patients was found to diminish after repeated exposure to carbon dioxide (Griez \& van den Hout, 1986; van den Hout et al., 1987a), thus indicating that the fear of bodily sensations habituates over the course of exposure. Recently, evidence was provided that perceived control is an important factor in the experience of fear of bodily sensations. Sanderson et al. (1989) ascertained that panic patients who were given an illusion of control over carbon dioxide induced panic reported less panic symptoms, less subjective anxiety and less catastrophic cognitions than patients who believed they could not control the inhalation.

Differences in cognitions between panic patients with and without agoraphobia have also been investigated. With increasing levels of agoraphobia, panic patients were more likely to believe that situations influence their thoughts, that both situations and thoughts can trigger a panic attack, and accordingly, that they can avoid the onset of panic (Rapee \& Murrell, 1988). In comparison to panic patients without agoraphobia, agoraphobic patients reported more intrusive thoughts and cognitive styles, such as catastrophizing and giving selective attention to cues of danger. However, these cognitions were not only related to the severity of phobias, but also to depression and generalized anxiety (Ganellen et al., 
1986). Measures of fear of fear were found to be related to the severity of agoraphobia (Chambless et ai., 1984; Chambless, 1985: Chambless \& Gracely, 1989). Several studies indicated that panic patients with agoraphobia report significantly more fear of bodily sensations than panic patients without agoraphobia (Chambless \& Gracely, 1989; de Ruiter et al., 1987, 1989c; de Ruiter \& Garssen, 1989).

Thoughts about social disapproval also seem. to play an important role in panic attacks, especially in agoraphobic patients. Ottaviani and Beck (1987) found that $40 \%$ of the panic patients reported fears of social humiliation as a result of a panic attack. Moreover, physical sensations and subsequent panics were triggered by (thoughts of) stressful social situatinns or negative social evaluations in 10 out of the 30 patients. In a study by Mizes et al. (1987), agoraphobia was found to be related to concerns about disapproval from others and thoughts about others seeing that there is something wrong with them. Questionnaire studies indicated that panic patients with agoraphobia report more concerns about social and behavioral consequences of panic than panic patients without agoraphobia (Fleming \& Faulk, 1989; Telch et al., 1989). Concerns about social evaluations are further reflected in an enhanced interpersonal sensitivity. Panic patients with agoraphobia scored higher than panic patients without agoraphobia on the interpersonal sensitivity factor of the SCL-90 (Thyer et al., 1985; Aronson \& Logue, 1987; de Ruiter et al., 1987; de Ruiter \& Garssen, 1989). Finally, few differences were found between agoraphobic patients and social phobics in concerns about social evaluations: more than $50 \%$ of the subjects in both groups reported cognitions about acting foolish and loosing control (Craske et al., 1986).

In summary, cognitive models conceptualize panic as fear of bodily sensations. Panic patients tend to spend selective attention to bodily sensations and are more likely to interpret these sensations as an indication of impending danger. Cognitive models also provided an alternative explanation to the results of panic induction studies. Recent studies indicated that the perception of control is an important factor in the experience of panic after carbon dioxide inhalation. Finally, agoraphobic patients were found to display more fear of fear and selective attention to cues of danger than panic patients without agoraphobia. Especially thoughts about social consequences of panic seem to be more prominent in agoraphobia.

\subsection{Microsocial Factors}

At the microsocial level, relationships with intimate others as well as life events will be evaluated. In the case of agoraphobia, attachment theory offered interesting assumptions about patterns of interaction in the parental family. Consequently, evidence will be reviewed concerning characteristics of the parental family and early life events. Furthermore, hypotheses and studies about life events prior to the onset of panic disorder and agoraphobia will be summarized. Finally, the role of mate selection and marital interaction in agoraphobia will be evaluated.

\subsection{1. attachment and early life events}

Bowlby (1973) pointed at the resemblance between school phobia in childhood and agoraphobia in adult life. He stressed that not only withdrawal, escape and avoidance are indicative of fear, but also seeking the proximity of persons or objects. The behavior that reduces the distance from persons or objects that are expected to bring protection is 'attach- 
ment behavior'. Bowlby further related agoraphobia to patterns of interaction in the parental family. 'Agoraphobic' families were described as having serious (although sometimes hidden) difficulties. Quarrels, violence, alcoholism and an almost complete absence of affection were thought to be common. In these families, the patient was often exposed to threats of being abandoned or rejected by dominant and overprotective parents. Especially mothers have been described as ambivalent, threatening and rejecting as well as overconcerned and anxious, while the fathers were absent. In other cases, the patient experienced prolonged parental separations, while the family was broken by death, divorce or illness.

Similar characteristics of the parental family have been mentioned in clinical descriptions (Hafner, 1982; Guidano and Liotti, 1983). In the survey by Thorpe and Burns (1983), about $42 \%$ of the agoraphobic subjects described their fathers as strict and their mothers as over-anxious. Questionnaire data indicated that agoraphobic patients received less maternal care than a group of matched controls (Parker, 1979). In another study, agoraphobic patients rated both parents as less caring, but more protective than normal controls ( $\mathrm{Si}$ love, 1986). In a similar way, Arrindell et al. $(1983,1989)$ found that agoraphobic patients describe their parents as giving less emotional warmth and their mothers as more rejecting than normal controls. Nevertheless, patients with other types of phobias rated their parents behavior even more negative than agoraphobics. Other studies failed to find significant differences in parental care between agoraphobics, other types of phobics and normal controls (Kolk, 1989). Since all these studies rely on retrospective material, the reliability and validity of the findings can be questioned. Only a few efforts have been made to study actual patterns of interaction in the parental family. In a recent study on panic attacks in adolescents aged 13 to 18 years, severe panickers reported more school and family pressure, more depression and less social support by the family (Macaulay \& KJeinknecht, 1989).

Separation anxiety and school phobia in childhood have also been assumed to predispose to the development of agoraphobia (Klein, 1964; A.P.A., 1980, 1987). But, there is a lot of conflicting evidence about the incidence of childhood separation anxiety and school phobias in agoraphobic patients. In some studies, 50 to $60 \%$ of the agoraphobic patients reported school phobias and/or separation anxiety in childhood (Klein, 1964; Gittelman \& Klein, 1984; Deltito et al., 1986). Breier et al. (1986) found a history of childhood separation disorder in only $18 \%$ of the agoraphobic patients. And in a recent study of adolescents with panic disorder, only 2 out of the 17 subjects (12\%) had a childhood separation disorder (Last \& Strauss, 1989). Moreover, there is little evidence for the hypothesis that separation anxiety and school phobias are sperifically predisposing to agoraphobia. Several studies failed to find significant differences in childhood histories of separation anxiety and school phobias between agoraphobic patients and neurotic or normal controls (Berg et al., 1974; Buglass et al., 1977; Raskin et al., 1982; van der Molen et al., 1989). In one study, a childhood history of school phobias with separation anxiety was found to be much more prevalent in panic patients with agoraphobia than in panic patients without agoraphobia (Deltito et al., 1986). In other studies, however, no significant differences in childhood separation anxiety were found between panic patients with different levels of agoraphobic avoidance (Rapee \& Murrell, 1988; Ayuso et al., 1989), and only minor differences emerged between panic patients with and without separation anxiety and school phobias in childhood in terms of clinical features, such as symptom severity, comorbidity with other disorders and the course of illness (Perugi et al., 1988b; Ayuso et al., 1989). Fur- 
thermore, other childhood disorders than the separation anxiety disorder have been found to occur frequently in the histories of agoraphobic patients. Aronson \& Logue (1987) found that $20 \%$ of panic patients had a history of separation anxiety disorder, $39 \%$ had a history of overanxious disorder (mostly with lifelong high trait anxiety), and $14 \%$ had histories of childhood major depression. They reported a significant association between adult agoraphobia and all childhood disorders. Therefore, it can not be concluded that childhood histories of separation anxiety and school phobias specifically predispose to the development of agoraphobia in adulthood.

Finally, differences in actual parental separation during childhood have been investigated. Thorpe and Burns (1983) found that most agoraphobics were brought up by both parents, although $38 \%$ of these subjects were separated from their parents for at least 3 months. Some studies also indicated that actual parental separation did occur more frequently in the histories of agoraphobic patients than in panic patients without agoraphobia (Faravelli et al., 1988). Agoraphobic patients with panic attacks reported more events between the age of 4 and 15, like maternal separation and parental divorce than normal controls (Faravelli et al, 1985). Tweed et al. (1989), on the other hand, found that maternal death before age 10 increased the risk for agoraphobia with panic attacks, while parental separation or divorce increased the risk for both agoraphobia and panic disorder. In other studies, no higher frequencies of actual parental separation or parental death were found in the histories of agoraphobic patients in comparison to panic patients without agoraphobia, normal and neurotic controls (Buglass et al., 1977; Silove, 1986; Thyer et al., 1988; Kolk, 1989; van der Molen et al., 1989).

In summary, Bowlby's (1973) attachment theory led to interesting hypotheses about patterns of interaction in the parental family of agoraphobic patients. Nevertheless, retrospective studies failed to provide unequivocal evidence for the assumed higher incidence of negative parental rearing practices, childhood histories of separation anxiety disorder and specific early life events in agoraphobic patients. The role of developmental factors in panic disorder and agoraphobia is difficult to judge on the basis of retrospective information. Therefore, prospective studies of childhood disorders and their relationship to patterns of familial interaction are warranted.

\subsection{2. life events prior to illness}

Adjustment to important changes in life, to 'major life events' may have an impact on mental health. Accordingly, life events prior to the development of panic disorder and agoraphobia have been studied. Bowlby (1973) reported that in a high proportion of cases, agoraphobic symptoms were precipitated by bereavement, serious illness of the patient or a relative or by some other major change in familial circumstances. In this view, the correspondence between anxiety and depression is emphasized. According to Brown and Harris (1978), anxiety occurs in cases of uncertainty: the more complete a loss (actual rather than threatened, death rather than separation) the more depressed and the less anxious the reaction will tend to be. Evidence to support this proposition was found in a study of 164 . women attending a general practitioner (Finlay-Jones \& Brown, 1981). Severe loss was found to be related to depression and severe danger events occurred more often in women with anxiety complaints. 
Studies about the relationship between specific life events and panic disorder and agoraphobia provided contradictory findings. Kolk (1989) found that agoraphobic patients reported more events related to (imminent) separation than social phobics. Some evidence was also provided for the higher occurrence of major life events (both loss and threat related events) in panic patients one year prior to their first panic attack, when compared to normals (Faravelli, 1985; Faravelli \& Pallanti, 1989). In another study, no more separation or loss related events were found in panic patients than in normal controls, but panic patients reported more moves to other neighborhoods and/or cities, more health related events and an increased workload, as well as a more negative impact of these events than normals (Roy-Byme et al., 1986a). Panic patients who had experienced a major loss event in the year prior to illness were found to be at a higher risk for developing secondary major depression than panic patients who did not experience loss related events (Roy-Byme et al., 1986b). Furthermore, panic patients did not experience more life events prior to illness than patients with other anxiety disorders (Raskin et al., 1982; de Loof et al., 1989; Rapee et al., 1990a). In comparison to patients with other anxiety disorders and normal controls, panic patients did not differ significantly in the number of events occurring 6 months prior to onset (or during an equivalent period of time for the normal controls), but patients with panic or other anxiety disorders reported that these events had a more negative impact than those reported by normal controls (Rapee et al., 1990a). In general, we can not conclude that specific major life events are predisposing to the development of panic disorder and agoraphobia.

There is, however, substantial evidence that the onset of panic and agoraphobia is often preceded by a stressful period with a number of (sometimes minor) stressful events. Several studies identified periods of psychological or physical stress prior to the onset of the first panic attack (Raskin et al., 1982; Uhde et al., 1985a/b; Breier et al., 1986; Aronson \& Logue, 1987; Ottaviani \& Beck, 1987; Barlow \& Craske, 1988; Lelliot \& Marks, 1988; Rapee \& Murrell, 1988; Merckelbach et al., 1989a; Craske et al., 1990) as well as prior to the onset of agoraphobia (Buglass et al., 1977; Thorpe \& Burns, 1983; Last et al., 1984a; Kleiner \& Marshall, 1987; Pollard et al., 1989). Frequently occurring stressors prior to illness were: interpersonal conflict, pregnancy, miscarriage, birth, death or illness of a relative or friend, major surgery, illness, excessive alcohol or drug use, stress at work or school, change in job or moves. Rapee \& Murrell (1988) also reported high rates of panic patients having experienced one or more life stressors in the six months prior to the first attack, yet no significant differences were found between panic patients with different levels of agoraphobia.

In summary, the onset of panic disorder and agoraphobia is often preceded by life events. Most evidence suggests that panic patients and agoraphobics experience a period of enhanced life stress and a number of major or minor life events prior to onset. However, it was not possible to identify specific life events predisposing to panic disorder or agoraphobia. Given the fact that all studies rely on retrospective information, no definite conclusions can be drawn on the role of specific life events in panic disorder and agoraphobia.

\subsection{3. marital relationships}

In clinical descriptions, agoraphobia has been related to mate selection and marital interaction. According to Fry (1962), spouses of agoraphobic patients are often jealous, negati- 
vistic, anxious, compulsive and they suffer from (covered) agoraphobic complaints. The marriage is described as dissatisfying and the agoraphobic symptoms are thought to keep the couple together. Goldstein (1982) attributed agoraphobic symptoms to dissatisfaction with marriage and a conflict between the need for dependency and the wish to divorce. Hafner (1982) described spouses of agoraphobic patients as having problems of personal development and adjustment, as well as doubts about their competence, assertiveness and sexuality. Agoraphobic complaints are then an attempt to adjust to the constraints, demands and conflicts of marriage. Furthermore, successful treatment of the agoraphobic patient would urge a re-evaluation of the spouse's position in marriage and might elicit an exacerbation of neurotic symptoms in the spouse, marital conflict, and finally, a relapse of the patient.

Little empirical evidence has been provided to support these assumptions. Marital conflicts were found to precede the onset of agoraphobia in a number of cases (Thorpe \& Burns, 1983; Last et al., 1984a; Kleiner \& Marshall, 1987), and agoraphobic complaints may put considerable strain on the marital relationship (Thorpe \& Burns, 1983). Nevertheless, several studies failed to find differences in marital satisfaction between agoraphobic patients, non-phobic patients and normal controls (Buglass et al., 1977; Fisher \& Wilson, 1985; Arrindell \& Emmelkamp, 1986). Neither was marital satisfaction related to the severity of agoraphobia (Chambless, 1985; Peter \& Hand, 1988) or to treatment outcome (Arrindell \& Emmelkamp, 1986; Himadi et al., 1986a). Furthermore, husbands of agoraphobic women did not differ from normal controls and non-phobic controls in ratings of neuroticism and psychosocial functioning (Buglass et al., 1977; Arrindell \& Emmelkamp, 1985). In fact, control couples have been found to resemble each other more than agoraphobic couples (Buglass et al., 1977; Arrindell \& Emmelkamp, 1985). From a systematic review of studies, Arrindell (1987b) concluded that statements about the relationship between agoraphobia and marital interaction are based on fiction, not on facts. Recently, some attempts have been made to relate agoraphobia to specific communication styles. Irrespective of marital satisfaction, frequent communication between spouses was found to be associated with exposure treatment efficacy (Craske et al., 1989). In another study, preliminary findings indicated that a favorable long-term treatment outcome was related to high expressed. emotion, especially criticism between spouses (Peter \& Hand, 1988).

In summary, although marital conflicts may precede the onset of agoraphobia and agoraphobia may have a negative impact on the marital relationship, little evidence was found in favor of a relationship between marital satisfaction and agoraphobic symptomatology, severity and treatment outcome. Research about specific communication styles may be more worthwhile. In section 2.4.4., the significance of intimate relationships for agoraphobic patients will be further evaluated.

\subsection{Macrosocial Factors}

Theories at the macrosocial level link mental health problems to social structures and culturally held beliefs and norms. At this level, mental health problems are considered as a communication of the patient's 'dis-ease' in terms that are recognizable and interpretable to the community the person lives in (deVries et al., 1982; Tan, 1988). Cultural factors determine how a disorder will manifest itself, as well as which behavior will be seen as a disorder. Accordingly, different manifestations of anxiety exist across cultures (Good \& 
Kleinman, 1985; Tan, 1988). From an antropological perspective, agoraphobia is described as a Western 'culture bound syndrome' that typically occurs in women with a lower socioeconomic status, who cling to traditional roles and display behavior that can be conceptualized as an exaggeration of ferninine role behaviors (Littlewood \& Lipsedge, 1985, 1987; Richters, 1988). The high prevalence of agoraphobia in women in Western countries urges us to elucidate social and cultural determinants of this 'dis-ease'.

\subsection{1. socioeconomic factors}

Mental health problems and help-seeking behavior are not only related to sex, but also to socioeconomic factors and demographic characteristics, such as age, marital status and social class. In terms of dennographic variables, agoraphobic subjects can be considered as a special group. According to the ECA study, the prevalence of agoraphobia is higher in women with lower educational levels and a lower socioeconomic status (Weissman \& Merikangas, 1986; Bourdon et al., 1988). Data from clinical samples are less unequivocal. Most of the studies about differences between panic patients with and without agoraphobia, did not include demographic characteristics. Fleming \& Faulk (1989) found no differences between panic patients with and without agoraphobia in terms of age, race, marital status and number of children; but agoraphobic patients received significantly less years of education and were less likely to have a job outside the home. Other studies failed to find differences between panic patients and agoraphobic patients in educational level (Ganellen et al., 1986; de Ruiter et al., 1987). But, in a large sample of agoraphobic outpatients, increasing levels of agoraphobia were found to be associated with a decreasing socioeconomic status (Chambless, 1985).

Agotaphobia has further been related to the socially isolated position of housewives (Bekker, 1986). Roberts (1964) described agoraphobia and panic in 'housebound housewives'. Agoraphobic women are often married and unemployed (Marks \& Herst, 1970; Thorpe \& Burns, 1983). In a comparative study between social phobic and agoraphobic patients, important differences in employment, income, education and marital status were found (van Zuuren, 1983). Agoraphobic patients were less educated and had a lower employment status than social phobic patients. More agoraphobic than social phobic patients lived together with a partner and children. Almost all women in the agoraphobic sample were housewives. Van Zuuren (1983), therefore, stated that agoraphobic women lead a 'small-scaled life' according to fixed role patterns that are traditionally prescribed to women in our culture.

It is not clear, however, whether being a housewife increases the risk of becoming agoraphobic, or whether unemployment is a common consequence of agoraphobia. Young adults relatively often reported absence of work or loss of job as a consequence of being agoraphobic (Angst \& Dobler-Mikola, 1985). In another survey, 29\% of the agoraphobic subjects were employed and $76 \%$ of those working outside the home felt that their agoraphobia hindered their ability to work. Moreover, $83 \%$ of the unemployed subjects stated that they would take a job if they would not be agoraphobic (Thorpe \& Burns, 1983). Further evidence for the fact that the onset of agoraphobia often preceeds unemployment, especially in women, was given in a recent study among Dutch agoraphobic outpatients (Rijken et al., 1990). The percentage of subjects who reported to be employed at onset ( $81 \%$ of the men and $46 \%$ of the women) did not differ from the percentages of employed 
men and women in the general population. At the time of the study (on the average after 5 years of illness), only $49 \%$ of the male and $18 \%$ of the female patients were employed. Agoraphobic complaints may especially influence the employment status of women, since to stop working outside the home is more socially acceptable for women than for men in our culture. But, having a job may also have a positive effect on the severity of agoraphobic complaints. Diana Chambless (1989) even stated that since the number of women working outside the home in the United States has increased, agoraphobic women less often develop extensive avoidance than 15 years ago when more women were housewives.

In summary, epidemiological studies in the general population demonstrated that agoraphobia is more prevalent among women with a lower socioeconomic status. Other findings indicated that agoraphobia is more common among women with a traditional role: unemployed, married women with children. Unemployment may increase the risk of developing severe agoraphobic fears, but it can also be a consequence of agoraphobia. In the following section, we will further highlight the relationship between agoraphobia and feminine role behavior.

\subsection{2. stereotypes about femininity}

Feminist theories relate sex differences in agoraphobia to stereotyped feminine sex roles. Feminine sex roles refer to activities, interests and tasks that are socially prescribed for women in our culture (Spence \& Helmreich, 1978). Fodor (1974) suggested that obedience, flight and phobia are typical feminine options. Brehony (1983) and Wolfe (1984a) pointed at developmental aspects of sex differences in personality traits that are related to agoraphobia. According to Wolfe (1984b), agoraphobic wornen are reared to be dependent, and when life events or interpersonal conflicts arise, they are faced with the threat of a disruption in their dependency. In a similar way, Al Issa (1980) stated that women react to stress with an intensification of stereolyped feminine behavior, such as dependency, helplessness, avoidance and withdrawal from social contacts. Symonds (1981) further noted that young women often become housebound after marriage. In spite of this, these women describe their marriages as satisfying and their husbands as kind, gentle and helpful. According to Symonds, marriage means for these women a declaration of dependency and a consolidation of their womanliness. Every sign of independence or assertiveness is avoided, since it can be considered as masculine and could lead to marital conflict.

Only a few studies investigated the relationship between agoraphobia and sex role stereotyping (for an overview: Chambless. 1989). Most studies used questionnaires, such as the Personal Attributes Questionnaire (PAQ; Spence \& Helmreich, 1978), measuring masculinity and femininity as two independent traits. Femininity is reflected in relational skills: being helpful, devoted to others, kind, understanding and aware of other people's feelings. Masculinity is defined in terms of 'instrumental' skills: being self-confident, active, independent and competitive. Women with high scores on the femininity scale and low scores on the masculinily scale and men with low scores on the femininity scale and high scores on the masculinity scale are labeled 'sex stereotyped'. People with high scores on both scales are 'androgynous' and people with low scores on both scales are 'undifferentiated'. The results of these studies indicated that both agoraphobic men and women had similar scores on the femininity scale than normal subjects of the same sex, yet they had significantly lower scores on the masculinity scale (Chambless \& Mason, 1986; Goumay, 1989). 
Chambless and Mason (1986) also correlated masculinity and femininity scores to measures of psychopathology for agoraphobic men and women separately. For both sexes, significant negative correlations were found between masculinity and most measures of psychopathology (e.g., measures of social anxiety, depression and trait anxiety). Moreover, partial correlation analysis revealed that the correlation between gender and agoraphobic avoidance disappeared when the effects of masculinity were removed.

In summary, feminist theories relate agoraphobia to stereotyped feminine role behavior. Recent studies about sex roles of agoraphobic patients indicated that agoraphobia is associated with lower levels of masculinity in both sexes. These studies demonstrated that agoraphobia is related to a stereotyped feminine sex role. Still, they also suggested that agoraphobia should not be conceptualized as exaggerated femininity, buth rather as a lack of 'masculine' skills, such as assertiveness, instrumentality and active approach behavior. In the following sections, the social and cultural meaning of agoraphobic situations will be evaluated. The influence of sex roles on the meaning of these situations will be further examined.

\subsection{3. the social and cultural meaning of public places}

From an interactionistic perspective, behavior is conceptualized as an interaction between the person and the situation. In this view, situations are important determinants of behavioral variance (e.g., Endler, 1976). At the point of intersection between the individual and the situation is 'identity' (Schlenker, 1984). Identity involves: a sense of inner sameness and continuity over time, and a sense of mutuality between the individual and the social environment (Erikson, 1968). The sense of identity is experienced as being a specific, indivisible, autonomous individual, but it is not an invariable trait of the person. It is continuously adjusted in interaction with the environment; it is 'the actually attained but forever to-be-revised sense of the reality of the Self within social reality' (Erikson, 1968, p. 211). In this section, we will explore how the social and cultural meaning of places influences the sense of identity.

Marking out a personal territory is an important value in Western society. The personal territory acknowledges the sense of identity, autonomy and uniqueness. Bakker \& Bakker (1974) conceptualized the 'sphere of action' as the domain in which one is active, competent and skilled. Within this territory, people experience freedom of action. When the person does not have sufficient information, experience or skills to enter a situation, he/she will experience anxiety. The acquisition of skills to enter a specific domain is of important relevance to the emotional value that will be attached to that domain.

Agoraphobia is characterized by fear and avoidance of public places. It can be hypothesized that agoraphobic subjects lack important skills that are needed 10 enter these type of situations. The acquisition of these skills depends on cultural rules and limitations. Public places apparently have different connotations to men and women in our culture. Bourdon et al. (1988) investigated prevalence rates of various fears in the general population and found the largest sex differences in ratings of fear of going out of the house (F:M 4.8:1). De Swaan (1981) related sex differences in the féar of public places to social developments in the 19 th century. He noted that Western cities grew enormously with industrialization and became crowded by individuals from the lower class. Beggars and jobhunters 
were described as filling the streets. For members of the 'petit bourgeois' middle class, it became increasingly difficult to maintain distance from these individuals. Men could not avoid them, because they had to leave home to go about their daily business, but the behavior of women could be controlled by men. Limitations were imposed on their out-ofhome behavior in order to protect them from dangerous, rough, insulting, or - even worse - seductive contacts with the mob. According to de Swaan, the prevalence of agoraphobia rose as women acquired more freedom at the end of the 19 th century and could even appear on the streets unaccompanied.

Breaking rules and learning new ones seems to bring 'dis-ease'. It can be argued, however, that the cultural view of the street as a threatening place with potentially dangerous and erotic encounters for women still holds. Chaperones are used to protect (young) women. In an ethnography of school girls aged between 12 and 16 years old, de Waal (1989) noted that boys do have more behavioral freedom than girls. The mobility of girls is restricted in space (only 'street girls' hang around), in time (not after sunset, certainly not late at night), in company (not with 'bad' friends, boys) and in activities (sex, drugs). Instead of leaming how to cope with public situations, girls are encouraged to avoid them: "Women and girls who venture out of the doors late at night or go to a pub alone are considered as outlaws ... To keep their daughters from making slips, from indecent assaults and imputations, parents rigorously limit their daughter's freedom of action. Most of these limitations can be nullified, however, by choosing an appropriate protection. Many girls are therefore chaperoned if they go into the public domain." (p. 53)

In summary, the personal territory was described as providing acknowledgement to the sense of identity. Fear and avoidance of public places was related to a lack of skills to enter the public domain. Limitations imposed on the behavior of women in our culture may hamper the acquisition of these skills. From an historical point of view, sex differences in the fear of public places can be related to the social and cultural meaning of public places in the 19th century, leading to the restricted mobility of women. A description of actual restrictions enforced on the behavior of young girls in public places illustrates that girls are often encouraged to avoid public places.

\subsection{4. the sacial and cultural meaning of being alone}

Fear and avoidance of being alone are also important characteristics of agoraphobia. But experiences of discomfort in solitary situations are not exclusively linked to agoraphobia. Studies about experiences of solitude in normal subjects indicated that daily separations from significant others, even voluntary separations of a short duration, have a negative impact on mood (for a review, see: Larson, 1990). In normal subjects, however, being alone is also related to positive experiences: A greater ease of concentration and a greater sense of control in solitary situations have been reported. Furthermore, the negative impact of solitary experiences was found to diminish over age. Older adults experienced separations from others as less painful than adolescents.

Besides this, the type of social contacts with other people may be more relevant than being alone or not. People behave differently depending on who is present in a situation. There is some evidence indicating that agoraphobic patients participate less in large social groups than normal controls (Buglass et al., 1977). In social situations, agoraphobic patients often 
experience fear of negative social evaluations and fear of acting foolish or loosing control in front of others (section 2.2.4). The presence of intimate others, on the other hand, increases feelings of safety and well-being in agoraphobic patients (section 1.1). Therefore, the social and cultural meaning of intimate relationships will be further explored.

Intimacy is a dynamic interpersonal process (Reis \& Shaver, 1988). The process involves the communication of formerly private aspects of the self to another person. The disclosure of private feelings and experiences depends on the members' goals, motives and needs as well as on (preexisting or situationally determined) expectations about each other's behavior. The response of the other person validates the individual as a unique human being and results in feelings of connectedness, acceptance and mutual underslanding. 'Validation' refers to the belief that another person values, supports and appreciates one's personal characteristics and world views (Reis, 1990). The relationship usually implies frequent interactions across several behavioral and situational domains. Over time, the members of the relationship develop stable expectancies about each other, resulting in a 'sense of knowing and being known' (Chelune et al., 1984). The development of the relationship can be described as a process of 'identity bargaining' in order to determine who each member will be in the relationship and which roles they will enact (Schlenker, 1984). Relationships progress when this process reaches mutually acceptable conclusions. Discrepancies between the identity one perceives or enacts in a relationship and the desired identity are potential sources of distress. In enduring relationships, after repeated interactions across a wide range of situations, people have more opportunities to bargain and to resolve discrepancies between perceived and desired identities. When people lack experiences and skills to enter a particular social domain, expectations about how they should behave may be unknown or ambiguous. Discrepancies between their actual behavior, desired behavior and perceived expectations of others are more likely to occur and may result in experiences of discomfort and expectations about negative social evaluations.

The ability to function in different types of social situations is acquired during different developmental stages. The capacity to be alone and the acquisition of relational skills are developmental tasks faced in adolescence. Adolescents develop a sense of identity and autonomy from parents (Erikson, 1968). One way to overcome family attachments is to form and maintain relationships with persons outside the family. In the peer group, adolescents learn to know who they are in the world beyond their family (Lidz, 1983). Being alone, on the other hand, provides an occasion to consolidate a personally defined self (Larson, 1990). There are, however, important sex differences in this shift towards independence. In an ESM study on use of time of adolescents, boys tended to spend more time alone and engaged more in instrumental activities (such as schoolwork and sports) than girls (Richards \& Larson, 1989). Adolescent girls reduced their involvement in instrumental activities and became more and more involved in social activities. Girls spent more time interacting with family members and friends. Furthermore, important differences have been noted in adolescent boys and girls' friendships (Allan, 1989). Boys are more likely to operate in larger social groups, and these groups are more often hierarchically organized. Competition, dominance and a fighting spirit are needed in order to acquire and maintain a specific position within the peer group. Girls are more likely to function in a dyadic relationship with an intimate friend, a 'soul mate'. Girls communicate more personal information and disclose more private feelings to their friends, while boys more often focus on shared activities and achievements. Together with the restrictions imposed on the 
girl's public behavior (section 2.4.3.), girl's friendships may hamper social contacts in a larger social group (de Waal, 1989). Close dyadic relationships allow girls to develop important relational skills. The drawback is that they provide little opportunity to develop a sense of autonomy out of the small circle of intimates.

The finding that the fear of being alone is much more prevalent in women than in men (F:M 3.9:1) (Bourdon et al., 1988) may be related to developmental factors. It can be hypothesized that agoraphobia is characterized by deficiencies in the development of a sense of autonomy and the acquisition of skills to function in a larger social group. Life events, such as illness or a prolonged separation from parents, as well as interpersonal problems with peers or parents during adolescence may have influenced the acquisition of social skills in agoraphobic patients. Research about the relationship between agoraphobia and early life events (section 2.3.1) provided little evidence for an higher incidence of parental separation or negative parental rearing practices in the childhood of agoraphobic patients. Still, most of these studies focused on early childhood and not on adolescence. There is, however, substantial evidence that panic disorder and agoraphobia occur relatively often in adolescence (Sheehan et al., 1981; Wittchen, 1988; Last \& Strauss, 1989; Macaulay \& Kleinknecht, 1989).

On the other hand, some evidence was presented indicating that traditional feminine sex roles provide fewer opportunities to acquire the necessary skills to function in a larger social group. During adolescence, girls' experiences are often limited to close, intimate relationships. The acquisition of skills to function in other types of relationships may largely depend on later experiences during adulthood. The higher prevalence of agoraphobia in women with lower educational levels and a lower socioeconomic status (section 2.4.1) may be related to the fact that employed women with higher educational levels are more likely to be confronted with situations, encouraging the acquisition of instrumental skills. Studies on the development of sex roles during adolescence and young adulthood demonstrated that age and career involvement are related to an increase of self-perceived masculinity in females (for a review: Huston, 1983). The finding that agoraphobic women with higher educational and occupational attainment levels scored higher on the PAQ masculinity scale (Chambless, 1989) further indicates that employment is related to the acquisition of instrumental skills, such as being self-confident, active, independent and competitive. Furthermore, employment creates the right set of circumstances to become involved in social relationships outside the family (Allan, 1989).

In summary, the ability to cope with negative effects of being alone has been related to developmental tasks faced in adolescence. Important sex differences in adolescent development have been noted. Boys engage more in solitary and instrumental activities. Traditional feminine sex roles encourage girls to acquire relational skills, that are needed to establish close, intimate relationships. They provide, however, few possibilities to obtain the necessary skills to function in a larger social group. Education and employment have been described as critical steps in the development of a sense of identity and autonomy in the absence of intimates. 


\subsection{5. acknowledgement by significant others}

A thought-provoking theoretical formulation about the mechanism by which situations affect. agoraphobic behavior is offered by the Durch psychologist van Zuuren (1982), who isolated 'behavioral freedon' and 'acknowledgement' as crucial characteristics of situations. Behavioral freedom refers to what is allowed, expected and prohibited in a specific situation, to rules and limitations that are imposed on the behavior of the person in that situation. Acknowledgement is similar to the formerly presented concept of 'validation' (section 2.4.4). It refers to the extent that the situation provides a direct reaction to the person's behavior and enhances the sense of identity. Acknowledgement can be provided by other people, by the environment and by activities. Acknowledgement by other people means that the person is identified by others as a specific and unique person. Environments may be acknowledging in that a familiar environment remembers the person who he/she is. Activities associated with a fixed role may acknowledge the person in that specific role and thereby enhance the sense of identity. Van Zuuren hypothesized that agoraphobic patients experience difficulties when normative directions are lacking and when they cannot identify themselves with a fixed role. In situations in which behavioral prohibitions exist, but for which agoraphobics feel that expectations or rules about how one should behave are absent, deficiencies in their sense of identity come forward. They feel "at a loss" if they cannot act in conformity with a specific role and if they are not continuously acknowledged by significant others.

Van Zuuren's typology characterizes various social situations, such as going into crowded places, being with an intimate person or being alone, in terms of acknowledgement and normative directions. Situations are classified into 4 main types: solitary, intimate, personal and anonymous situations. Solitary situations are situations in which no other persons are present, for instance being alone at home. In this type of situation, there are few normative directions, but no acknowledgement by other people. Intimate situations are defined as situations in which one is in the company of trusted persons in a familiar environment, e.g., at home with family. In intimate situations, one is recognized as a specific, unique person. There is a lot of acknowledgement by other people with relatively few normative directions. The members have clear expectations about each other's behavior, and discrepancies between actual and desired behaviors are less likely to occur (section 2.4.4). Personal situations are situations in which there is direct contact with another person in a specific role, e.g., with a client. In personal situations there are a lot of behavioral rules and moderate acknowledgement by other people. Anonymous situations are defined as situations in which someone is not accompanied by a signiticant other, yet other people are present with whom the person has hardly anything to do and if: in a neutral way, as mere numbers in a system. In anonymous situations, there are a lot of prohibitions, but few $\mathrm{u}$ les about: how one should behave. According to van Zuuren (1982), it is primarily because of the lack of acknowledgement by other people that agoraphobic patients experience discomfort in this type of situations. Agoraphobic patients get into trouble if they are not continuously acknowledged in their uniqueness by other people, and therefore, will fear and avoid solitary and anonymous situations.

Van Zuuren (1982) used questionnaires to investigate the reaction of phobic patients and normal controls to different types of situations. Unfortunately, the patients were not diagnosed according to DSM III criteria. The classification was mainly based on a written re- 
port of an intake interview. Phobic patients who reported fear or avoidance of solitary and anonymous situations in this interview were classified as 'agoraphobic'. In a first study, subjects received a list with descriptions of different types of situations and a list of behaviors with different levels of activation and control. Subjects had to judge whether the different behaviors were allowed in a specific situation. Phobic patients felt more restrictions to their behavior in different types of situations than normal controls. Especially behaviors with high levels of activation and low levels of control (e.g., shaking) were more often judged to be not allowed. Moreover, agoraphobics, especially agoraphobic women identified more obligations in different types of situations than patients with other phobias. In another study, different types of situations were related to feelings. In agoraphobic patients, feelings about a loss of identity were associated with situations with little acknowledgement by other people (solitary and anonymous situations). Although these results provide some evidence for van Zuuren's theory, they have to be interpreted with great caution, since these studies suffer from serious methodological drawbacks. The reliability and validity of the questionnaire data as well as the classification of the subjects can be questioned, and the data for subjects with specific phobias are based on small samples.

In summary, in this section the emotional meaning of agoraphobic situations was further explored. According to van Zuuren, agoraphobic patients experience discomfort in situations without acknowledgement by significant others, such as solitary and anonymous situations. Some evidence from questionnaire studies supporting this assumption was reviewed.

\subsection{Key Issues in Research on Panic Disorder and Agoraphobia}

Panic disorder has been related to biological, psychological and microsocial factors. At the biological level, some evidence for a familial link in panic disorder was presented. It is not clear, however, whether familial links are due to genetic factors or to patterns of familial interaction. Panic induction studies further led to the assumption that panic disorder is related to psychophysiological abnormalities in the acid base balance. Nevertheless, no specific biological mechanisms have been identified that sufficiently explain the results of these studies. Another indication of the role of biological mechanisms in panic disorder was found in drug treatment studies. These studies indicated that serotonergic pathways are implicated in panic disorder. Still, we can not conclude that biological abnormalities cause panic disorder. At the psychological level, studies about cognitive factors demonstrated that the response to panic induction procedures largely depends on expectations and the perception of control. Panic was then reconceptualized as fear of bodily sensations. Panic patients were found to spend selective attention to bodily sensations and to interpret these sensations as an indication of an impending disaster. At the microsocial level, the onset of panic disorder was found to be preceded by life events. Most evidence suggested that panic patients experienced a period of enhanced life stress and a number of major or minor life events prior to onset.

These factors did not differentiate panic patients without agoraphobia from panic patients with agoraphobia. In general, studies on biological factors provided little evidence for differences in biological vulnerabilities between panic patients with and without agoraphobia. Family studies indicated, however, that agoraphobia affects male and female relatives in a different way: female relatives of agoraphobic patients often develop anxiety disor- 
ders, while male relatives are at an higher risk for alcohol abuse. These findings may reflect culturally determined differences in response styles between men and women. Cultural factors may increase sex differences in the prevalence of agoraphobia: agoraphobic fears may be masked by alcohol abuse in men, but alcohol abuse in women may also be masked by agoraphobia.

Studies on psychological factors involved in panic disorder and agoraphobia revealed that agoraphobic patients experience more social anxiety than panic patients without agoraphobia. Thoughts about the social consequences of panic were also more prominent in agoraphobic patients. Furthermore, there is some evidence that panic disorder with agoraphobia is a more severe condition than pure panic disorder: panic patients with agoraphobia displayed more social anxiety, chronic anxiety and depression (section 2.2.2) and more fear of fear (section 2.2.4.). Psychoanalysts focused on the fear of leaving home and family instead of the fear of the street and public places. The role of separation anxiety, the fear of abandonment and proximity seeking in agoraphobia was highlighted in Bowlby's attachment theory. A similar shift in attention from fear of public places to the conceptualization of agoraphobia as anxiety in the absence of farniliarity and safety was noted in the safely signal perspective. Attachment theory led to a number of hypotheses about early life events, childhood anxiety disorders and child rearing practices in the parental family. Retrospective studies failed to provide evidence for these assumptions. Hypotheses based on psychoanalytic theories about the role of proximity seeking and separation anxiety in agoraphobia are difficult to test. Evidence for the safety signal perspective is based on animal studies. Evidence in men is mainly based on clinical observations. The lack of empirical evidence to support these theoretical assumptions may be due to methodological shortcomings.

At the macrosocial level, hypotheses about the social and cultural meaning of agoraphobic situations have been generated. At this level, agoraphobic fear and avoidance behavior was related to a lack of skills to function in the public domain and in the absence of significant others. Being in a familiar environment and in the presence of intimates has been described as providing acknowledgement to the sense of identity. Cultural factors influencing sex differences in the acquisition of these skills have been discussed. Furthermore, specific types of situations have been described that potentially increase or reduce the sense of safety in agoraphobic patients. Two types of situations have been identified, that are feared and avoided by agoraphobic patients, namely solitary and anonymous situations. On the other hand, intimate situations have been described as a potential source of positive experiences. Van Zuuren (1982) added the concept of 'acknowledgement' as a crucial characteristic of situations. Acknowledgement by significant others, by a familiar environment or by clearly goal-oriented activities that are associated with a fixed role enhance the sense of identity. Still, according to van Zuuren, acknowledgement by significant others is the most important characteristic predicting what agoraphobic patients will experience in different types of situations.

In the present study, we will describe the experiences of panic patients with and without agoraphobia in the course of daily life. First, we will focus on potential differences between panic patients with and without agoraphobia in the frequency and intensity of experiences of panic. Secondly, we will explore whether panic patients with and without agoraphobia differ in the amount of time spent in different types of daily life situations. 
And finally, we will try to identify individual, temporal and situational factors that potentially influence the occurrence of panic symptoms. The literature reviewed in chapter 1 and 2 thereby urges us to highlight the following issues: (1) individual variation; (2) demographic characteristics and associated social roles; (3) social anxiety and the severity of psychopathology; and (4) the role of acknowledgement by significant others in agoraphobia.

\subsection{1. individual variation}

Based on theories about the onset and maintenance of panic attacks, reviewed in this chapter, we do not expect to find large differences in the frequency and severity of panic attacks between panic patients with and without agoraphobia at the group level. Within groups, however, large individual variation can be expected. Literature about the relationship between panic disorder and agoraphobia indicated that there is a lot of individual variation in the patterning and severity of symptoms (chapter 1). In chapter 3, further evidence for individual variations in the frequency and severity of panic symptoms from studies conducted in the natural environment will be presented.

Based on the diagnostic criteria of agoraphobia, we would expect to find differences in the use of time in daily life between panic patients with and without agoraphobia. We can expect that agoraphobic avoidance behavior will be reflected in lower frequencies of specific types of daily life situations. Moreover, panic disorder with agoraphobia seems to be a more severe condition than panic disorder without agoraphobia and is often accompanied by other types of psychopathology, such as social anxiety and depression. Therefore, more severe psychosocial impairment and resiricted mobility may be expected in the agoraphobic group. Nevertheless, panic disorder and agoraphobia were both found to be associated with varying degrees of constrictions in life style. Impairment of work, leisure, domestic activities and social relationships have been noted in both groups (chapter 1). Daily life measures thus may be used to depict individual variations in psychosocial impairments within groups.

In the present study, daily life measures will be used to describe individual variations in the experience of panic and in the use of time. In chapter 5, differencis in the frequency and severity of panic experiences between panic patients with and without agoraphobia will be investigated. Variability in the experience of panic between and within individuals will be highlighted. Differences in the amount of time spent in different types of daily life situations between panic patients with and without agoraphobia and individual variations in the use of time within groups will be described in chapter 6 . And finally. in chapter 7 , the likelihood of observing panic experiences in the natural environment will be related to a number of individual, situational and temporal factors.

\subsection{2. demographic characteristics and associated social roles}

Agoraphobia is related to specific social roles. Epidemiological studies demonstrated that agoraphobia is more prevalent among women with a specific socioeconomic position: unemployed, married women with a lower socioeconomic status. Moreover, agoraphobia has been related to stereotyped feminine sex roles (section 2.4.2). In previous studies, little attention has been paid to the relationship between demographic characteristics and symp- 
toms of panic and agoraphobia. And this is an important shortcoming, since differences between panic patients with and without agoraphobia on daily life measures may reflect differences that are associated with demographic characteristics and social roles.

Differences in demographic characteristics between panic patients with and without agoraphobia, registered in the present study, will be presented in chapter 4 . Differences between panic patients with and without agoraphobia in the use of time in daily life will be described in chapter 6 . At the same time, we will try to estimate how differences in the use of time between these groups are affected by differences on demographic factors, such as sex, age, employment etc. And finally, in chapter 7 , we will explore whether demographic characteristics are related to fluctuations in the presence or absence of panic experiences.

\subsection{3. social anxiety and severity of psychopathology}

Panic disorder and agoraphobia often co-exist with other types of psychopathology, such as social fears, depression and generalized anxiety (chapter 1). Moreover, there is some evidence indicating that these co-existing symptoms are more prominent in panic patients with agoraphobia than in panic patients without agoraphobia (section 2.2.2.). Therefore, differences on daily life measures between panic patients with and without agoraphobia may also be due to the presence of other types of psychopathology. Differences in the use of time between panic patients with and without agoraphobia may, for instance, be related to differences between both groups in the presence of co-existing symptoms of depression. Depressed patients may have different life styles and display more severe forms of psychosocial impairments than non-depressed patients.

In the present study, panic patients with and without agoraphobia will be compared on retrospective measures of psychopathology, namely trait anxiety, social phobia and depression. Moreover, we will investigate how the severity of psychopathology is related to daily life measures of the frequency and severity of panic experiences as well as to the use of time in daily life.

In other studies, e.g. on patterns of interaction in the parental studies (section 2.3.1.), significant differences were often demonstrated between patients with panic disorder or agoraphobia and normal controls, but not between panic or agoraphobic patients and patients with other disorders. Therefore, daily life experiences of panic patients with and without agoraphobia will be contrasted to those of a group of normal controls and a group of neurotic controls (i.e., patients with other disorders) in order to distinguish factors that are specifically related to panic disorder or agoraphobia from factors that are more generally related to the presence of mental health problems.

\subsection{4. the role of acknowledgement by significant others in agoraphobia}

In this chapter, a number of hypotheses have been generated about characteristics of daily life situations that potentially increase or reduce the sense of safety in agoraphobic patients. The cultural and emotional meaning of agoraphobic situations was further explored. Fear of public places was related to a lack of skills to enter the public domain. Fear of being alone, on the other hand, was related to the incapacity to function autonomously out 
of the small circle of intimates. According to van Zuuren (1982), agoraphobic paticnts experience discomfort when there is a lack of acknowledgernent by intimate others. She hypothesized that agoraphobic patients get into trouble if they are not continuously acknowledged in their uniqueness by significant others. Based on these propositions, we felt that it is important to focus on characteristics of the social context in agoraphobia, and particularly on the presence or absence of significant others.

In the present study, a first attempt will be made to identify characteristics of daily life situations that affect experiences of panic in panic patients with and without agoraphobia. Subjects will describe the situational context of their experiences at randomly choosen moments in their daily life. These daily life situations will then be classified into different types according to their cultural and emotional meaning, using a coding system based on van Zuuren's (1982) typology. Daily life situations will be further evaluated according to the amount of acknowledgement by other people, by the environment and by activities. The coding system will be presented in further detail in chapter 4 . We expect that agoraphobic avoidance will be reflected in the amount of time spent in daily life situations. Based on the theoretical propositions presented in this chapter, we also can expect that agoraphobic patients will be more likely to experience symptoms of panic in situations with low levels of acknowledgement, and particularly in situations with a lack of acknowledgement by the presence of significant others. Acknowledgement by significant others is thus supposed to be the most important characteristic of daily life situations, that is specifically related to experiences of panic in agoraphobic patients. In chapter 6 , panic patients with and without agoraphobia will be compared in terms of the amount of time they spend in different types of situations. In chapter 7, the probability of observing a panic experiences will be related to characteristics of daily life situations.

\subsection{Research Questions}

Three main topics will be explored in the present study: (1) experiences of panic; (2) the use of time; and (3) the relationship between panic experiences and individual, temporal and situational factors in the course of daily life. Thereby, the following questions will be adressed:

(1) Panic experiences in daily life (chapter 5)

- can we provide a valid description of the experience of panic in daily life?

- do panic patients with and without agoraphobia differ in the frequency and severity of panic experiences in daily life?

how large is the amount of individual variation in the frequency of panic experiences?

- is the frequency and severity of panic experiences related to the severity of psychopathology? 
(2) Time allocation and avoidance in daily life (chapter 6)

- do panic patients with agoraphobia differ from panic patients without agoraphobia, neurotic and normal controls in the amount of time spent in different types of daily life situations?

- do panic patients with agoraphobia differ from panic patients without agoraphobia, neurotic and normal controls in the amount of time spent in situations with different levels of acknowledgement by other people, by the environment and by activities?

- is time use related to agoraphobia and to other measures of psychopathology? and

- how large is the individual variability in the amount of time spent in different types of situations?

(3) The predictability of panic experiences (chapter 7)

- are fluctuations in the presence or absence of panic experiences related to specific characteristics of daily life situations?

- are fluctuations in the presence or absence of panic experiences related to demographic and diagnostic characteristics of the subject?

- are fluctuations in the presence or absence of panic experiences related to temporal factors?

The methods and subjects will be introduced in further detail in chapter 4 . But, before we move on with a description of the methods, an overview of studies on panic disorder and agoraphobia in daily life will be presented in the next chapter. 


\author{
DAILY LIFE
}

The aim of the present chapter is to provide a comprehensive overview of studies on panic disorder and agoraphobia in daily life. First, two essential features of daily life research will be introduced, i.e. the ecological validity of this type of research and the prospective nature of the data. Secondly, the methods that have been used to study panic and agoraphobia in daily life will be reviewed. Next, the most important results of daily life studies about psychophysiological, psychological and behavioral responses associated with panic and agoraphobia will be summarized. Finally, some individual, situational and temporal factors related to naturally occurring panic attacks will be discussed.

\title{
3.1. Essential Features of Daily Life Research
}

Most of the studies about panic disorder and agoraphobia are carried out in the laboratory and rely on retrospective recall. In daily life studies about panic disorder and agoraphobia, prospective data are gathered in the natural environment or at least in a naturalistic setting. The power of daily life studies in comparison to studies based on experiments, cross-sectional questionnaires and clinical interviews lies in their ecological validity and in the lack of retrospective distortions. Therefore, methods presented in this chapter will be evaluated in terms of their ecological validity and according to the amount of retrospection that is needed.

\subsection{1. ecological validity}

Daily life studies are carried out in an environment that enhances ecological validity. Ecological validity refers to the occurrence and distribution of stimulus variables in the natural or customary habitat of an individual (Brunswick, 1949). Based on this definition, an investigation is considered to be ecologically valid if it is carried out in the natural environment and involves situations and activities from daily life. This definition is, however, too namow. As Bronfenbrenner (1979) pointed out, the ecological validity of a study should not depend merely on the setting in which it is carried out, but also to what extent the research procedure measures to what it is supposed to measure. Bronfenbrenner (1979), therefore, extended the definition of ecological validity: 'Ecological validity refers to the extent to which the environment experienced by the subjects in a scientific investigation has the properties it is supposed or assumed to have by the investigator' (p. 29). This definition urges that the research setting is evaluated in terms of their psychological meaning to the subjects. Characteristics of the research setting may influence the processes that take place within that situation and affect the interpretation and generalizability of the findings. If our goal is to provide true to life descriptions of panic disorder and agoraphobia, research has to be carried out in the natural environment or in carefully selected settings, having similar connotations as daily life situations. 


\subsection{2. prospective data}

Another crucial characteristic of studies using ambulatory monitoring devices is that they prospectively describe the actual behavior and the ongoing experience in the natural con text, and therefore prevent retrospective distortions. Looking back upon events may provide a totally different view on momentary experiences. Variance in subjects' retrospective reports of agoraphobic avoidance, for instance, has been reported as a major source of bias in diagnostic interviews (Manuzza et al., 1989; section 1.3.). Moreover, there is evidence that mood influences memory. From an extensive overview of studies about the relationship between (depressive) mood states and memory, Blaney (1986) concluded that mood-congruent events are more easily recalled. Martin et al. (1983) further demonstrated that selective recall of negative information about the self is associated with neuroticism, irrespective of depression. Subjects with high scores on a neuroticism scale were found to be more likely to selectively attend to negative information. In panic patients, selective information processing is thought to play an important role. Panic patients were found to spend selective attention to bodily sensations (section 2.2 .4 .). Therefore, we can expect to find higher frequencies of bodily sensations and panic symptoms in retrospect.

Retrospective measures and self-monitoring measures provide different results. Unfortunately, only a few studies have been carried out investigating differences between prospective and retrospective reports of patients with panic disorder. Diary studies on the relationship between anxiety and the menstrual cycle challenged the findings from retrospective studies, showing a retrospective exaggeration of premenstrual anxiety symptoms. Prospective data did not reveal a systematic exacerbation of anxiety and panic symptoms premenstrually (Cameron et al., 1987, 1988; Stein et al., 1989b). Moreover, there is also evidence that the frequency and severity of panic attacks is over-reported in retrospective reports (Rapee et al., 1990b; Margraf et al., 1987b). Margraf et al. (1987b) found important differences between retrospective and prospective reports of panic symptoms. Event samplings of panic symptoms indicated that palpitations, dizziness, dyspnea, nausea, sweating and chest pain or discomfort were noted most frequently. Fear of going crazy, faintness, trembling or shaking and fear of dying were reported more often in retrospect than in panic diaries. Furthermore, a larger number of symptoms was reported retrospectively, indicating a tendency toward retrospective exaggeration (Rapee et al., 1990b; Margraf et al., 1987b).

On the other hand, differences between retrospective measures and self-monitoring data may be due to some extent to the reactive nature of monitoring techniques (Nelson, 1977; Barlow et al., 1984c). In studies comparing the self-monitored frequency of panic attacks to interview data based on a period of time prior to the self-monitoring period (e.g., Rapee et al., 1990b), the therapeutic reactivity of self-monitoring can play some role. Nevertheless, in other studies comparing prospective and retrospective data over the same period of time (e.g. Cameron et al., 1987, 1988), the same discrepancies between ambulatory monitored and retrospective measures were demonstrated. Therefore, it seems more likely that retrospective exaggerations are due to a tendency to selectively recall negative information. 


\subsection{Methods of Research in Daily Life}

In this review, studies about panic disorder and agoraphobia in daily life will be classified according to the setting in which they are carried out, according to the types of responses that are measured, and according to the method used to collect the data. In this chapter, studies carried out in two types of settings will be reviewed: either the natural or a naturalistic environment. Measurements include three types of responses: psychophysiological measures (e.g., heart rate, physical activity), psychological measures (e.g., self-reports about mood, cognitions, symptoms of panic and anxiety) and behavioral measures (e.g., performances during behavioral tests). The methods used to collect the data can be classified into three main categories: event sampling, time sampling and continuous recordings. In event sampling studies, subjects are instructed to collect information about the occurrence of specific events. In time sampling studies, subjects record information about their actual experience at different time points during the day. Continuous recordings are mainly used to monitor psychophysiological responses. Classification of studies along these dimensions results in a matrix as depicted in figure 3.1. Actually, the studies can not be classified into a single cell of this matrix. Most of the studies involved different combinations of cells.

\section{figure 3.1.}

Classification of daily life studies about panic disorder and agoraphobia.



\subsection{1. ambulatory monitoring during behavioral avoidance tests}

Behavioral avoidance tests can be divided in two major types: standardized and individualized behavioral avoidance tests. Standardized behavioral avoidance tests involve a behavioral walk along a fixed route, which is divided in parts of approximately equal lenght. Individualized behavioral avoidance tests involve exposure to situations that are feared and avoided by the individual. First, a hierarchy of phobic situations is constructed for each subject separately. Then, situations with different levels of severity are selected and the subject is instructed to attempt increasingly difficult steps. In both types of bchavioral avoidance tests, the number of completed steps is used as a measure of avoidance. In most studies, subjects rate the amount of subjective anxiety experienced at each step. In some 
studies, ambulatory monitoring devices were added to measure psychophysiological responses during the behavioral avoidance test. An overview of ambulatory psychophysiological monitoring techniques is given by Turpin (1985).

This type of studies was found to be useful to describe behavioral, psychological and psychophysiological responses to agoraphobic situations. Heart rate responses during repeated behavioral walks and resting baseline phases have been compared for agoraphobic patients and matched healthy controls (Holden \& Barlow, 1986). One study focused on changes in psychophysiological measures in panic attacks experienced during an individualized behavioral avoidance test (Woods et al., 1987). Behavioral avoidance tests have further been used as outcome measures in many treatment studies (Barlow et al., 1980; Vermilyea et al., 1984; Jansson et al., 1986; Craske et al., 1987b; Michelson et al., 1985, 1990a). A discussion on the use of behavioral avoidance tests as outcome measures to evaluate the treatment of agoraphobia is given by Himadi et al. (1986b). Additional cognitive assessments have been carried out in a number of studies (Last et al., 1984a/b, 1985a; Michelson, 1986; Marchione et al., 1987; Kenardy et al., 1988). Cognitive assessments consisted of audiotaping verbalized thoughts during behavioral tests.

\subsection{2. self-monitoring in daily diaries}

A second approach, that has been used for many years to measure treatment outcome is self-monitoring in daily diaries. Two major types of diaries have been used: (1) anxiety/ panic diaries, including information about the frequency, severity, duration and symptoms of panic and anxiety; and (2) behavioral diaries, including questions on activities outside the home. A detailed description of self-monitoring devices is given by Barlow et al. $(1984 \mathrm{c})$.

In a number of treatment outcome studies, subjects completed daily diaries beginning at least 1 week before treatment and continued throughout treatment with sometimes an additional week at follow-up (Barlow et al., 1984a, 1989; Waddel et al., 1984; Borkovec \& Matthews, 1988; Adler et al., 1989). In the diaries used in these studies, subjects rated their level of generalized anxiety 3 or 4 times a day and reported information about discrete periods of intense anxiety, including panic attacks. The diary was filled out at specified time points during each day. Improvement in daily ratings of generalized anxiety and the frequency, duration and intensity of intense anxiety episodes was often compared to improvement rates on other outcome measures (clinical ratings, questionnaires and psychophysiological measures during relaxation and stressor tasks in the laboratory). In one study, subjects also recorded their thoughts during episodes of intense anxiety (Waddel et al., 1984).

Diaries have also been used to study the relationship between symptoms of anxiety or panic and the menstrual cycle (Cameron et al., 1987, 1988; Stein et al., 1989b). The frequency and severity of panic attacks, panic symptoms, generalized anxiety, symptoms of depression and premenstrual complaints were rated daily for at least one full menstrual cycle. 


\subsection{3. combinations of diaries and behavioral avoidance tests}

Several treatment outcome studies combined diaries with assessments during behavioral avoidance tests. Examples of the combination of panic diaries with behavioral avoidance tests were given by Mavissakalian et al. (1987) and Clark et al. (1985). In vivo assessments of cognitions and continuous recordings of heart rate measures during behavioral avoidance tests have been added to daily panic records by Michelson et al. (1990b). Diaries about activities outside the home, including anxiety ratings during these activities, were used to evaluate different types of treatment (Mavissakalian \& Michelson, 1983, 1986; Barlow et al., 1984b; Micheison \& Mavissakalian, 1985; Rachman et al., 1986; Mavissakalian, 1987b). The results of continuous recordings of heart rate during behavioral avoidance tests have been described by Michelson and Mavissakalian (1985) and by Mavissakalian (1987b). Other studies combined behavioral avoidance tests and panic diaries with self-monitoring of activities outside the home (Arnow et al., 1985; Telch et al., 1985; Johnston et al., 1988).

\subsection{4. event sampling techniques}

With event sampling methods, reports are linked to a specific event. Subjects are asked to complete a self-report each time a specific event (e.g., a panic attack) occurs. Event sampling techniques have been used in a number of studies in order to estimate the frequency and distribution of panic attacks and anxiety episodes in daily life. Uhde et al. (1985a), for instance, briefly described the results of daily self-monitoring in a study about the longitudinal course of panic disorder. In this study, retrospective life-charts were completed with prospective data from daily self-ratings and weekly staff-rated measures in 10 panic patients over a period of 2 years.

Event sampling in diaries was further used to investigate the frequency and distribution of different types of panic attacks. In a study by Gurguis et al. (1988), patients with panic disorder or agoraphobia with panic attacks were asked to record the occurrences of four types of panic attacks during one week. The panic attacks were categorized as unexpected or situational panic attacks and as full blown or limited symptom attacks.

Other studies compared daily panic diaries of panic patients with and without agoraphobia (Street et al., 1989; Ganellen et al., 1986). Street et al. (1989), for instance, investigated the frequency and the nature of panic attacks in panic patients with different levels of agoraphobia. Subjects filled out questionnaires during or immediately after the occurrence of each of three consecutive panic attacks. The questionnaires included questions about the extent to which the panic attack was expected, whether the attack was associated with external cues, whether they expected to panic again in similar circumstances in the future, whether they expected to have a good or bad day. Subjects also rated items about mood, stressful life events, maladaptive thoughts, fear and severity of bodily sensations at the time of the attack. Ganellen et al. (1986), on the other hand, instructed subjects to classify panic attacks as spontaneous major panic (no apparent cause, at least 3 symptoms), spontaneous minor attacks ( 1 or 2 symptoms) and situational attacks (in a phobic situation or during anticipation of a phobic situation, 3 or more symptoms). 
Başoğlu et al. (1992) used a 'modified event sampling' procedure in a group of panic patients with agoraphobia. Subjects were asked to record information on three (not necessarily consecutive) days that were typical of their life style, daily events and symptoms. At the same time, subjects were instructed to select days when they did have panic attacks. They started with the registration of episodes of anxiety and panic from the first moment they felt anxious or panicky throughout the rest of the day. Episoces of anxiety and panic were classified into two categories: situational/expected/predictable versus spontaneous/unexpected/unpredictable. The classification was mainly based on two questions: (1) whether the patient had expected the episode; and (2) whether the episode was linked to a situation that usually triggered similar episodes.

\subsection{5. combinations of event sampling techniques and continuous recordings of psy- chophysiological responses}

Studies combining event sampling with ambulatory monitorings of psychophysiological responses further highlight characteristics of naturally occurring panic allacks. Hibbert and Pillsbury (1988, 1989) investigated the role of hyperventilation during panic attacks by combining ambulatory transcutaneous carbon dioxide monitoring with event sampling in diaries. Subjects were instructed to complete a diary immediately after experiencing symptoms. The experience of symptoms was recorded by an event marker button. Diaries included information about the level of anxiety, physical exertion, the nature of the activity and physical symptoms experienced. If a period of severe anxiety was experienced, subjects were questioned later in order to determine whether the event was a DSM III defined panic attack. Patients were encouraged to go out and to enter phobic situations. Normal controls continued their normal daily activities, but were instructed not to undertake formal exercise. At the end of the monitoring period, subjects underwent a hyperventilation provocation test.

Taylor et al. (1986) combined event samplings of panic attacks with continuous ambulatory monitorings of heart rate and physical activities during 6 days. On at least one day, an ECG monitor was added to the equipment to validate the heart rate recordings and to determine whether the subjects had arrhythmias. Subjects were instructed to record in a diary all panic attacks and all episodes of anticipatory anxiety. Subjects classified the episodes as major spontaneous panic attacks (sudden onset, little or no provocation, 3 or more symptoms), minor attacks (spontaneous, fewer than 3 symptoms), situational panic attacks (in a feared situation, 3 or more symptoms) or anticipatory anxiety episodes (fewer than 3 symptoms). Independent observers rated panic attacks based on criteria for heart rate accelerations without physical activity (definite panic attack) or greater than expected from the level of physical activity (probable panic attack). Observer-rated panic attacks were compared to self-repoited panic attacks. Heart rates and levels of physical activity during self reported panic attacks were further compared to those occurring exactly 24 hours later. Margraf et al. (1987b; in preparation) used the same procedure in panic patients with and without agoraphobia and in normal controls. In addition to the panic diaries, subjects recorded information about activities outside the home. 


\subsection{6. time sampling techniques}

In time sampling studies, subjects are asked to describe several times a day how they feel, where and with whom they are, what they do and so on. Subjects are instructed to fill out a self-report form either at fixed or at randomized time points during the day. In the present study, a random time sampling technique, called the Experience Sampling Method (ESM), will be used. ESM is designed to obtain self-reports about experiences at randomly chosen moments in daily life (deVries, 1987, 1992). To accomplish this, the subjects carry a terminal watch that signals them several times a day. At each signal the subject completes a self-report form (instruments and procedures are described in further detail in section 4.3).

ESM has been applied in a case study to evaluate treatment outcome in an agoraphobic patient by Delle Fave \& Massimini (1992). Data were gathered at nine repeated sampling periods during one year. In this study, ESM was used in order to detect steady changes in the experiences over time in the progress of therapy. The relationship between experiences of anxiety and the situational context is further illustrated in a case study by Dijkman \& deVries (1987). Preliminary findings of the present study have been reported by Dijkman $\&$ deVries (1991). A comparison between panic patients and patients with other disorders has been offered by deVries et al. (1988). ESM has also been combined with time samplings of psychophysiological measures. Nicolson (unpublished data) combined ESM with measures of salivary cortisol. As soon as possible after each signal, subjects completed ESM forms and simultaneously collected saliva samples.

An example of time sampling of psychological and psychophysiological responses at fixed time points is found in prospective studies on circadian rhythms in the severity of symptoms in patients with panic disorder (Cameron et al., 1986b). Panic patients and normal subjects rated their level of anxiety 5 times a day at fixed time points. Time of sleep and waking was recorded. Pulse rates and oral temperature were measured at each time point. The results of this study were compared to a retrospective study on fluctuations in anxiety levels.

\subsection{7. combinations of time sampling techniques and continuous recordings of psy- chophysiological responses}

A first example of the combination of time sampling with continuous monitoring techniques was given by Taylor et al. (1983), who ambulatory monitored heart rate and physical activity during a $24 \mathrm{~h}$. period in 10 panic patients. Every 15 minutes the subjects completed a diary about their activity level, anxiety and panic. Shear et al. (1987) further investigated rhythm disturbances and heart rates in panic patients by means of 23 hours ambulatory ECG recordings. Symptoms were rated during 15 minute intervals throughout the period of recording. Intervals during which the patient experienced symptoms of anxiety or panic were examined for arhythmias. Heart rate changes during panic and anxiety were examined by comparing the peak heart rate to the peak heart rate in the previous interval. And finally, Gaffney et al. (1988) ambulatory monitored ECG's, heart rates and physical activity levels in panic patients and normal controls for a period of 3 to 6 days. Psychophysiological changes during spontaneous panic attacks were compared to those occurring 
during lactate induced panic attacks. Hourly diaries were completed, including information on panic episodes and activities that might increase heart rate.

\subsection{8. combinations of event sampling and time sampling techniques}

Time and event sampling techniques have been combined by adding an event marker button to the time sampling equipment. Freedman et al. (1985), for instance, collected physiological data through 24 hours ambulatory monitoring on two consecutive days in panic patients and normal controls. Self-ratings of anxiety and an event diary were completed after each recording hour. An event marker button was added in order to register the occurrence of panic attacks. Additional information was gathered after each panic attack. In a similar way, Anastasiades et al. (1990) combined continuous recordings of various psychophysiological responses (ECG, respiration, transcutaneous carbon dioxide and physical activity) with time sampled diaries and mood scales at fixed intervals. An event marker was added to indicate significant events. In another study, heart rate, physical activity levels and cognitions were sampled during a. 6 to 8 hour period of normal daily activity in 5 patients with panic disorder (Kenardy et al., 1989). Subjects were instructed to report their cognitions as they occurred. The device included an event marker button to indicate when thoughts were reported or when anxiety was experienced. The event marker was further used to indicate the severity of distress. Subjects were also asked to report their cognitions in a self-report form at 30-minute intervals, after a signal was given by timer. Instructions and a training period were given during the morning hours. Subjects were then asked to do what they would normally do during that day and to return in the evening.

Recently, more sophisticated devices have been developed. Taylor et al. (1990), for instance, used a prograrnmable hand-held computer to collect time and event sampling data in 20 panic patients. The device produced a signal and administered a set of questions at every hour between $7.00 \mathrm{a} . \mathrm{m}$. and $11.00 \mathrm{p} . \mathrm{m}$. Subjects were further instructed to answer the same set of questions when they were having a panic altack. The computer recorded the time when the questions were completed. Data were collected during 7 days. On the average, subjects completed. $88 \%$ of the hourly ratings. Compliance rates ranged between $64 \%$ and $98 \%$. The mean interval between the signal and the response was 2.6 minutes.

\subsection{Responses associated with panic disorder and agoraphobia}

Over the last 10 years, a large number of studies about panic disorder and agoraphobia in daily life have been conducted. In general, the results of these studies demonstrate that ambulatory monitoring techniques are useful tools to provide a clear picture of panic and anxiety in daily life. Ambulatory monitoring during behavioral avoidance tests allowed to describe behavioral, psychological and psychophysiological responses during exposure to agoraphobic situations. Daily diaries provided valid treatment outcome measures of anxiety and panic frequency and intensity. Several studies demonstrated significant improvement on diary measures of panic frequency and measures of anxiety during behavioral tests after treatment (Mavissakalian et al., 1987; Clark et al., 1985; Michelson et al., $1990 \mathrm{~b}$ ). In this section, results of outcome studies will only be included if they highlight psychophysiological, psychological and behavioral responses associated with panic disorder and agoraphobia. 


\subsection{1. psychophysiological responses}

The combination of event samplings of panic attacks with ambulatory transcutaneous carbon dioxide monitoring revealed that hyperventilation is not a necessary condition for the experience of panic attacks. Hyperventilation occurred in some panic attacks of some patients, but not in all. Hyperventilation during panic attacks was not associated with a specific cluster of physical symptoms. Neither was there a significant association between responses to hyperventilation provocation tests and the ambulatory monitoring of hyperventilation during panic attacks in the natural environment (Hibbert \& Pillsbury, 1988, 1989).

Assessments of heart rate responses during repeated behavioral walks and resting baseline phases (before and after the exposure) revealed important differences between agoraphobic patients and matched healthy controls (Holden \& Barlow, 1986). Agoraphobic patients had significantly higher heart rates during the test as well as during baseline episodes. Moreover, the variability in heart rate between different steps of the behavioral walk was significantly larger in agoraphobic patients than in healthy control. Patients experiencing panic attacks during exposure also displayed larger heart rate responses than matched healthy controls (Woods et al., 1987). Blood pressure, MHPG and cortisol responses did not differentiate patients from healthy subjects. Growth hormone and prolactine responses were slightly smaller in patients than in controls.

Naturally occurring panic attacks were often found to be associated with elevated heart rate responses (Taylor et al., 1983, 1986; Freedman et al., 1985; Margraf et al., 1987b, in preparation; Shear et al., 1987; Woods et al., 1987; Gaffney et al., 1988; Kenardy et al., 1988, 1989). Only a minority of panic attacks was found to be associated with simple arhythmias (Shear et al., 1987; Gaffney et al., 1988). Margraf et al. (in preparation) demonstrated that heart rate elevations aiso occurred during baselines prior to panic episodes. Nevertheless, naturally occurring panic attacks are not always associated with increased heart rates (Gaffney et al., 1988; Margraf et al., in preparation). Gaffney et al. (1988), for instance, compared psychophysiological changes during spontaneous panic attacks to those occurring during lactate induced panic attacks. Large increases in heart rate were observed in response to lactate infusion, both in panic patients and normal controls. About half of the naturally occurring panic attacks were, however, not associated with heart rate changes. Eight out of the 31 panic attacks were associated with increased heart rates; and 6 attacks were associated with increased heart rates and increased activity levels.

High mean heart rates were observed during continuous recordings of heart rate responses of panic patients in daily life (Kenardy et al., 1989), but this study did not include a reference group of normal controls. Freedman et al. (1985) demonstrated that panic attacks were characterized by heart rate increases and changes in peripheral temperature, but no differences were found in the average levels of heart rate and peripheral temperature between panic patients and normal controls. Similar findings were reported by Cameron et al. (1986b): no significant differences were found between panic patients and normal controls in pulse rates and oral temperature. In a recent study, panic patients were found to have significantly higher heart rate levels (both during sleep and during the waking day) and significantly more variable heart rates than normal controls (Anastasiades et al., 
1990). But, it is not clear whether the panic patients experienced panic attacks during the sampling period.

In general, heart rates were often found to be elevated in panic patients during panic attacks, during exposure to fear-provoking situations as well as immediately before and after exposure, but it is not clear yet whether heart rate responses are increased in panic patients during episodes with little anxiety.

An important problem in interpreting results of ambulatory monitored heart rate responses is the reliability and validity of these measurements (Turpin, 1985). Low test-retest reliability of heart rate responses (and other psychophysiological measures) has been demonstrated in normal subjects during assessments in the laboratory (Arena et al., 1983). Heart rate responses during baseline assessments were found to be moderately stable when the assessments were repeated within one week. In reaction to laboratory stressor tasks, however, normal subjects displayed extremely variable heart rate responses. Most of the studies reviewed in this chapter, provide little information on the reliability and validity of psychophysiological measurements. In several studies, only coefficients of agreement between raters counting heart beats have been computed (e.g., Vermilyea et al., 1984; Michelson et al., 1985, 1990a/b). Taylor et al. (1986) validated ambulatory monitored heart rates through concurrent ECG assessments. Low test-retest reliability of heart rate responses during behavioral avoidance tests was found in one study (Holden \& Barlow, 1986). The reliability and validity of ambulatory monitored psychophysiological responses certainly warrants further study.

\subsection{2. cognitive responses}

Cognitive measures during exposure provided clear phenomenological descriptions of cognitions occurring during episodes of anxiety and panic in fear-provoking situations. Anxiety and panic were found to be associated with negative cognitions (Last et al, 1985a; Kenardy et al., 1988, 1989). Studies using ambulatory monitoring during behavioral avoidance tests (Marchione et al., 1987; Michelson et al., 1990b) and diary studies (Waddel et al., 1984) indicated that treatment outcome is associated with increases in the frequency of positive cognitions and decreases in the frequency of negative cognitions.

The reliability and validity of cognitive assessments can be questioned. Assessments of cognitions were found to be poor indicators of treatment outcome. A marked decrease in the number of negative cognitions often occurred during the pretreatment baseline phase and extreme variability of cognitions across sessions was demonstrated (Last et al., 1984b). In 4 agoraphobic patients, the in vivo cognitive assessment was compared to imaginal cognitive assessment and thought-listing procedures (Last et al., 1985b). During the imaginal cognitive assessment, subjects were asked to imagine a difficult phobic situation. When they obtained a clear image of the situation, they verbalized their thoughts. The thought-listing procedure consisted of a written report of thoughts during exposure, which were recalled immediately after the in vivo cognitive assessment. Results obtained with each of these measures were very unstable over time, even without intervention. Furthermore, there was little congruency between the 3 measures. The amount of variability over time even without any therapeutic intervention, together with the lack of congruency be- 
tween different types of cognitive assessments, questions the generalizability and validity of findings about cognitive changes during treatment.

\subsection{3. behavioral responses}

On behavioral diary measures, improvement after treatment was reflected in a large decrement in anxiety during activities outside the home. All subjects increased frequencies of excursions and the total time spent outside the home (Mavissakalian \& Michelson, 1983, 1986). However, improved subjects reported significantly less subjective anxiety during these outings than subjects with little improvement. In a longitudinal ESM case study, improvement in anxiety symptoms was also found to be associated with significant changes in activities (Delle Fave \& Massimini, 1992).

Several studies included self-monitorings of activities outside the home. But in general, little information was gathered about differences in the frequency and type of excursions outside the home between panic patients and normal controls, and between panic patients with and without agoraphobia. In one study, panic patients without agoraphobia reported more anxiety during activities outside the home than normal controls, but both groups did not differ in the number or type of excursions (Margraf et al., 1987b).

Differences between panic patients with and without agoraphobia in the amount of time spent in different types of situations have further been investigated with ESM. Preliminary results of the present study indicated that restricted mobility is not only found in agoraphobic patients, but also in panic patients without agoraphobia and patients with other disorders (Dijkman \& deVries, 1987; deVries et al., 1988).

\subsection{4. desynchrony between response systems}

Desynchrony between behavioral, psychological and psychophysiological response systems (Hodgson \& Rachman, 1974) has been demonstrated in several studies. In studies using behavioral avoidance tests as outcome measures, synchroneous changes in subjective anxiety and heart rates over time were only found in some of the patients (Barlow et al., 1980; Vermilyea et al., 1984; Jansson et al., 1986; Craske et al., 1987b; Michelson \& Mavissakalian, 1985; Michelson et al., 1985, 1990a; Mavissakalian, 1987b). It has also been hypothesized that synchrony between response systems is associated with a better treatment outcome (Barlow et al., 1980; Michelson \& Mavissakalian, 1985; Michelson et al., 1985). Several studies failed, however, to demonstrate a significant relationship between synchrony and treatment response (Vermilyea et al., 1984; Craske et al., 1987b; Mavissakalian, 1987b).

Results of studies about the relationship between treatment outcome and synchrony between response systems are difficult to compare, since different outcome criteria and difle. rent operationalisations of synchrony/desynchrony have been used. Moreover, studies about the relationship between treatment outcome and ambulatory monitored measures during behavioral avoidance tests are often based on small samples. For instance, the number of subjects included in the studies reviewed in section 3.1.1 vary between 3 subjects (Barlow et al., 1980) and 39 subjects assigned to 3 different treatment conditions (Miche]son et al., 1985). 
In event and time sampling studies, psychophysiological and cognitive responses were not always found to be associated with a subjective experience of panic. Kenardy et al. (1988, 1989), for instance, demonstrated that panic attacks were associated or precipitated by heart rate accelerations and an increasing frequency of negative cognitions. But negative cognitions and increasing subjective anxiety were also reported during periods of accelerated heart rate, that were not identified as panic attacks. Neither was there a consistent association between heart rates and cognitions.

Discrepancies between psychological and behavioral responses were further demonstrated in diary studies. Panic and behavioral diaries do not always show consistent improvement. Johnston et al. (1988), for instance, investigated the efficacy of clomipramine hydrochloride in the treatment of agoraphobia. In this study, daily diaries of anxiety and activities outside the home were combined with ambulatory monitoring of heart rate and self-reported anxiety during a behavioral avoidance test. Significant differences emerged between the clomipramine and the placebo groups on cross-sectional questionnaire data and on one index based on the daily anxiety scale, i.e. the number of days during the week in which panic episodes were reported. Other measures based on the daily diaries and the behavioral avoidance test failed to distinguish between the clomipramine and the control groups. In other studies, improvement was demonstrated both in panic and in activity diaries, depending on the type of treatment (Amow et al., 1985; Telch et al., 1985).

In general, measures of the same type of response gathered with different methods (e.g., performance in a behavioral test and behavioral diaries) provided more consistent results than measures of different response systems gathered with one method (e.g., heart rates and subjective anxiety during behavioral tests). Nevertheless, it can not be excluded that desynchrony between responses also exists within the same response system. Desynchrony may occur, for instance, between different cognitive responses (section 3.3.2).

\subsection{Individual, Situational and Temporal Factors related to Panic}

Retrospective reports indicated that symptoms of panic and agoraphobia fluctuate on a day-to-day basis (section 1.7). Repeated measurements during the course of daily life are especially suited to study fluctuations in the experience of panic and agoraphobia over a short period of time. Studies carried out in the natural environment highlight the variability in experiences between and within subjects. These studies allow to relate fluctuations in symptoms of panic to characteristics of the individual and to characteristics of the situational context in which these symptoms are experienced. Moreover, daily life studies may uncover diumal patterns in the onset of panic symptoms.

\subsection{1. characteristics of the individual}

Event samplings of panic attacks allow to estimate the frequency and distribution of panic experiences in daily life. Large variability in the frequency of panic attacks, as well as in symptoms associated with panic, were found both between and within individuals (Taylor et al., 1983; Unde et al., 1985; Margraf et al., 1987b; Rapee et al., 1990b; Başoglu et al., 1992). In the study by Margraf et al. (1987b), for instance, the number of panic attacks per subjects varied considerably. Each patient reported at least 1 panic attack, most patients noted 1 or 2 attacks, but some reported 8 or 9 attacks in 6 days. Moreover, 
evidence was found for large intra-individual variations in the experience of panic symptoms: different symptoms were registered by the same subject during separate attacks (Rapee et al., 1990b).

Untill now, little research has been carried out to investigate characteristics of patients that may be related to individual variations in the frequency and severity of panic attacks. In some studies, systematic differences between panic patients with different levels of agoraphobic avoidance have been explored, but in general these diagnostic categories were not found to be associated with important differences in the experience of panic symptoms in daily life. In event sampling studies, few differences have been found between panic patients with and without agoraphobia in the frequency and types of panic attacks (Street et al., 1989; Margraf et al., in preparation). Neither were there significant differences in heart rate or physical activity levels between panic patients with and without agoraphobia (Margraf et al., in preparation). Even anxiety episodes in panic patients and normal controls were found to be similar, although the episodes were more intense and associated with a larger number of symptoms in panic patients (Margraf et al., 1987b).

The results of the different studies are difficult to compare, because of different classifications of panic attacks. Street et al. (1989) found no significant differences between panic patients with mild agoraphobia and panic patients with moderate or severe agoraphobia in the frequency and type of attacks (cued/uncued and expected/unexpected). Ganellen et al. (1986) also failed to find significant differences between panic patients with and without agoraphobia in the frequency of minor, situational or the total number of panic attacks, as well as in the intensity of attacks. The panic patients without agoraphobia reported, how ever, significantly more spontaneous major panic attacks than the agoraphobic subjects.

\subsection{2. characteristics of the situational context}

In studies carried out in the natural environment, a majority of panic attacks was found to be associated with external or internal cues and precipitating events (Freedman et al., 1985; Margraf et al., 1987b; Street et al., 1989; Başoğlu et al., 1992). In one study, panic attacks which were expected and associated with external cues occurred with more stressful life events at the time of the attack than uncued and unexpected panic attacks (Street et al., 1989). In other studies, spontaneous attacks were found to occur more often at home than situational panic attacks (Margraf et al., 1987b; Başoglu et al., 1992). In the study by Margraf et al. (1987b), situational attacks were registered most frequently in a car, and often while driving on a freeway. When a spontaneous attack occurred at home, little information was gathered about the circumstances. Nevertheless, in the few cases that a description of the circumstances was provided, patients were alone or just had a fight with their spouses. A rather large amount of the so-called spontaneous attacks then appeared to occur in the same situations as situational attacks, for instance while eating in a restaurant, leaving home or driving a car. Başoğlu et al. (1992) more systematically registered antecedent cues of spontaneous panic attacks. In this study, all the spontaneous panic attacks occurring during waking hours were found to be preceded by 'minor events', such as ringing of the telephone, worries, arguments with relatives, etc.

In several studies, situational and expected panic attacks were found to be more severe and intense than spontaneous/unexpected panic attacks. Expected panic attacks were found to 
be associated with more physical sensations prior to panic and more disturbing thoughts during panic than unexpected panic attacks (Street et al., 1989). Situational panic attacks were found to be more intense and were associated with more symptoms than other types of panic attacks and anxiety episodes (Taylor et al., 1986; Margraf et al., 1987b). Başoglu et al. (1992) found no significant differences between situational and spontaneous panic attacks in intensity, number of symptoms, anxiety levels prior to the panic episode, duration and time of onset. Panic attacks occurring outside the home tended, however, to differ from those occurring at home in duration (shorter) and in the type of symptoms (less intense palpitations and dyspnoea, more shaking/trembling). But, the validity of subjects' ratings of cues and situations in which panic attacks occur can be questioned. In the study by Street et al. (1989), for instance, subjects identified cognitions and dreams as 'external' cues.

\subsection{3. temporal factors}

Conflicting evidence was found in studies about the distribution of panic attacks over time. Some studies failed to find systematic fluctuations in the onset of panic (Uhde et al., 1985a). In other studies, panic attacks were also found to be randomly distributed during the day, with the exception that major spontaneous panic attacks were more often recorded during the evening and the night than situational attacks (Taylor et al., 1986; Margrat' et al., 1987b). Margraf (1990) further conducted a meta-analysis on circadian thythms in the onset of 911 panic attacks recorded in 5 event sampling studies (Taylor et al., 1986; White \& Baker, 1986; Margraf et al., 1987b, in preparation; Shear et al., unpublished data). These data indicate a circadian pattern with a peak in the moming hours (between 9 a.m. and 14 p.m.). In a similar way, Başoglu et al. (1992), found that panic attacks occurred most frequently between $8 \mathrm{a} . \mathrm{m}$. and 4 p.m. and least between midnight and 8 a.m. Cameron et al. (1986b), on the other hand, found that anxiety levels and the frequency of panic attacks increased in the late afternoon. Finally, some evidence for the clustering of panic attacks, especially unexpected full blown panic attacks, on certain days was found (Gurguis et al., 1988).

\subsection{Discussion}

A large number of innovative and increasingly sophisticated techniques have been developed to study panic disorder and agoraphobia in daily life. Different methods may provide different types of information. The choice of the method is of paramount importance if we want to quantify specific aspects of panic disorder and agoraphobia. The diversity in ambulatory monitoring techniques should allow the researcher to select a method, that is optimally suited to adress specific questions about daily life experiences. Different sampling procedures have different advantages and drawbacks. In the present study, we will describe daily life experiences of panic patients with and without agoraphobia by means of the Experience Sampling Method. The choice of ESM was mainly based on three considerations. First, we wanted to enhance the ecological validity by minimizing the potential reactivity of the method. Secondly, we wanted to minimize retrospective distortions and to gather detailed information about compliance. And finally, our aim was to provide a general picture of the daily life of panic patients with and without agoraphobia without narrowing our vision to symptoms and illness. 
As we have pointed out in section 3.1., the choice of the sampling technique may enhance the ecological validity of the study. Studies using ambulatory monitoring devices during exposure to fear-provoking stimuli, for instance, are not always conducted in the natural environment of the patient. The setting is - sometimes literaly - situated half-way the laboratory and the home environment. The psychological meaning of the setting in which assessments are carried out, should ascertain the ecological validity of these studies. Especially in individualized behavioral avoidance tests, settings are selected in order to be representative of fear-provoking situations in which the agoraphobic subject experiences difficulties in daily life. Nevertheless, it can not be ruled out that the behavioral task is not experienced as a daily life situation. In a study by Barlow et al. (1984b), for instance, some subjects were able to complete a standardized behavioral avoidance test though they reported they would not have been able to do so if it were not a 'test'. Moreover, some studies relied on rather intrusive methods, such as blood samples, to assess psychophysiological responses (e.g., Woods et al., 1987). The ecological validity of this study can be questioned. Subjects were removed in the midst of the exposure to obtain blood samples. Moreover, this type of assessment may be fear-provoking in itself. Continuous ambulatory monitoring or less intrusive methods of physiological assessments would have been preferable.

Event and time sampling techniques can both be supplemented by psychophysiological measures, although this type of assessment may also disrupt daily activities. An important disadvantage of the study by Cameron et al. (1986b), for instance, is that the sampling method largely interferes with normal daily routine: Subjects were instructed to sit or lie down for at least 10 minutes and to avoid intense exercise for at least 30 minutes before the measurement of pulse rates and oral temperature, and these measurements were repeated 5 times a day.

In comparison to psychophysiological assessments carried out in the laboratory, continuous ambulatory monitoring techniques enhance the ecological validity of this type of measurements. In spite of this, the ecological validity of these studies can also be questioned. The research is carried out in the natural environment, but it is difficult to judge whether the psychological meaning of the setting changes by wearing the ambulatory monitoring equipment. Only a few attempts have been made to investigate the possible reactivity of psychophysiological measurements in panic patients. Margraf et al. (in preparation) hypothesized that wearing physiological monitoring equipment may be reassuring to the patients. In order to test this hypothesis, they compared panic attack diaries kept during two periods of 3 days either with or without concurrent psychophysiological monitoring. No significant differences emerged in the frequency of panic attacks noted during both sampling periods.

Diary approaches and event sampling techniques can be applied rather easily in the natural environment and usually cause little interference with normal daily activity. An important advantage of diaries and event sampling procedures is that they reduce the risk of failing to catch an event with a short duration or a low frequency, such as a panic attack or an agoraphobic subject going to a public place. Yet, estimates of the frequency of panic attacks and of activities outside the home may suffer from the reactive nature of monitoring techniques (Nelson, 1977; Barlow et al., 1984). Reactivity can be minimized by using appropriate sampling devices and by choosing random time sampling procedures (Delespaul, 1992). The unpredictability of ESM signals avoids anticipation effects on behavior 
and thus minimizes reactivity. Only occasionally, the nature of the activity or the situation (like swimming, going to the cinema) interfered with compliance, but in general compliance of panic patients with ESM was good and most subjects found that the ESM reports gave a good impression of their normal daily life (Dijkman \& deVries, 1991; see also chapter 4). Furthermore, an important difference between the present ESM study and other studies about agoraphobia and panic disorder in daily life is that daily life situations will be evaluated in terms of their social and cultural meaning. Therefore, the ecological validity of this study refers not only to the natural setting in which the research has been carried out, but also to the fact that the emotional meaning of the sampled settings will be evaluated.

Daily life studies can be further evaluated according to the amount of retrospection that is needed. In diaries, the amount of retrospective distortion is small in comparison to crosssectional questionnaires and clinical interviews. In spite of this, diary studies do differ in the amount of retrospective recall that is needed to complete the reports. Subjects may be instructed to fill out the diaries once a day, or at several fixed time points during the day (time sampling). Ratings of symptoms of anxiety and panic on fixed time points are often completed with information on panic episodes. Sometimes subjects are explicitely instructed to record additional information during or as soon as possible after the occurrence of a panic attack (event sampling).

With event sampling techniques, the amount of retrospection is kept to a minimum, at least when the reports are filled out immediately after the occurrence of the event. Intortunately, several studies did not include information about the time the event sampling reports were filled out. In one study, a majority of patients (77\%) completed the self-report within 1 hour after the panic attack, but only $31 \%$ completed the form immediately after the attack (Rapee et al., 1990b). Moreover, there is some evidence that event sampling reports of the time of onset of panic attacks are not always accurate. Margraf et al. (1987b) noted that a large proportion of panic attacks were reported to occur on the full or half hour. An advantage of time sampling techniques is that the number of missing responses is also registered. In event sampling studies, it is difficult to find out whether and when the subjects failed to record an event. Even when an event is recorded, a lot of studies do not include information on the delay between the occurrence of the event and the response. Therefore, we recommend that data about compliance should be included in research reports.

Time sampling techniques require that information is gathered about momentary experiences. In comparison to diary and event sampling approaches, the distortion due to retrospective recall is kept to a minimum. Even when this type of distortion is of less importance in diaries than in retrospective information over large periods of time, diaries also may suffer from selective recall. A comparison of ESM data with diary records from time budget studies revealed that 'idling' is reported with ESM and not with diary approaches (Csikszentmihalyi \& Larson, 1992). Likewise, a comparison of diaries and ESM reports (Dijkman, unpublished manuscript) showed that contacts with friends and colleagues and activities outside the home were more often reported in diaries than with ESM. At the end of the day, subjects seem to select types of behavior that they find worthwhile to mention in a diary, although they were instructed to report all types of activities and social contacts. 
A final advantage of ESM, and time sampling approaches in general, is that it not only focuses on panic and illness. ESM was found to be a useful method to evaluate treatment outcome at the level of the individual, not only by quantifying a decrease in symptoms, but also by adding a description of optimal experiences (Delle Fave \& Massimini, 1992). Event sampling studies usually lack descriptions of positive experiences. A second advantage of time sampling techniques is that it is easier to compare panic patients with normal controls or with patients with other diagnoses. The relatively low incidence of panic attacks in normal subjects and patients with other disorders may hamper the comparison of event sampling data in different groups (Taylor et al., 1986; Margraf et al., 1987b). In the study by Taylor et al. (1986), for instance, normal controls reported no panic attacks and only four episodes of anticipatory anxiety, with no more than 1 symptom.

In the present study, ESM will be used to describe experiences of panic in the course of daily life of panic patients with and without agoraphobia. Instead of asking subjects to define or classify experiences of panic, we instructed our subjects to rate the severity of panic symptoms, based on the DSM III criteria of panic attacks (chapter 5). At the same time, a description of the situational context is provided by the subject. A coding system for daily life situations, based on theories about macrosocial factors in agoraphobia, has been developed in order to evaluate daily life situations in terms of their social and cultural meaning. Results about the amount of time panic patients spent in different types of daily life situations will be presented in chapter 6 . And finally, panic experiences will be related to individual, situational and temporal factors (chapter 7). A detailed description of methods, subjects and codings for situaional factors will be given in chapter 4 . 


\title{
CHAPTER 4 EXPERIENCE SAMPLING RESEARCH ON PANIC DISORDER
}

\author{
AND AGORAPHOBIA
}

The aim of this chapter is to introduce the methods that have been used in the present study. First, the different subject groups will be described in terms of demographic variables and cross-sectional questionnaire data. Previous research demonstrated that panic patients with agoraphobia differ from panic patients without agoraphobia on cross-sectional measures of generalized anxiety, social anxiety and depression (section 2.2.2.), as well as on demographic variables (section 2.4.1.). Nevertheless, large individual variations have been found within groups of panic patients with and without agoraphobia, both on cross-sectional measures (chapter 1) and on daily life measures (chapter 3 ). In the present study, differences on daily life measures between and within groups will be related to demographic characteristics and to cross-sectional measures of psychopathology. Therefore, differences between samples on demographic variables and on questionnaire scores will be described in great detail. In order to interpret questionnaire data, the mean scores found in the present study will be compared to those reported for anxiety patients in other studies. Next, the Experience Sampling Method will be introduced. The method was already briefly described in chapter 3. In this chapter, a more detailed description of instruments and procedures will be provided. Furthermore, we argued that it is important to gather detailed information about compliance in daily life studies (section 3.5). In the present chapter, data about compliance and possible experimental effects of ESM will be presented.

\subsection{Subjects}

Sixty five subjects meeting the DSM III criteria for panic disorder, agoraphobia with panic attacks (A.P.A., 1980) or DSM III(R) criteria for panic disorder with or without agoraphobia (A.P.A., 1987) were recruited in two academic behaviorally-oriented outpatient clinics in Maastricht, the Netherlands. In both settings, multiple diagnostic evaluations were made before subjects participated in any study. All subjects participated in the present study during a diagnostic screening phase before treatment began. The patients were diagnosed according to DSM III(R) criteria by (at least two) experienced clinicians during a semi-structured interview. The clinicians were regularly trained in the use of DSM III(R) diagnostic criteria. When disagreement existed over diagnosis, a consensus diagnosis was assigned.

Thirty patients were diagnosed as having 'panic disorder without agoraphobia' (DSM III(R): 300.01) and 35 as having 'panic disorder with agoraphobia' (DSM III(R): 300.21). One panic patient without agoraphobia was discarded from the study for reasons of compliance (see section 4.6.1.). The final sample consisted of 23 men and 41 women.

A group of 20 neurotic controls was sampled in one of the two behavior therapy units. To be included in this study neurotic controls had to be a patient in the same health care setling as the panic patients, with a diagnosis corresponding to the DSM III(R) criteria for unipolar affective disorders, somatoform disorders or anxiety disorders with exception of panic disorder and agoraphobia. Here again, 1 subject was discarded from the study for 
reasons of compliance. The final sample consisted of 10 men and 9 women. DSM III(R) diagnoses included: recurrent major depression $(\mathrm{N}=1)$, dysthymia $(\mathrm{N}=1)$, somatoform disorder $(\mathrm{N}=2)$, generalized anxiety disorder $(\mathrm{N}=5)$, social phobia $(\mathrm{N}=2)$, simple phobia $(\mathrm{N}=4)$, obsessive compulsive disorder $(\mathrm{N}=2)$ and atypical anxiety disorder $(\mathrm{N}=2)$.

Normal subjects were recruited from the registers of general practitioners (not currently in treatment) for the purpose of another study. The group of normal controls consisted of 11 men and 9 women.

\subsection{1. demographic differences between panic patients with and without agora- phobia, neurotic and normal controls}

Demographic data for the different groups are displayed in table 4.1. Differences on the variables sex, marital status and work were tested by means of chi-squares. Chi-squares for differences between two groups ( $2 \times 2$ tables) were corrected for continuity. Differences in age were tested by means of t-tests. The findings can be summarized as follows:

Sex: The agoraphobic subjects were predominantly women $(83 \%)$ and in this respect they differed significantly from panic patients without agoraphobia $\left(X_{(1)}^{2}=10.12 ; p<.01\right)$, normal controls $\left(\mathrm{X}^{2}{ }_{(1)}=6.86 ; \mathrm{p}<.01\right)$ and neurotic controls $\left(\mathrm{X}_{(1)}^{2}=5.83 ; \mathrm{p}<.05\right)$. Differences between panic patients without agoraphobia, neurotic and normal controls were not statistically significant.

Marital status: Although the group of panic patients with agoraphobia and normal controls included larger percentages of married subjects than the groups of panic patients without agoraphobia and normal controls, differences in marital status were not statistically significant.

Family life: Agoraphobic patients tended to live alone less often than neurotic controls $\left(X^{2}(1)=2.99 ; p=.08\right)$. Normal controls also lived alone less often than neurotic controls $\left(X^{2}{ }_{(1)}=3.91 ; p<.05\right)$. Other differences of interest on this dimension between panic patients with and without agoraphobia, normal and neurotic controls were all not statistically significant.

Work: Agoraphobic patients tended to be more often unemployed than panic patients without agoraphobia $\left(\mathrm{X}_{(1)}^{2}=3.61 ; \mathrm{p}=.06\right)$, neurotic controls $\left(\mathrm{X}_{(1)}^{2}=3.31 ; \mathrm{p}=.07\right)$ and normal controls $\left(\mathrm{X}^{2}{ }_{(1)}=2.73 ; \mathrm{p}=10\right)$. Differences between panic patients without agoraphobia, neurotic and normal controls were not statistically significant.

Age: The agoraphobic patients tended to be older than the panic patients without agoraphobia $\left(t_{\langle i 2}=-1.85 ; p=.07\right)$. Neurotic and normal controls did not differ significantly from both panic groups.

In terms of demographic data, agoraphobic patients can be considered as a 'special' group of panic patients. The group of panic patients with agoraphobia included more women than the groups of panic patients without agoraphobia, normal and neurotic controls. Agoraphobics tended to live alone less often than neurotic controls. Agoraphobic subjects tended to be more often unemployed than subjects in the other groups. Agoraphobic patients further tended to be older than the panic patients without agoraphobia. 
table 4.1.

Demographic data: panic patients with and without agoraphobia, normal and neurotic controls.

$\begin{array}{llll}\begin{array}{l}\text { panic disorder } \\ \text { with }\end{array} & \begin{array}{l}\text { panic disorder } \\ \text { without }\end{array} & \begin{array}{l}\text { neurntic } \\ \text { controls }\end{array} & \begin{array}{l}\text { normal } \\ \text { controls }\end{array} \\ \begin{array}{l}\text { agoraphobia } \\ \mathrm{N}=35\end{array} & \begin{array}{l}\text { agoraphobia } \\ \mathrm{N}=29\end{array} & \mathrm{~N}=19 & \mathrm{~N}=20\end{array}$

sex

$\begin{array}{lcccr}\text { male } & 6(17 \%) & 17(59 \%) & 10(53 \%) & 11(55 \%) \\ \text { female } & 29(83 \%) & 12(41 \%) & 9(47 \%) & 9(45 \%)\end{array}$

marital status

$\begin{array}{lcccr}\text { married } & 26(74 \%) & 17(59 \%) & 10(53 \%) & 15(75 \%) \\ \text { unmarried } & 9(26 \%) & 12(41 \%) & 9(47 \%) & 5(25 \%)\end{array}$

family life

$\begin{array}{lcccc}\text { living alone } & 2(6 \%) & 3(10 \%) & 5(26 \%) & 0 \\ \text { not alone } & 33(94 \%) & 26(90 \%) & 14(74 \%) & 20(100 \%)\end{array}$

work

$\begin{array}{llllr}\text { employed/student } & 10(29 \%) & 16(55 \%) & 11(58 \%) & 11(55 \%) \\ \text { unemployed } & 25(71 \%) & 13(45 \%) & 8(42 \%) & 9(45 \%)\end{array}$

age

$\begin{array}{lcllc}\text { meãn } & 37.4 & 32.8 & 34.9 & 35.3 \\ \text { s.d. } & 9.8 & 10.1 & 12.2 & 9.5 \\ \text { range } & 19-57 & 19-61 & 20-64 & 20-54\end{array}$

The fact that the group of panic patients with agoraphobia significantly differed from the other subject groups in terms of demographic characteristics may have important consequences for ESM research. Agoraphobic avoidance and the impairment of work, leisure and social activities that is known to be associated with it (section 1.7) may result, for instance, in differences in the use of time in daily life. Agoraphobic patients are expected to be less often in agoraphobic situations and more often at home in the company of significant others. But, demographic variables are also related to the use of time. Older unemployed women living in a family probably will spend more time at home with members of their family than single employed men. In order to control for the influence of demo graphic characteristics on the use of time, we could have matched subjects in different groups on demographic characteristics. We decided not to do so, since the differences be- 
tween panic patients with and without agoraphobia do reflect characteristic differences found in epidemiological research (section 2.4.1). The finding that the group of agoraphobic patients included more women and more unemployed subjects is not a coincidence. In order to obtain a clear picture of the daily life of panic patients, no specific selection criteria have been specified. Matching on demographic characteristics could result in subject groups that are not representative of the population of panic patients with and without agoraphobia. Some categories of patients might have been difficult to find, e.g. young employed men with agoraphobia. Instead, we will describe patterns in the use of time in daily life in panic patients with and without agoraphobia and we will try to estimate how these patterns are related to differences in demographic characteristics (chapter 6).

\subsection{2. cross-sectional data of panic patients with and without agoraphobia and neu- rotic controls}

Panic patients with and without agoraphobia and neurotic controls completed the agoraphobia and the social phobia scale of the Fear Questionnaire (FQ) (Marks \& Mathews, 1979), on the Self-rating Depression Scale (SDS) (Zung, 1965), and on the state and trait scale of the State Trait Anxiety Inventory (STAI) (Spielberger et al., 1970). Only the agoraphobia and the social phobia scales of the Fear Questionnaires will be used. The use of the total score, the anxiety-depression scale and the one-item scales (global phobia and main target phobia) of the Fear Questionnaire may produce invalid and/or unreliable results. The agoraphobia, social phobia and blood injury scales within the Fear Questionnaire, on the other hand, were found to be reliable and valid measures of fear in phobic samples (Arrindell et al., 1984). Statistics of questionnaire data for the different groups are displayed in table 4.2 .

Agoraphobic patients reported more avoidance on the agoraphobia scale of the Fear Questionnaire than panic patients without agoraphobia $\left(\mathrm{t}_{(61)}=-7.91 ; \mathrm{p}<.001\right)$ and neurotic controls $\left(t_{(51)}=-8.38 ; p<.001\right)$. There was a trend for agoraphobic patients to have higher depression scores on the SDS than panic patients without agoraphobia $\left(\mathrm{t}_{(53)}=-1.95 ; \mathrm{p}=.06\right)$. According to the SDS, panic patients without agoraphobia were significantly less depressed than neurotic controls $\left(\mathrm{t}_{(41)}=-2.85 ; \mathrm{p}<.01\right)$. The agoraphobic group had a significantly higher mean score on the trait-anxiety scale of the STAI $\left(t_{(51)}=2.45 ; p<.05\right)$ than the neurotic controls. No statistically significant differences on the state-anxiety scale of the STAI and on the social phobia scale of the Fear Questionnaire were found between groups.

In order to interpret the questionnaire data, we compared the mean scores found in this study to those reported in other studies. For the agoraphobia scale of the Fear Questionnaire, different cut-off points have been suggested. Van Zuuren (1988) stated that the optimal cut-off point is 19 for a diagnosis of agoraphobia. According to Oei et al. (1989), a cut-off score of 25 differentiates best between panic patients with and without agoraphobia. Mavissakalian (1986) proposed a cut-off score of 30 to identify homogeneous groups of agoraphobic patients without severe social phobias. Compared to these cut-off points, panic patients with agoraphobia scored high on the agoraphobia scale of the Fear Questionnaire. All subjects but one in the group of panic patients with agoraphobia scored 19 or more and $71 \%$ of the patients had a score of 30 or more on the agoraphobia scale. In the group of panic patients without agoraphobia, $7 \%$ of the subjects had a score of 30 or more. In the group of neurotic controls, only 1 subject scored more than 30 . 
Panic patients and neurotic controls scored relatively high on the social phobia scale of the Fear Questionnaire. Using a cut-off score of 18, as suggested by van Zuuren (1988), 62\% of the agoraphobic patients, $55 \%$ of the panic patients without agoraphobia and $63 \%$ of the neurotic controls fall into the social phobic range.

table 4.2.

Questionnaire scores compared for panic patients with and without agoraphobia and neurotic controls.

$$
\begin{aligned}
& \text { panic disorder } \\
& \text { with } \\
& \text { agoraphobia } \\
& \mathrm{N}=35
\end{aligned}
$$

32.1

6.5

$18-40$

range

missing

mean FQ-social phobia

21.9

10.0

4-40

range

missing

mean SDS

s.d.

range

missing

mean STAI-trait anxiety

60.8

8.1

$37-66$

5

52.5

48.4

7.4

34-62

4

9.1
$0-31$

18.0

17.8

9.8

9.4

2-35

0-32

55.7

9.5

38-78

।

58.9

55.0

s.d.

range

missing

7.9

42-76

1

mean STAI-state anxiety $\quad \mathbf{5 3 . 6}$

13.2

20-79

3
9.0

39-74

3

9.0

36-70

48.0

12.0

26-70

31-71 missing

3 
Panic patients with agoraphobia and neurotic controls scored high on the SDS. A mean SDS score of 43 was reported for outpatients with anxiety complaints, a mean score of 51 for depressive outpatients and a mean score of 59 for depressive inpatients (Zung, 1965; Zung et al., 1965)'. With the Dutch SDS scale, a mean SDS score of 54.1 was found for depressive outpatients and a mean SDS score of 42.2 for non-depressive outpatients (Dijkstra, 1974). The mean SDS score of panic patients with agoraphobia and neurotic controls is comparable to those reported for depressive patients. Panic patients without agoraphobia scored lower on the SDS than panic patients with agoraphobia and neurotic controls, yet their mean score was higher than those reported for anxious outpatients.

On the average, panic patients with agoraphobia in this study scored higher on the STAI state and trait anxiety scales than anxiety patients (Spielberger et al., 1970). In other studies, mean state anxiety scores between 46.5 and 51.6 and mean trait anxiety scores between 42.8 and 55.5 have been reported for patients with panic disorder and agoraphobia (Anderson et al., 1984; Chambless, 1985; Barlow et al., 1986; Tumer et al., 1986b). The mean trait anxiety score of panic patients without agoraphobia was also higher; their mean state anxiety score was comparable to those reported in other studies. The mean state and trait anxiety scores of the neurotic controls in this study were similar to those reported by Spielberger et al. (1970) for patients with depression or anxiety.

In summary, panic patients with agoraphobia scored higher on the agoraphobia scale of the Fear Questionnaire and on the trait-anxiety scale of the STAI than neurotic controls. Neurotic controis had significantly higher depression scores than panic patients without agoraphobia. In contrast to the literature reviewed in chapter 2 (section 2.2.2. and 2.5.3.), fow differences in cross-sectional measures of depression, social anxiety and trait anxiety were identified between panic patients with and without agoraphobia. Although they tended to have higher scores for depression, agoraphobic patients only differed significantly from panic patients without agoraphobia on the agoraphobia scale of the Fear Questionnaire. In other words, both groups of panic patients with and without agoraphobia did not diffier significantly on cross-sectional measures of social phobia, depression, trait and state anxiety. They clearly differ, however, on a cross-sectional measure of agoraphobic fear.

\subsection{The Experience Sampling Method (ESM)}

The Experience Sampling Method was designed to study subjective experiences of people in the natural environment. ESM provides a description of moments in a person's daily life. It uses a signaling device to alert subjects to fill out self-reports at preselected but randomized time points. The self-report asks information about the physical and social context, activities, thoughts, mood and complaints.

Since 1975, ESM has been applied by different research groups in a large number of studies (for an overview, see: deVries, 1992). Csikszentmihalyi and associates at the University of Chicago investigated daily activities and experiences of large samples of (mainly adolescent) normal subjects (Csikszentmihalyi \& Larson, 1984). Similar techniques were developed by Hurlburt for the study of thought content (Hurlburt \& Melan-

1 SDS indices reported in the literature, are reported here as total SDS scores. 
con, 1987) and by Massimini et al. (1987) for the study of optimal experiences. deVries and his associates applied the method to samples of psychiatric patients. The research group in Maastricht carried out ESM research on patients with schizophrenia (deVries et al., 1986; Delespaul \& deVries, 1992; deVries \& Delespaul, 1992), affective disorders (Kraan et al., 1992), somatization disorder (NWO 900-715-157) and anxiety disorders (Dijkman \& deVries, 1987, 1991; deVries et al., 1987, 1990, 1992). The Maastricht group further used ESM to study acute stress (Nicolson, 1992) and drug use in non-clinical samples (deVries et al., 1991; Kaplan, 1992).

\subsection{Instruments and Procedures}

Subjects carried a programmed terminal-watch that signaled thern 10 times a day between 7.30 a.m. and 10.30 p.m. during 6 days. The mean interval between two signals was 90 minutes; the minimum interval was 15 minutes. Signals were randornized in order to occur unpredictably. At every signal, subjects completed a self-report form (appendix 2), including a range of questions about the subject's mental state and the environment. Subjects were asked what they thought, where they were, what they were doing and who they were with at the moment of the beep. They evaluated their thoughts, mood, current activities and physical well being on seven-point Likert-type scales ranging from 1 'not at all' to 7 'extremely'. Patients in this study also rated the presence of 2 'individualized complaints' in each ESM report. Individualized complaints are complaints, that are idiosynchratic to the subject (individualized complaints reported by panic patients and neurotic controls are listed in appendix 4; for a discussion on this topic, see section 5.1.2.). Furthermore, the ESM reports of panic patients and neurotic controls included 5 items for panic related symptoms, based on DSM III criteria for panic attacks. The construction of the ESM panic scale will be described in further detail in section 5.1.

During an initial standardized interview, the 'briefing', the purpose of the method was explained and informed consent was obtained. The subject was instructed to fill out an ESM format at every signal. The necessity to describe daily life with all its joys and problems on the very moment of each beep was stressed. Situations in which the use of ESM might be difficult and possible solutions to it were discussed. Subject were told, however, that they were always allowed to tum the watch off if they wanted to go to sleep or if they felt they needed privacy. Then, individualized complaints were choosen. Subjects were instructed to select 2 complaints, that were important to them and that occuried rather frequently during the last weeks. The use of the watch and the ESM formats was explained and the subject filled out a format to practice. Next, the subject was provided with 6 booklets of ESM formats, one for each day. Each booklet included a telephone number where the interviewer could be reached during the sampling period in case of 'any question or complication'. ESM data were gathered during the next 6 days.

The final interview, the 'debriefing', was planned as soon as possible after the sixth day. The subject was asked about reasons for missing data and about the impact of the research procedure on daily life. If necessary, information was gathered in order to limit potential coding problems of open ended questions. In addition, subjects filled out the Fear Questionnaire (Marks \& Mathews, 1979), the State Trait Anxiety Inventory (Spielberger et al., 1970; Dutch version: van der Ploeg et al., 1979) and the Self-rating Depression Scale (Zung, 1965; Dutch version: Dijkstra, 1974). 


\subsection{Codings for Situations}

ESM is especially suited to study behavior in naturally occurring daily life situations. In a laboratory setting or during a behavioral avoidance test, the range of possible situations that can be studied is reduced. The advantage of this reduction many possible confounding factors can be kept under control. But, naturalistic situations are always created or selected by the researcher. No matter how much care is taken by the researcher to select situations that are representative to the type of situations in which individual person experiences anxiety (or at least retrospectively reports to do so), this procedure will always reduce the ecological validity of the study (see chapter 3 ). If situations are created or selected by the researcher, they can not be selected or avoided by the person (Hormuth, 1992). Still, it may be not only relevant to study the behavior of the person during exposure to a specific type of situation, but also to describe the selection of types of situations in daily life. Nevertheless, in order to identify typical patterns in the use of time in daily life and in people's emotional reactions to specific types of situations, the total range of situations has to be reduced. In the present study, a coding system for daily life situations was developed based on van Zuuren's (1982) situation typology (section 2.4.4.).

The codings were assigned according to the answers to the open ended questions 'where are you?', 'with whom are you?' and 'what are you doing?'. Each daily life situation was coded in detail, but due to the relatively low incidence of some types of situations codes have been aggregated into broader categories for the present analyses. The codings are described in further detail in appendix 3.

First, situations have been classified into different types. Situations were classified into four main categories: solitary situations, intimate situations, personal situations and anonymous situations. Solitary situations are situations in which the subject is alone in a familiar environment, e.g., alone at home or alone at work. Intimate situations are situations in which the person is in a familiar environment and in the company of significant others. Examples of intimate situations are: at home with family, visiting relatives or friends, etc. Personal situations are situations in which there is a direct contact with another person in a specific role, e.g. a hairdresser, salesman or plumber. Personal situations also involve contacts with colleagues and acquaintances and 'group matters', such as being at a party, in a club, ... Anonymous situations are situations in which the person is alone, although others may be present, but they are strangers and there is no direct contact with them. The subject is either in a public place or in a transport situation (driving a car, sitting in a train, ...).

Sometimes mixed types of situations occur. For instance, being in a shop with a friend is a mixed anonymous/intimate situations. In order to deal with this rather common type of situation, separate codings were given to anonymous situations in which significant others are present. Personal situations with significant others (e.g., together with husband and plumber) were coded as 'else', because of the low frequency of this type of situations.

Other situations can be considered as transition situations. For instance, leaving home alone is not a typical solitary situation (alone at home). Neither is it an anonymous situation (alone in a public place), since the person is still at home. This type of situation was coded as a transition from a solitary situation to an anonymous situation. Due to the low fre- 
quencies of transition situations, subjects reactions to these types of situations can not be analyzed separately and, therefore, transition situations were recoded into the 'else' category. By doing so, we made sure that the categories for specific types of situations included 'pure' types of situations and no transitions from one to the other.

Secondly, we will describe different types of situations in terms of the level of acknowledgement by other people, by the environment and by the activity. Acknowledgement by other people depends on the presence of intimate others. In the presence of members of their own family or household members, the level of acknowledgement by other people is judged to be high. In the presence of relatives, friends, acquaintances and others with whom there is a personal contact in a specific role (such as the hairdresser), the level of acknowledgement by others is moderate. And when the subject is alone or in the company of strangers, the level of acknowledgement by other people is low. Acknowledgement by the environment refers to the extent that the environment is a familiar one. In the familiar environment of the home, the level of acknowledgement by the environment is high. In a relatively familiar environment, such as at work, in the house of friends or relatives, in the parental home, etc. the level of acknowledgement by the environment is jugded to be moderale. In public places, in the streets and in transport situations the level of acknowledgement by the environment is low. Acknowledgement by activities is evaluated by judging the goal-orientedness of activities. High levels of acknowledgement by activities occur when one has clearly goal oriented activities, i.e., when working, taking care of others or the environment or maintenance activities. During leisure activities and during active transport (such as riding a bicycle or driving a car), the level of acknowledgement by activities is moderate. And finally, the level of acknowledgement by activities is low when doing nothing, when resting, sitting, sleeping and during passive transport, i.e. when the person is a passenger in a car, in a bus, train, ...

In order to investigate the agreement between raters on codings for daily life situations, one booklet of each of 61 subjects with panic disorder was coded by two independent raters. After excluding missing responses, Cohen's unweighted Kappa's were computed for 492 valid reports. Kappa's for the different codes are displayed in appendix 4. In general, the interrater agreement about codings was high (total Kappa $=.85$ ). The interrater agreement on different types of situations is high, with the exception of the category 'else'. This category will, however, not be used as a separate category in further aralyses. The interrater agreement for transition situations (transition from one situation to another) was also somewhat lower $(\mathrm{Kappa}=.60)$. But transition situations have low frequencies and this category is only used to select situations in which there is no transition. The interrater agreement for codings of the level of acknowledgement by other people, by the environment and by activities was high.

\subsection{Data Analysis}

ESM can be used to answer questions about persons and questions about situations (J arson \& Delespaul, 1992). Depending on the type of question, ESM data will be analyzed either at the subject level or at the beep level. In the beep level analysis, the repeated ESM reports, 'beeps' are used as the fundamental unit of analysis. At this level, a maximum of 60 repeated ESM reports can be analyzed for each subject. In the subject level analysis, the subject is used as the unit of analysis. The subject level analysis uses one- 
time subject measurements as well as aggregated scores. One-time measurements include cross-sectional questionnaires, demographic data, DSM III diagnoses, briefing and debriefing information. Aggreghated data are, for instance, mean panic scores per subject or the percentage of beeps a subject was in a particular situation.

Beep level analysis are easier to carry out and easier to understand than anaylis at the aggregated level of the subject. But, when the analysis is carried out at the beep level, the number of units in the analyses is inflated and the different observations are not independent from each other. Moreover, the number of valid responses per subject is not always the same resulting in unequal weightings of subjects. The results of beep level analyses, therefore, are more easily biased by individual outliers. Subject level analysis is more conservative and the assumption of independence between observations is not violated. From this, we could conclude that a subject level analysis is always better than a beep level analysis. Nevertheless, a beep level analysis may be more adequate to describe individual, temporal and situational variations in experiences and behavior.

In the present study, both subject level and beep level analyses have been carried out. The pro's and con's of both types of analyses have been dealt with by examining competing explanations whenever necessary. The analyses have been concentrated around three major topics: the occurrence of panic experiences in daily life (chapter 5), the amount of time spent in specific daily life situations (chapter 6) and fluctuations in the presence of panic experiences in relationship to individual, situational and temporal factors (chapter 7).

\subsection{Compliance and Reactivity Issues}

The aim of the ESM procedure is to study subjective experiences of people during daily life. The method's usefulness depends on how much it measures up to this ideal. Subject compliance is a key element to ESM studies. The establishment of a solid research alliance is of paramount importance. Briefing and debriefing procedures have to be carried out with care. Clear standardized instructions and a researcher that can be reached to discuss possible questions or technical problems, encourage subject's compliance. Nevertheless, it is our aim to get a sample of experiences during daily life. The method has to be adapted to the person's life style, instead of the person adapting his life to the method. Therefore, we take it for granted that people do not respond to all 60 beeps.

The validity and reliability of the ESM method has been adressed in several studies with a total population of more than 600 subjects (Csikszentmihalyi \& Larson, 1992). The following compliance and reactivity issues have been adressed in the present study: (1) the compliance of psychiatric patients; (2) special reasons for missing responses; (3) the deviation of the research week from normal daily routine; (4) the influence of ESM on daily life; and (5) the difficulty of the task and the amount of impedement. Validity issues concerning the ESM measurement of panic experiences will be discussed in chapter 5.

\subsection{1. the compliance of psychiatric patients}

In order to use ESM to study normal daily experiences of psychiatric patients, one has to be sure that the subjects can be motivated to fill out a sufficient number of ESM formats within an acceptable time limit after a beep occurred. The choice of this time limit is ra- 
ther arbitrary. In fact, we want the delay between beep and response to be as small as possible. But, we have to take into account that the reported response time is not al ways exact. Subjects were, for instance, more likely to report 10:15 a.m. as response time than $10: 14$ or $10: 16$. Others reported the response time from another whatch with a slightly different time schedule.

In this study, a response to a beep signal was considered valid and was kept in the analysis, when the response was given within 15 minutes after the beep occurred. Only subjects with at least 20 valid responses were included in the analysis. In our total sample, 2 subjects did not meet this criterion and therefore were discarded from the study. One panic patient without agoraphobia completed 58 ESM reports, but in 47 reports the response time was either not filled out or did not correspond to the beep time. Another subject from the group of neurotic controls completed 53 reports, but only 12 responses were valid. In both cases the reason for the mismatch between beep and response time was unknown. The analyses were based on 103 valid subjects.

Of all programmed beeps, $74 \%$ were responded to within the limit of 15 minutes (table 4.3). In $4 \%$ of all cases an 'out of range' response was given, meaning either that the delay between beep and response time was larger than 15 minutes, that beep and response time did not correspond to each other, or that the response time was missing. Finally, $22 \%$ of all beeps were not recorded. For all valid responses, the mean delay between beep and response time was less than 3 minutes. Fourty percent of all valid responses occurred within one minute and $89 \%$ of all valid responses were obtained after 5 minutes.

\section{table 4.3.}

Delay between beep and response time.

\begin{tabular}{lccc}
\hline number of responses after & 1 minute & 1816 & $29 \%$ \\
& 5 minutes & 4058 & $65 \%$ \\
10 minutes & 4449 & $72 \%$ \\
& 15 minutes & 4550 & $74 \%$ \\
\hline & & 253 & $4 \%$ \\
& missing & 1377 & $22 \%$ \\
\hline
\end{tabular}

total number of responses

Numbers of valid, out of range and missing responses in the different groups are displayed in table 4.4. The largest percentage of valid responses was provided by agoraphobic patients (79\%). Panic patients without agoraphobia, on the other hand, produced the 
least valid responses $(68 \%)$. Normal and neurotic controls took an intermediate position with $73 \%$ and $74 \%$ of valid responses respectively.

table 4.4 .

Number of valid and missing responses in different subject groups.

$\begin{array}{llll}\begin{array}{l}\text { panic disorder } \\ \text { with }\end{array} & \begin{array}{l}\text { panic disorder } \\ \text { without }\end{array} & \begin{array}{l}\text { neurotic } \\ \text { controls }\end{array} & \begin{array}{l}\text { normal } \\ \text { controls }\end{array} \\ \begin{array}{l}\text { agoraphobia } \\ \mathrm{N}=35\end{array} & \begin{array}{l}\text { agoraphobia } \\ \mathrm{N}=29\end{array} & \mathrm{~N}=19 & \mathrm{~N}=20\end{array}$

$\begin{array}{lcccc}\text { valid responses } & 1656(79 \%) & 1178(68 \%) & 838(74 \%) & 878(73 \%) \\ \text { out of range } & 44(2 \%) & 128(7 \%) & 26(2 \%) & 55(5 \%) \\ \text { missing responses } & 400(19 \%) & 434(25 \%) & 276(24 \%) & 267(22 \%)\end{array}$

The mean number of valid responses completed per subject was 44 . Panic patients without agoraphobia completed an average of 41 reports per subject (ranging from 23 to 57 valid responses). Agoraphobic patients completed an average of 47 valid reports per subject (ranging from 30 to 58 responses). Normal and neurotic controls both completed an average of 44 valid responses per subject, with a range from 23 to 58 reports per subject in normals and from 32 to 55 in neurotic controls.

High compliance rates were found in different samples of psychiatric patients. The method has been applied succesfully in studies on schizophrenia (Delespaul \& deVries, 1992; deVries \& Delespaul, 1992), multiple personality disorders (Loewenstein et al. 1987), alcoholism (Filstead et al., 1985), bulimia (Johnson \& Larson, 1982) and affective disorders (Kraan et al., 1992). The compliance rates found in this study are comparable to those obtained in other studies (Csikszentmihalyi \& Larson, 1992). Some authors do report higher compliance rates in normals, but the criteria for valid responses are often less stringent in these studies.

In summary, only 2 patients were discarded from the study, because they did not meet the criterion of having filled out at least 20 ESM reports within a time limit of 15 minutes after the beep. The final sample completed about three quarters of all ESM reports within the time limit, providing an average of 44 valid responses per subject. The delay between beep and response time was generally small; most responses were given within 5 minutes after the beep. Considering the applicability of ESM in groups of psychiatric patients, it is noteworthy that patient groups are not less compliant than normal subjects. 


\subsection{2. reasons for missing responses}

Missing responses can be due to a variety of reasons. In terms of the reliability and validity of the method, it is important to ascertain that there is no systematic underreporting of specific situations. The response frequency at different beep times, research days and weekdays are displayed in figures 4.1 through 4.3 .

Figure 4.1 shows that the least valid responses are obtained early in the morning and late at night. The first beep (between 7:30 and 9:00 a.m.) only received $41 \%$ of valid responses. Few differences in the percentage of valid responses were registered between beep 3 (from 10:30 a.m.) and beep 9 (till 9:00 p.m.). After 9:00 p.m., there was again a small decline in the number of valid responses. One reason for missing or out of range responses in the moming and evening hours was that subjects were still or already asleep. Since subjects were asked to fill out the time they woke up in the morning and went to sleep in the evening, the percentages of missing or out of range responses due to sleep could be calculated. Of all missing and out of range responses, $27 \%$ were known to be due to the fact that the beep occurred before the subject woke up in the morning, while another $2 \%$ is due to going to sleep before the last beep occurred. A total of 467 reports are known to be lost while subjects were asleep. Sleep was the reason for missing and out of range responses in $47 \%$ of all first beeps in the moming. The fact that more responses were missed due to sleep in the moming than in the evening indicates that the time series focused on 'early birds'. In future samplings, a time series starting later in the morning may be more appropriate.

The percentage of valid responses at different research days did not show much variation (see figure 4.2). A small decline in valid responses was found towards the end of the study. This decline can be due to a decrease in motivation. One panic patient stopped filling out the booklets after 3 days because he 'had enough'. Another reason was mentioned by a subject from the group of normal controls: the last 2 booklets were not completed, because the watch malfunctioned.

The percentage of valid responses at different weekdays shows that less valid responses were given in the weekend, especially on Sundays (see figure 4.3). This was dite mainly to the fact that people sleep longer in the weekend. On Sundays, for instance, the first beep between 7:30 and 9:00 only received $16 \%$ of valid responses; $72 \%$ of the responses were missing while the subjects were asleep.

Debriefing interviews and notes in the booklets revealed other reasons for missing and out of range responses, such as not hearing the watch in a noisy environment (working with machines, vacuum cleaning), engaging in sports, forgeting the watch at home, taking a nap during the day, driving a car, swimming or taking a shower (the watch is not waterproof), going to church, business appointments and meetings at work, etc. A relatively often mentioned reason for missing responses in the moming, was forgetting to turn the watch on.

In summary, the most important reason for missing and out of range responses is that subjects were still asleep in the moming or were already asleep before the last beep occurred. Sleep was the reason for $41 \%$ of all missing and out of range responses. It also explains 
why more beeps were lost early in the morning and on weekend days. There was some deciline in response frequency towards the end of the research week, mainly because two subjects quited the study after 3 and 4 days respectively. The fact that the remaining missing and out of range responses were due to a variety of reasons makes systematic underreporting of events unlikely. Here again, similar results were obtained in other studies (Csikszentmihalyi \& Larson, 1992).

\section{figure 4.1.}

Percentages of valid responses during the day.

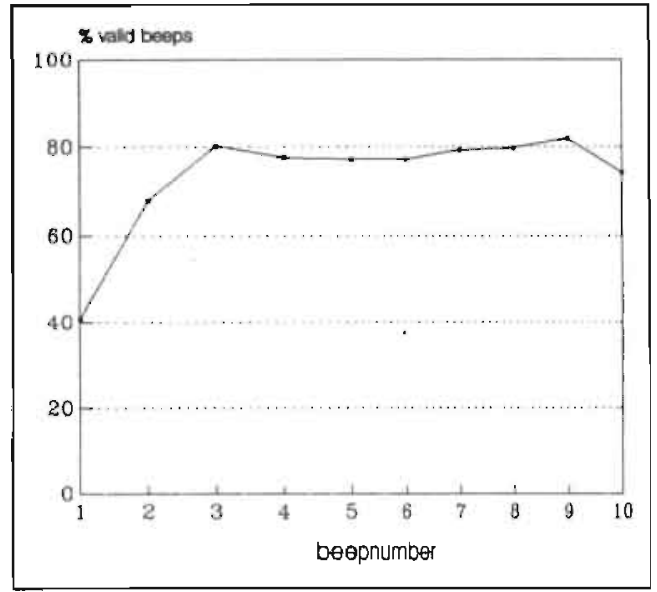

\section{figure 4.2.}

Percentages of valid responses at different research days.

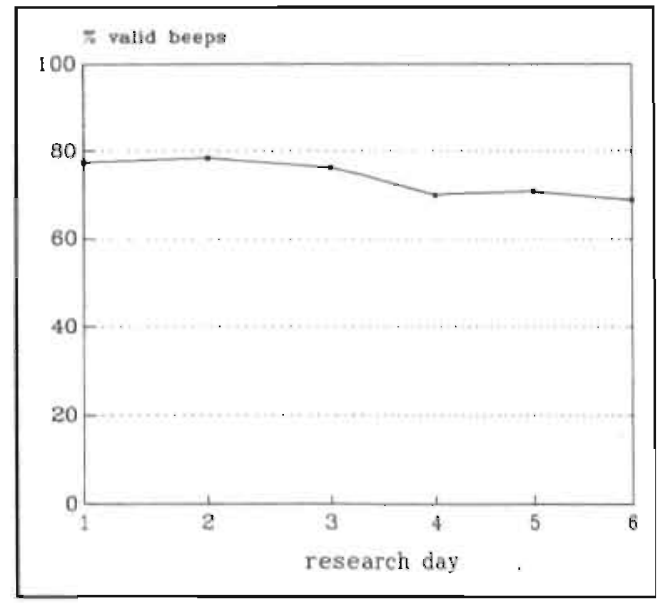




\section{figure 4.3.}

Percentages of valid responses at different weekdays.

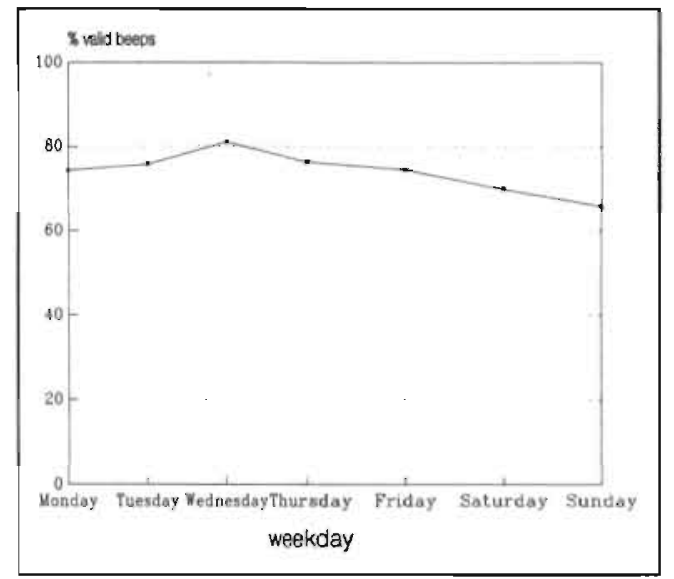

\subsection{3. deviations from normal daily routine}

Since the research week is just one week in a subject's daily life, it is possible that it deviates from normal daily routine. Therefore, we asked our subjects whether the research week was 'special' in some respect. Unfortunately, these data were not available for al] subjects. Twenty five patients explicilly said the research week gave a good impression of their normal daily life. Twenty one patients found the week to be unusual in some respect. 'Unusual' factors were: having less complaints $(\mathrm{N}=11)$ or more complaints $(\mathrm{N}=4)$; holidays $(\mathrm{N}=4)$ : parners or children having holidays or being on sick-leave $(\mathrm{N}=3)$. Five pattients reported they were more often at home. This was, however, not necessarily an effect of ESM: one subject stayed at home because the wheather was to bad to go out and another one because he wanted to watch the Tour de France.

In the group of normal controls, only one subject said it was an unusual week, because he started to work again after a rather long leave. Six normal subjects mentioned that one day had been unusual and named various reasons, ranging from Mothering Sunday to hang-. overs. Other authors reported that $80 \%$ of their (normal adult) subjects felt that the reports: captured the week well (Hormuth, 1985).

In summary, both patients and normals reported that the research week sometimes deviated from normal daily routine. Since patients have more complaints than normals, having more or less complaints happens to be of greater significance to them and was reported more often as a reason why the research week was 'unusual'. For the sake of completeness, we have to mention here that the research was postponed if a subject was ill and confined to bed or went away on holiday in order to avoid that the research week would deviate too much from sampling normal daily life. 


\subsection{4. experimental effects}

In order to know whether participating in ESM research produced experimental effects, debriefing interviews included questions about the possible influence of the method on the subject's daily life (see table 4.5.).

table 4.5 .

Experimental effects: the method's influence on daily life as recorded during debriefing interviews.

experimental

$\begin{array}{lll}\text { panic } & \text { neurotic } & \text { normal } \\ \text { disorder } & \text { controls } & \text { controls }\end{array}$

effects

$\mathrm{N}=64 \quad \mathrm{~N}=19 \quad \mathrm{~N}=20$

little or none

$26(47 \%)$

$8(50 \%)$

$15(78 \%)$

positive

$12(21 \%)$

$3(19 \%)$

$2(11 \%)$

negative

$18(32 \%)$

$5(31 \%)$

$2(11 \%)$

unknown

8

3

1

About half of the patients said the method had litte or no influence on their thoughts, moods, activities and social contacts. Positive effects of participating in ESM research were mentioned by $21 \%$ of the patients. Positive effects were: feeling better, more secure, safe and cheerful; knowing that there is or will be help encourages and gives hope; it's nice to give a moment's thoughts to things you normally take for granted; it gives relief, an opportunity to unload troubles and negative feelings; it gives control over complaints; it makes you aware of thoughts and feelings; it helps to write down difficult feelings; it allows you to write down what you can't tell others; it brings distraction; it gives a goal, something to do; and it helps to see and remember happy moments.

Negative effects, on the other hand, were reported by $32 \%$ of the patients. Higher awareness of feelings was also mentioned as a negative effect. Nine patients said the method confronted them with their feelings and the higher awareness led to more anxiety, depression and physical complaints. Distraction was sometimes mentioned as a negative effect in that it hindered concentration and interfered with activities. Nine patients reported almost obsessive thinking about ESM, waiting all day for beeps. Others were afraid to lose or damage to watch, to make mistakes or to miss a beep $(N=4)$. Six patients said they sometimes waited to engage in a certain activity till after the beep. Negative feelings were reported as an effect of the method by patients: they felt more tense $(\mathrm{N}=9)$, sensible or irritable $(\mathrm{N}=4)$, inhibited or impeded $(\mathrm{N}=3)$. Two patients felt it as an intrusion on their privacy, as a sort of 'Big Brother'. Finally, five patients found it troublesome to fill out the ESM format in the company of others: they got tired of explaining other people what ESM is about. 
Normal subjects reported no influence of the ESM method on daily life in $78 \%$ of the cases. Two subjects (11\%) reported an influence on their thoughts, but only during the first day: they had to think about beeps all the time. Two subjects mentioned positive effects: one 'received nice responses from other people' and another got 'aware of feeling better than some time ago'. Higher awareness of feelings, without telling whether this was a positive or a negative experience, was mentioned by one subject. And finally, two normal subjects mentioned negative effects: either the method made them 'jumpy' or 'indecisive' about what to write down.

In summary, both positive and negative effects of participating in ESM research have been reported. About half of the patients said the method had no influence on daily life. About one third of the patients mentioned negative effects of participating in ESM research. Patients reported more often negative effects than normal subjects, but the nature of the effects did not differentiate them. Both normals and patients reported higher awareness of feelings as an effect. Higher awareness of negative feelings (anxiety and depression) in the patient group explains why patients label this more often as a negative effect. Normals and patients mentioned both some 'mental preoccupation' with watches and beeps, but normals adapted more quickly, so that this effect disappeared after one day. Patients sometimes developed almost obsessive thoughts about ESM.

\subsection{5. task difficulty and impedement}

In order to get an idea of how difficult the task is we impose on subjects when we ask them to participate in ESM research, we asked them during the debriefing interview whether ESM was 'troublesome' and whether they were willing to participate again. Finally, an evaluation of how disturbing separate beeps were, was given in the ESM reports.

table 4.6.

Impedement as recorded during debriefing interviews.

\begin{tabular}{llll}
\hline & $\begin{array}{l}\text { panic } \\
\text { disorder }\end{array}$ & $\begin{array}{l}\text { neurotic } \\
\text { controls }\end{array}$ & $\begin{array}{l}\text { normal } \\
\text { controls }\end{array}$ \\
$\begin{array}{l}\text { did you find ESM } \\
\text { 'troublesome'? }\end{array}$ & $\mathrm{N}=64$ & $\mathrm{~N}=20$ \\
no & $26(40 \%)$ & $7(36 \%)$ & $12(60 \%)$ \\
a little/sometimes & $23(36 \%)$ & $6(32 \%)$ & $5(25 \%)$ \\
yes & $15(24 \%)$ & $6(32 \%)$ & $3(15 \%)$ \\
unknown & - & - & - \\
\hline
\end{tabular}


A majority of the patients reported during the debriefing interview that they found the method either not troublesome or only a little or sometimes (table 4.6.). Only $21 \%$ of the panic patients and $36 \%$ of the neurotic controls said the method was troublesome. They found it particularly annoying to complete ESM reports during activities that need concentration and in the company of other people. Sixty percent of the normals reported that ESM caused no trouble; $25 \%$ said ESM disturbed them a little or sometimes; and the remaining 3 subjects (15\%) found it troublesome 'while working', 'because the beeps occurred on the most awkward moments' or 'since the overlap between questions gave rise to confusion'.

In answer to the question whether they were willing to cooperate another time with ESM, $63 \%$ of the patients said they were (although most of them preferred to take a break); $9 \%$ was willing to cooperate again 'if necessary' and $28 \%$ did not want to cooperate again. In some cases enthusiasm was very high. One subject spontaneously mentioned that she thought it would be a good idea to sample her for about six months. Another one asked if she could have some more booklets and have the debriefing appointment a week later.

The ESM format of patients included an item about the amount of disturbance caused by each beep. Patients rated whether the beep was disturbing on a scale from 1 'not' till 7 'very'. Of all valid responses, $45 \%$ was rated as 'not disturbing' (score 1) and $22 \%$ as 'disturbing' (score 5 or higher).

Similar results were obtained in other studies. In a study on German adults, $22 \%$ reported that ESM disrupted daily routine and $75 \%$ were willing to cooperate again with ESM (Hormuth, 1985). In a sample of American adults, $32 \%$ of the subjects reported that the method was getting annoying by the end of the week (Csikszentmihalyi \& Larson, 1992). In our sample, both getting tired towards the end of the week as well as habituation were mentioned.

In summary, most subjects found ESM not troublesome or only a little. A majority of the patients was willing to cooperate again with ESM. Still, about one quarter of the patients did not want to participate again. In the ESM formats of patients, about half of the beeps were rated as not disturbing. These data demonstrate that ESM can be used with good results in samples of both normal and psychiatric patients. 
In the present chapter, ESM data will be used to describe experiences of panic in panic patients with and without agoraphobia as they occur in the natural context. ESM was designed to select a representative sample of a person's experiences during daily life. ESM may, however, provide a different picture of panic experiences in daily life than event sampling techniques (section 3.5.). An important advantage of event sampling approaches is that the probability of catching an event with a relatively low frequency and a short duration, such as panic attacks, is higher than with ESM. With ESM, it is possible that a subject experiences a great number of panic experiences, but never on the moment of the beep. Therefore, the frequency of panic experiences may be underestimated with ESM. On the other hand, ESM studies provide a more complete picture of the variability in experiences of panic patients than event sampling studies. Event sampling studies ask subjects to describe panic symptoms and attacks. ESM reports describe panic experiences, as well as anxiety-free moments. Another difference between ESM and event sampling studies concerns the operationalization of panic experiences in daily life. In event sampling approaches, subjects select expeniences which they label as 'panic attacks'. The reliability of subject defined panic attacks and situational cues can be questioned (section 3.4.2.). Neither is it clear whether subject-defined panic experiences correspond to the DSM III(R) criteria of panic attacks. In the present study, we will develop criteria to identify panic experiences based on DSM III criteria of panic attacks. We label the presence of panic symptoms according to DSM III(R) 'panic experiences' and not 'panic attacks', because we only know whether the symptoms are present on the very moment of the ESM signal, and not whether these experience are part of a sudden and discrete period of panic, the panic attack.

First, some measurement and validity issues will be adressed (section 5.1.). The selection of ESM panic items was based on literature about symptoms that are specific to panic experiences and differentiate between panic and other types of anxiety (section 5.1.1.). The construction of the ESM panic scale will be described in section 5.1.2. In order to demonstrate that a valid and reliable description of the experience of panic in daily life can be provided with ESM, some validity and scalability issues will be adressed (section 5.1.3.). A procedure to select moments in daily life in which panic is experienced will be presented. In order to investigate the construct validity of the scale, we will investigate whether experiences of panic gathered with ESM differentiate panic patients from patients with other disorders (section 5.1.4.). In section 5.2., we will investigate whether panic patients with and without agoraphobia differ in the frequency and severity of panic experiences in daily life. Individual variations in the frequency of panic experiences will be described in section 5.3. The relationship of panic experiences to the severity of psychopathology will be adressed in section 5.4 . 


\subsection{Measurement and Validity Issues}

\subsection{1. the measurement of symptoms of panic}

Several lines of evidence indicate that the experience of panic is quantitavely and qualitatively different from other types of anxiety. Panic attacks were found to be characterized by symptoms with a higher intensity and a specific nature. Ratings of the frequency and intensity of all panic symptoms mentioned in DSM III(R) during daily life would be ideal. Since the number of items that can be included in ESM questionnaires is restricted, a selection of panic symptoms had to be made. There is, however, little consensus about which symptoms are most specific to the experience of panic and differentiate best between panic and other anxious experiences.

Different studies were conducted in order to identify specific panic symptoms. Borden and Turner (1989) compared 17 panic patients, 29 patients with obsessive compulsive disorders and 12 patients with generalized anxiety disorders using retrospective self-reports and a semi structured interview. A panic factor was derived containing 17 items from the Fear Survey Schedule and the SCL-90-R. The total factor score was significantly higher in patients with panic disorder than in patients with either obsessive compulsive or generalized anxiety disorders. Significant differences further emerged on 12 separate items. Panic patients scored significantly higher than both other groups on the following items: trembling, heart pounding, trouble getting breath, and spells of terror or panic. Panic patients scored higher than patients with obsessive compulsive disorders on the items: faintness, hot/cold spells and numbness. And finally, panic patients scored higher than patients with generalized anxiety disorders on the items: suddenly scared for no reason, thoughts of dead or dying and the feeling that something bad will happen. Five of the 17 panic items correlated significantly with trait anxiety: nervousness, suddenly scared for no reason, something wrong with mind, losing control and thoughts of being mentally ill. Borden and Turner concluded that panic refers to a specific cluster of symptoms differentiating patients with panic disorders from patients with obsessive compulsive and generalized anxiety disorders. Although panic and state/trait anxiety appeared to be not totally independent, and all groups of patients did experience panic symptoms, these authors argue that panic is qualitatively different and not a mere exacerbation of normal anxiety. These findings are, however, difficult to compare to ESM measures of panic symptoms in daily life, since questionnaires such as the SCL-90-R ask about the general level of distress caused by each symptom, and not specifically about the presence of symptoms during a panic attack.

Anderson et al. (1984) also compared symptom profiles of panic patients and patients with generalized anxiety disorders. The results supported the distinction between panic disorder and generalized anxiety disorder. Panic patients reported more symptoms of autonomic hyperactivity than patients with generalized anxiety disorders. The following symptoms were reported significantly more often by panic patients than by patients with generalized anxiety disorders: palpitations, chest pain, sweating/flushing, tinnitus, dyspnea, faintness/ lightheadedness, dizziness/imbalance, blurred vision and (muscular) weakness.

Thyer \& Himle (1987) compared 20 panic patients to 20 simple phobics on a questionnaire (ASQ) containing 55 items commonly associated with anxiety. Panic patients were asked to complete the checklist with respect to what they feel during a typical spontaneous 
panic attack; and simple phobics with respect to what they feel when confronting a phobic stimulus. Panic patients consistently rated the intensity of symptoms as more severe than simple phobics ( 46 out of 55 items). The following items discriminated best between both groups and had high severity ratings in panic patients: things seem unreal, skipped heart beats, feel as if you were going crazy, pain or discomfort in the chest, numb or tingling, spots on the skin, feel as if you might black out (faint), feel as if you were dying, pounding sensations in the chest, sweating, feeling that things are spinning around you and the feeling of doom.

Others identified few differences between paric and other types of anxiety. Barlow et al. (1985) investigated severity ratings of panic symptoms in patients with anxiety disorders and major depression (total $\mathrm{N}=108$ ). Differences in severity ratings were only significant for 2 items, namely: dizziness and fear of going crazy or losing control. Patients with panic disorder or agoraphobia with panic attacks reported more severe dizziness than patients with social phobia, simple phobia or major depression. Panic patients further had the highest severity ratings on the item fear of going crazy or losing control. Panic patients scored significantly higher on this item than patients with social phobias, generalized anxiety disorders and major depressive episodes. Agoraphobic patients with panic attacks scored also higher on this item than patients with social phobias and generalized anxiety disorders. The following symptoms had the highest severity ratings in patients with panic disorder: fear of going crazy or losing control, palpitations, feelings of unreality, dizziness and shaking. Agoraphobic patients with panic attacks rated the following items as most severe: palpitations, fear of going crazy or losing control, dizziness, hot/cold flushes, shaking and fainting.

Başoglu et al. (1992) investigated differences between episodes of panic and anxiety in a group of panic patients with agoraphobia by means of a modified event sampling technique. The patients had to start continuous recordings of anxiety and panic symptoms from the first moment they felt anxious or panicky throughout the rest of the day. The subjects labeled the episodes either as 'panic' or as 'anxiety', but only a minority of the episodes that were labeled by the patients as panic corresponded to DSM III(R) criteria of panic attacks. Episodes labeled as 'panic' were found to be briefer, more intense and having more symptoms than anxiety episodes. Symptoms discriminating best between episodes of panic and anxiety were: shaking/trembling, dizziness, sweating, depersonalization, faintness, choking/smothering, flushes and fear of going crazy or losing control.

Differences in panic experiences between panic patients with different levels of agoraphobia were also investigated. Noyes et al. (1987) studied panic symptoms in 82 panic patients, divided in 3 groups with increasing levels of agoraphobia. The following symptoms were reported less frequently by panic patients without agoraphobia than by patients with limited or extended agoraphobia: faintness or lightheadedness, dizziness or imbalance, trouble concentrating and fear of dying or going crazy. In another group of 144 panic patients, subjects with increasing levels of agoraphobia again reported more symptoms of faintness, dizziness and unsteadiness (Schneier et al., 1991).

Telch et al. (1989) rated the severity of DSM III(R) panic symptoms in 35 panic patients and 40 panic patients with agoraphobia. The following symptoms were rated as most severe in panic patients without agoraphobia: palpitations, shaking or trembling, fear of dying, 
derealization and fear of losing control. Panic patients with agoraphobia rated as most severe symptoms: palpitations, feeling faint, dizziness, shaking or trembling and fear of dying. Panic patients with agoraphobia scored significantly higher on only 2 items ('feeling faint' and 'dizziness') than panic patients without agoraphobia. Nevertheless, panic patients with agoraphobia showed a consistent trend of higher severity on almost all DSM III(R) symptoms.

From this review, we can conclude that most studies provide evidence in favor of the view that panic is both quantitavely and qualitatively different from other types of anxiety: symptoms of panic are more intense and different in nature. Most of the studies indicate that three types of symptoms are most exclusively related to panic, namely (1) fear of death, going crazy or losing control; (2) faintness and dizziness and (3) heart complaints. Especially panic patients with agoraphobia were more likely to report symptoms of faintness and dizriness. Other symptoms, like breathlessness, sweating, feelings of unreality, may be very common in panic patients, but did not always differentiate between panic patients and patients with other disorders. In the next paragraph, the construction of the panic scale will be described, including panic items that are thought to be representative of the total domain of items about panic experiences.

\subsection{2. the construction of the ESM panic scale}

A first step to ensure content validity of the items designed to measure the experience of panic in daily life is the selection of items conceming the most prominent features and specific symptoms of panic. This selection was based on the literature presented above. The aim is to develop an ESM scale, including items about the experience of panic.

The standard ESM questionnaire includes a range of questions about thoughts, mood, individualized complaints, current activities and physical well-being. The ESM questionnaire also includes an item about anxious mood ('feeling anxious'). The questionnaire then had to be completed with an additional module of items about panic related symptoms. An expert panel of clinicians and researchers in the domain of anxiety disorders created a module of 5 panic items, grouping the most relevant DSM III criteria for panic attacks:

shorness of breath, tightness, suffocating

- palpitations, chest pain or discomfort

- feeling weak, faint, dizzy, unsteady

- feeling unreal

- fear of dying, going crazy or doing something uncontrolled.

Subjects were further able to create some items from their own experience. Individualized complaints were chosen individually by each subject. Most individualized complaints chosen by panic patients, but also by neurotic controls are related to anxiety (table 5.1; see also appendix 5).

In general, few differences were found between the type of individualized complaints chosen by panic patients and neurotic controls, although panic patients tended to mention physical complaints related to panic/anxiety more frequently than neurotic controls $\left(\mathrm{X}_{(4)}=8.6\right.$; $p<.10$ ). The ESM report used in the present study thus includes 7 items, that are related to the experience of panic and anxiety: 5 panic module items, feeling anxious and the main individualized complaint. 
The list of individualized complaints mentioned by panic patients can be considered as a pool of relevant panic items that can be used in future daily life studies. Individualized complaints provide a description of symptoms of panic patients in their own words. The inclusion of the major individualized complaint in the panic scale, therefore, introduces a 'subjective' component into the scale. This subjective component is, however, in our opinion essential in order to add personal detail and a true-to-life colour to the standard panic experience described in DSM III(R). This strategy resists the general trend of what van Praag (1992) called the 'preoccupation with the objective' and at the sarne time offers the possibility to create a panic scale that is appealing to the individual subject without loosing psychometric qualities.

table 5.1.

Individualized complaints chosen by panic patients and nexrotic controls.

panic patients

individualized complaints
$N(\%)$ neurotic controls

$N(\%)$

$\begin{array}{lclc}\text { anxiety/fear/panic } & 38 & (30 \%) & 13(34 \%) \\ \text { nervousness } & 8 & (6 \%) & 5(13 \%) \\ \text { physical complaint related to panic/anxiety } & 64 & (50 \%) & 10(26 \%) \\ \text { other psychological complaints } & 8(6 \%) & 3(8 \%) \\ \text { other physical complaints } & 10(8 \%) & 7(18 \%)\end{array}$

total

128

38

\subsection{3. scalability of items related to panic and anxiety}

The next question is whether the ESM items about anxiety and panic measure a single underlying dimension. Unidimensional scaling procedures allow us to test whether the operationalization of panic can be conceptualized as an underlying unidimensional continuum. The model of Mokken (Mokken, 1971; Stokman \& van Schuur, 1980) is based on the assumption that a one dimensional latent variable exists on which each subject has a certain (unknown) value, indicating the amount of the attribute of the subject. There is also a set of items that is assumed to be homogeneous with respect to the latent variable, meaning that all items measure the same latent concept. When the items are dichotomized, the probability of a positive response on each item has to increase monotonically over the subject's value. Items have different levels of difficulty, and the value of an item on the latent variable is equal to that of a subject giving a positive response with a probability of .50 . When a subject gives a positive response to a more difficult item, the answer to all the easier items should be positive too. If this is true for all items and subjects, a perfect scale would have been identified. In Mokken scale analysis, small errors against this rule are allowed. Still, subjects with an higher value should be more likely to give a positive response than subjects with a lower value on the latent continuum. The function giving the pro- 
bability of a positive response for each item and each value of subjects is called a trace line. In the model of Mokken, these trace lines have to be double monotone: they do not decrease and they do not intersect. And finally, it is assumed that the responses of a subject are statistically independent: the probability of responding positively to a pair of items is the product of the probabilities of responding positively to each item separately.

For a double monotone set of items the order of the items on the continuum is estimated from the proportion of subjects giving a positive response to that item. The order of the subjects can be estimated likewise from the number of positive responses, i.e. the summation scores per subject. The goodness of fit of a Mokken model can be tested by the following scalability criteria. Homogeneity coefficients (Hij) test the scalability of two items $\mathrm{i}$ and $\mathrm{j}$. Hij coefficients are based on the observed number of errors against the perfect scale model and are computed for each pair of items. Loevinger's coefficient of homogeneity $(\mathrm{H})$ is computed for the whole scale, based on the weighted average of all Hij's. A high homogeneity coefficient means that a scale: has been identified with only a few deviations from a perfect scale, which allows a perfect ordering of items and subject on the latent variable. Futhermore, item coefficients $\mathrm{Hi}$ are computed for each item with respect to all other items in the scale. Hi coefficients are indicative of the scalability of different items separately. If all $\mathrm{Hi}^{\prime}$ s are larger than or equal to .50 , a strong scale has been identified. The Mokken scale analysis provides also an estimation of the reliability coefficient rho, based on the nonparametric model of double monotonicity (Sijtsma \& Molenaar, 1987).

Mokken scale analyses were used in order to investigate whether the previously selected ESM items measure an underlying continuum that can be interpreted as 'panic'. Subjects were patients with panic disorder $(\mathrm{N}=64)$ and neurotic controls $(\mathrm{N}=19)$. Ratings on panic items were not available for normal subjects. ESM data could not be analyzed at the beep level, since responses of the same subject at different moments can not be considered as independent observations. Therefore, only one beep per subject was selected and a Mokken scale analysis with a maximum of 83 records was carried out. The Mokken scale analysis was repeated for each beep separately, thus checking whether a scale can be identified that is stable over time. A total of 60 analyses were performed: day 1 - beep 1, day 1 - beep $2, \ldots$ day 6 - beep 10 . The mean number of valid beeps per analysis was 56 .

Originally, Mokken scale analysis was developed for dichotomized items. Now procedures are available to perform the analysis on items with more response altematives. Since only a sinall number of subjects were included in each analysis and all items are strongly negatively skewed (see below: figure 5.1), the 7-point Likert type items in the ESM questionnaire were dichotomized. The items were dichotomized as follows: value 1 ('not') $=0$ and the values $2-7=1$. Mokken scale analyses with a stepwise search procedure and the estimation of homogeneity and reliability coefficients were performed with the package MSP (Debets \& Brouwer, 1986).

In 25 out of 60 analyses all items were included in the scale with Hi values greater than .50. Using $\mathrm{Hi}$ coefficients greater than .40 as a criterion, indicating a medium to strong scale, 52 out of the 60 analyses included all previously selected items in the Mokken scale. Poor results were mainly due to the small number of valid reports, e.g. early in the morning. Homogeneity coefficients $(\mathrm{H})$ for the total scale varied between .57 and .73 , 
while reliability coefficients (rho) varied between .84 and .91 . Therefore, we can conclude that a very strong scale has been identified that is stable over time.

The items included in the scale, from the most easy to the most difficult item are listed in table 5.2, together with the estimates of item difficulties, i.e. percentages of positive responses to each item over all beeps. The results of the Mokken scale analyses are important in that they indicate that experiences of anxiety and panic do not constitute two distinct dimensions. The item difficulties demonstrate that there is a continuum from rather frequently occurring experiences of anxiety till fear of dying, going crazy or doing something uncontrolled. These results show that differences between panic and other types of anxiety are rather a matter of degree than of kind. Items related to anxiety, but not specifically related to experiences of panic (e.g., feeling anxious and the main individualized complaint) are included in the same scale and measure the same underlying dimension as items based on the DSM III(R) criteria of panic attacks (e.g., feeling unreal, fear of death). On the other hand, the kind of experiences of panic patients may be different from those of patients with other disorders in that some symptoms occur exclusively in panic disordered patients. In the next section, differences between panic patients and neurotic controls will be described in greater detail.

table 5.2.

The ESM panic scale: items classified according to item difficulty.

item

$\%$ of valid beeps

with positive response

individualized complaint

dizziness

feeling anxious

palpitations

shortness of breath

feeling unreal

fear of dying
$55 \%$

$52 \%$

$48 \%$

$42 \%$

$38 \%$

$34 \%$

$22 \%$

\subsection{4. aspects of construct validity}

The results of the scalability analyses demonstrated that all items measure one underlying dimension. Now construct validity has to be studied in order to know how this dimension can be interpreted or, in other words, what construct accounts for the variability in scores on this scale. According to Cronbach (1970), 3 phases can be distinguished in the establishment of construct validity: first, to suggest what construct might account for the test scores; secondly, to generate testable hypotheses based on theoretical considerations related to the construct; and, finally, to carry out empirical studies to test these hypotheses. Following this procedure, we hypothesized that the construct of 'panic' explains the variability in scores on the items in the Mokken scale. The results of the Mokken scale analy- 
ses indicate that there is a single dimension ranging from anxiety to extreme fear of dying. Based on the literature concerning the experience of panic, summarized in section 5.1.1, it is expected that the experience of panic in panic patients is quantitatively and qualitatively different. from anxiety experiences in patients with other diagnoses (neurotic controls). More concretely, it is hypothesized that (1) panic patients will have higher scores on the panic scale than neurotic controls; and (2) panic patients will experience different symptoms than neurotic controls. We presume that panic patients and neurotic controls will share experiences of anxiety, but will be differentiated on the more difficult panic items.

Frequencies of scores on the different items in the panic scale in different diagnostic groups are displayed in figure 5.1. The total panic score was operationalized as the mean of the 7 items in the panic scale. The score on the total panic scale was only computed if at least 4 out of the 7 items were completed. Frequencies of the scores on the total panic scale in different diagnostic groups are given in figure 5.2.

First, percentages of high scores will be compared. High scores are scores higher than or equal to a score of 5 on the 7-point scale (from 'rather' to 'very'). These scores are marked by black bars in figure 5.1 and 5.2. An inspection of the graphs in figure 5.1 reveals that neurotic controls had fewer high scores on the most difficult panic items. For instance, high scores on the most easy item, namely the main individualized complaint, occurred with almost equal frequencies in neurotic controls (13\% of all valid beeps) and in panic patients (18\%). Feeling anxious is also an experience panic patients and neurotic controls share, although it is more common in panic patients than in neurotic controls (11\% of all valid beeps in neurotic controls and $20 \%$ in panic patients). With increasing item difficulties, more discrepancies were found in the frequencies of high scores in panic patients and neurotic controls. High scores on items about physical symptoms (dizziness, heart complaints and shortness of breath) were reported about twice as much by panic patients than by neurotic controls.

Scores on the most difficult items, feelings of unreality and fear of dying, going crazy or losing control discriminated best between both diagnostic groups. Strong feelings of unreality were rather uncommon in neurotic controls: only $2 \%$ of all valid beeps compared to $9 \%$ of all valid reports in panic patients. Fear of dying, going crazy or losing control only received a high score in $1 \%$ of all valid beeps in neurotic controls, compared to $9 \%$ in panic patients. As can be seen in figure 5.2, high scores on the total panic scale clearly differentiated neurotic controls and panic patients. Panic patients had a score of 5 or higher on the total panic scale in $12 \%$ of all valid beeps. In neurotic controls, high scores on the total panic scale were only noted in $1 \%$ of all valid beeps.

Since the frequencies of these scores are computed at the beep level, the number of units in the analyses is inflated and the results may be influenced largely by individual outliers. For instance, high scores on the panic scale in the group of neurotic controls may be due to a single subject. Likewise, a subject in the group of panic patients who is scoring continuously high may greatly influence the data. Therefore, differences between diagnostic groups were also tested at the level of the subject. Means per subject were computed for each item and for the total panic scale. Means and standard deviations of subject's means on different items and on the panic scale are displayed in table 5.3. Differences between panic patients and neurotic controls were tested by means of t-tests. 
figure 5.1.

Frequencies of high and low scores on panic items in different diagnostic groups.
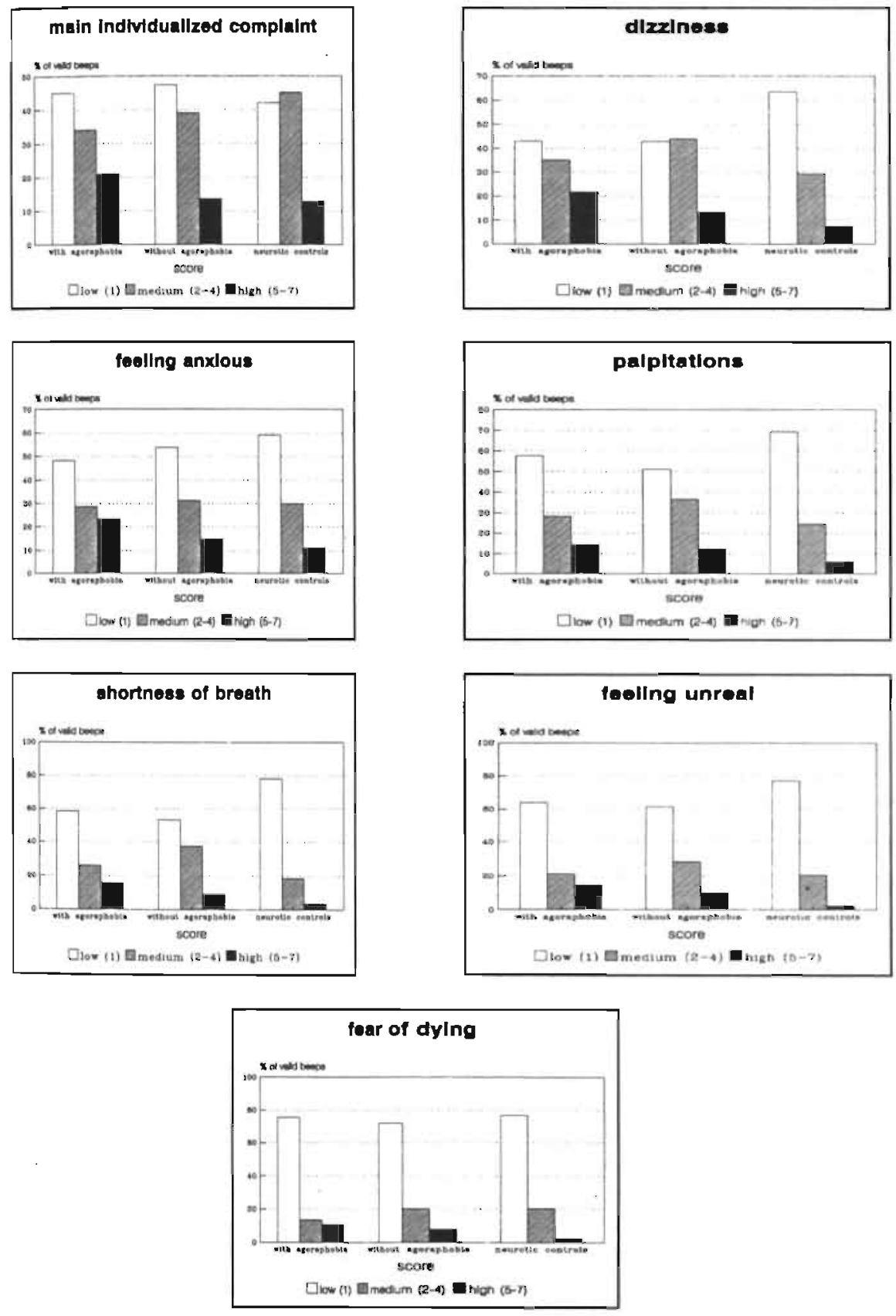
figure 5.2.

Frequencies of scores on the total panic scale in different diagnostic groups.



table 5.3.

Means and standard deviations of subject's means on panic items and on the total panic scale in panic patients and neurotic controls.

mean (SD)

$$
\begin{array}{ll}
\text { panic disorders } & \text { neurotic controls t-test } \\
(\mathrm{N}=64) & (\mathrm{N}=19)
\end{array}
$$

$\begin{array}{llll}\text { individualized complaint } & 2.75(1.5) & 2.56(1.1) & \mathrm{t}_{(81)}=0.50 ; n . \mathrm{s} . \\ \text { dizziness } & 2.79(1.6) & 1.89(0.9) & \mathrm{t}_{(55)}=3.07 ; \mathrm{p}<0.01 \\ \text { feeling anxious } & 2.66(1.6) & 2.08(1.1) & \mathrm{t}_{(81)}=1.48 ; \mathrm{n} . \mathrm{s} . \\ \text { palpitations } & 2.40(1.3) & 1.71(1.0) & \mathrm{t}_{(81)}=2.07 ; \mathrm{p}<0.05 \\ \text { shortness of breath } & 2.27(1.3) & 1.49(0.7) & \mathrm{t}_{(59)}=3.38 ; \mathrm{p}<0.01 \\ \text { feeling unreal } & 2.17(1.5) & 1.55(0.9) & \mathrm{t}_{(53)}=2.20 ; p<0.05 \\ \text { fear of dying } & 1.81(1.3) & 1.18(0.3) & \mathrm{t}_{(78)}=3.67 ; p<0.001 \\ \text { total panic scale } & 2.38(1.3) & 1.73(0.7) & \mathrm{t}_{(59)}=2.93 ; p<0.01\end{array}$

Subjects' means on the main individualized complaint and the item 'feeling anxious' did not differ significantly between panic patients and neurotic controls. Differences in subject's means on the items about dizziness, palpitations, shortness of breath, feelings of unreality and fear of dying as well as differences in subject's means on the panic scale were all statistically significant. Patients with panic disorders had significantly higher mean scores than patients with other disorders on items about dizziness, heart complaints, shortness of breath, feelings of unreality and fear of dying. The distinction between experiences of 
anxiety in panic patients and patients with other disorders was supported. Data at the subject level confirm the previous findings at the beep level. Panic patients and patients with other disorders had some experiences in common, such as individualized complaints and feelings of anxiety. These experiences did not differentiate panic patients from patients with other disorders. Panic patients only differed from patients with other disorders on the more difficult items. Finally, the mean score on the total panic scale clearly discriminates experiences of panic in panic patients from experiences of anxiety in neurotic controls.

Based on these results, a 'panic experience' was operationalized as a score of 5 or higher on the total panic scale. This cut-off point discriminates well between panic patients and neurotic controls. A cut-off score of 6 would discriminate these groups even better. In fact, a score higher than 6 on the 7-point scale was not observed in the group of neurotic controls. But, a score higher than 6 was only observed in $5 \%$ of the panic patients without agoraphobia and in $8 \%$ of the panic patients with agoraphobia. By using a cut-off point of 6. too little observations of panic experiences would be left and this would hamper the analysis of the relationship between panic experiences and individual, temporal and situational characteristics.

In summary, the results reported in this section support the construct validity of the panic scale. The scale contains easy items about anxiety and individualized complaints that did not differentiate panic patients from neurotic controls as well as more difficult items receiving only very infrequently high scores in neurotic controls. A mean score of 5 or higher on the total panic scale clearly differentiates between neurotic controls and panic paticrits. The result are also consistent with literature indicating both quantitative and qualitative dif ferences between panic and anxiety.

\subsection{Panic Experiences in Panic Patients with and without Agoraphobia}

Retrospectively, few differences were found between panic patients with and without agoraphobia in the severity and frequency of panic attacks and in the number of symptoms associated with panic (Rapee \& Murrell, 1988; Adler et al., 1989; Fleming \& Faulk, 1989; Telch et al., 1989). Only a few studies carried out in the natural environment compared panic experiences of panic patients with and without agoraphobia (section 3.3.3): In event sampling studies, few differences have been found between panic patients with and without agoraphobia in the frequency, intensity and duration of panic attacks (Ganellen et al., 1986; Street et al., 1989; Margraf et al., in prep.). In one study, panic patients without agoraphobia reported more spontaneous panic attacks than panic patients with agoraphobia (Ganellen et al., 1986). Based on these studies, we expect to find few differences between panic patients with and without agoraphobia in the frequency and severity of panic experiences in daily life and if any, we expect that panic patients with agoraphobia will have panic experiences more frequently than panic patients without agoraphobia.

Frequencies of scores on the different items in the panic scale of panic patients with and without agoraphobia were displayed in figure 5.1. Frequencies of mean scores on the total panic scale were given in figure 5.2. Differences between panic patients with and without agoraphobia were much smaller than differences between panic patients and neurotic controls. There was, however, a tendency for agoraphobic patients to report more high scores than panic patients without agoraphobia. And this tendency to report more high scores is 
manifest on all items, irrespective of item difficulty. For instance, high scores on the item feeling anxious were noted in $15 \%$ of all valid beeps in panic patients without agoaphobia and in $21 \%$ in panic patients with agoraphobia. Accordingly, feelings of unreality received a. high score in $10 \%$ of all valid beeps in panic patients without agoraphobia and in $15 \%$ in panic patients with agoraphobia. High scores on the item fear of dying, going crazy or losing control were observed in $8 \%$ of panic patients without agoraphobia and in $11 \%$ of panic patients with agoraphobia. High mean scores on the total panic scale occurred in $9 \%$ of panic patients without and in $14 \%$ of all valid beeps in panic patients with agoraphobia. These results indicate that higher panic scores occur in agoraphobic patients than in panic patients without agoraphobia. It is, however, difficult to interpret these results, since individual differences may account for these data. A subgroup of subjects having almost continuously panic experiences may account for these findings. Therefore, it is important to take the results of the analyses at the subject level into account.

Means and standard deviations of subject' means on different items and on the total panic scale of panic patients with and without agoraphobia are displayed in table 5.4. Analyses at the subject level show that the differences in mean scores on panic items between panic patients with and without agoraphobia did not reach statistical significance.

table 5.4.

Means and standard deviations of subject's means on panic items and on the total panic scale in panic patients with and without agoraphobia.

mean (SD)

\begin{tabular}{|c|c|}
\hline $\begin{array}{l}\text { panic disorder } \\
\text { without } \\
\text { agoraphobia } \\
(\mathbf{N}=29)\end{array}$ & $\begin{array}{l}\text { panic disorder } \\
\text { with } \\
\text { agoraphobia } \\
(\mathrm{N}=35)\end{array}$ \\
\hline
\end{tabular}

\begin{tabular}{llll}
\hline individualized complaint & $2.55(1.3)$ & $2.92(1.7)$ & $\mathrm{t}_{(62)}=-0.99 ;$ n.s. \\
dizziness & $2.60(1.5)$ & $2.94(1.8)$ & $\mathrm{t}_{(61)}=-0.82 ;$ n.s. \\
feeling anxious & $2.42(1.4)$ & $2.86(1.8)$ & $\mathrm{t}_{(62)}=-1.09 ;$ n.s. \\
palpitations & $2.43(1.4)$ & $2.38(1.4)$ & $\mathrm{t}_{(62)}=0.16 ;$ n.s. \\
shortness of breath & $2.16(1.2)$ & $2.36(1.4)$ & $\mathrm{t}_{(61)}=-0.56$; n.s. \\
feeling unreal & $2.15(1.5)$ & $2.20(1.6)$ & $\mathrm{t}_{(61)}=-0.13 ;$ n.s. \\
fear of dying & $1.89(1.3)$ & $1.74(1.2)$ & $\mathrm{t}_{(61)}=0.46 ;$ n.s. \\
total panic scale & $2.28(1.2)$ & $2.47(1.3)$ & $\mathrm{t}_{(61)}=-0.58 ;$ n.s. \\
\hline
\end{tabular}

The combination of results at the beep and at the subject level shows that there were only few differences in the experience of panic patients with and without agoraphobia. In general, high scores on panic items and on the total panic scale have been reported more frequently by panic patients with agoraphobia. After aggregating these scores at the subject 
level, no significant differences between panic patients with and without agoraphobia were found. Therefore, it seems likely that high panic scores were provided by a small number of patients who almost continuously experienced panic. The exact nature of individual ditferences within different diagnostic groups will be further described in section 5.3.

\subsection{Individual Variation}

In this section, individual variations in the frequency of panic experiences will be compared across diagnostic groups. A panic experience is defined as a score of 5 or higher on the total panic scale. As can be seen in figure 5.2, panic experiences account for $9 \%$ of all valid beeps in panic patients without agoraphobia, for $14 \%$ of all valid reports in agoraphobic subjects, and for only $1 \%$ of valid beeps in neurotic controls. In order to highlight individual variations, we computed the frequency of panic experiences per subject. Percentages of patients in different diagnostic groups reporting different frequencies of panic experiences during the ESM week are displayed in figure 5.3.

In the group of panic patients without agoraphobia, a total number of 100 panic experiences were registered by 28 subjects; i.e. an average of 4 panic experiences per subject. One subject was discarded from this analyses. No panic score could be computed, since he filled out only one item per module. Large individual variation is evident. Half of the patients in this group (14 out of 28 subjects) never reported a panic experience. Three subjects $(11 \%)$ reported 10 or more panic experiences during the ESM week: 1 subject reported 28 panic experiences and 2 subjects reported 17 panic experiences each.

In the group of panic patients with agoraphobia, 215 panic experiences were registered by 35 subjects, an average of 6 panic experiences per subject. Large individual variation was also found in this group. Again half of the patients (18 out of 35 patients) never reported a panic experience during the ESM week. As can be seen in figure 5.3, high frequencies of panic experiences are more common in this group: 7 out of the 35 patients (20\%) reported 10 or more panic experiences during the sampling period. Even higher frequencies of panic experiences were identified in this group. Two subjects reported 10 panic experiences and others reported $15,26,38,42$ and 53 panic experiences.

In the group of neurotic controls only 8 panic experiences were reported by 5 out of the 19 subjects (26\%). The highest number of panic experiences in one subject was 3.

The frequency of panic experiences clearly discriminates between panic patients and patients with other disorders. High frequencies of panic experiences in subjects without panic disorders (neurotic controls) were not found. High frequencies of panic experiences occurred also in increasingly smaller numbers of panic patients.

Only few differences between panic patients with and without agoraphobia were identified. Large individual variation was evident in both groups. Irrespective of agoraphobia, about half of the panic patients never reported panic experiences during the research week, at least not at the moment of the beep. Panic patients with agoraphobia reported on the average more panic experiences than panic patients without agoraphobia. In the group of panic patients with agoraphobia, high frequencies of panic experiences within one subject (10 or more panic experiences during the ESM week) were observed more often than in 
panic patients without agoraphobia. A small group of agoraphobic patients who almost continuously experienced high levels of panic anxiety was thus identified.

figure 5.3.

Percentages of subjects in different diagnostic groups reporting different frequencies of panic experiences.



\subsection{Severity of Psychopathology}

In the previous sections, differences between groups as well as individual differences within groups have been highlighted. At the group level, few differences in the experience of panic between panic patients with and without agoraphobia have been found. At the level of the individual, however, large differences in the frequency and severity of panic were identified. In this section, we will investigate whether individual differences in the severity and frequency of panic experiences are related to the severity of agoraphobia and other measures of psychopathology.

Pearson correlation coefficients were computed between the mean panic score as well as the percentage of panic experiences per subject and scores on the agoraphobia and the social phobia scale of the Fear Questionnaire, the trait-anxiety inventory (STAI) and Zung's SDS depression scale for the total group of panic patients $(N=64)$. The results are displayed in table 5.5 .

Correlations between measures of psychopathology and the frequency (percentage of panic experiences per subject) and severity of panic experiences (the subject's mean panic score) were all statistically significant. When controlling for other measures of psychopathology, no significant partial correlations were found between the severity and frequency of panic experiences and measures of social phobia and depression. The severity of agoraphobic fears tended to be significantly related to panic severity $(r=.30 ; n=45 ; p=.02)$ and panic frequency $(r=.27 ; n=45 ; p=.04)$ when controlling for social phobia, trait anxiety and depression scores. Partial correlations between trait anxiety scores and panic experiences were highly significant. Irrespective of agoraphobia, social phobia and depression, trait anxiety was related to panic severity $(r=.63 ; n=45 ; p<.001)$ and panic frequency $(r=.48 ; n=45 ; p<.001)$.

\section{table 5.5.}

Pearson correlations between panic frequency (percentage of panic experiences per subjects) and panic severity (mean panic score per subject) and measures of agoraphobia, social phobia, trait anxiety and depression.

$\begin{array}{llll}\text { FQ } & \text { FQ } & \text { STAI } & \text { ZUNG } \\ \text { agoraphobia } & \text { social phobia } & \text { trait-anxiety } & \text { depression }\end{array}$

\begin{tabular}{|c|c|c|c|c|}
\hline \multirow[t]{3}{*}{ severity } & .43 & .42 & .68 & .36 \\
\hline & $\mathrm{p}<.001^{*}$ & $p<.001$ & $p<.001$ & $p<.01$ \\
\hline & $N=62$ & $N=62$ & $\mathrm{~N}=59$ & $\mathrm{~N}=54$ \\
\hline \multirow[t]{3}{*}{ frequency } & .38 & .34 & .53 & .24 \\
\hline & $\mathrm{p}=.001$ & $p<.01$ & $\mathrm{p}<.001$ & $p<.05$ \\
\hline & $N=63$ & $\mathrm{~N}=63$ & $N=60$ & $N=55$ \\
\hline
\end{tabular}

* one-tailed significance test 


\subsection{Discussion}

In order to investigate the experience of panic in daily life, a panic scale based on items in the ESM questionnaire was constructed. The ESM panic module was created by an expert panel based on DSM III criteria for panic attacks as well as on empirical studies about the nature of panic. These studies indicated that the experience of panic is quantitatively and qualitatively different from other types of anxiety: symptoms of panic were found to be more intense and different in nature than symptoms of anxiety. Mokken scale analyses identified a very strong scale, thus indicating that ESM items about anxiety and panic measure one underlying dimension. Results about differences between diagnostic groups demonstrated that it is legitimate to interpret this dimension as 'panic'. Quantitative differences were demonstrated between the experiences of panic patients and patients with other disorders: panic patients had significantly higher scores on the panic scale than neurotic controls. At the same time qualitative differences were evident: panic patients and neurotic controls shared symptoms of anxiety, but symptoms such as feelings of unreality and fear of dying were very uncommon in neurotic controls. The results presented in this chapter demonstrate that ESM can be used to provide a valid description of panic experiences in daily life.

Nevertheless, panic experiences were not completely absent in the group of neurotic controls: $26 \%$ of the neurotic controls reported at least 1 panic experience during the research week. Similar incidence rates of panic attacks in non-panic subjects have been reported in other studies. Barlow et al. (1985) found that at least $75 \%$ of patients with anxiety disorders (other than panic disorder and agoraphobia with panic attacks) experienced panic attacks meeting DSM III criteria (except for panic frequency). In nonclinical samples, 34 to $49 \%$ of the subjects reported at least one panic attack during the past year, and about $25 \%$ of the subjects reported at least one attack during the last 3 weeks (Norton et al., 1985, 1986; Margraf \& Ehlers, 1988; Brown \& Cash, 1989).

Important differences between ESM and event sampling data about the frequency of panic experiences in panic patients may be noted. Margraf et al. (1987b), for instance, found that each subject recorded at least one panic attack during a period of 6 days. With ESM, about half of the panic patients never reported a panic experience. As we have argued before, the frequency of panic experiences may be underestimated with ESM. It is, however, unlikely that this type of measurement effect operates differently in both groups of panic patients. In other words, if ESM underestimates the frequency of panic experiences, it will do so both in panic patients with and without agoraphobia.

In general, few differences between panic patients with and without agoraphobia were observed. In both groups of panic patients, about half of the subjects never experienced panic during the research week. Although extremely high frequencies of panic experiences were only recorded in some of the agoraphobic subjects, both groups largely overlap. These results are consistent with findings from retrospective studies (chapter 1) and studies carried out in the natural environment (chapter 3), indicating that there are few differences in panic experiences between panic patients with and without agoraphobia. Furthermore, it is important to note that large individual variations in the frequency and severity of panic experiences were observed within groups. In the group of panic patients with agoraphobia, the frequency of panic experiences varied from subjects never experiencing panic to sub- 
jects who almost continuously experienced panic. Correlations between measures of psychopathology and measures of panic in daily life indicate that panic frequency and severity are not only related to agoraphobia, but especially to the level of trait anxiety. The amount of individual variation in panic experiences within groups demonstrates that panic patients with and without agoraphobia should not be conceptualized as two mutually exclusive groups. The data support the view that panic patients rather represent a continuum in the severity and frequency of panic experiences and in the severity of levels of psychopathology. Panic patients, who never reported experiences of panic during the research week comprise one end of the continuum. These patients were also more likely to report less agoraphobic and social fears, and less depression and trait anxiety on cross-sectional questionnaires. At the other end of the continuum, we found panic patients who almost continuously experienced symptoms of panic. This pattern was observed exclusively in panic patients with agoraphobia. Moteover, high frequencies of panic experiences and high mean levels of panic anxiety were found to be closely related to the level of trait anxiety. It is clear, however, that both ends of this continuum are not exclusively included in two distinct diagnostic groups of panic patients with and without agoraphobia. If all the cases at the severe end of the continuum were included in the group of panic patients with agoraphobia and all the cases at the other end of the continuum. in the group of panic patients without agoraphobia, we would have found significant differences between panic patients with and without agoraphobia in the frequency and severity of panic experiences, as well as on cross-sectional measures of social phobia, trait anxiety and depression. In this study, few differences were found between panic patients with and without agoraphobia in the experience of panic in daily life. Neither were there significant differences between both groups on cross-sectional measures of social phobia, trait anxiety and depression (section 4.1.2). These results are consistent with Klein's multistage modell of panic disorder, stating that after a stage of recurrent paric attacks, patients develop anticipatory anxiety, chronic tension, increasing autonomic distress and agoraphobic avoidance (section 1.4.). At least, if we take into account that the course of illness is variable: some patients develop agoraphobic fears, but never develop high levels of chronic anxiety (Klein \& Gorham, 1987). In the present chapter, a similar variability in the frequency and severity of panic experiences was demonstrated during the course of daily life.

In chapter 6, we will explore how panic patients with and without agoraphobia differ in the amount of time spent in specific daily life situations. In chapter 7 , fluctuations in the presence or absence of panic experiences will be related to individual, temporal and situational characteristics. 


\section{CHAPTER 6 TIME ALLOCATION AND AVOIDANCE IN DAILY LIFE}

In the previous chapter, experiences of panic in the daily life of panic patients with and without agoraphobia have been described. Few systematic differences between panic patients with and without agoraphobia were identified. In this chapter, we will investigate whether panic patients with and without agoraphobia differ from each other and from neurotic and normal controls in the amount of time they spend in different types of daily life situations. The process of entering daily life: situations and spending a certain amount of time in these situations will be referred to as 'time allocation'.

Several studies indicated that panic disorder and agoraphobia are characterized by impairment of work, leisure and social activities (section 1.7). In one study, however, few differences were found between agoraphobic patients and normal controls in (retrospective reports of) domestic activities and social contacts with family and friends (Buglass et al., 1977). Studies conducted in the natural environment are especially suited to investigate the amount of time that is allocated to daily life situations. Nevertheless, studies about panic disorder and agoraphobia in daily life (reviewed in chapter 3) provided little information about differences in time allocation between panic patients with and without agoraphobia, and between panic patients, patients with other disorders and normal subjects. Moreover, most of these studies focused exclusively on activities outside the home. For instance, an event sampling study was conducted in order to investigate differences between panic patients and normal controls in the number and type of activities outside the home. In this study, panic patients (without agoraphobia) did not differ from normal controls in the number or type of activities outside the home, although panic patients reported more anxiety during these activities (Margraf et al., 1987b).

In the present study, a description of other types of daily life situations will be added. Daily life situations will be classified according to the coding system described in section 4.4. First, situations described in the ESM reports will be categorized into different types of situations, namely solitary, intimate and anonymous situations. Next, daily life situations will be differentiated according to the amount of acknowledgement by other people, by the environment and by activities.

Time allocation and avoidance can not be measured directly with ESM. ESM data do not necessarily include all situations people are confronted with in daily life. In spite of this, we can expect that ESM provides a representative sample of situations, since. ESM beeps occur on random moments in daily life. The percentage of beeps people spend in specific situations can be considered as an estimate of the percentage of time people were in these. situations. Furthermore, we can expect that agoraphobic avoidance will be reflected in lower amounts of time spent in agoraphobic situations, and accordingly that agoraphobic patients will have lower relative frequencies of these situations in their ESM reports.

The following questions will be adressed:

- do panic patients with agoraphobia differ from panic patients without agoraphobia, neurotic and normal controls in the amount of time allocated to different types of situations? (section 6.2) 
- do panic patients with agoraphobia differ from panic patients without agoraphobia, neurotic and normal controls in the amount of time allocated to situations with different levels of acknowledgement by other people (section 6.3), by the environment (section 6.4) and by activities (section 6.5)?

- is time allocation related to agoraphobia and to other measures of psychopathology? (section 6.6); and

- how large is the individual variability in the amount of time allocated to different types of situations? (section 6.7).

\subsection{Statistical Analysis of Time Allocation Data}

The fact that subjects differ on demographic characteristics (section 4.1.1) may influence the time allocation results obtained with ESM. Married housewives with children are of course expected to be more often at home with their family than employed men. In a similar way, high percentages of missing responses urge us to question the assumption that ESM provides a representative sample of moments in a person's daily life. Differences in time allocation variables, therefore, will be adjusted for demographic characteristics and the percentage of missing responses per subject.

Panic patients with and without agoraphobia as well as neurotic and normal controls will be compared in terms of the amount of time they spent in different types of situations. The codings of these types of situations were based on the answers to the open questions: 'where are you?', 'with whom?' and 'what are you doing?'. To control for possible effects of demographic variables and missing responses, the differences between groups with respect to relative time allocated to different situations were analysed using multivariate analysis of covariance. This analysis provides a statistical control for the influence of covariates. It shows what the results of the analyses would have been if the covariates were held constant.

The following variables were used as covariates in the analyses: sex (male/female), marital status (married/unmarried), family life (living alone or not), work (employed/unemployed), age and the percentage of missing responses per subject. The impact of different covariates on time allocation variables will not be described in full detail. It is, however, important to mention that the percentage of missing responses had no significant effect on the estimated percentage of beeps spent in specific daily life situations, meaning that there is no evidence for the systematic underreporting of specific types of situations.

The results are presented as crude (unadjusted) and adjusted (for potential effects of demographic characteristics and missing responses) means and standard errors of the mean. Significance levels of multivariate F-tests (MF) and standard F-tests (UF) for differences of group means are also presented. Univariate tests for equality of group means or other contrists were only calculated in cases where the multivariate test for equality of mean vectors (adjusted or unadjusted) was significant. As an informal correction of the overall error rate when testing a multitude of hypotheses, only differences with p-values $<.01$ are deerned 'significant'. The analysis was done with the MGLH module of SYSTAT (Wilkinson, 1988), after we assured that the assumptions of multivariate analysis of covariance were not violated. 


\subsection{Time Allocation to Different Types of Situations}

\subsection{1. differences in time allocation to different types of situations}

Four main types of situations and 1 residual type will be included in the analysis. The main categories are:

- solitary situations: either alone at home or alone at. work, a friend's house, ...

- intimate situations: at home with family or friends, or visiting family, friends,...

- anonymous situations with significant others: together with family or friends in public places or in transport situations

- anonymous situations without significant others: either in public places or in transport situations

The residual category contains the remaining categories: personal situations, the 'else' category and all transition situations.

Agoraphobia is characterized by fear and avoidance of being alone or in public places (section 1.1). Van Zuuren (1982) further stated that agoraphobic patients avoid situations in which there is little acknowledgement by significant others and instead will seek situations with high levels of acknowledgement by other people (section 2.4.5). Therefore, we can expect that agoraphobic patients will be less often in solitary situations, less often in anonymous situations without significant others and more often in intimate situations than panic patients without agoraphobia, neurotic and normal controls.

The means and standard errors of percentages of beeps subjects spent in different types of situations are displayed in table 6.1. Table 6.1 shows, for instance, that agoraphobic patients on the average reported to be in an intimate situation in $49 \%$ of ali beeps.

Agoraphobic patients differed significantly from panic patients without agoraphobia in the amount of time they allocated to different types of situations $(\mathrm{MF}: \mathrm{p}<.001)$. Agoraphobic patients spent significantly more time in intimate situations than panic patients without agoraphobia (UF: $p<.001$ ). Panic patients with agoraphobia also tended to be less often in anonymous situations without significant others than panic patients without agoraphobia (UF: $p=.04$ ). Differences between agoraphobic patients and normal subjects were also highly significant (MF: $p<.001$ ). Again, agoraphobics spent more time in intimate situations than normal controls (UF: $p<.001$ ) and less time in anonymous situations without significant others (UF: $p<.01$ ). Differences between agoraphobic patients and neurotic controls were in the expected direction, but they did not reach statistical significance (MF: $p=.04$ ). Neither were there significant differences between panic patients without agoraphobia, neurotic and normal controls in the amount of time allocated to different types of situations.

In summary, agoraphobic patients were found to be significantly more often in intimate situations than panic patients without agoraphobia and normai controls. Agoraphobic patients also spent significantly less time in anonymous situations without significant others than normal controls, and they tended to be less often in this type of situation than panic patients without agoraphobia. In the following section, we will explore how these time allocation data are influenced by demographic characteristics and missing responses. 
table 6.1.

Time allocation to different types of situations: means and standard errors (s.e.) of subject's percentages of beeps spent in different types of situations.

$\begin{array}{lllll}\text { mean } & \text { panic disorder } & \text { panic disorder } & \text { neurotic } & \text { normal } \\ \text { (s.e.) } & \text { with } & \text { without } & \text { controls } & \text { controls } \\ & \begin{array}{l}\text { agoraphobia } \\ (\mathrm{N}=35)\end{array} & \begin{array}{l}\text { agoraphobia } \\ (\mathrm{N}=29)\end{array} & (\mathrm{N}=19) & (\mathrm{N}=20)\end{array}$

\begin{tabular}{lcccc}
\hline $\begin{array}{lccc}\text { solitary } \\
\text { situation }\end{array}$ & 17.57 & 16.93 & 23.00 & 22.85 \\
& $(2.17)$ & $(2.35)$ & $(2.94)$ & $(2.85)$ \\
$\begin{array}{l}\text { intimate } \\
\text { situation }\end{array}$ & 49.29 & 32.35 & 34.58 & 30.05 \\
& $(2.65)$ & $(2.87)$ & $(3.58)$ & $(3.48)$ \\
$\begin{array}{l}\text { anonymous } \\
\text { with signifi- }\end{array}$ & 3.57 & 3.55 & 3.90 & 3.95 \\
cant others & $(0.75)$ & $(0.81)$ & $(1.02)$ & $(0.99)$ \\
& & & & \\
anonymous & 1.43 & 3.31 & 3.00 & 4.75 \\
without signi- & $(0.60)$ & $(0.65)$ & $(0.81)$ & $(0.78)$ \\
ficant others & & & & \\
& & & & \\
else & 6.86 & $(1.59)$ & $(1.98)$ & $(1.93)$ \\
& $(1.47)$ & & & \\
\hline
\end{tabular}

6.2.2. time allocation to different types of situations after the adjustment for demographic characteristics and missing responses

Table 6.2 shows the means and standard errors of the percentages of beeps subjects spent in different types of situations after the adjustment for demographic characteristics and missing responses.

The adjustment for demographic characteristics and missing responses shows a profile of means differing somewhat from the crude mean profile in table 6.1. Agoraphobic patients did not differ significantly from panic patients without agoraphobia and from neurotic controls in the percentage of beeps they spent in different types of situations. In comparison to normal controls, agoraphobic patients did show significant differences in the time allocated to different types of situations (MF: $p<.01$ ). Agoraphobics reported to be significantly more often in intimate situations than normal controls (UF: $p<.001$ ). Agoraphobic patients also tended to be less often in solitary situations (UF: $p=.02$ ) and less often in anonymous situations without significant others than normal controls (UF: $p=.02$ ). Panic patients without agoraphobia, normal and neurotic controls did not differ significantly from each other in the amount of time spent in different types of situations. 
table 6.2.

Time allocation to different types of situations: means and standard errors (s.e.) of subject's percentages of beeps spent in different types of situations after the adjustment for demographic variables and missing responses.

\begin{tabular}{lllll}
$\begin{array}{l}\text { mean } \\
\text { (s.e. })\end{array}$ & $\begin{array}{l}\text { panic disorder } \\
\text { with } \\
\text { agoraphobia } \\
(\mathrm{N}=35)\end{array}$ & $\begin{array}{l}\text { panic disorder } \\
\text { without } \\
\text { agoraphobia } \\
(\mathrm{N}=29)\end{array}$ & $\begin{array}{l}\text { neurotic } \\
\text { controls }\end{array}$ & $\begin{array}{l}\text { nurmal } \\
\text { controls }\end{array}$ \\
\hline $\begin{array}{l}\text { solitary } \\
\text { situation }\end{array}$ & 15.61 & 19.58 & 20.71 & $(\mathrm{~N}=20)$ \\
intimate & $(2.21)$ & $(2.33)$ & $(2.78)$ & 24.37 \\
situation & 43.93 & 36.78 & 38.20 & $(2.68)$ \\
anonymous & $(2.37)$ & $(2.49)$ & $(2.98)$ & 29.70 \\
with signifi- & $(0.80)$ & $(0.84)$ & 4.29 & $(2.87)$ \\
cant others & & & $(1.00)$ & 3.70 \\
& & & & $(0.96)$ \\
anonymous & 2.09 & 3.12 & 2.35 & 4.48 \\
without signi- & $(0.62)$ & $(0.65)$ & $(0.78)$ & $(0.75)$ \\
ficant others & & & & 10.46 \\
else & 8.07 & 9.20 & 7.32 & $(1.77)$ \\
\hline
\end{tabular}

\subsection{3. discussion}

Agoraphobia was reflected in clear differences in time allocation. Agoraphobic patients were significantly more often in intimate situations than panic patients without agoraphobia and normal controls. We expected that agoraphobic patients would be less often in anonymous situations without significant others than the other groups. This was, only partly true. Agoraphobic patients spent significantly less time in anonymous situations without significant others than normal controls. Differences between panic patients with and without agoraphobia in the time allocated to this type of situation tended to be in the expected direction, but did not reach statistical significance. And finally, agoraphobic patients were not less often in solitary situations than the other groups: no significant differences between groups were found in the amount of time allocated to solitary situations.

These differences in time allocation have to be interpreted with caution, since differences, in demographic characteristics may influence the amount of time spent in different types of situations. After the adjustment for demographic characteristics and missing responses, agoraphobic patients did not differ significantly from panic patients without agoraphobia 
and neurotic controls in the amount of time allocated to different types of situations. Time allocation data after these adjustments indicated that agoraphobia is most clearly reflected in the amount of time allocated to intimate situations. Agoraphobic patients spent significantly more time in intimate situations than normal controls. Panic patients without agoraphobia and neurotic controls took an intermediate position between agoraphobics and normals in the time they allocated to intimate situations. Agoraphobic patients further tended to be less often in solitary situations and in anonymous situations without significant others than normal controls.

Time allocation data presented in this section provided only little evidence for differences in the amount of time allocated to solitary and anonymous situations. Agoraphobic patients spent significantly more time in intimate situations than normal controls. In terms of van Zuuren's theory, intimate situations are characterized by high levels of acknowledgement by other people and by the environment. In the next sections, differences in time allocation to daily situations with different levels of acknowledgement by other people, by the environment and by activities will be further explored.

The finding that panic patients without agoraphobia took an intermediate position between agoraphobic patients and normal controls may-lead to the hypothesis that more time is allocated to intimate situations with increasing levels of agoraphobia. In this section, panic patients with and without agoraphobia were considered as 2 mutually exclusive groups. In chapter 5 , we demonstrated that both groups may largely overlap. In section 6.6 , we will further investigate whether the amount of time allocated to intimate situations is related to the severity of agoraphobic fears.

Another important finding is that neurotic controls did not differ significantly from panic patients with and without agoraphobia in the percentage of beeps spent in different types of situations. This finding may suggest that the time allocation patterns observed in agoraphobic patients are not specifically related to agoraphobia, but rather to other measures of psychopathology. In section 6.6., we will explore whether the amount of time spent in different types of situations is related to measures of social phobia, depression and trait anxiety.

\subsection{Time Allocation and Acknowledgement by Significant Others}

\subsection{1. differences in acknowledgement by significant others}

Acknowledgement by other people was coded from the answers to the question 'with whom were you at the moment of the beep?'. The level of acknowledgement by other people is:

low

moderate with a nameable other with whom there is a direct contact (e.g., hairdresser, mailman, client) or with relatives, friends, neighbours and acquaintances

high with own family (household members) 
On the basis of van Zuuren's theory, we expect that agoraphobic patients will be more often in situations with high levels of acknowledgement and less often in situations with low levels of acknowledgement by other people than panic patients without agoraphobia, neutotic and normal controls. No significant differences between panic patients without agoraphobia, neurotic and normal controls are expected.

The means and standard errors of percentages of beeps subjects spent in situations with different levels of acknowledgement by others are displayed in table 6.3.

table 6.3.

Time allocation to situations with different levels of acknowledgement by other people: means and standard errors (s.e.) of subject's percentages of beeps.

\begin{tabular}{lllll}
$\begin{array}{l}\text { mean } \\
(\text { s.e. })\end{array}$ & $\begin{array}{l}\text { panic disorder } \\
\text { with } \\
\text { agoraphobia } \\
(\mathrm{N}=35)\end{array}$ & $\begin{array}{l}\text { panic disorder } \\
\text { without } \\
\text { agoraphobia } \\
(\mathrm{N}=29)\end{array}$ & $\begin{array}{l}\text { neurotic } \\
\text { controls }\end{array}$ & $\begin{array}{l}\text { normal } \\
\text { controls }\end{array}$ \\
\hline low & 19.94 & 21.55 & 27.00 & $(\mathrm{~N}=20)$ \\
& $(2.30)$ & $(2.49)$ & $(3.11)$ & 28.05 \\
moderate & 11.80 & 15.59 & $14.02)$ \\
& $(1.92)$ & $(2.08)$ & $(2.59)$ & 15.35 \\
high & 46.20 & 26.90 & 26.05 & $(2.52)$ \\
& $(3.00)$ & $(3.25)$ & $(4.05)$ & 28.80 \\
& & & & $(3.94)$ \\
\hline
\end{tabular}

Highly significant differences emerged between panic patients with and without agoraphobia (MF: $p<.001$ ). Panic patients with agoraphobia spent significantly more time in situations with high levels of acknowledgement by other people than panic patients without agoraphobia (UF: $p<.001$ ). The time allocation pattems of agoraphobic patients and normal controls were also significantly different (MF: $p<.01$ ). Again agoraphobic patients spent more time in situations with high levels of acknowledgement by other people than normal controls (UF: $p<.01$ ). There was also a trend for agoraphobic subjects to be less often in situations with low levels of acknowledgement by other peopie than normal controls (UF: $p=.04$ ). Time allocation patterns of agoraphobic patients further differed significantly from those of neurotic controls $(\mathrm{MF}: \mathrm{p}<.01)$. Agoraphobic patients spent more time in situations with high levels of acknowledgement by other people than neurotic controls (UF: $p<.001$ ). No significant differences in the amount of time allocated to situations with different levels of acknowledgement by other people were found between panic patients without agoraphobia, neurotic and normal controls.

In summary, agoraphobic patients were significantly more often in situations with high levels of acknowledgement by other people than panic patients without agoraphobia, neurotic and normal controls. There was a trend for panic patients with agoraphobia to be less 
often in situations with low levels of acknowledgement by other people than normal controls.

6.3.2. differences in acknowledgement by significant others after the adjustment for demographic characteristics and missing responses

Table 6.4 shows the means and standard errors of subject's percentages of beeps spent in situations with different levels of acknowledgement by other people after the adjustment for demographic characteristics and missing responses.

\section{table 6.4}

Time allocation to situations with different levels of acknowledgement by other people: means and standard errors (s.e.) of subject's percentages of beeps after the adjustment for demographic variables and missing responses.

\begin{tabular}{lllll}
$\begin{array}{l}\text { mean } \\
(\text { s.e. })\end{array}$ & $\begin{array}{l}\text { panic disorder } \\
\text { with } \\
\text { agoraphobia } \\
(\mathrm{N}=35)\end{array}$ & $\begin{array}{l}\text { panic disorder } \\
\text { without } \\
\text { agoraphobia } \\
(\mathrm{N}=29)\end{array}$ & $\begin{array}{l}\text { neurotic } \\
\text { controls }\end{array}$ & $\begin{array}{l}\text { normal } \\
\text { controls }\end{array}$ \\
\hline low & 17.99 & 24.01 & 25.44 & $(\mathrm{~N}=20)$ \\
& $(2.25)$ & $(2.35)$ & $(2.84)$ & 29.09 \\
moderate & 13.54 & 14.98 & 12.30 & 15.60 \\
& $(1.87)$ & $(1.95)$ & $(2.35)$ & $(2.27)$ \\
high & 39.44 & 31.97 & 33.28 & 26.45 \\
& $(2.46)$ & $(2.56)$ & $(3.09)$ & $(2.98)$ \\
\hline
\end{tabular}

After the adjustment for demographic characteristics and missing responses, agoraphobic patients did not differ significantly from panic patients without agoraphobia and neurotic controls. Agoraphobic patients only differed significantly from normal controls in the time allocated to situations with different amounts of acknowledgement by others (MF: $p<.01)$. Large differences in the percentage of beeps spent in situations with either low (UF: $\mathrm{p}<.01$ ) or high (UF: $\mathrm{p}<.01$ ) acknowledgement by other people were found between normal subjects and agoraphobic patients. No significant differences were found between panic patients without agoraphobia, neurotic and normal controls.

\subsection{3. discussion}

Agoraphobia was reflected in clear differences in time allocation. As was expected from van Zuuren's theory, agoraphobic patients spent significantly more time in situations with high levels of acknowledgement by other people than panic patients without agoraphobia, neurotic and normal controls. Furthermore, there was a trend for agoraphobic patients to be less often in situations with low levels of acknowledgement by other people than nor- 
mal controls. No significant differences emerged between panic patients without agoraphobia, neurotic and normal controls.

After the adjustment for demographic characteristics and missing responses, differences between panic patients with and without agoraphobia were no longer statistically significant. Differences in time allocation between panic patients with and without agoraphobia thus may reflect differences in demographic characteristics. Agoraphobic patients did not differ from other panic patients with comparable demographic characteristics in the amount of time allocated to situations with different levels of acknowledgement by other people.

The differences in time allocation between agoraphobic patients and normal controls are in line with van Zuuren's theory. Agoraphobic patients spent significantly less time in situations with low levels of acknowledgement and more time in situations with high levels of acknowledgement by other people than normal controls. Agoraphobic patients displayed a clearly distinct pattern of time allocation to situations with different levels of acknowledgement by other people. In the following section, the importance of acknowledgernent by the environment will be further explored.

\subsection{Time Allocation and Acknowledgement by the Environment}

\subsection{1. differences in acknowledgement by the environment}

The amuunt of acknowledgement by the environment is coded from the answers on the question 'where were you at the moment of the beep?' and is judged to be:

low in public places or in transport situations

moderate at work, at friend's houses or in health care setting high at home

Fear and avoidance of public places is often mentioned as an important characteristic of agoraphobia. Van Zuuren stated that public places are avoided while they bring little acknowledgement. She predicts that agoraphobic patients will avoid places with little acknowledgement and will seek highly acknowledging environments. Therefore, we expect that agoraphobic patients will be more often in an highly acknowledging environment (at home) and less often in an environment with little acknowledgement (in public places, transport) than panic patients without agoraphobia, neurotic and normal controls.

The means and standard errors of percentages of beeps subjects spent in situations with different levels of acknowledgement by the environment are given in table 6.5 .

Agoraphobic patients differed significantly from panic patients without agoraphobia in the amount of time they allocated to environments with different levels of acknowledgement (MF: $p<.001$ ). Agoraphobic patients were more often in an highly acknowledging environment than panic patients without agoraphobia (UF: $p<.001$ ). Agoraphobic subjects and normal controls also differed significantly in the amount of time they allocated to environments with different levels of acknowledgement (MF: p<.01). Agoraphobic patients were less often in an environment with moderate levels of acknowledgement than normal con- 
trols (UF: $p=.01$ ). Agoraphobic subjects further spent significantly more time in highly acknowledging environments than normal controls (UF: $p<.01$ ). The differences between panic patients with agoraphobia and neurotic controls were in the expected direction, but they did not reach statistical significance (MF: $p=.05$ ). Finally, no significant differences between panic patients without agoraphobia, neurotic and normal controls were found.

\section{table 6.5}

Time allocation to situations with different levels of acknowledgement by the environment: meins and standard errors (s.e.) of subject's percentages of beeps.

\begin{tabular}{lllll}
$\begin{array}{l}\text { mean } \\
\text { (s.e. })\end{array}$ & $\begin{array}{l}\text { panic disorder } \\
\text { with } \\
\text { agoraphobia } \\
(\mathrm{N}=35)\end{array}$ & $\begin{array}{l}\text { panic disorder } \\
\text { without } \\
\text { agoraphobia } \\
(\mathrm{N}=29)\end{array}$ & $\begin{array}{l}\text { neurotic } \\
\text { controls }\end{array}$ & $\begin{array}{l}\text { normal } \\
\text { controls }\end{array}$ \\
\hline low & 6.60 & $(\mathrm{~N}=19)$ & $(\mathrm{N}=20)$ \\
& $(1.14)$ & 9.45 & 8.95 & 7.80 \\
moderate & 9.86 & $(1.24)$ & $(1.54)$ & $(1.50)$ \\
& $(2.23)$ & 12.38 & 15.84 & 19.50 \\
high & 62.43 & $(2.42)$ & $(3.02)$ & $(2.93)$ \\
& $(3.11)$ & 44.66 & 48.26 & 45.40 \\
& & $(3.37)$ & $(4.20)$ & $(4.08)$ \\
\hline
\end{tabular}

In summary, agoraphobic patients spent significantly more time in the highly acknowledging environment of the home than panic patients without agoraphobia and normal controls. Furthermore, they were significantly less often in environments with moderate acknowledgement than normal controls.

\subsection{2. differences in acknowledgement by the environment after the adjustment for demographic characteristics and missing responses}

Table 6.6 shows the means and standard errors of percentages of beeps subjects spent in situations with different levels of acknowledgement by the environment after the adjustment for demographic characteristics and missing responses.

After the adjustment for demographic characteristics and missing responses, no statistically significant differences emerged between the different groups.

\subsection{3. discussion}

We expected that agoraphobic patients would be more often in an highly acknowledging environment and less often in an environment with little acknowledgement than panic patients without agoraphobia, neurotic and normal controls. Time allocation data showed that 
agoraphobic patients spent significantly more time in highly acknowledging environments than panic patients without agoraphobia and normal controls. But, agoraphobic patients did not spend significantly less time in environments with little acknowledgement than the other groups. Panic patients with agoraphobia only spent significantly less time in moderately acknowledging environments than normal controls.

table 6.6.

Time allocation to situations with different levels of acknowledgement by the environment: means and standard errors (s.e.) of subject's percentages of beeps after the adjustment for demographic variables and missing responses.

\begin{tabular}{lllll}
$\begin{array}{l}\text { mean } \\
\text { (s.e. })\end{array}$ & $\begin{array}{l}\text { panic disorder } \\
\text { with } \\
\text { agoraphobia } \\
(\mathrm{N}=35)\end{array}$ & $\begin{array}{l}\text { panic disorder } \\
\text { without } \\
\text { agoraphobia } \\
(\mathrm{N}=29)\end{array}$ & $\begin{array}{l}\text { neurotic } \\
\text { controls }\end{array}$ & $\begin{array}{l}\text { normal } \\
\text { controls }\end{array}$ \\
\hline low & 6.39 & 10.00 & 8.68 & 7.68 \\
& $(1.21)$ & $(1.26)$ & $(1.52)$ & $(1.47)$ \\
moderate & 12.90 & 11.07 & 12.96 & 19.21 \\
& $(2.16)$ & $(2.25)$ & $(2.72)$ & $(2.62)$ \\
high & 53.92 & 51.93 & 51.54 & 46.19 \\
& $(2.44)$ & $(2.54)$ & $(3.07)$ & $(2.96)$ \\
\hline
\end{tabular}

After the adjustment for demographic characteristics and missing responses, no evidence was found for differences in time allocation to situations with different levels of acknowledgement by the environment. These data indicate that agoraphobic patients are more often in highly acknowledging environments than panic patients without agoraphobia and normal controls, but also that time allocation to environments with different levels of acknowledgement is largely influenced by demographic data. Taking into account demographic characteristics, we maintain that time allocation to situations with high levels of acknowledgement by significant others is a more prominent feature of agoraphobia than seeking highly acknowledging environments. This conclusion is also in line with van Zuuren's theory which states that acknowledgement by other people is more important to agoraphobic patients than other types of acknowledgement. In the following section, differences in time allocation to activities with different levels of acknowledgement will be investigated.

\subsection{Time Allocation and Acknowledgement by Activities}

\subsection{1. differences in acknowledgement by activities}

Acknowledgement is not only provided by the presence of significant others or by the environment, but depends also on activities. The amount of acknowledgement by activities is 
coded from the answers on the open question 'what were you doing at the moment of the beep?'. The amount of acknowledgement by activities is:

low while doing nothing, resting, sleeping, ...

moderate during leisure activities, self care, transport (active)

high while taking care for others or the environment and while working

Van Zuuren pointed out that agoraphobic patients get into trouble in situations in which there is a lack of acknowledgement. She hypothesized that agoraphobic patients will avoid activities with little acknowledgement, like resting or waiting. Therefore, we expect that agoraphobic patients will allocate less time to activities with little acknowledgement and more time to highly acknowledging activities.

The means and standard errors of percentages of beeps subjects spent in situations with different levels of acknowledgement by activities are displayed in table 6.7.

\section{table 6.7 .}

Time allocation to situations with different levels of acknowledgement by activities: means and standard errors (s.e.) of subject's percentages of beeps.

\begin{tabular}{llllc}
$\begin{array}{l}\text { mean } \\
\text { (s.e. })\end{array}$ & $\begin{array}{l}\text { panic disorder } \\
\text { with } \\
\text { agoraphobia } \\
(\mathrm{N}=35)\end{array}$ & $\begin{array}{l}\text { panic disorder } \\
\text { without } \\
\text { agoraphobia } \\
(\mathrm{N}=29)\end{array}$ & $\begin{array}{l}\text { neurotic } \\
\text { controls }\end{array}$ & $\begin{array}{l}\text { normal } \\
\text { controls }\end{array}$ \\
\hline low & 12.60 & 9.59 & 9.26 & $(\mathrm{~N}=20)$ \\
& $(1.15)$ & $(1.25)$ & $(1.56)$ & 6.80 \\
moderate & 41.31 & 37.21 & 41.21 & $(1.51)$ \\
& $(2.15)$ & $(2.33)$ & $(2.90)$ & 38.25 \\
high & 24.66 & 18.69 & 22.42 & 27.90 \\
& $(2.05)$ & $(2.22)$ & $(2.77)$ & $(2.69)$ \\
& & & & \\
\hline
\end{tabular}

Significant differences emerged between panic patients with and without agoraphobia in the amount of time allocated to activities with different levels of acknowledgement (MF: $p<.01$ ). Agoraphobic patients tended to have more highly acknowledging activities than panic patients without agoraphobia (UF: $p=.05$ ). Normal and neurotic controls did not differ significantly from any of the other groups. 
6.5.2. differences in acknowledgement by activities after the adjustment for demographic characteristics and missing responses

Table 6.8 shows the means and standard errors of subject's percentages of beeps spent in situations with different levels of acknowledgement by activities after adjustment for demographic characteristics and missing responses.

\section{table 6.8}

Time allocation to situations with different levels of acknowledgement by activities: means and standard errors (s.e.) of subject's percentages of beeps after the adjustment for demographic variables and missing responses.

\begin{tabular}{lllll}
$\begin{array}{l}\text { mean } \\
(\text { s.e. })\end{array}$ & $\begin{array}{l}\text { panic disorder } \\
\text { with } \\
\text { agoraphobia } \\
(\mathrm{N}=35)\end{array}$ & $\begin{array}{l}\text { panic disorder } \\
\text { without } \\
\text { agoraphobia } \\
(\mathrm{N}=29)\end{array}$ & $\begin{array}{l}\text { neurotic } \\
\text { controls }\end{array}$ & $\begin{array}{l}\text { normal } \\
\text { controls }\end{array}$ \\
\hline low & 11.26 & 11.02 & 8.73 & $(\mathrm{~N}=20)$ \\
& $(1.24)$ & $(1.31)$ & $(1.56)$ & 7.48 \\
moderate & 39.60 & 39.54 & 41.17 & $(1.50)$ \\
& $(1.72)$ & $(1.82)$ & $(2.17)$ & 37.90 \\
high & 21.84 & 22.20 & 22.90 & $(2.09)$ \\
& $(1.84)$ & $(1.94)$ & $(2.31)$ & 27.37 \\
& & & & $(2.23)$ \\
\hline
\end{tabular}

After the adjustment for demographic characteristics and missing responses, no statistically significant differences were found between the different groups.

\subsection{3. discussion}

We expected that agoraphobic patients would spend less time doing activities with little acknowledgement and more time doing highly acknowledging activities than panic patients without agoraphobia, normal and neurotic controls. Panic patients with agoraphobia indeed reported more highly acknowledging activities than panic patients without agoraphobia. But after the adjustment for demographic characteristics and missing responses, no statistically significant differences were found between groups. Moreover, normal controls had on the average the most highly acknowledging activities and the least activities with little acknowledgement. Therefore, it can not be concluded that seeking activities with high levels of acknowledgement or avoiding activities with little acknowledgement is a specific feature of agoraphobia.

These findings are further in line with the conclusion that agoraphobia is most markedly reflected in pattems of time allocation to situations with different levels of acknowledge- 
ment by other people than to situations with different levels of acknowledgement by either the environment or by activities.

\subsection{Time Allocation and Severity of Psychopathology}

In the previous sections, differences between groups were highlighted. Some evidence was found indicating that agoraphohia is related to the amount of time allocated to situations with either high or low levels of acknowledgement by other people. In these analyses, panic patients with and without agoraphobia were treated as two mutually exclusive groups. Studies about the relationship between panic disorder and agoraphobia (reviewed in chap(tr 1), as well as the results about the experience of panic in daily life (reported in chapter $5)$, indicate that differences between panic patients with and without agoraphobia are rather a matter of degree than kind. In this section, we will focus on gradual differences in agoraphobic fears, namely whether agoraphobic fears (as measured with the agoraphobia scale of the Fear Questionnaire) are related to the amount of time spent in different types of situations. At the same time, we will explore whether time allocation is related to the severity of depression, social fears and trait anxiety in panic patients.

Subjects are the total group of panic patients with different levels of agoraphobia $(\mathrm{N}=64)$. Pearson correlation coefficients have been computed between the percentages of beeps subjects spent in different types of situations and their scores on the agoraphobia scale and the social phobia scale of the Fear Questionnaire, the trait-anxiety inventory (STAI) and Zung's SDS depression scale. The results are displayed in table 6.9.

Significant correlations were found between scores on the agoraphobia scale of the Fear Questionnaire and the amount of time spent in intimate situations, in anonymous situations without significant others, in situations with low and high levels of acknowledgement by other people, and moderate and high levels of acknowledgement by the environment. With increasing levels of agoraphobia, panic patients spent more time in intimate situations, in situations with high levels of acknowledgement by other people and high levels of acknowledgement by the environment. Panic patients with increasing levels of agoraphobia further spent less time in anonymous situations without significant others, in situations with low levels of acknowledgement by other people and in situations with moderate acknowledgement by the environment.

'The amount of time allocated to situations with high and moderate levels of acknowledgement by the environment was not only related to increasing levels of agoraphobia. Time allocation to situations with high levels of acknowledgement by the environment was also related to increasing levels of social phobia. And the amount of time spent in situations with moderate acknowledgement by the environment was significantly related to the severity of social phobia and trait anxiety. Therefore, partial correlations were computed between the percentage of beeps spent in environments with different levels of acknowledgement and measures of psychopathology. When controlling for other measures of psychopathology, only the correlation between the agoraphobia score on the Fear Questionnaire and the percentage of beeps spent in environments with high levels of acknowledgement by the environment tended to be significant $(r=.32 ; n=46 ; p=.03)$. 
table 6.9.

Pearson correlations between the percentage of beeps spent in different types of situations and measures of agoraphobia, social phobia, trait anxiety and depression.

$\begin{array}{llll}\text { FQ } & \text { FQ } & \text { STAI } & \text { ZUNG } \\ \text { agoraphobia } & \text { social phobia } & \text { trait-anxiety } & \text { depression } \\ (\mathrm{N}=63) & (\mathrm{N}=63) & (\mathrm{N}=60) & (\mathrm{N}=55)\end{array}$

type of situation

$\begin{array}{lllll}\text { solitary } & -.03 & .14 & .07 & .17 \\ \text { intimate } & .55 * * & .25 & .15 & .22 \\ \begin{array}{l}\text { anonymous with } \\ \text { significant others }\end{array} & .05 & .04 & .03 & -.06 \\ \begin{array}{l}\text { anonymous without } \\ \text { significant others }\end{array} & -.33 * & -.20 & -.09 & -.25\end{array}$

acknowledgement

by other people

$\begin{array}{lllll}\text { low } & -.32 * & -.03 & .04 & -.003 \\ \text { moderate } & -.25 & -.20 & -.31 & -.07 \\ \text { high } & .41 * * & .17 & .20 & .06\end{array}$

acknowledgement

by the environment

$\begin{array}{llllr}\text { low } & -.28 & -.18 & -.05 & -.26 \\ \text { moderate } & -.33^{*} & -.31^{*} & -.32 * & -.14 \\ \text { high } & .41 * * & .35 * & .28 & .25\end{array}$

acknowledgement

by activities

$\begin{array}{lrrrr}\text { low } & .08 & -.02 & .20 & .28 \\ \text { moderate } & -.01 & .11 & .05 & -.05 \\ \text { high } & -.05 & -.10 & -.20 & -.18\end{array}$

* $\mathrm{p} \leq .01$, two-tailed significance test

${ }^{* *} \mathrm{p} \leq .001$ 
As can be predicted from van Zuuren's theory, agoraphobia is most clearly reflected in the following pattern of time allocation: panic patients with increasing agoraphobia spend more time in intimate situations, more time in situations with high levels of acknowledgement by significant others and less time in anonymous situations without significant others and in situations with low or moderate levels of acknowledgement by other people. Fear and avoidance of being alone and in public places is not the most prominent characteristic of agoraphobia, since the severity of agoraphobic fears was not significantly related to time allocation to solitary situations and to public places (situations with little acknowledgement by the environment).

In the following section, we will take a closer look at individual variations in the amount of time allocated to different types of situations.

\subsection{Individual Variations in Time Allocation}

Differences between panic patients with and without agoraphobia were quite small at the group level. Correlations between the severity of agoraphobia and time allocation data indicated, however, that the severity of agoraphobic fears is related to the amount of time spent in different types of situations. In this section, some data will be presented in order to illustrate individual variations within groups.

A time allocation pattern with high frequencies of intimate situations and low frequencies of the other types of situations was the most common in agoraphobic patients. More heterogeneous patterns were observed in panic patients without agoraphobia, in neurotic and normal controls. On the other hand, there is no specific time allocation pattern that is exclusively linked to agoraphobia. The 'agoraphobic' pattern was also found in panic patients without agoraphobia, in neurotic controls and even in normal controls. For instance, 18 out of the 35 agoraphobic subjects $(51 \%)$ were never in an anonymous situation without significant others. But, also 8 out of the 29 panic patients without agoraphobia (28\%), 4 out of the 19 neurotic controls $(21 \%)$ and 2 out of the 20 normal controls $(10 \%)$ never reported to be in an anonymous situation without significant others.

In summary, time allocation patterns of agoraphobic patients are characterized by high amounts of time allocated to intimate situations. Moreover, about half of the agoraphobic patients were never in an anonymous situation without significant others. Nevertheless, the members of the different subject groups showed great individual variation.

\subsection{General Discussion}

Although avoidance can not be measured directly with ESM, agoraphobia was found to be refiected in specific patterns of time allocation. Using multivariate analyses of covariance, we were able to investigate differences in time allocation after the adjustment for demographic characteristics and missing responses.

After these adjustments, clear differences emerged between agoraphobic patients and normal controls in the amount of time allocated to three types of situations. Agoraphobic patients spent significantly more time in intimate situations and in situations with high levels of acknowledgement by other people, and significantly less time in situations with low le- 
vels of acknowledgement by other people than normal controls. Furthermore, panic patients with agoraphobia tended to spend less time in anonymous situations without significant others than normal controls. Panic patients without agoraphobia and neurotic controis took an intermediate position, they did not differ significantly from agoraphobic patients and normal controls on any of the time allocation variables. Moreover, the severity of agoraphobia in panic patients was found to be significantly related to the amount of time spent in intimate situations, in anonymous situations without significant others and in situations with either low or high levels of acknowledgement by other people. High frequencies of intimate situations and situations with high levels of acknowledgement by other people and low frequencies of situations with low levels of acknowledgement by other people are thus the most specific features of time allocation in agoraphobia.

After the adjustment for demographic characteristics and missing responses, differences in time allocation to environments with different levels of acknowledgement were no longer statistically significant. Agoraphobic patients reported more often to be in the highly acknowledging environment of the home than panic patients without agoraphobia and normal controls, but these differences were largely influenced by differences in demographic characteristics. Agoraphobic patients were more often at home, but not more often than one would expect on the basis of their demographic characteristics. Correlations between the percentages of beeps spent in situations with different levels of acknowledgement and measures of psychopathology further indicated that the amount of time spent in highly and moderately acknowledging environments is not only related to the severity of agoraphobia, but also to the severity of social phobias and trait anxiety. Partial correlations controlling for other measures of psychopathology revealed that panic patients with increasing levels of agoraphobia only tended to spend more time in the highly acknowledging environment of the home.

Time allocation data about activities with different level of acknowledgement provided little evidence in favour of the expectation that agoraphobic patients spend less time doing activities with little acknowledgement and more time doing highly acknowledging activities. Neither were there significant relationships between measures of psychopathology and the percentage of time spent to activities with different levels of acknowledgement.

Taking together the findings about time allocation to different types of situations and to situations with different levels of acknowledgement, we now can conclude that agoraphobia is most clearly reflected in differences in time allocation to intimate situations and to situations with different levels of acknowledgement by other people. As predicted from van Zuuren's (1982) theory, acknowledgement by the presence of significant others is more important in agoraphobia than other types of acknowledgement. These findings indicate that it is more useful to conceptualize agoraphobic situations in terms of the amount of acknowledgement by the presence of intimates than in terms of places. Nevertheless, there seems to be an interaction between the acknowledgement by other people and the acknowledgement by the environment. Agoraphobic patients spent more time in intimate situations, but not more time in anonymous situations with significant others. Agoraphobic patients seek the proximity of intimates, yet they prefer to do so in a familiar environment.

By adjusting time allocation data for demographic variables, we were able to estimate the amount of time agoraphobic patients would spend in specific situations if they would not 
differ from the other groups on these variables. This method has also some disadvantages, since the fact that the group of agoraphobic patients included more women and more unemployed subjects (section 4.1.1) can not be considered as mere coincidence. Agoraphobia is closely related to specific demographic characteristics and some of these characteristics may be the consequence of being agoraphobic. If agoraphobic patients loose their jobs because they are unable to leave home, adjusting time allocation data for demographic characteristics may eliminate crucial differences between panic patients with and without agoraphobia. If these changes in social roles are inevitable consequences of agoraphobia, it makes no sense to estimate the amount of time agoraphobic patients would have spent in specific situations if these changes would not have happened. More research is needed about the relationship of agoraphobia with (changes in) social roles. Until now, it is not clear whether specific social roles increase the risk of developing agoraphobic ayoidance behavior or whether they are a consequence of agoraphobia. Panic patients with traditional female roles may be more likely to seek the proximity of significant others and to develop agoraphobic behavior. Recent questionnaire studies provided some evidence that agoraphobia is indeed related to stereotyped feminine sex roles (section 2.4.2). On the other hand, restricted mobility and changes in social roles (e.g., loss of employment) may be the consequence of agoraphobia (section 2.4.1.). The results of the present study do not allow to conclude that there is a causal relationship between social roles and the development of agoraphobia. The data about demographic characteristics of agoraphobic patients show, however, that - although a majority of the agoraphobic patients in this study were unemployed - agoraphobia is not necessarily associated with unemployment. These data suggest that demographic characteristics and associated social roles may determine the type of situations that panic patients will actually enter in daily life and raise the possibility that panic patients become agoraphobic because of particular social circumstances.

Van Zuuren (1983) stated that agoraphobic patients often lead a 'small-scaled life'. Agoraphobic patients get anxious as soon as they leave the small circle of intimates and enter situations outside the familiar environment. Time allocation data indicated that agoraphobic patients seek acknowledgement by significant others. But the time allocation data presented above do not allow us to judge whether agoraphobic patients are less anxious in situations in which there is a lot of acknowledgement by significant others. The relationship between fluctuations in the experience of panic and different types of situations will be further investigated in chapter 7 . 
7.1. Introduction

What the ESM data about daily life experiences of panic patients have demonstrated up to now is that there are a lot of individual variations in the frequency and severity of naturally occurring panic experiences as well as in the amount of time spent in specific daily life situations. In this chapter, ESM data about the occurrence of panic experiences and about the use of time will be tied together. What we would like to know is whether panic experiences are more likely to occur in specific situations, in subjects having specific demographic and diagnostic features or at specific points in time. The aim of the analysis presented in this chapter is to systematically explore a number of factors that are potentially related to the occurrence of panic experiences.

Since ESM provides repeated measurements of the presence of panic experiences during the day, we are able to provide a more dynamic description of panic experiences. Panic experiences will not only be related to characteristics of the subject and to characteristics of the situation in which they occurred, but also to experiences at earlier points in time. In this way, panic experiences will not be treated as isolated events. Instead, panic experiences will be studied as part of an ongoing experience. Therefore, we will study fluctuations in the presence or absence of panic experiences over time, rather than the mere occurrence of a panic experience.

In this chapter, we will focus on fluctuations in the occurrence of panic experiences in relationship to situational, demographic, diagnostic and temporal factors. We will investigate whether the probability of observing fluctuations in the presence or absence of panic experiences changes as a function of:

- characteristics of daily life situations,

- demographic characteristics of the subject,

- the diagnosis of the subject (panic disorder with or without agoraphobia), and

- temporal factors (the time of the day or the week).

\subsection{1. characteristics of daily life situations}

First, panic experiences will be related to characteristics of the situation in which they occurred. The question is how the probability of observing fluctuations in the presence or absence of panic experiences changes according to characteristics of the situation. Based on the DSM III(R) criteria for panic disorder (appendix 1), we did not expect to find important situational triggers of panic experiences: at least some of the panic attacks should occur unexpectedly. Based on the criteria for agoraphobia, on the other hand, we expect that panic experiences more often occur in public places and when the subject is alone. In a similar way, van Zuuren (1982) predicts that the probability of having a panic experience will be larger in situations with little acknowledgement by other people, by the environment and by the activity. Particularly the lack of acknowledgement by significant others would provoke panic experiences in panic patients with agoraphobia. 
In previous research about the relationship between panic experiences and the situational context, the presence of significant others, the familiarity of the environment and the role of the activity was not systematically investigated. Questionnaire data indicated that agoraphobic patients are more likely to experience discomfort in situations with little acknowledgernent by other people (van Zuuren, 1982). However, as we have argued in section 2.4.5., these data have to be interpreted with caution, because of methodological shortcomings. Studies carried out in the natural environment are especially suited to investigate the relationship between panic experiences and characteristics of the situation in which they naturally occur. Daily life studies demonstrated that a majority of panic attacks are associated with external cues and precipitating events (Freedman et al., 1985; Margraf et al., 1987b; Street et al., 1989). But, these studies did not provide a systematic description of specific situational cues related to panic attacks (section 3.4.2.). Margraf et al. (1987b) found, for instance, that spontaneous panic attacks (i.e. attacks with a sudden onset and little or no provocation) occurred more often at home than situational panic attacks. However, when a description was given of the circumstances in which some of the so-called spontaneous attacks occurred at home, subjects were often alone or just had a fight with their spouses. In fact, 'spontaneous' attacks occured in the same type of situations as 'situational' attacks. Furthermore, only a phenomenological description of the situational context in which panic attacks occurred was provided. The significance of specific characteristics of the situation was not statistically tested.

In the present study, the situational context will be evaluated irrespective of the patients' perception of an association between the situation and the onset of a panic experience. The situational context will be systematically classified according to the level of acknowledgement by significant others, by the environment and by activities. The classification of daily life situations according to the amount of acknowledgement by significant others, the environment and activities further allows to test the relative significance of characteristics of the situation. In chapter 6 , for instance, we demonstrated that high frequencies of situations with high levels of acknowledgement by significant others and low frequencies of situations with low levels of acknowledgement by significant others are the most specific features of time allocation in agoraphobic patients. After the adjustment for demographic characteristics and missing responses, agoraphobic patients could only be differentiated from normal controls according to the amount of time spent in situations with different levels of acknowledgement by other people and not according to the time spent in environments with different levels of acknowledgement. In the present chapter, we will explore how fluctuations in the presence or absence of panic experiences are related to levels of acknowledgement by other people, by the environment and by activities.

\subsection{2. demographic characteristics}

Secondly, the influence of demographic characteristics will be evaluated. We will investigate whether fluctuations in the presence or absence of panic experiences are related to demographic characteristics of the subject (sex, age, marital status, family life and employment). Demographic characteristics can be expected to affect daily life experiences. Depending on the demographic characteristics of the subject, the situational context may have different connotations and therefore affect the probability of having a panic experience in a different way. 
Demographic characteristics are thought to play an important role in agoraphobic patients. Epidemiological studies demonstrated clear sex differences in the prevalence of agoraphobia (section 1.2.). Family studies indicated that agoraphobia affects male and female relatives in a different way: female relatives were found to be at risk for developing anxiety disorders and male relatives for alcohol abuse (section 2.1.1.). Little evidence was found for sex differences in biological vulnerabilities (section 2.1.4.). Moreover, agoraphobia was not only found to be more prevalent in women than in men, but was also found to be associated with specific demographic characteristics: unemployed, married women with a lower socioeconomic status (section 2.4.1.). Theories about the social and cultural meaning of public places (section 2.4.3) and solitary situations (section 2.4.4.) indicate that agoraphobic situations have a different connotation to men and women in our culture. In particular, women with a traditional feminine sex role may have had few opportunities to acquire the skills that are needed to function in these types of situations.

Previous studies paid little attention to the influence of demographic characteristics on the occurrence of panic experiences in daily life. We demonstrated, however, that demographic factors largely influence the use of time in daily life. Few differences were found between panic patients with and without agoraphobia in the amount of time allocated to daily life situations (chapter 6). Agoraphobic patients spent more time in situations with high levels of acknowledgement by significant others and in situations with high levels of acknowledgement by the environment than panic patients without agoraphobia. But when we took demographic differences into account, panic patients with agoraphobia could only be differentiated from normal controls. In the present chapter, we will further explore whether demographic characteristics influence the probability of observing fluctuations in the presence or absence of panic experiences.

\subsection{3. panic disorder with and without agoraphobia}

Next, we will evaluate whether the diagnosis of the subject (panic disorder with or without agoraphobia) is related to fluctuations in the presence or absence of panic experiences. Based on previous studies about the relationship between panic disorder and agoraphobia (chapter 1), we do not expect to find large differences between panic patients with and without agoraphobia in the frequency of panic experiences. Patterns of fluctuations in the presence or absence of panic experiences could, however, be different for panic patients with and without agoraphobia. Furthermore, we can expect to find differences between panic patients with and without agoraphobia in the relationship between specific sequences of panic experiences and the situational context. The relationship between the occurrence of panic experiences and characteristics of the situational context may be stronger in agoraphobic patients than in panic patients without agoraphobia.

Previous research provided little evidence for differences between panic patients with and without agoraphobia in the frequency of panic experiences. In studies carried out in the natural environment, few differences were found between panic patients with and without agoraphobia in the type of panic attacks (Street et al., 1989; Margraf et al., in prep.; see section 3.4.1.). In the present study, few differences were found between panic patients with and without agoraphobia in the frequency and severity of panic experiences (section 5.2.). Large individual variations in the frequency of panic experiences were observed within both groups (section 5.3.). Evidence about the relationship between panic expe- 
riences and the situational context in panic patients with and without agoraphobia is less unequivocal. In some studies, no significant differences were found between panic patients with severe and mild agoraphobia in the frequency of cued/uncued and expected/unexpected panic attacks (Street et al., 1989). In another study, however, panic patients without agoraphobia reported significantly more spontaneous major panic attacks than panic patients with agoraphobia (Ganellen et al., 1986).

\subsection{4. temporal factors}

Next, fluctuations in the presence or absence of panic experiences will be related to temporal factors. Thereby, we will explore how panic experiences are distributed over time. Two types of temporal factors will be evaluated: the time of the day and the day of the week. The subsequent ESM signals were given within time blocks of 90 minutes from 7.30 a.m. till 10.30 p.m. (section 4.3.); signal 1 always occurred between 7.30 and 9.00 a.m., signal 2 between 9.00 and 10.30 a.m., etc. A peak of panic experiences within specific time blocks can be identified by relating the probability of having a panic experience to the number of the ESM signal. Furthermore, we will include the day of the week as a potential predictive factor. The day may provide an indication of the occurrence of panic experiences on specific days. The day of the week was included, because it can be considered as an important factor in the use of time. For instance, on weekdays subjects may have other types of social contacts and other types of activities than on weekend days.

Previous studies on panic disorder and agoraphobia in daily life provided conflicting evidence about the distribution of panic attacks over time (section 3.4.3.). Some studies identified no systematic fluctuations in the onset of panic during the day (Uhde et al., 1985a; Taylor et. al., 1986; Margraf et al., 1987b). A meta-analysis on circadian rhythms in the onset of panic indicated a peak of panic experiences in the moming between 9 a.m. and 14 p.m. (Margraf, 1990), while others found that anxiety levels and the frequency of panic attacks increased in the late afternoon (Cameron et al., 1986b). In another study, some evidence was found for the clustering of panic attacks within days (Gurguis et al., 1988).

\subsection{Statistical Analysis}

The aim of the present analysis was to model the dynamical aspects of panic experiences and to describe evolving fluctuations in the presence or absence of panic experiences in relation to demographic, diagnostic and situational factors.

The data of an arbitrary subject on an arbitrary weekday can be represented as follows:

$\begin{array}{lllllllllll}\text { ESM signal } & 1 & 2 & 3 & 4 & 5 & 6 & 7 & 8 & 9 & 10 \\ \begin{array}{l}\text { panic } \\ \text { experience }\end{array} & 0 & 0 & 0 & 1 & 0 & 1 & 1 & 0 & 0 & 0\end{array}$

where 0 denotes the absence and 1 denotes the presence of a panic experience. (A panic experience is present when the subject has a score of 5 or higher on the ESM panic scale; see section 5.1.4.). 
In order to describe panic experiences as they evolve in time, we studied the dependence of the four possible transitions in panic experiences $0 \rightarrow 0,1 \rightarrow 0,0 \rightarrow 1$ and $1 \rightarrow 1$ on situational, diagnostic, demographic and temporal factors. This was done by developing a statistical model for the transition probabilities $P_{00}(t), P_{01}(t), P_{10}(t)$ and $P_{11}(t)$, where - for example - $P_{01}(t)$ is the probability that a panic experience is present at time $t$ given its absence at time $1-1$.

The transition probabilities are conditional probabilities and describe the dependence of the present on the most recent past. A more complete notation would be, for example,

$P_{01}(t)=P(Y(t)=1 \mid Y(t-1)=0, S(t), D)$,

denoting that the probability of observing a transition in panic experiences from absent to present $P_{01}(t)$ is the probability that a panic experience is present at time $t(Y(t)=1)$ given its absence at time $t-1(Y(t-1)=0)$ and depending on situational factors at time $t(S(t))$ and on demographic and diagnostic characteristics of the subjects (D). Only two transition probabilities need to be studied, namely $P_{01}(i, w, t)$ and $P_{11}(i, w, t)$ because the other probabilities are complementary, i.e. $P_{01}(i, w, t)+P_{00}(i, w, t)=1$.

The dependence of the transition probabilities on situational, demographic and diagnostic factors is modelled through logistic regression. The results can be interpreted by comparing transition probabilities for subjects and situations with different features. Comparing these transition probabilities could tell us, for instance, whether female subjects are more likely than male to report a panic experience at the present ESM signal when they had or had not a panic experience at the previous signal, and whether these differences are also determined by situational, diagnostic and/or other demographic characteristics. Full details on the statistical modelling and on computing ratios to compare transition probabilities are given in appendix 6.

When reading the results the following important points should be kept in mind.

For statistical modelling purposes some simplifying assumptions were made:

1. observations recorded at a particular ESM signal are representative of experiences occurring in the whole time interval into which the signal was given.

2. observations at consecutive signals can be considered as discrete units of experience.

3. the experiences of a subject on a given day are considered to be independent of the experiences of the subject on the previous day and on future days.

The first two assumptions reflect the fact that we do not have continuous observations of (transitions in) the presence or absence of panic experiences. We do not have information on the duration of panic experiences, nor on the presence or absence of panic symptoms between ESM signals. Observing that a panic experience is present at two subsequent ESM signals, therefore, may indicate that subjects have multiple panic experiences or that the panic experience remains present during a prolonged period of time. The third assumption is only made for statistical modelling purposes and was at least partly testable. No evidence for the dependence of observations on the day of the week was found (see appendix 6 for more details). The experiences of the same subject on different days are of course not independent from each other, but the impact of characteristics of the subject is measured indirectly by including diagnostic and demographic factors in the analysis. 
Statistical analysis was complicated by the many missing values for time dependent variables (panic experiences and situational factors). Moreover, the missing data are clearly not missing at random as missing values cluster at the beginning and end of days (see also section 4.6.). This means that all statistical analyses reported here are biased and that care must be taken when interpreting results (see also appendix 6).

\subsection{Results}

Fluctuations in the presence or absence of panic experiences between subsequent ESM signals can be described in a transition matrix, listing the proportion of cases in which the state at time $t-1$ is followed either by the same or by a different state at time $t$. The proportions of transitions observed in the present study are summarized in table 7.1.

table 7.1.

Transition matrix: proportions (and frequencies) of changes in the presence or absence of panic experiences from time $t-1$ to time $t$.

panic experience

time !

time $1-1 \quad$ absent $(0) \quad$ present (1)

absent (0)

present (1)
$.96(1752)$

$.28(69)$
$.04(76)$

$.72(174)$

Table 7.1. shows that the presence or absence of panic experiences at a specific point in time depends to a large extent on the experience at the previous ESM signal. The presence or absence of panic experiences was found to be a relatively stable state. When a panic experience was noted at the previous ESM signal (time $t-1$ ), it would be most likely to observe another panic experience at the present signal (time $t$ ). In almost three-quarter of the cases in which a panic experience was reported at the previous signal, a panic experience would be noted at the present signal. When a panic experience was absent at the previous signal, on the other hand, it would be rather unlikely to observe a panic experience at the present signal. The presence or absence of a panic experience at the previous ESM signal, therefore, can be considered as a strong predictor of the presence or absence of a panic experience at the present signal. However, the proportions of changes in the presence or absence of panic experiences listed in the transition matrix in table 7.1. provide only a good estimation of the probability to observe a panic experience at the present ESM signal if the matrix is constant over time and remains the same irrespective of diagnostic and demographic features of the subjects and irrespective of characteristics of the situation. This is not very likely, and therefore, the transition probabilities should be adjusted for demographic, diagnostic and situational factors. No significant effect of temporal factors (time of the day or day of the week) on transition probabilities was found. For some factors, a time dependent relationship was found. This means that the factor was related in a different way to the probability of observing a panic experience depending on whether a 
panic experience was present at the previous ESM signal. Moreover, the probability to observe (fluctuations in the presence of panic experiences was not found to be directly related to the diagnosis of the subject. A number of factors were, however, related in a different way to the probability of observing panic experiences in panic patients without agoraphobia than in panic patients with agoraphobia. Characteristics of the subject and the situation having a significant effect on the probability of observing (fluctuations in the presence of) panic experiences are summarized in table 7.2 .

table 7.2.

Demographic and situational factors having a significant effect on the probability to observe a panic experience.

demographic factor situational factor

main effect - - acknowledgement activities

time dependent effect age

dependent on diagnosis sex acknowledgement other people

marital status

employment

both time dependent and family life

acknowledgement environment

dependent on diagnosis

Only one situational factor was found to be directly related to the probability of observing a panic experience, namely the level of acknowledgement by activities. Panic experiences were less likely to occur in situations with moderate or high levels of acknowledgement by activities than in situations with low levels of acknowledgement by the activity. In other words, when a panic experience was present, subjects were more likely to be engaged in activities providing little acknowledgement (such as resting, sitting, ...) than in activities with moderate or high levels of acknowledgement (such as leisure, work and maintenance activities). No significant difference in the probability to observe a panic experience was found between activities with moderate and activities with high levels of acknowledgement.

For a number of factors, the transition matrix was found to be time dependent. The age of the subject, for instance, was related in a different way to the probability of observing a panic experience when no panic experience was present than when a panic experience was present at the previous ESM signal. When no panic experience was noted at the previous signal, subjects younger than 32 years more frequently reported a panic experience at the present signal than older subjects. When a panic experience was already present at the 
previous ESM signal, on the other hand, the likelihood of observing another panic experience at the present signal was slightly higher in subjects in the age group between 32 and 38 years than in subjects aged below 32 or above 38 years.

Other factors were related in a different way to the probability of observing panic experiences depending on the diagnosis of the subject. The demographic factors sex, marital status and employment were found to have a different impact in panic patients with agoraphobia than in panic patients without agoraphobia. In the group of panic patients without agoraphobia, panic experiences were more likely to be reported by men than by women, and unmarried subjects were more likely to report panic experiences than married subjects. For employment, little differences were found in the probability to report panic experiences in the group of panic patients without agoraphobia. In the group of panic patients with agoraphobia, panic experiences were more likely to occur in female than in male subjects, in married than in unmarried subjects and in unemployed than in employed subjects. Furthermore, one situational factor was found to be differently related to the probability of having a panic experience depending on the diagnosis of the subject, namely the level of acknowledgement by other people. Panic patients without agoraphobia were more likely to report panic experiences in situations with low levels of acknowledgement by other people (alone or with strangers) than in situations with moderate or high levels of acknowledgement by others. In panic patients with agoraphobia, however, panic experiences were much more likely to occur in situations with high levels of acknowledgement by other people (i.e., in the presence of significant others) than in situations with low or moderate levels of acknowledgement by others.

Significant differences in the probability to observe a panic experience were further found according to another demographic characteristic, namely family life, and according to another situational factor, namely the level of acknowledgement by the environment. But, the relationship between the probability to observe a panic experience and these factors was even more complex. The relationship between these factors and the probability to observe a panic experience was not only found to be time dependent, but depended also on the diagnosis of the subject. For family life, the following relationship was observed. In panic patients without agoraphobia, panic experiences were more likely to occur in subjects living in a family than in subjects living alone. In panic patients with agoraphobia, on the other hand, panic experiences were more likely to occur in subjects living alone, at least when no panic experience was notud at the previous ESM signal. When a panic experience was present at the previous signal, no differences were found in the probability to observe another panic experience between agoraphobic patients living alone or not. But it is important to remind that in the group of agoraphobic patients, only 2 subjects lived alone $(6 \%)$. For the level of acknowledgement by the environment, the probability of observing a panic experience also depended on the diagnosis of the subject and on the presence or absence of a panic experience at the previous ESM signal. When no panic experience was noted at the previous signal, panic patients without agoraphobia were most likely to report a panic experience when they were in a situation with low levels of acknowledgement by the environment, while agoraphobic patients were more likely to report a panic experience when they were in a situation with moderate levels of acknowledgement by the environment. But when a panic experience was already present at the previous signal, both panic patients with and without agoraphobia were most likely to report another panic experience when they were in environments with high levels of 
acknowledgement (i.e., at home). Panic experiences at two subsequent ESM signals were most unlikely to be reported by agoraphobic subjects in environments with low levels of acknowledgement (i.e., in public places or transport situations).

The results presented above suggest that there are general trends of factors influencing transition probabilities. It is important to note that the probability to observe a panic experience changes over time, from subject to subject and from situation to situation. The effect of almost any factor on the probability to observe a panic experience depends on different diagnostic, demographic and situational characteristics. Either a change in subject characteristics or a change in situational characteristics can make a radical difference in the likelihood of observing fluctuations in the presence or absence of panic experiences. The general trends for situational factors described here may, for instance, only occur in subgroups of panic patients with specific diagnostic and demographic characteristics. When a panic experience occurred at the previous ESM signal, and when the subject is in a specific type of situation, some patients with specific diagnostic and demographic features will almost always report another panic experience at the present ESM signal. For instance, once a panic experience occurred in female married unemployed agoraphobic patients, panic experiences will be most likely to be present at subsequent ESM signals, at least when these subjects are in situations with high levels of acknowledgement by other people and by the environment and low levels of acknowledgement by activities. Agoraphobic subjects with different demographic characteristics being in different types of situations, however, may be very unlikely to report panic experiences at two subsequent ESM signals.

\subsection{Discussion}

In most cases, no changes in panic experiences were observed between two subsequent ESM signals. Within days, panic experiences were found to be most likely to remain either present or absent. No direct relationship was found between fluctuations in the presence of panic experiences and other temporal factors. Other studies provided conflicting evidence about the time of the day that panic attacks would be most likely to occur (section 7.1.3.). In the present study, no clustering of panic experiences on specific days of the week or times of the day was found. The increased likelihood of having a panic experience after a preceding panic experience is, however, consistent with the finding from Gurguis et al. (1988) that panic attacks are clustering within one day. Panic patients typically seem to have 'good' almost panic-free days and 'bad' days with repeated or longlasting paric experiences.

Despite the fact that relatively little fluctuations in the presence or absence of panic experiences have been observed between subsequent ESM signals, a number of situational factors have been identified that influence the likelihood of observing (fluctuations in the presence of) panic experiences. The level of acknowledgement by activities, for instance, was found to be directly related to the occurrence of panic experiences, irrespective of the presence or absence of panic experiences at the previous ESM signal. A panic experience was more likely to occur in situations with low levels of acknowledgement by the activity. According to van Zuuren (1982), a lack of acknowledgement may cause panic symptoms, especially in panic patients with agoraphobia. In this study, however, no significant interaction effect was found between the diagnosis and the level of acknowledgement by activi- 
ties. Both in panic patients with and without agoraphobia, panic experiences were found to be associated with activities providing little acknowledgement. This association can be interpreted in two ways. First, a lack of acknowledgement by activities, i.e. having no specific goal-oriented activities, may trigger panic symptoms. But, on the other hand, the experience of panic symptoms may force subjects to cease activities with higher levels of acknowledgement. The association between panic experiences and a lack of acknowledgement by activities then may simply indicate that panic experiences largely interfere with work, maintenance and leisure activities (high or moderate levels of acknowledgement). Based on the present data, we are not able to draw causal inferences about the relationship between the occurrence of panic symptoms and specific activities. Further behavioral micro-analyses are needed to study sequences and changes in activities before, during and after the occurrence of panic experiences.

Acknowledgement by other people and by the environment were found to have a different effect on the probability of observing fluctuations in the presence or absence of panic experiences according to the diagnosis of the subject. Based on the theory of van Zuuren (1982), we expected to find a negative relationship between the level of acknowledgement and the probability of having a panic experience in agoraphobic subjects. In other words, we expected that panic experiences would be more likely to occur in agoraphobic patients when they were alone or with strangers (situations with low levels of acknowledgement by other people) and when they were in public places or transport situations (low levels of acknowledgement by the environment), and less likely when they were in the company of their own family (high levels of acknowledgement by others) and while they were at home (high acknowledgement by the environment). Contrary to these expectations, agoraphobic patients were more likely to report panic experiences when they were in situations with high levels of acknowledgement by other people and they were more likley to report panic experiences at subsequent ESM signals when they were in situations with high levels of acknowledgement by the environment.

These findings can be explained in different ways. Being at home and being in the presence of significant others may provoke panic experiences in agoraphobic subjects, but having - or anticipating - a panic experience may also result in hiding in the safe environment of the home and/or seeking the companionship of significant others. Again the data do not allow to make inferences about a causal relationship between the repeated or long-lasting occurrence of panic experiences and characteristics of the social context and the environment. In the present study, subjects were able to choose their own social context, environment and activities. Subjects were allowed to select solitary situations and excursions out of the home that provoke little anxiety. The finding that agoraphobic patients were particularly likely to report panic experiences when they were in the company of significant others, therefore, may indicate that agoraphobic patients seek the proximity of a trusted companion in a safe environment when they experience or anticipate symptoms of panic. Panic patients with agoraphobia may he more likely to avoid solitary situations and situations outside the home and may be only willing to enter these situations under very special circumstances. The finding that panic patients with agoraphobia spend much more time in situations with high levels of acknowledgement by other people and by the environment (chapter 6) may point in this direction. 
Nevertheless, staying at home on 'bad days' with frequent and/or long-lasting panic experiences may be a more general strategy that is used by both panic patients with and without agoraphobia. Irrespective of a diagnosis of agoraphobia, panic patients were more likely to be in situations with high levels of acknowledgement by the environment when repeated or prolonged panic experiences occurred. Therefore, seeking the proximity of significant others appears to be a characteristic feature of agoraphobic behavior in daily life. Further research on the emotional meaning of the absence or presence of intimates in panic patients with and without agoraphobia is needed. Previous diary and event sampling studies including descriptions of agoraphobic behavior almost exclusively focused on excursions outside the home (section 3.3.3.). Systematic descriptions of the social contexts in which agoraphobic subjects experience symptoms of panic should be added.

Fluctuations in the presence or absence of panic experiences were further found to be related to characteristics of the subject. The likelihood of observing fluctuations in the presence or absence of panic experiences was, for instance, different in specific age groups. Subjects below age 32 were found to be more likely than older subjects to report a panic experience when no panic was registered at the previous signal. Repeated panic experiences at two subsequent ESM signals were, on the other hand, more frequently registered in subjects aged between 32 and 38 years. This finding may indicate that singte panic experiences occur more frequently in younger subjects. Although we did not record the age at onset and the duration of the illness, these findings may suggest that there is a typical course in the development of panic disorder, starting with isolated and rather infrequent panic experiences, exacerbating into a more severe stage of the disorder with frequently repeated or long-lasting panic experiences, and finally, evolving into a more stable state with a slight improvement in the frequency of repeated or long-lasting panic experiences. This pattern is consistent with Klein's multistage model of panic disorder (section 1.4.), stating that the disorder begins with the sudden appearance of infrequent panic attacks, then develops to a stage with recurrent panic attacks, increased anticipatory anxiety, chronic tension and autonomic distress, and culminates in the development of avoidance behavior, that may to some extent reduce the likelihood of having panic attacks. The description of the last stage is consistent with a recent study about the course and outcome of panic disorder indicating that the long-term course of symptoms is either stable-chronic or chronic with episodic exacerbations (Wittchen, 1988). It is important to note, however, that the improvement in the frequency of repeated or long-lasting paric experiences at a later stage of the disorder is not necessarily associated with the improvement of other symptoms or psychosocial impairments. After years of illness, patients often develop comorbid disorders (section 1.6.) and serious constrictions in life style (section 1.7.). In these patients, symptoms of panic may become less prominent. Of course, based on the cross-sectional data gathered in this study, we are not able to draw conclusions on the symptom course of panic disorder. Further longitudinal studies are needed in order to investigate the natural course of panic disorder and to describe variations in the frequency and severity of panic experiences within individuals over longer periods of time.

The probability of observing fluctuations in the presence or absence of panic experiences was not exclusively related to a diagnosis of panic disorder with or without agoraphobia, but largely depended on demographic characteristics. Panic patients having specific demographic characteristics were more likely to report panic experiences. In the group of panic patients without agoraphobia, male unmarried patients more frequently reported panic ex- 
periences. In the group of agoraphobic patients, however, female married and unemployed patients reported more panic experiences. In chapter 6 , demographic characteristics were already found to have an important influence on the use of time in daily life. In the present analysis, further evidence for the significance of demographic characteristics was provided. As we hypothesized in chapter 2 , these findings may be related to culturally determined sex differences in response styles. Married unemployed women having high frequencies of panic experiences may be most likely to fear and avoid agoraphobic situations, while this response style is very unusual in unmarried male panic patients, even if they have high frequencies of panic experiences.

The relationship between the occurrence of panic experiences and marital status or family life may raise questions about the quality of marriage and family life in panic patients. Retrospective studies provided little evidence in favor of a relationship between marital conflict or dissatisfaction and agoraphobia (section 2.3.3.). But, only a few studies evaluated actual patterns of interactions between parents and children (e.g., Macaulay \& Kleinknecht, 1989) or between spouses (e.g., Peter \& Hand, 1988; Craske et al., 1989). Prospective studies on patterns of interaction and specific communication styles in families of agoraphobic patients may be worthwhile to add. Moreover, studies about the relationship between the frequency and severity of panic symptoms and the quality of marital and other types of intimate relationships are lacking. The findings from the present study about the significance of marital and family relationships as well as about the influence of the presence of intimate others on the occurrence of panic experiences in daily life point out that the ability to develop and maintain different types of social relationships should be investigated in greater detail. We are, however, not able to conclude that specific social roles or social interactions predispose to the occurrence of panic experiences in daily life. As we have argued before, the significance of the presence of intimate others may indicate that agoraphobic patients seek the proximity of intimate others, while changes in social roles and accordingly in demographic characteristics may be the consequence of agoraphobia or panic disorder as well.

In the present study, fluctuations in the presence of panic experiences were found to be significantly related to demographic characteristics of the subject as well as to characteristics of daily life situations. In spite of this, the results of this study clearly show that the daily experiences of panic patients are characterized by large variations between and within individuals. The detailed description of daily life provided with ESM shows a lot of individual variation ranging from subjects never reporting panic experiences during the ESM research week to subjects who almost continuously experience panic, and from subjects reporting little psychosocial impairments to subjects requiring a constant companion. Moreover, the frequency and severity of symptoms of panic and psychosocial impairments may vary within subjects from day to day. Panic patients were found to have 'bad' days with long-lasting sequences of panic experiences and 'good' almost panic-free days. The results further point out that a diagnosis of panic disorder with or without agoraphobia is not a strong predictor of daily life behavior. In order to describe meaningful patterns in daily life behavior, demographic characteristics and associated social roles as well as the social and cultural meaning of social contexts and environments have to be evaluated.

Based on repeated observations of daily life experiences gathered with ESM, we were able to develop a statistical model that allows to estimate the probability of observing fluctua- 
tions in the presence or absence of panic experiences according to diagnostic and demographic features of the subject and according to characteristics of the situational context. Even a rather rough classification of daily life situations according to the level of acknowledgement by other people, by the environment and by activities was found to be useful in order to predict the occurrence of fluctuations in the presence of panic experiences in the natural context. The model presented above was based on a relatively small number of subjects. In a larger group of subjects, a more refined coding system of different types of daily life situations can be used. Then, specific characteristics of situations can be identified that are related to fluctuations in the presence of panic experiences. By amplifying the number of subjects and by refining coding sytems and sampling methods in order to minimize the number of missing observations, ESM data may allow us to make accurate predictions of the occurrence of panic experiences in a specific individual in a specific situation on a specific point in time. 


\section{CHAPTER 8 PANIC DISORDER AND AGORAPHOBIA IN DAILY LIFE: OVERVIEW, CONCLUSIONS AND IMPLICATIONS}

The aim of the present study was to describe panic disorder and agoraphobia in daily life. First, we investigated differences between panic patients with and without agoraphobia in the frequency and severity of panic experiences. Then, time allocation to daily life situations was compared for panic patients with and without agoraphobia, patients with other disorders (neurotic controls) and normal controls. Finally, fluctuations in the presence or absence of panic experiences have been related to diagnostic, demographic and situational factors. Hereby, we focused on 4 major topics:

(1) individual variation in panic experiences and in time allocation to daily life situations;

(2) the influence of demographic characteristics and associated social roles;

(3) the relationship between daily life measures and the severity of psychopathology; and

(4) the role of acknowledgement by significant others in agoraphobia.

In this chapter, the final conclusions of the study will be presented. The topics listed above thereby will serve as a guiding principle (section 8.2 ). Furthermore, diagnostic and therapeutic implications (including preventive measures) as well as implications for future research will be discussed (section 8.3). But first, we will provide an overview of the most important issues discussed in the previous chapters.

\subsection{Overview}

In chapter 1, the relationship between panic disorder and agoraphobia has been adressed. In clinical settings, almost all patients with agoraphobia suffer from panic attacks, and the onset of panic disorder was found to precede the onset of agoraphobia in a majority of cases. Therefore, it has been hypothesized that agoraphobia is a secondary stage in a multistage disorder starting with infrequent panic attacks. Epidemiological studies in the general population challenged this viewpoint. In these studies, agoraphobia without (a history of) panic disorder was found to be more prevalent than agoraphobia with panic disorder. Moreover, the course of illness was found to be variable: sometimes agoraphobia preceded the onset of panic disorder, and in other cases both disorders started more or less simultaneously. Furthermore, agoraphobia indeed frequently co-exists with panic disorder, but high comorbidity rates of panic disorder and agoraphobia with other disorders (major depression, social phobias, generalized anxiety disorder, obsessive compulsive disorder, somatization disorder and substance abuse) have also been found. Large individual variation in the patterning and sequences of various symptoms has been demonstrated.

Chapter 1 further described panic disorder and agoraphobia as epidemiologically significant disorders with a chronic and persistent course of illness, that often require treatment. Both panic disorder and agoraphobia were found to be associated with severe constrictions in life style. Impairment of activities (work, domestic and leisure activities) and social contacts (intimate relationships as well as contacts in a larger social group) interfere with the course of daily life. Agoraphobia is characterized by restricted mobility: in severe cases the patient becomes completely housebound and requires a constant companion. 
In chapter 2, several factors related to the onset and maintenance of panic disorder have been identified. Panic disorder (with and without agoraphobia) was found to be related to biological vulnerabilities, as well as to cognitive factors. At the microsocial level, the onset of panic disorder was often found to be preceded by a period of enhanced life stress. At these levels, few differences were found between panic patients with and without agoraphobia. There is only some evidence indicating that agoraphobia is a more severe condition: panic patients with agoraphobia experienced more social anxiety, chronic anxiety and depression.

At the macrosocial level, agoraphobia has been related to social and cultural factors. Epidemiological studies demonstrated that agoraphobia is much more prevalent in women, and especially in unemployed, married women with a lower socioeconomic status. Sex differences in agoraphobia have been further related to stereotyped feminine role behavior. Traditional feminine sex roles encourage the avoidance of public places by imposing serious restrictions on the behavior of girls and women in public places. At the same time, they provide little opportunities to acquire skills that are needed to function in a larger social group. Furthermore, the social and cultural meaning of agoraphobic situations has been evaluated. Hypotheses were generated about characteristics of situations that potentially increase or reduce the sense of safety in agoraphobic patients. The presence of a trusted companion was described as providing acknowledgement to the sense of identity. Situations without acknowledgement by intimate others were identified as potentially reducing the sense of safety in agoraphobia.

Empirical evidence to support these propositions is still sparse. An important disadvantage of most of the studies about panic disorder and agoraphobia is that they are carried out in the laboratory and rely on retrospective recall. Over the last 10 years, however, an increasing number of studies focused on panic disorder and agoraphobia in daily life (chapter 3). Diary and event sampling studies have been carried out, including self-monitoring of daily activities outside the home. These studies provide an opportunity to depict experiences of panic and psychosocial impairment in panic patients with and without agoraphobia during the course of daily life. But in general, little information was gathered about differences in the frequency and type of activities between panic patients with and without agoraphobia, and between panic patients and normal controls. Furthermore, few differences were identified between panic patients with and without agoraphobia in the frequency and types of panic attacks registered in daily life situations.

In the present study, a random time sampling technique, called the Experience Sampling Method (ESM), was used to investigate experiences of panic patients with and without agoraphohia in daily life. One of the most important differences between the present ESM study and other studies about agoraphobia and panic disorder in daily life is that we did not restrict ourselves to a description of symptoms and illness. By developing a coding system for daily life situations, based on theories about macrosocial factors in agoraphobia, we were able to evaluate daily life situations in terms of their social and cultural meaning. The ecological validity of the ESM study refers not only to the natural setting in which the research has been carried out, but also to the more important fact that the sampled settings have been evaluated in terms of their psychological meaning to the subject. 
The method has been described in further detail in chapter 4. ESM was designed to obtain self-reports about experiences at randomly chosen moments in daily life. To accomplish this, the subjects carried a terminal watch that signaled them 10 times a day during 6 days. At each signal the subject completed a self-report form about anxiety and panic symptoms and about the situational context. In the present study, $74 \%$ of all programmed beeps were responded to within 15 minutes.

In chapter 5, the experience of panic in daily life was investigated by means of a panic scale based on items in the ESM questionnaire. The ESM panic module was created by an expert panel based on DSM III criteria of panic attacks as well as on empirical studies about the nature of panic. A strong Mokken scale was identified, indicating that the ESM items about anxiety and panic measure one underlying dimension ranging from rather common anxiety complaints to more severe symptoms, such as fear of dying. Clear differences were demonstrated between the experiences of panic in panic patients and in patients with other disorders. Panic patients had significantly higher scores on the panic scale than neurotic non-panic controls. Moreover, panic patients and neurotic controls shared symptoms of anxiety, but symptoms such as feelings of unreality and fear of dying occurred with very low frequencies in neurotic controls. In general, few differences in panic experiences were observed between panic patients with and without agoraphobia. In both groups of panic patients, about half of the subjects never experienced panic during the research week. Extremely high frequencies of panic experiences were, however, only recorded in some of the agoraphobic subjects. But, the frequency and severity of panic experiences was not only related to the severity of agoraphobia. Irrespective of agoraphobia, depression and social phobic fears, the frequency and severity of panic experiences was found to be significantly related to the level of trait anxiety in panic patients.

Agoraphobia was further found to be related to specific patterns of time allocation (chapter 6). Using multivariate analyses of covariance, we investigated differences in time allocation adjusted for demographic characteristics and missing responses. Agoraphobic patients differed significantly from normal controls in the amount of time allocated to three types of situations. Agoraphobic patients spent more time in intimate situations and in situations with high levels of acknowledgement by other people, and less time in situations with low levels of acknowledgement by other people than normal controls. The severity of agoraphobic fear in panic patients - as measured with the Fear Questionnaire - was further found to be related to the amount of time spent in intimate situations, in anonymous situations without significant others and in situations with high and low levels of acknowledgement by other people. Spending a lot of time in the presence of intimate others was found to be the most specific feature of time allocation in agoraphobia. Differences in time allocation according to the level of acknowledgement by the environment were less evident. Agoraphobic patients reported more often to be at home than panic patients without agoraphobia and normal controls, but after the adjustment for demographic characteristics and missing responses, agoraphobic patients no longer differed from panic patients without agoraphobia, neurotic and normal controls. Furthermore, the amount of time spent in situations with different levels of acknowledgement by the environment was not only related to the severity of agoraphobia, but also to other measures of psychopathology, especially social phobia and trait anxiety. 
In chapter 7 , we investigated how fluctuations in the presence of panic experiences are related to diagnostic and demographic characteristics of the subject, to characteristics of the situational context and to temporal factors. The presence or absence of panic experiences was found to be a relatively stable state. Once a panic experience was noted, it would be most likely to remain present at the following ESM signal, thus indicating that panic experiences cluster within days. No significant relationship was found between transitions in panic experiences and other temporal factors, such as the time of the day or the day of the week. Neither was the probability of observing specific sequences of panic experiences directly related to the diagnosis of the subject (panic disorder with or without agoraphobia). Nevertheless, within diagnostic groups significant differences in the likelihood of reporting a panic experience were found according to demographic factors and according to characteristics of the situational context. In the group of panic patients without agoraphobia, for instance, panic experiences were more likely to occur in male, unmarried subjects and in situations with low levels of acknowledgement by significant others. In the group of agoraphobic patients, on the other hand, more panic experiences were reported by female, married and unemployed subjects and in situations with high levels of acknowledgement by other people, i.e., in the company of significant others. However, when a panic experience was already noted at the previous ESM signal, both groups of panic patients were more likely to report another panic experience at the present signal when they were in situations with high levels of acknowledgement by the environment, i.e., at home. Therefore, we suggested that staying at home might be be a more general strategy that is used by both panic patients with and without agoraphobia when repeated panic experiences occur, while seeking the proximity of significant others seems to be a specific characteristic of agoraphobic behavior in daily life.

\subsection{Conclusions}

The main conclusions of the present study can be summarized as follows:

(1) panic disorder with and without agoraphobia is characterized by large individual variations in the frequency and severity of panic experiences and in the amount of time spent in different types of daily life situations;

(2) agoraphobia is associated with specific demographic characteristics and demographic characteristics have an impact on the occurrence of panic experiences as well as on the use of time in daily life;

(3) within the group of panic patients, the frequency and severity of panic experiences and the use of time in daily life is not only related to the severity of agoraphobic fears, but also to the severity of other types of psychopathology;

(4) the lack of acknowledgement by other people, and especially the absence of intimate others, is a crucial characteristic of agoraphobic situations in daily life.

\subsection{1. individual variation}

Literature about the relationship between panic disorder and agoraphobia indicated that there is a lot of individual variation in the patterning and severity of symptoms. Based on the studies reviewed in chapter 1,2 and 3, we expected to find few differences between panic patients with and without agoraphobia at the group level, but large individual variation within groups. The results of the present study indeed provided little support for the classitication of panic patients with and without agoraphobia into two mutually exclusive 
groups. Daily life measures indicated that these patients rather represent a continuum in the severity and frequency of panic experiences, in the amount of time spent in agoraphobic situations, as well as in the severity of levels of psychopathology.

First, large individual variation was demonstrated in the frequency and severity of panic experiences. Panic patients with agoraphobia reported on the average more panic experiences than panic patients without agoraphobia, but this was largely due to a subgroup of agoraphobic patients having extremely high frequencies of panic experiences. In the group of panic patients with agoraphobia, the frequency of panic experiences varied from subjects never experiencing panic to subjects who almost continuously experienced panic. Besides this, about half of the patients in both groups never reported panic experiences during the research week. High frequencies of panic experiences occurred in a relatively small number of panic patients.

Individual variation was further demonstrated in the use of time in daily life. In general, time allocation in agoraphobic patients was characterized by high amounts of time spent in intimate situations. In spite of this, there was no specific pattern of time allocation that was exclusively observed in the members of a specific diagnostic group. Half of the subjects in the agoraphobic group were never in an anonymous situation without significant others; but also $28 \%$ of the panic patients without agoraphobia, $21 \%$ of the neurotic controls and $10 \%$ of the normal controls never reported to be in this type of situation.

Moreover, there were no clear differences between panic patients with and without agoraphobia in the likelihood of observing specific sequences of panic experiences. The probability of observing panic experiences was not significantly related to a diagnosis of agoraphobia as such, but largely depended on demographic and situational factors as well. Panic experiences were more likely to occur in female, married and unemployed agoraphobic patients. Furthermore, agoraphobic patients were more likely to report panic experiences when they were in situations with high levels of acknowledgement by other people. The model developed in chapter 7 clearly shows that within diagnostic groups, the probability of observing panic experiences varies from subject to subject, from situation to situation and from day to day. Thereby, it is clear that an additional diagnosis of agoraphobia is only a poor predictor of the daily life behavior of panic patients.

\subsection{2. demographic characteristics and associated social roles}

Epidemiological studies demonstrated that agoraphobia is related to specific demographic characteristics (section 2.4.1). Agoraphobic subjects in this study also differed from the other groups in terms of demographic characteristics (section 4.4.1). The group of agoraphobic patients included more women and more unemployed subjects than the groups of panic patients without agoraphobia, normal and neurotic controls. Agoraphobics tended to live alone less often than neurotic controls. And finally, agoraphobic patients tended to be older than panic patients without agoraphobia.

Agoraphobic patients have often been described as housebound housewives. In the present study, time allocation differences between panic patients with and without agoraphobia were found to be small and largely affected by demographic differences. Time allocation data (chapter 6) showed that 'homeliness' is indeed a common characteristic in agorapho- 
bia, but spending a lot of time in a familiar environment seems to depend on demographic characteristics of panic patients. Agoraphobic patients are thus not more 'housebound' than panic patients without agoraphobia having similar demographic characteristics.

By adjusting time allocation data for demographic variables, we were able to estimate the amount of time agoraphobic patients would have spent in specific daily life situations if they would not differ from the other groups on these variables. Nevertheless, demographic differences between panic patients with and without agoraphobia can not be considered as mere coincidence. Agoraphobia is closely related to specific social roles. Recent studies about social factors in agoraphobia indicate that agoraphobia is related to stereotyped feminine sex roles (section 2.4.2). Even in the general population, large sex differences in fear of going out of the house and fear of being alone have been noted (section 2.4.3 and 2.4.4). Differences in time allocation between panic patients with and without agoraphobia, therefore, may reflect differences in response styles that are associated with gender and social roles. Women with a traditional role may be more likely to seek the proximity of trusted companions and to hide within the safe environment of the home during periods of stress and illness. Family studies indicated that men are more likely to develop other response styles, such as alcohol abuse. Furthermore, the traditional division of labour between men and women decreases the possibility to withdraw from the work situation in men. Quitting a job and becoming a housekeeper is more socially acceptable in women than in men. Society thus offers more opportunities to women to develop agoraphobic avoidance behavior.

The results of the present study do not allow to conclude that there is a causal relationship between social roles, the course of the illness and the severity of symptoms in patients with panic disorder and agoraphobia. Restricted mobility and changes in social roles (e.g., loss of employment) may also be the consequence of agoraphobic fears and the severity of panic disorder. We demonstrated, however, that demographic characteristics have an important impact on fluctuations in the presence or absence of panic experiences as well as on the use of time in daily life. Panic experiences were more likely to occur in subgroups of panic patients with and without agoraphobia having specific demographic characteristics. Panic experiences were more frequently noted in male, unmarried panic patients without agoraphobia and in female, married and unemployed agoraphobic patients. Agoraphobic fears and avoidance behaviors, therefore, may reflect a response style that is related to a traditional female social role.

\subsubsection{Severity of psychopathology}

Studies about the relationship between panic disorder and agoraphobia (reviewed in chapter i) indicated that panic disorder and agoraphobia often co-exist with other disorders, such as major depression, social phobia, somatization disorder and generalized anxiety disorder. In the present study, panic patients with and without agoraphobia have been compared to a group of patients with other disorders (neurotic controls). Few differences in cross-sectional measures of depression, social anxiety and trait anxiety were identified between panic patients with and without agoraphobia and neurotic controls. Panic patients with agoraphobia reported higher levels of trait anxiety than neurotic controls; and neurotic controls reported significantly more depression than panic patients without agoraphobia (chapter 4). Nevertheless, the frequency and severity of panic experiences recorded in 
daily life clearly differentiated panic patients (with and without agoraphobia) from neurotic non-panic controls. On the other hand, agoraphobic patients did not differ from panic patients without agoraphobia and neurotic controls on time allocation variables, at least when we took demographic differences into account. Agoraphobic subjects could be differentiated from normal controls on time allocation variables. Panic patients without agoraphobia and neurotic controls took an intermediate position: they did not differ significantly from agoraphobic patients and normal controls on any of the time allocation variables.

Because of the relatively small number of subjects in this study, we had to restrict the number of factors included in the model that was developed in order to predict specific transitions in panic experiences (chapter 7). Measures of psychopathology were therefore not included in the model. Some indication of the relevance of the severity of psychopathology was given by computing correlations between measures of psychopathology and daily life variables. First, the severity and frequency of panic experiences was related to measures of agoraphobia, social phobia, depression and trait anxiety. When controlling for other measures of psychopathology, partial correlations between trait anxiety scores and measures of the frequency and severity of panic: experiences were highly significant (section 5.4.). High frequencies of panic experiences as well as high mean levels of panic anxiety experienced in daily life were found to be related to the level of trait anxiety. Secondly, measures of psychopathology were related to ESM measures of the use of time in daily life. The severity of agoraphobia was found to be significantly related to the amount of time spent in intimate situations, in anonymous situations without significant others and in situations with low and high levels of acknowledgement by other people. The amount of time spent in daily life situations with different levels of acknowledgement by the environment was however not only found to be related to the severity of agoraphobic fears, but also to the severity of social phobia and trait anxiety. When controlling for other measures of psychopathology, only the amount of time spent in an highly acknowledging environment (i.e., at home) tended to be related to the severity of agoraphobic fears.

In chapter $i$, we concluded that panic patients display various symptoms of anxiety, phobias, hypochondriasis and depression in mixed patterns, as well as varying degrees of constrictions in life style. The description of individual variations in experiences of panic and time allocation with ESM uncovered a similar variability within the smaller frame of daily life. Further studies are needed to unravel the complex relationship between different symptom patterns and variations in daily life behavior.

\subsection{4. acknowledgement by significant others}

In chapter 2, we generated hypotheses about characteristics of situations that potentially increase or reduce the sense of safety in agoraphobic patients. The agoraphobic fear of public places was described as a lack of skills to enter the public domain. Likewise, fear and avoidance of being alone was related to the capacity to function autonomously in the absence of intimates. Instead of focusing at the fear of being alone, we argued that it is more important to study different types of social contacts in daily life. We hypothesized that a trusted companion provides acknowledgement to the sense of identity of agoraphobic patients. The presence of intimates was thus thought to be crucial in enhancing a sense of safety in agoraphobic patients. 
In the present study, subjects described the situational context of various experiences at randomly choosen moments in their daily life. First, we investigated differences between panic patients with and without agoraphobia in the amount of time that was spent in different types of situations. Secondly, the probability of observing specific sequences of panic experiences was related to characteristics of the situation.

We demonstrated that spending a lot of time in intimate situations and in situations with high levels of acknowledgement by other people and little time in situations with low levels of acknowledgement by other people are the most specific features of time allocation in agoraphobia. Acknowledgement by the presence of significant others was found to be more important than other types of acknowledgement. Time allocation data indicated that agoraphobic patients do not spend more time at home than panic patients without agoraphobia, neurotic and normal controls having similar demographic characteristics. The finding that agoraphobic patients spent more time in the presence of intimate others may indicate that agoraphobic behavior in daily life is characterized by seeking the proximity of significant others.

Acknowledgement by the presence of significant others was further found to be an important characteristic of the situational context in which agoraphobic patients experience panic. Based on the theory of van Zuuren, we expected that agoraphobic patients would be more likely to experience panic in situations with low levels of acknowledgement. We found that the probability of observing repeated or long-lasting panic experiences was related in a different way to the level of acknowledgement by other people and by the environment according to the diagnosis of the subject. Contrary to our expectations, only panic patients without agoraphobia were found to be more likely to report panic experiences in situations with low levels of acknowledgement by other people (i.e., alone or with strangers). Panic patients with agoraphobia were more likely to report panic experiences in situations with high levels of acknowledgement by other people. As we have argued in chapter 7 , we are not able to draw causal inferences about the relationship between characteristics of the situational context and panic experiences. Panic patients with agoraphobia may be more likely to have a 'bad day' when they are in the presence of intimates, or they may be more likely to seek the proximity of intimates when they experience or anticipate panic symptoms. When a panic experience was already present at the previous ESM signal, panic patients with agoraphobia were also found to be more likely to report a panic experience at the present signal when they were in the highly acknowledging environment of the home. But this pattern was not exclusively found in agoraphobic patients. Panic patients without agoraphobia were also more likely to be found at home when panic experiences were reported at two subsequent ESM signals. We, therefore, advocate that it might be more useful to conceptualize agoraphobia in terms of seeking the proximity of intimate others than in terms of avoidance of places.

\subsection{Diagnostic, Therapeutic and Research Implications}

\subsection{1. diagnostic implications}

First, we argued that seeking the proximity of significant others is a more important characteristic of agoraphobic behavior in daily life than the avoidance of places. In clinical descriptions, the importance of the proximity of trusted companions has often been stres- 
sed (section 1.1). According to the diagnostic criteria of DSM III(R), agoraphobia is characterized by fear and avoidance of being alone and in public places. Agoraphobic situations are thus defined both in terms of social contexts and places. Based on the findings of the present study, we advocate that the social context is more important than places. Furthermore, being alone or not alone was not the most prominent feature of daily life situations that are avoided by agoraphobic patients. The presence or absence of trusted and intimate companions was found to be more important. Therefore, a diagnostic description of agoraphobia that highlights the seeking of proximity to trusted persons fits the data better than conceptualizations based on fear and avoidance of being alone or in public places.

Secondly, there is some research evidence indicating that agoraphobia is related to stereotyped feminine sex role behavior. We hypothesized that women are more likely to develop agoraphobic avoidance behavior, while men are more likely to develop other response styles, such as alcohol abuse. Nevertheless, sex differences in agoraphobia may be to some extent an artifact of diagnostic procedures, especially clinical interviews. The higher prevalence of agoraphobia in women may be biased by the fact that clinicians are more likely to label the habitual response style of female panic patients with a traditional role as 'agoraphobia'. On the other hand, epidemiological studies in the general population indicate that the prevalence of agoraphobia without (a history of) panic disorder is much higher than in clinical populations (section 1.5). An important reason why agoraphobic patients without panic disorder are less prevalent in health care settings, is probably that panic disorder is a more urgent (and perhaps a more legitimate) reason to seek medical treatment (section 1.2). Another reason, however, might be that the prevalence of agoraphobia without panic attacks is underestimated in clinical settings. Research on the comorbidity of agoraphobia with other disorders indicated that agoraphobia often co-exists with major depression, obsessive compulsive symptoms, social phobias and somatoform disorders (section 1.6). In cases with other disorders, secondary agoraphobia may be more easily overlooked. Therefore, the use of standardized diagnostic procedures to describe comorbid symptoms and disorders is recommended.

As a consequence, the classification of mental health problems into mutually exclusive diagnostic categories can be challenged. Data on individual variations in panic experiences and time allocation variables show that this type of classifications provides few information about the individual daily life experience of illness. Few differences were found between panic patients with and without agoraphobia on daily life measures. Furthermore, demographic characteristics and the severity of other types of psychopathology were also found to be related to daily life measures of panic and agoraphobia. Therefore, DSM III(R) classifications of individual cases are of limited descriptive, clinical and prognostic value. New classification systems should be developed, in which subjects are not assigned to a diagnostic category according to 'all or none' criteria. A polythetic classification system in which subjects can be assigned to several categories at the same time and in which the 'resemblance' between the subject and the 'pure types' of diagnostic categories are evaluated, would provide a more precise description of health and illness as it occurs in the natural context (van Meter et al., 1987). Daily life measures then could be added to the diagnostic procedures in order to describe the severity of symptoms and the amount of psychosocial impairment experienced in every day life. By following this procedure, quantitative and replicable descriptions of individual variations in the experience of symptoms 
and in the quality of life can be gathered, that are more useful to both clinicians and researchers.

\subsection{2. implications for therapy and prevention}

Treatment studies demonstrated that exposure in vivo is one of the most powerful therapeutic ingredients in the treatment of agoraphobia (Emmelkamp, 1990). During exposure therapy, the patient is confronted with situations that are feared and avoided. In many cases, a hierarchy of behavioral tasks with increasing levels of difficulty is constructed and the patient is instructed to attempt the different exposure tasks. An important characteristic of effective treatment is that the therapy is optimally suited to the needs and problems of the individual patient. Behavior therapy is based on the results of a detailed functional analysis. The functional analysis potentially allows to provide a description that is close to the 'polythetic diagnostic classification system' described in the previous section. ESM data can be used to supplement the results of this analysis and to establish therapeutic approaches that are suited to the individual patient (Dijkman \& deVries, 1987). ESM data not only provide information on the frequency and severity of panic experiences (as many other self-monitoring approaches do), but also highlight sources of positive experiences. If the goal of the therapeutic strategies goes beyond the reduction of symptoms and problem behavior, knowledge about sources of positive experiences can be used to develop stategies to increase the number of these experiences. Instead of fear and phobia reduction, the therapeutic intervention then creates possibilities to improve the general quality of life.

Moreover, ESM provides a detailed description of social activities and social impairments in daily life. In this study, the presence or absence of intimates was found to be an important characteristic of daily life situations in agoraphobic patients. In chapter 2 , we hypothesized that agoraphobic fears are related to developmental tasks of adolescence. Adolescence was described as a crucial stage in the development of the capacity to be alone and in the acquisition of skills that are needed to function in social groups outside the family. Future investigations are needed to study the role of developmental aspects in the capacity to be alone and in the reliance on acknowledgement by intimate others. Next, the possible therapeutic use of these explanations should be considered. In clinical practice, more attention could be directed to socially prescribed behaviors and to patterns of time allocation, in the present as well as during different developmental stages. Therapeutic strategies then should include remedial developmental and behavioral techniques in order to leam more active approach behaviors and to develop coping skills that enhance the sense of identity across various social settings.

Finally, the development of coping strategies and skills for independent functioning should not be restricted to the consultation room of therapists. As D. Chambless (1989) argued, therapists should go beyond phobia reduction, because as long as independent and active approach behavior is considered to be 'masculine' and undesirable for women in our culture, the prevalence of agoraphobia will continue to be higher in women than in men. Preventive measures should be taken in order to allow girls and women to acquire the necessary skills for autonomous functioning in larger social groups. On the other hand, measures could be taken in order to enhance the sense of safety by increasing the number of social contacts in the public domain, e.g. in residential areas. After all, anonymous situa- 
tions are created by culture. Large shopping centres, huge skycrapers and dormitory suburbs increase the number of anonymous situations people are confronted with. By restricting the range of social interactions to a small nuclear family, the number of significant others that are able to enhance our sense of identity will also be limited. Preventive measures therefore should create opportunities to enlarge the group of significant others. Stralegies to stimulate the educational and occupational attainment of girls and women may play an important role in this process. Employment and education both provide an opportunity to have social contacts independently of the family and to ascertain a sense of identily through identification with a group of people having common interests and concerns.

\subsection{3. research implications}

In the present study, a relatively new methodology was used to describe the behavior and experiences of panic patients with and without agoraphobia in the natural environment. ESM was found to be particularly useful to delineate a detailed picture of individual variations in the frequency and distribution of panic experiences and in the use of time in daily life. Based on the results of this study, some methodological recommendations and directions for future research will be given.

First, further attention has to be paid to the development of appropriate time sampling schemes and strategies to ameliorate compliance rates. We demonstrated that ESM can be used with succes in samples of panic patients: panic patients were not less compliant than normal subjects. Furthermore, we argued that the method should be adapted to the subjects' life style, instead of subjects adapting their life to the method. From this point of view, an average response rate of 44 out of 60 possible valid responses per subject is largely sufficient. On the other hand, if our aim is to describe a representative sample of daily life situations, every effort should be made in order to minimize the number of missing responses. Each missing response results in a loss of information and in potential distortions of the results. Accordingly, it is of paramount importance to ascertain that there is no systematic underreporting of specific situations. In the present study, some information about the type of situations that have been underreported has been gathered in debriefing interviews. The most important reason for missing and out of range responses was that subjects were sleeping. Also, the number of valid responses declined towards the end of the research week. No evidence was found for a systematic underreporting of specific events by all subjects. Therefore, we can expect that compliance rates can be elevated rather easily by adapting the sampling scheme, for instance, by programming less signals in the early moming or by changing the number of research days or the number of ESM signals on one day. The application of ESM in different samples and settings over the last 10 years now allows us to select time sampling procedures and ambulatory signaling devices that are optimally suited to specific samples and research questions (Delespaul, 1992).

Secondly, the measurement of panic experiences and the use of time of panic patients with ESM should be compared to measures used in other daily life studies. An important problem thereby is that the results of daily life studies are often difficult to compare because of different operationalizations of panic attacks and other target behaviors. Most event sampling studies registered subject defined panic attacks. In the present study, a panic scale was constructed by an expert panel based on DSM III criteria for panic attacks as 
well as on empirical studies about the nature of panic. A careful comparison of the measurement of panic experiences with ESM to event samplings of subject defined panic attacks can be used to provide additional tests of the reliability and validity of the measurement of panic in the natural environment. At the same time, a comparison of ESM to event sampling recordings would provide information about the potential underestimation of the frequency of panic experiences with ESM. Theoretically, the probability of catching an event with a relatively low frequency and a short duration, such as panic attacks, is higher with event sampling techniques than with ESM. We can not exclude that even on the so-called 'good' days subjects had a lot of panic experiences, but never on the moment of the ESM signial.

Another important issue is the development of statistical models to analyze the complex ESM data set. ESM produces data with a high level of individual, situational and temporal detail. Different statistical analyses varying in complexity allow to uncover different parts of daily life experiences. In the present study, elementary statistics have been used to describe the frequency and severity of panic experiences in panic patients with and without agoraphobia (chapter 5). Multivariate analyses of covariance were performed in order to test between group differences in the use of time after the adjustment for demographic characteristics and missing responses (chapter 6). And finally, a model for logistic regression was developed in order to describe the dependence of sequences of panic experiences on demographic, diagnostic and situational factors. Further effort should be spent to develop statistical methods that are optimally suited to answer similar types of questions about daily life experiences. A guidebook for simple descriptive analyses has already been given by Larson \& Delespaul (1992). When a larger data set is available, more sophisticated statistical models can be developed in order to identify specific individual, situational and temporal factors that are related to the onset of panic atlacks in the natural environment.

In particular, the relationship between the occurrence of panic symptoms and specific situations warrants further study. Dairy and event sampling studies only gathered information about excursions out of the home. In these studies, little attention was paid to the impact of social contexts and activities on panic experiences in daily life. In the present study, transitions in panic experiences were found to be associated with specific types of activities, social contexts and places. Yet, little information was gathered about the sequencing of events. For instance, we demonstrated that subjects who experienced panic at the previous ESM signal would be more likely to report another panic experience if they were at home at the present signal. Because of the relatively large number of missing values, we were not able to relate the occurrence of panic experiences at the present ESM signal to the presence of panic experiences at earlier points in time. Neither could we relate the likelihood of observing panic experiences to characteristics of the situation at previous ESM signals. Moreover, we did not gather information about potential changes in pinic experiences or in situational factors in between signals. Therefore, we do not know whether changes in the presence or absence of panic experiences are followed by changes in situational contexts or vice versa. Behavioral micro-analyses of fluctuations in panic symptoms and synchronous changes in social contexts, environments or activities may provide more insight into the patterning of experiences in the natural environment. Proximity seeking and avoidance then can be described as ongoing dynamic processes having their impact on the onset and recovery from panic experiences. 
It is also important to remind that the subjects in this study were asked not to change their habitual life style. As a consequence, agoraphobic subjects were allowed to avoid solitary and anonymous situations. Time allocation data demonstrated that agoraphobic patients did enter these types of situations. But, we can not exclude that they selected specific situations that were not particularly anxiety provoking. By coding the level of acknowledgement by other people, by the environment and by activities in daily life situations, we tried to identify characteristics of the situational context that potentially increase or reduce the sense of safety in agoraphobic patients. The classification of daily life situations according to the level of acknowledgement by other people, by the environment and by activities was found to be useful in order to predict fluctuations in the presence of panic experiences in the natural context. It is difficult, however, to evaluate the emotional meaning of a particular situation to a specific subject. Most agoraphobic subjects fear and avoid multiple situations and although some situations, such as driving a car, are feared by a majority of patients, they are not necessarily anxiety provoking to all patients. And even within subjects, only minor changes in the situational context, such as the presence of talismen, may alter the emotional meaning of the situation. At the level of the individual, ESM can be used to ascertain clear relationships between ongoing mood states and situational contexts (e.g., Dijkman \& deVries, 1987; delle Fava \& Massimini, 1991). At the group level, individualized records of safe and threatening situations could be kept. But, an important problem of focusing at specific individualized anxiety provoking situations is that they are likely to occur with very low frequencies. Because of the low frequencies of specific types of situations, only a rough classification of situations could be used in the present analyses. In order to evaluate the effect of specific types of situations with low frequencies, hughe numbers of ESM observations would be needed. Studies focusing on the impact of specific situational contexis, therefore, may be better off with event sampling strategies. Still, there are also problems inherent to this approach. For instance, we do not know whether situations that are retrospectively described as anxiety provoking are the most relevant categories of situations. In previous event sampling studies, subjects selected panic attacks and situational cues and, by using this strategy important information has been overlooked. Margraf et al. (1987b), for instance, failed to describe the situational context of panic attacks, that were identified by patients as 'spontaneous', i.e., attacks with little or no provocation. An alternative solution to the problem of low frequencies of anxiety provoking situations is to combine ESM with experimental approaches. When special attention is paid to the ecological validity of exposure tasks (see section 3.1.1), a combination of ESM with individualized behavioral avoidance tests could be used to register mood and symptoms of panic in situations that are similar to those that are feared and avoided by the individual subject in daily life.

Finally, the impact of demographic characteristics and associated social roles on daily life behavior should be investigated in greater detail. Demographic characteristics were found to have an important influence on daily life experiences. The data presented in chapter 6 indicate that demographic characteristics and associated social roles may determine the type of situations that panic patients actually enter in daily life. Furthermore, the statistical model developed in chapter 7 clearly showed that the probability of observing specific transitions in panic experiences varies largely according to the demographic characteristics of the subject. But, the model was based on a relatively small number of subjects and some categories of patients with specific demographic characteristics, e.g., male agoraphobic patients, were largely underrepresented. By using larger samples of panic patients with 
and without agoraphobia and carefully selected control groups, the influence of demographic characteristics and social roles on potential restrictions in mobility and psychosocial functioning can be investigated.

In summary, further research on daily life experiences of patients with panic disorder and agoraphobia is needed. The present study focused at panic experiences and at the use of time of panic patients with and without agoraphobia in the natural environment. Some individual, situational and temporal factors that are related to panic experiences have been described. Hereby, only a small part of the veil has been lifted. Most of the work still needs to be done. 
Panic disorder and agoraphobia are epidemiologically significant disorders that often coexist (chapter 1). Several factors related to the onset and maintenance of panic disorder have been identified in previous studies, but only a few differences were found between panic patients with and without agoraphobia (chapter 2). Based on theories abcut the social and cultural meaning of agoraphobic situations, we hypothesized that the lack of acknowledgement by intimate others is the most crucial characteristic of agoraphobic situations.

Over the last 10 years, an increasing number of studies focused on daily life experiences of panic patients (chapter 3). Few differences were identified between panic patients with and without agoraphobia in the frequency and types of panic attacks. But, little information was gathered about the frequency and type of activities in daily life. The aim of the present study, therefore, was to describe the experience of panic, the annount of time spent in different types of daily life situations, and the relationship between panic experiences and individual, situational and temproal factors in panic patients with and without agoraphobia. Patients with other disorders and normal controls were used a reference groups. Daily life experiences were investigated by means of a random time sampling technique: the Experience Sampling Method (ESM). At randomly chosen moments in daily life, subjects completed a self-report about anxiety/panic symptoms and about the situational context (chapter 4).

Panic experiences in daily life were rated on a Mokken scale, including ESM items about anxiety and panic (chapter 5). Clear differences were demonstrated between panic patients and patients with other disorders. Panic patients had significantly higher scores on the panic scale than non-panic patients. Few differences were observed between the panic experiences of panic patients with and without agoraphobia. Panic patients with and without agoraphobia showed large individual variations in the frequency and severity of panic experiences and both groups largely overlapped. About half of the subjects in both groups never experienced panic during the research week. Correlations between measures of psychopathology and daily life measures of panic further indicated that the frequency and severity of panic experiences was significantly related to the level of trait anxiety in panic patients.

Agoraphobia was found to be related to specific patterns of time allocation (chapter 6). But, agoraphobia was also found to be associated with specific demographic characteristics and these demographic characteristics affect the type of situations that panic patients enter in daily life. After the adjustment for demographic characteristics and missing responses, no significant differences in time allocation were found between panic patients with and without agoraphobia and patients with other disorders. Agoraphobic patients only differed significantly from normal controls in the amount of time allocated to three types of situations: Agoraphobic patients spent more time in intimate situations and in situations with high levels of acknowledgement by other people, and less time in situations with low levels of acknowledgement by other people than normal controls. The severity of agoraphorbia in panic patients was found to be related to the amount of time spent in different types. of social contexts. But, the amount of time spent in different types of environments was. not only related to the severity of agoraphobia, but also to other measures of psychopathology, especially social phobia and trait anxiety. 
Fluctuations in the presence or absence of panic experiences were related to temporal factors, to diagnostic and demographic characteristics of the subject and to characteristics of the situational context (chapter 7). Panic experiences were found to be a relatively stable state: once a panic experience was noted it would be most likely to be present again at the subsequent ESM signal. The probability of observing a panic experience was further found to be related to interactions between diagnostic, demographic and situational factors. Agoraphobic patients, for instance, were more likely to report repeated panic experiences when they had specific demographic features (female married and unemployed subjects) and when they were in specific types of situations (at home, with significant others). The results demonstrate that the probability of having a panic experience changes over time and varies from subject to subject and from situation to situation.

Finally, the conclusions of the study have been presented and diagnostic and therapeutic implications as well as implications for future research have been discussed (chapter 8). The main conclusions can be summarized as follows:

(1) panic disorder with and without agoraphobia is characterized by large individual variations in the frequency and severity of panic experiences and in the amount of time spent in different types of daily life situations;

(2) agoraphobia is associated with specific demographic characteristics and demographic characteristics have an impact on the occurrence of panic experiences as well as on the use of time in daily life;

(3) within the group of panic patients, the frequency and severity of panic experiences and the use of time in daily life is not only related to the severity of agoraphobic fears, but also to the severity of other types of psychopathology;

(4) the lack of acknowledgement by other people, and especially the absence of intimate others, is a crucial characteristic of agoraphobic situations in daily life. 


\section{Samenvatting}

De paniekstoomis en de agorafobie zijn epidemiologisch significante stoomissen, die vaak samen voorkomen (hoofdstuk 1). Uit eerder onderzoek zijn een aantal factoren bekend die verband houden met het ontstaan of voortbestaan van de paniekstoornis, maar in het algemeen werden er slechts weinig verschillen gevonden tussen paniekpatiënten met en zonder agorafobie (hoofdstuk 2). Uitgaande van theorieen over de sociale en culturele betekenis van agorafobische situaties, veronderstelden we dat een gebrek aan bevestiging door belangrijke anderen het belangrijkste kenmerk is van agorafobische situaties.

Gedurende de laatste 10 jaar richtten meer en meer studies zich op ervaringen van paniekpatiënten in het dagelijks leven (hoofdstuk 3). De resultaten toonden weinig verschillen tussen paniekpatiënten met en zonder agorafobie wat betreft de frequentie en de aard van de paniekaanvallen. Maar deze studies leverden slechts weinig informatie over de frequentie en de aard van de activiteiten in het dagelijks leven. Het doel van dit onderzoek was dan ook om een beschrijving te geven van paniekervaringen, de wijze van tijdsbesteding en de relatie tussen paniekervaringen en individuele, situationele en temporele factoren in paniekpatiënten met en zonder agorafobie. Patiënten met andere stoomissen en normale controles werden gebruikt als referentiegroepen. De dagelijkse ervaringen werden onderzocht door middel van een 'random time sampling' techniek: de Experience Sampling Methode (ESM). Op willekeurig gekozen momenten in het dagelijks leven vulden de subjecten een vragenlijst in met betrekking tot symptomen van angst/paniek en de situationele context (hoofdstuk 4).

Paniekervaringen werden gemeten met een Mokken schaal, bestaande uit ESM items over angst en paniek (hoofdstuk 5). Tussen paniekpatiënten en patiënten met andere stoornissen werden duidelijke verschillen gevonden. De paniekpatiënten scoorden significant hoger op de paniekschaal dan niet-paniek patiënten. Weinig verschillen werden gevonden tussen de paniekervaringen van paniekpatiënten met en zonder agorafobie. Beide groepen werden gekenmerkt door grote individuele verschillen en beiden overlapten elkaar aanzienlijk. Ongeveer de helft van de patiënten in beide groepen rapporteerden geen paniekervaringen tijdens de onderzoeksweek. Correlaties tussen maten voor psychopathologie en maten voor paniek toonden een significant verband aan tussen de frequentie en intensiteit van paniekervaringen en de mate van angstgeneigdheid ('trait anxiety') in paniekpatiënten.

Agorafobie werd gekenmerkt door specifieke patronen van tijdsbesteding (hoofdstuk 6). Maar, agorafobici verschilden ook qua demografische kenmerken van andere groepen en deze demografische kenmerken beinvloeden de manier van tijdshesteding. Nadat de resultaten gecorrigeerd werden voor demografische kenmerken en ontbrekende gegevens, vonden we geen significante verschillen in tijdsbesteding tussen paniekpatiënten met en zonder agorafobie en patiënten met andere stoomissen. Agorafobiepatiënten verschilden wel significant van normale controles in de tijd die besteed werd in drie typen van situaties: agorafobiepatiënten besteedden meer tijd in intieme situaties en in situaties met veel bevestiging door anderen en minder tijd in situaties met weinig bevestiging door anderen dan normale controles. De emst van de agorafobische angsten in paniekpatiënten hield verband met de mate van tijd besteed in verschillende types van sociale contexten. De tijd besteed in verschillende types van omgevingen hield echter niet alleen verband met de emst van de ago- 
rafobie, maar ook met andere maten van psychopathologie, in het bijzonder met de mate van sociaal fobische angsten en de mate van angstgeneigdheid.

Veranderingen in de aan- of afwezigheid van paniekervaringen werden in verband gebracht met temporele factoren, met diagnostische en demografische kenmerken van het subject en met kenmerken van de situationele contexl (hoofdstuk 7). De aanwezigheid van paniekervaringen bleek een relatief stabiele toestand te zijn: wanneer een paniekervaring geregistreerd werd, was dese in een meerderheid der gevallen ook bij het daaropvolgend signaal aanwezig. De kans op het hebben van een paniekervaring bleek afhankelijk te zijn van interacties tussen diagnostische, demografische en situationale factoren. Agorafobiepatiënten, bijvoorbeeld, waren eerder geneigd om (herhaalde) paniekervaringen te rapporteren wanneer ze specifieke demografische kenmerken hadden (gehuwde, werkeloze vrouwen) en als ze zich in bepaalde situaties bevonden (thuis, met significante anderen). De resultaten tonen aan dat de kans op het hebben van een paniekervaring verandert doorheen de tijd en verschilt van persoon tot persoon en van situatie tot situatie.

Tenslotte zijn we ingegaan op de conclusies van het onderzoek en op de implicaties voor diagnostiek, therapie en onderzoek (hoofdstuk 8). De belangrijkste conclusies kunnen als volgt samengevat worden:

(1) de paniekstoornis met en zonder agorafobie wordt gekenmerkt door grote individuele verschillen in tijdsbesteding en in de frequentie en de emst van paniekervaringen in het dagelijks leven.

(2) agorafobie hangt samen met specifieke demografische kenmerken en demografische kenmerken hebben een invloed op de kans op het optreden van paniekervaringen en op de manier van tijdsbesteding in het dagelijks leven.

(3) binnen de groep van paniekpatiënten, houdi de frequentie en de emst van paniekervaringen en de manier van tijdsbesteding niet alleen verband met de emst van de agorafobische angsten, maar ook met de emst van andere vormen van psychopathologie.

(4) het gebrek aan bevestiging door anderen, en in het bijzonder de afwezigheid van vertrouwde anderen is een cruciaal kenmerk van agorafobische situaties in het dagelijks leven. 


\section{References}

Adler C.M., Craske M.G., Kirschenbaum S. \& Barlow D.H. (1989)

'Fear of panic': An investigation of its role in panic occurrence, phobic avoidance and treatment outcome. Behavior Research and Therapy, vol. 27, no. 4, 391-396.

Alagna S.W. \& Hamilton J.A. (1987)

Periodic mood disorders: A critical review. Paper presented at the Annual Meeting of the American Psychiatric Association, May 1987, Chicago.

Al-Issa I. (1980)

Women and phobia. In: The Psychopathology of Women, Prentice Hall, New Yersey, 128-147.

Allan G. (1989)

Friendship. Developing a sociological perspective. Studies in Sociology, Har-vester Wheatsheaf, New York.

Anastasiades P., Clark D.M., Salkovskis P.M. et al. (1990)

Psychophysiological responses in panic and stress. Journal of Psychophysiology, vol. 4, 331-338.

Anderson J.A., Noyes R.jr. \& Crowe R.R. (1984)

A comparison of panic disorder and general anxiety disorder. American Journal of Psychiatry, vol. 141, no. 4, 572-575.

Angst J. \& Dobler-Mikola A. (1985)

The Zurich study V. Anxiety and phobia in young adults. European Archives of Psychiatry and Neurological Sciences, vol. 235, 171-178.

Angst J. \& Dobler-Mikola A. (1986)

Assoziation von Angst und Depression auf syndromaler und diagnostischer Ebene. In: Helmchen H. \& Linden M. (Eds.) Die Differenzierung von Angst und Depression. Springer-Verlag, Berlin/New York, 75-82.

A.P.A.- American Psychiatric Association (1980)

Diagnostic and Statistical Manual of Mental Disorders: DSM III (Third Edition) Washington D.C.

A.P.A.- American Psychiatric Association (1987)

Diagnostic and Statistical Manual of Mental Disorders: DSM III(R) (Third Edition-Revised) Washington D.C.

Arena J.G., Blanchard E.B., Andrasik F. et al. (1983)

Reliability of psychophysiological assessment. Behavior Research and Therapy, vol. 21, no. 4, 447-460.

Amow B.A., Taylor C.B., Agras W.S. \& Telch M.J. (1985)

Enhancing agoraphobia treatment outcome by changing couple communication patterns. Behavior Therapy, vol. 16, 452-467.

Aronson T.A. \& Logue C.M. (1987)

On the longitudinal course of panic disorder: Developmental history and predictors of phobic complications. Comprehensive Psychiatry, vol, 28, no. 4, 344-35.5.

Arrindell W.A. (1980)

Dimensional structure and psychopathology correlates of the Fear Survey Schedule (FSS-III) in a phobic population: A factorial definition of agoraphobia. Behavior Research and Therapy, vol. 18, 229-242. 
Arrindell W.A., Emmelkamp P.M.G., Monsma A. \& Brilman E. (1983)

The role of perceived parental rearing practices in the aetiology of phobic disorders: A controlled study. British Joumal of Psychiatry, vol. 143, 183-187.

Arrindell W.A., Emmelkamp P.M.G. \& van der Ende J. (1984)

Phobic dimensions: I. Reliability and generalizability across samples, gender and nations. Advances in Behavior Research and Therapy, vol. 6, 207-254.

Arrindell W.A. \& Emmelkamp P.M.G. (1985)

Psychological profile of the spouse of the female agoraphobic patient: Personality and symploms. British Joumal of Psychiatry, vol. 146, 405-414.

Arrindell W.A. \& Emmelkamp P.M.G. (1986)

Marital adjustment, intimacy and needs in female agoraphobics and their partners: A controlled study. British Joumal of Psychiatry, vol. 149, 592-602.

Arrindell W.A. \& Emmelkamp P.M.G. (1987a)

Psychological states and traits in female agoraphobics: A controlled study. Joumal of

Psychopathology and Behavioral Assessment, vol. 9, no. 3, 237-253.

Arrindell W.A. (1987b)

Marital Conflict and Agoraphobia: Fact or Fantasy? Dissertation University of Groningen.

Arrindell W.A., Kwee M.G.T., Methorst G.J. et al. (1989)

Perceived parental rearing styles of agoraphobic and socially phobic in-patients. British Journal of Psychiatry, vol. 155, 526-535.

Asso D. (1986)

The relationship between menstrual cycle changes in nervous system activity and psychological, behavioral and physical variables. Biological Psychology, vol. 23, 53-64.

Ayuso J.L., Alfonso S. \& Rivera A. (1989)

Childhood separation anxiety and panic disorder: A comparative study. Progress in Neuro-Psychopharmacology and Biological Psychiatry, vol. 13,665-671.

Bakker C.B. \& Bakker-Rabdau M.K. (1974)

Verboden Toegang: Verkenning rond het menselijk territorium. De Nederlandsche Boekhandel, Antwerpen/Amsterdam.

Ballenger J.C. (1990)

Efficacy of benzodiazepines in panic disorder and agoraphobia. Joumal of Psychiatric Research, vol. 24, suppl. 2, 15-25.

Bariow D.H., Mavissakalian M.R. \& Schoffield L.D. (1980)

Patterns of desynchrony in agoraphobia: A preliminary report. Behavior Research and Therapy, vol. 18, 441-448.

Barlow D.H., Cohen A.S., Waddell M.T. et al. (1984a)

Panic and generalized anxiety disorders: Nature and treatment. Behavior Therapy, vol. $15,431-449$.

Barlow D.H., O'Brien G.T. \& Last C.G. (1984b)

Couples treatment of agoraphobia. Behavior Therapy, vol. 15, 41-58.

Barlow D.H., Hayes S.C. \& Nelson R.O. (1984c)

The Scientist Practitioner: Research and accountability in clinical and educational settings. Pergamon Press, New York.

Barlow D.H. (1985)

The dimensions of anxiety disorders. In: Tuma A.H. \& Maser J. (Eds.) Anxiety and the Anxiety Disorders. Lawrence Frlbaum Ass. Publ., New Jersey/London, 479-500. 
Barlow D.H., Vermilyea J., Blanchard E.B. et al. (1985)

The phenomenon of panic. Joumal of Abnormal Psychology, vol. 94, no. 3, 320-328.

Barlow D.H., Di Nardo P.A., Vermilyea B.B. et al. (1986)

Comorbidity and depression among the anxiety disorders. The Journal of Nervous and

Mental Disease, vol. 174, no. 2, 63-72.

Barlow D.H. (1988)

Anxiety and its Disorders. Guilford Press, New York.

Barlow D.H. \& Craske M.G. (1988)

The phenomenology of panic. In: Rachman S. \& Maser J.D. (Eds.) Panic: Psychological Perspectives. Lawrence Erlbaum Associates, New Jersey, 11-35.

Barlow D.H., Craske M.G., Cerny J.A. \& Klosko J.S. (1989)

Behavioral treatment of panic disorder. Behavior Therapy, vol. 20, 261-282.

Başoğlu M., Marks I.M. \& Şengün S. (1992)

A prospective study of panic and anxiety in agoraphobia with panic disorder. British Journal of Psychiatry, 160, 57-64.

Beck A.T. (1988)

Cognitive approaches to panic disorder: theory and therapy. In: Rachman S. \& Maser J.D. (Eds.) Panic: Psychological Perspectives. Lawrence Erlbaum Associates, New Jersey, 91-109.

Bekker M. (1986)

Agorafobie in relatie tot de maatschappelijke positie van de huisvrouw. Tijdschrift voor Psychotherapie, vol. 12, no. 2, 94-104.

Benedikt M. (1870)

Uber Platzschwindel. Allgemeiner Wiener Medizinische Zeitung, vol. 15, 488.

Berg I., Marks I., Mc Guire R. \& Lipsedge M. (1974)

School phobia and agoraphobia. Psychological Medicine, vol. 4, 428-434.

Blaney P.H. (1986)

Affect and memory: A review. Psychological Bulletin, vol. 99, no. 2, 229-246.

den Boer J.A., Westenberg H.G.M., Kamerbeek W.D.J. et all. (1987)

Effect of serotonin uptake inhibitors in anxiety disorders: a double blind comparison of clomipramine and fluvoxamine. International Clinical Psychopharmacology, vol. 2, 2132.

den Boer J.A. (1988)

Serotonergic mechanisms in anxiety disorders: An inquiry into serotonin function in panic disorder. Dissertation, University of Utrecht.

den Boer J.A. \& Westenberg H.G.M. (1988)

Effect of a serotonin and noradrenaline uptake inhibitor in panic disorders: A double blind comparative study with fluvoxamine and maprotiline. International Clinical Psychopharmacology, vol. 3, 59-74.

Borkovec T.D. \& Mathews A.M. (1988)

Treatment of nonphobic anxiety disorders: A comparison of nondirective, cognitive, and coping desensitization therapy. Joumal of Consulting and Clinical Psychology, vol. 56, no. 6, 877-884.

Borden J.W. \& Tumer S.M. (1989)

Is panic a unique emotional experience? Behavior Research and Therapy, vol. 27, no. 3, 263-268. 
Boulenger J.Ph. \& Uhde T.W. (1987)

Crises aigues d'angoisse et phobies, aspects historiques et manifestations cliniques du syndrome d'agoraphobie. Annales Médico-Psychologiques, vol. 145, no. 2, 113-131.

Bourdon K.H., Boyd J.H., Rae D.S. et al. (1988)

Gender differences in phobias: Results of the ECA community survey. Joumal of Anxiety Disorders, vol. 2, 227-241.

Bowlby J. (1973)

Attachment and Loss: vol. 2 Separation, Anxiety and Anger. The Hogarth Press and the Institute of Psycho-Analysis. (reprint Pelican Books, 1985).

Boyd J.H., Burke J.D., Gruenberg E. et al. (1984)

Exclusion criteria of DSM III: A study of co-occurrence of hierarchy-free syndromes. Archives of General Psychiatry, vol. 42, 983-989.

Boyd J.H. (1986)

Use of mental health services for the treatment of panic disorder. American Journal of Psychiatry, vol. 143, no. 12, 1569-1574.

Brehony K.A. (1983)

Women and agoraphobia: A case for the etiological significance of the feminine sexrole stereotype. In: Franks V. \& Rothblum E.D. (Eds.) The Stereotyping of Women: Its effects on mental health. Springer Publ., New York, Springer Series: Focus on Women, vol. 5, 112-128.

Breier A., Chamey D.S. \& Heninger G.R. (1986)

Agoraphobia with panic attacks. Archives of General Psychiatry, vol. 43, 1029-1036.

Bronfenbrenner U. (1979)

The Ecology of Human Development: Experiments by nature and design. Harvard University Press, Cambridge.

Brown T.A. \& Cash T.F. (1989)

The phenomenon of panic in nonclinical populations: further evidence and methodological considerations. Joumal of Anxiety Disorders, vol. 3, 139-148.

Brown G.W. \& Harris T. (1978)

Social Origins of Depression: a study of psychiatric disorders in women. Tavistock Publishers, London.

Brunswick E. (1949)

Systematic and Representative Design of Psychological Experiments. University of Catlifornia Press, Berkeley/Los Angeles. cited in Hormuth (1986)

Buglass D., Clarke J., Henderson A.S. et al. (1977)

A study of agoraphobic housewives. Psychological Medecine, vol. 7, 73-86.

Cameron O.G., Thyer B.A., Nesse R.M. \& Curtis G.O. (1986a)

Symptom profiles of patients with DSM III anxiety disorders. American Journal of Psychiatry, vol. 143, no. 9, 1132-1137.

Cameron O.G., Lee M.A., Kotun J. \& McPhee K.M. (1986b)

Circadian symptom fluctuations in people with anxiety disorders. Journal of Affective Disorders, vol. 11, 213-218.

Cameron O.G., Kuttesch D. \& Mc Phee K. (1987)

Anxiety and the menstrual cycle. Neuroendocrinology Letters, vol. 173, 173.

Cameron O.G., Kuttesch D., McPhee K. \& Curtis G.C. (1988)

Menstrual fluctuations in the symptoms of panic anxiety. Journal of Affective Disorders, vol. 15, 169-174. 


\section{Chambless D.L. (1982)}

Characteristics of agoraphobics. In: Chambless D.L. \& Goldstein A.J. (Eds.) Agoraphobia: Multiple Perspectives on Theory and Treatment. J. Wiley \& Sons, New York, $1-18$.

Chambless D.L., Caputo G.C., Bright P. \& Gallagher R. (1984)

Assessment of fear of fear in agoraphobics: The Body Sensations Questionnaire and the Agoraphobic Cognitions Questionnaire. Joumal of Consulting and Clinical Psychology, vol. 52, 1090-1097.

Chambless D.L. (1985)

The relationship of severity of agoraphobia to associated psychopathology. Behavior Research and Therapy, vol. 23, no. 3, 305-310.

Chambless D.L. \& Mason J. (1986)

Sex, sex-role stereotyping and agoraphobia. Behavior Research and Therapy, vol. 24, no. $2,231-235$.

Chambless D.L. (1989)

Gender and phobias. In: Emmelkamp P.M.G., Everaerd W.T.A.M., Kraaimaat F. \& Son M.J.M. (Eds.) Fresh Perspectives on Anxiety Disorders. Annual Series of European Research in Behavior Therapy. Swets \& Zeitlinger, Lisse, 133-141.

Chambless D.L. \& Gracely E.J. (1989)

Fear of fear and the anxiety disorders. Cognitive Therapy and Research, vol. 13, no. 1. 9-20.

Chelune G.J., Robison J.T. \& Kommor M.J. (1984)

A cognitive interactional model of intimate relationships. In: Derlega V.J. (Ed.) Communication, Intimacy and Close relationships. Academic Press Inc., New York, 11-40.

Clark D.M., Salkovskis P.M. \& Chalkley A.J. (1985)

Respiratory control as a treatment for panic attacks. Joumal Behavior of Therapy and Experimental Psychiatry, vol. 16, no. 1, 23-30.

Clark D.M. (1988)

A cognitive model of panic attacks. In: Rachman S. \& Maser J.D. (Eds.) Panic: Psychological Perspectives. Lawrence Erlbaum Associates, New Jersey, 71-89.

Clark D.M., Salkovskis P.M., Gelder M. et al. (1988)

Tests of a cognitive theory of panic. In: Hand I. \& Wittchen H.U. (Eds.) Panic and Phobias II. Treatment and Variables Affecting Course and Outcome. Springer-Verlag, Berlin New York, 149-158.

Cox B.J., Norton G.R., Swinson R.P. \& Endler R.P. (1990)

Substance abuse and panic-related anxiety: A critical review. Behavior Research and Therapy, vol. 28, no. 5, 385-393.

Craske M.G., Rachman S.J. \& Tallman K. (1986)

Mobility, cognitions and panic. Journal of Psychopathology and Behavioral Assessment, vol. 8, no.3, 199-210.

Craske M.G., Sanderson W.C. \& Barlow D.H. (1987a)

The relationship among panic, fear and avoidance. Joumal of Anxiety Disorders, vol. $1,153-160$.

Craske M.G., Sanderson W.C. \& Barlow D.H. (1987b)

How do desynchronous response systems relate to the treatment of agoraphobia: $A$ follow-up evaluation. Behavior Research and Therapy, vol. 25, no. 2, 117-122. 
Craske M.G., Burton T. \& Barlow D.H. (1989)

Relationships among measures of communication, marital satisfaction and exposure during couples treatment of agoraphobia. Behavior Research and Therapy, vol. 27, no. 2, 131-140.

Craske M.G., Miller P.P., Rotunda R. \& Barlow D.H. (1990)

A descriptive report of features of initial unexpected panic attacks in minimal and extensive avoiders. Behavior Research and Therapy, vol. 28, no. 5, 395-400.

Cronbach L.J. (1970)

Essentials of Psychological Testing, Harper \& Row, New York.

Crowe R.R., Noyes R., Pauls D.L. \& Slymen D. (1983)

A family study of panic disorder. Archives of General Psychiatry, vol. 40, 1065-1069.

Csikszentmihalyi M. \& Larson R. (1984)

Being adolescent. Conflict and growth in the teenage years. Basic Books, New York.

(sikszentmihalyi M. \& Larson R. (1992)

Validity and reliability of the Experience Sampling Method. In: deVries (ed.) The Experience of Psychopathology. Cambridge University Press, New york, 43-57.

Da Costa J.M. (1871)

Irritable heart: The clinical study of a form of functional cardiac disorder and its consequences. American Joumal of Medical Sciences, vol. 71, 17-52.

Debets P. \& Brouwer E. (1986)

MSP: A program for Mokken scale analysis for polychotomous items. Amsterdam, Technisch Centrum.

Delle Fave A. \& Massimini F. (1992)

The Experience Sampling Method and the measuring of clinical change: A case of anxiety disorder. In: deVries (ed.) The Experience of Psychopathology. Cambridge University Press, New york, 280-289.

Delespaul P.A.E.G. \& deVries M.W. (1987)

The daily life of ambulatory chronic mental patients. In: deVries (ed.) The Experience of Psychopathology. Cambridge University Press, New york, 110-122.

Delespaul P.A.E.G. (1992)

Technical note: devices and time-sampling procedures. In: deVries (ed.) The Experience of Psychopathology. Cambridge University Press, New York, 363-373.

Deltito J.A., Perugi G., Maremmani I. et al. (1986)

The importance of separation anxiety in the differentiation of panic disorder from agoraphobia. Psychiatric Developments, vol. 3, 227-236.

Deutsch H. (1929)

The genesis of agoraphobia. The International Joumal of Psychoanalysis, vol. 10, 51 69.

deVries M.W., Berg R.L. \& Lipkin M. jr. (Eds.) (1982)

The Use and Abuse of Medecine. Praeger, New York.

deVries M.W., Delespaul Ph.A.E.G., Theunissen J. \& Dijkman C.I.M. (1986)

Temporal and situational aspects of severe mental disorders. In: Massimini F. \&

Inghillieri (Eds.) L'Esperienza Quotidiana. F. Angeli, Milano, 477-493.

deVries M.W. (1987)

Investigating mental disorders in their natural setting. Journal of Nervous and Mental

Disease, vol. 175, no. 9, 509-513. 
deVries M.W., Delespaul Ph.A.E.G. \& Dijkman C.L.M. (1987)

Affect and anxiety in daily life. In: Racagni G. \& Smeraldi E. (Eds.) Anxious

Depression: Assessment and Treatment, Raven Press, New York, 21-32.

deVries M.W., Dijkman C.I.M. \& Delespaul Ph.A.E.G. (1988)

De ontbrekende schakel: diagnostick in de natuurlijk omgeving. Tijdschrift voor Psy-

chiatrie, vol. 30 , no. 2, 94-113.

deVries M.W., Dijkman C.I.M. \& Delcspaul Ph.A.E.G. (1990)

The sampling of experience: A method of measuring the co-occurrence of anxiety and depression in daily life. In; Maser J.D. \& Cloninger C.R. (Eds.) Comorbidity of Mood and Anxiety Disorders, American Psychiatric Press, Washington D.C., 707726.

deVries M.W., Kaplan C., Dijkman-Caes C.I.M. \& Blanche P. (1991)

The experience of drug craving in daily life. In: Platt J. E. et al. (Eds) The Effectiveness of Drug Abuse Treatment. Krieger, Florida.

deVries M.W. (1992)

The Experience of Psychopathology. Cambridge University Press, New York.

deVries M.W. \& Delespaul Ph.A.E.G. (1992)

Variability in schizophrenia symptoms. In: deVries (ed.) The Experience of Psychopathology. Cambridge University Press, New York, 97-109.

deVries M.W., Delespaul Ph.A.E.G. \& Dijkman C.I.M. (1992)

Consequences of depression for the experience of anxiety in daily life. In: deVries (ed.) The Experience of Psychopathology. Cambridge University Press, New York, 129-140.

Dijkman C.I.M. \& deVries M.W. (1987)

The social ecology of anxiety. Theoretical and quantitative perspectives. Journal of Nervous and Mental Disease, vol. 175, no. 9, 550-557.

Dijkman C.I.M. \& deVries M.W. (1991)

Daily life situations and anxiety in panic disorder and agoraphobia. Journal of Anxiety Disorders, vol. 5, 343-357.

Dijkman C.I.M. (unpublished manuscript)

Resultaten vergelijking ESM en dagboeken $(\mathrm{N}=10)$. november 1987.

Dijkstra P. (1974)

De zelf-beoordelingsschaal voor depressie van Zung. In: van Praag H.M. \& Rooymans H.G.M. (Eds.) Stemming en Ontstemming: Theorie en praktijk bij de diagnostiek en behandeling van depressie. Erven Bohn, Amsterdam, 98-120.

Di Nardo P.A., O'Brien G.T., Barlow D.H. et al. (1983)

Reliability of DSM III anxiety disorder categories using a new structured interview. Archives of General Psychiatry, vol. 40, 1070-1074.

Di Nardo P.A. \& Barlow D.H. (1990)

Syndrome and symptom co-occurrence in the anxiety disorders. In: Maser J.D. \& Cloninger C.R. (Eds.) Comorbidity of Mood and Anxiety Disorders. American Psychiatric Press, Inc, Washington, 205-230.

Dixon W.J. (Ed.) (1990)

BMDP Statistical Software Manual, Vol. I \& II. BMDP Statistical Software, Inc., Los Angeles.

Eaton W.W. \& Kessler L.G. (Eds.) (1985)

Epidemiological Field Methods in Psychiatry. The NIMH Epidemiological Catchment Area Program. Academic Press, New York. 
Ehlers A., Margraf J. \& Roth W.T. (1986a)

Experimental induction of panic attacks. In: Hand I. \& Wittchen H.U. (Eds.) Panic and Phobias. Empirical Evidence of Theoretical Models and Longterm Effects of Behavioral Treatments. Springer-Verlag, Berlin/New York, 53-66.

Ehlers A., Margraf J., Davies S. \& Roth W.T. (1988a)

Selective processing of threat cues in subjects with panic attacks. Cognition and Emotion, vol. 2, no. 3, 201-219.

Ehlers A., Margraf J., Roth W.T. et al. (1988b)

Anxiety induced by false heart rate feedback in patients with panic disorder. Behavior Research and Therapy, vol. 26, no. 1, 1-11.

Ehlers A. \& Margraf J. (1989)

The psychophysiological model of panic attacks. In: Emmelkamp P.M.G., Everaerd W.T.A.M., Kraaimaat F. \& Son M.J.M. (Eds.) Fresh Perspectives on Anxiety Disorders. Annual Series of European Research in Behavior Therapy. Swets \& Zeitlinger, Amsterdam/Lisse, 1-29.

Emmelkamp P.M.G. (1990)

Anxiety and Fear. In: Bellack A.S., Hersen M. \& Kazdin A.E. (Eds.) International Handbook of Behavior Modification and Therapy (2nd ed.). Plenum Press, New York, 283-305.

Endler N.S. (1976)

The case for person-situation interactions. In: Endler N.S. \& Magnusson D. (Eds.) Interactional Psychology and Personality. Hemisphere Publ. Corp., Washington D.C., 58-70.

Erikson E.H. (1968)

Identity, Youth and Crisis. Norton Company, New York.

Eriksson E. (1987)

Brain neurotransmission in panic disorder. Acta Psychiatrica Scandinavia, vol. 76, suppl. 335, 31-37.

Faravelli C. (1985)

Life events preceding the onset of panic disorder. Journal of Affective Disorders, vol. 9, 103-105.

Faravelli C., Webb T., Ambonetti A. et al. (1985)

Prevalence of traumatic life events in 31 agoraphobic patients with panic attacks. American Journal of Psychiatry, vol. 142, no. 12, 1493-1494.

Faravelli C., Pallanti S., Frassine R. et al. (1988)

Panic attacks with and without agoraphobia: A comparison. Psychopathology, vol. 21, 51-56.

Faravelli C. \& Pallanti S. (1989)

Recent life events and panic disorder. American Joumal of Psychiatry, vol. 146, no. 5, 622-626.

Fava G.A., Grandi S. \& Canestrari R. (1988)

Prodromal symptoms in panic disorder with agoraphobia. American Joumal of Psychiatry, vol. 145, no. 12,1564-1567.

Filstead W., Reich W., Parrella D. \& Rossi J. (1985)

Using electronic pagers to monitor the process of recovery in alcoholics and drug abusers. Paper presented at the 34 th International Congress on Alcohol, Drug Abuse and Tobacco, Calgary, Alberta, Canada. 
Finlay-Jones R. \& Brown G.W. (1981)

Types of stressful life event and the onset of anxiety and depressive disorders. Psychological Medicine, vol. 11, 803-815.

Fisher L.M. \& Wilson G.T. (1985)

A study of the psychology of agoraphobia. Behavior Research and Therapy, vol. 23, no. 2, 97-107.

Fleming B. \& Faulk A. (1989)

Discriminating factors in panic disorder with and without agoraphobia. Joumal of Anxiety Disorders, vol. 3, 209-219.

Fodor I. (1974)

The phobic syndrome in women: Implications for treatment. In: Franks V. \& Burtle V. (Eds.) Women in Therapy. Brunner/Mazel Inc., New York.

Frances A. \& Dunn P. (1975)

The attachment-autonomy conflict in agoraphobia. International Journal of PsychoAnalysis, vol. 56, 435-439.

Freedman R., Janni P., Ettedgui E. \& Puthezhath N. (1985)

Ambulatory monitoring of panic disorder. Archives of General Psychiatry, vol. 42, 244-248.

Freud S. (1895)

On the grounds for detaching a particular syndrome from neurasthenia under the description 'anxiety neuroses'. In: J. Strachey (Ed.) The Standard Edition of the Complete Psychological Works of Sigmund Freud, Hogarth Press and the Institute of Psychoanalysis, London, 1962, vol. 3, 85-117.

Freud S. (1926)

Inhibitions, symptoms and anxiety. In: J. Strachey (Ed.) The Standard Edition of the Complete Psychological Works of Sigmund Freud, Hogarth Press and the Institute of Psychoanalysis, London, 1959, vol. 20. 75-175.

Fry W. (1962)

The marital context of an anxiety syndrome. Family Process, vol. 1, 245-252.

Gaffney F.A., Fenton B.J., Lane L.D. \& Lake C.R. (1988)

Hemodynamic, ventilatory, and biochemical responses of panic patients and normal controls with sodium lactate infusion and spontaneous panic attacks. Archives of General Psychiatry, vol. 45, 53-60.

Ganellen R.J., Matuzas W., Uhlenhuth E.H. et al. (1986)

Panic disorder, agoraphobia and anxiety relevant cognitive style. Journal of Affective Disorders, vol. 11, 219-225.

Garssen B., van Veenendaal W. \& Bloemink R. (1983)

Agoraphobia and the hyperventilation syndrome. Behavior Research and Therapy, vol. 21, no. 6, 643-649.

Garvey M.J. \& Tuason V.B. (1984)

The relationship of panic disorder to agoraphobia. Comprehensive Psychiatry, vol. 25, no. 5, 529-531.

Gittelman R. \& Klein D.F. (1984)

Relationship between separation anxiety and panic and agoraphobic disorders. Psychopathology, vol. 17, suppl. 1, 56-65.

Goldstein A.J. \& Chambless D.L. (1978)

A reanalysis of agoraphobia. Behavior Therapy, vol. 9, 47-59. 
Goldstein A.J. (1982)

Agoraphobia: treatment successes, treatment failures and theoretical implications. In: Chambless D.L. \& Goldstein A.J. (Eds.) Agoraphobia: Multiple Perspectives on Theory and Treatment. Wiley, New York, 183-213.

Good B.J. \& Kleinman A.M. (1985)

Culture and anxiety: Cross-cultural evidence for the patteming of anxiety disorders. In: Tuma A.H. \& Maser J. (Eds.) Anxiety and the Anxiety Disorders. Lawrence Erlbaum Ass. Publ., New Jersey/London, 297-323.

Gorman J.M., Askanazi J., Liebowitz M.R. et al. (1984)

Response to hyperventilation in a group of patients with panic disorder. American Journal of Psychiatry, vol. 141, no. 7, 857-861.

Gournay K. (1989)

The behavioural treatment of agoraphobia: The impact of sex role. In: Emmelkamp P.M.G., Everaerd W.T.A.M., Kraaimaat F. \& Son M.J.M. (Eds.) Fresh Perspectives on Anxiety Disorders. Annual Series of European Research in Behavior Therapy. Swets \& Zeitlinger, Amsterdam/Lisse, 143-150.

Gray J. (1971)

The Psychology of Fear and Stress. McGraw-Hill, New York.

Griez E. \& van den Hout M. (1982)

Effects of carbon dioxide oxygen inhalations on subjective anxiety and some neurovegetative parameters. Journal of Behavior Therapy and Experimental Psychiatry, vol. 13, 27-32.

Griez. E. \& van den Hout M. (1984)

Carbondioxide and anxiety. Dissertation - University of Limburg, Maastricht.

Griez E. \& van den Hout M. (1986)

$\mathrm{CO}_{2}$ inhalation in the treatment of panic attacks. Behavior Research and Therapy, vol. 24 , no. 2, 145-150.

Griez E., Lousberg H., van den Hout M.A. \& van der Molen G.M. (1987)

Carbon dioxide vulnerability in panic disorder. Psychiatry Research, vol. 20, 87-95.

Griez E., Zandbergen J., Pols H. \& de Loof C. (1990)

Response to $35 \% \mathrm{CO}_{2}$ as a marker of panic in severe anxiety. American Joumal of Psychiatry, vol. 147, no. 6, 796-797.

Gruppo Italiano Disturbi d'Ansia (1989)

Familial analysis of panic disorder and agoraphobia. Joumal of Affective Disorders, vol. 17, 1-8.

Guidano V.F. \& Liotti G. (1983)

Cognitive Processes and Emotional Disorders: A structural approach to psychotherapy. The Guilford Press, New York/London.

Gurguis G.N.M., Cameron O.G., Ericson W.A. \& Curtis G.C. (1988)

The daily distribution of panic attacks. Comprehensive Psychiatry, vol. 29, no. 1, 1-3.

Hafner R.J. (1982)

The marital context of the agoraphobic syndrome. In: Chambless D.L. \& Goldstein A.J. (Eds.) Agoraphobia: Multiple Perspectives on Theory and Treatment, Wiley, New York.

Hallam R.S. (1978)

Agoraphobia: A critical review of the concept. British Joumal of Psychiatry, vol. 133, 314-319. 
Hedlund M.A. \& Chambless D.L. (1990)

Sex differences and menstrual cycle effects in aversive conditioning: A comparison of premenstrual and intermenstrual women with men. Joumal of Anxiety Disorders, vol. 4, 221-231.

Hibbert G.A. (1984)

Ideational components of anxiety: Their origin and content. British Joumal of Psychiatry, vol. $144,618-624$.

Hibbert G. \& Pilsbury D. (1988)

Hyperventilation in panic attacks: Ambulant monitoring of transcutaneous carbon dioxide. Britisch Joumal of Psychiatry, vol. 153, 76-80.

Hibbert G. \& Pilsbury D. (1989)

Hyperventilation: Is it a cause of panic attacks? Britisch Joumal of Psychiatry, vol. $155,805-809$.

Himadi W.G., Cerny J.A., Barlow D.H. et al. (1986a)

The relationship of marital adjustment to agoraphobia treatment outcome. Behavior Research and Therapy, vol. 24, no. 2, 107-115.

Himadi W.G., Boice R. \& Barlow D.H. (1986b)

Assessment of agoraphobia II. Measurement of clinical change. Behavior Re-search and Therapy, vol. 24, no. 3, 321-332.

Himadi W.G. (1987)

Safety signals and agoraphobia. Journal of Anxiety Disorders, vol. 1, 345-360.

Hodgson R. \& Rachman S. (1974)

Desynchrony in measures of fear. Behavior Research and Therapy, vol. 12, 319-326.

Hoes M.J.A.J.M., Colla P., van Doom P. et al. (1987)

Hyperventilation and panic attacks. Joumal of Clinical Psychiatry vol. 48, no. 11 , 435-4.37.

Holden A.E. \& Barlow D.H. (1986)

Heart rate and heart rate variability recorded in vivo in agoraphobics and nonphobics.

Behavior Therapy, vol. 17, 26-42.

Hope D.A., Rapee R.M., Heimberg R.G. \& Dombeck M.J. (1990)

Representations of the self in social phobia: Vulnerability to social threat. Cognitive

Therapy and Research, vol, 14, no. 2, 177-189.

Hormuth S.E. (1985)

Methoden für psychologische Forschung im Fels. Diskussionspapier no. 43, Psychologischen Institut der Universität Heidelberg.

Hormuth S.E. (1992)

Experience Sampling and personality psychology: concepts and applications. In: deVries (ed.) The Experience of Psychopathology. Cambridge University Press, New York, 34-40.

Hosmer D.W. \& Lemeskow S. (1989)

Applied Logistic Regression. John Wiley \& Sons, New York.

van den Hout M.A \& Griez E. (1982a)

Cardiovascular and subjective responses to inhalation of carbon dioxide: a controlled

test with anxious patients. Psychotherapy and Psychosomatics, vol. 37, 75-82.

van den Hout M.A \& Griez E. (1982b)

Cognitive factors in carbon dioxide therapy. Journal of Psychosomatic Research, vol.

26 , no. $2,209-214$. 
van den Hout M.A \& Griez E. (1984)

Panic symptoms after inhalation of carbon dioxide. British Joumal of Psychiatry, vol. $144,503-507$.

van den Hout M.A \& Griez E. (1985)

Peripheral panic symptoms occur during changes in alveolar carbon dioxide. Compre-

hensive Psychiatry, vol. 26, no. 4, 381-387.

van den Hout M.A \& Griez E. (1986)

Experimental panic: Biobehavioral notes on empirical findings. In: Hand I. \& Wittchen

H.U. (Eds.) Panic and Phobias: Empirical evidence of theoretical models and longterm effects on behavioral treatments. Springer Verlag, New York, 44-52.

van den Hout M.A., van der Molen G.M., Griez E. et al. (1987a)

Reduction of $\mathrm{CO}_{2}$ induced anxiety in patients with panic attacks after repeated $\mathrm{CO}_{2}$ ex-

posure. American Joumal of Psychiatry, vol. 144, no. 6, 788-791.

van den Hout M.A., van der Molen G.M., Griez E. \& Lousberg H. (1987b)

Specificity of interoceptive fear to panic disorders. Journal of Psychopathology and Be-

havioral Assessment, vol. 9, no.1, 99-106.

van den Hout M.A (1988)

The explanation of experimental panic. In: Rachman S. \& Maser J.D. (Eds.) Panic:

Psychological Perspectives. Lawrence Erlbaum Associates, New Jersey, 237-257.

van den Hout M.A., Lavy I., Boek C. et al. (unpublished manuscript)

Aversive events in agoraphobic and non-agoraphobic places: Some indications of pre-

pared learning.

Humble M. (1987)

Aetiology and mechanisms of anxiety disorders. Acta Psychiatrica Scandinavia, vol.

76; suppl. $335,15-30$.

Hurlburt R.T. \& Melancon S.M. (1987)

'Goofed-up' images: Thought sampling with a schizophrenic woman. Joumal of Ner-

vous and Mental Disease, vol. 175, no. 9, 575-578.

Huston A.C. (1983)

Sex-typing. In: Mussen P.H. (Ed.) Handbook of Child Psychology, vol. 4: Hethering-

ton E.M. (volume ed.) Socialization, Personality and Social Development, Wiley, New

York, fourth edition, 387-467.

Ibrahim J.G. (1990)

Incomplete data in generalized linear models, J.A.S.A., vol. 85, 765-769.

Jansson L., Jerremalm A. \& Öst L.G. (1986)

Follow-up of agoraphobic patients treated with exposure in vivo or applied relaxation.

British Journal of Psychiatry, vol. 149, 486-490.

Johnson C. \& Larson R. (1982)

Bulimia: An analysis of moods and behavior. Psychosomatic Medicine, vol. 44, 341 351.

Johnson T.M. (1987)

Premenstrual syndrome as a western culture specific disorder. Culture, Medicine and

Psychiatry, vol. 11, 337-356.

Johnson J., Weissman M.M. \& Klerman G.L. (1990)

Panic disorder, comorbidity and suicide attempts. Archives of General Psychiatry, vol. 47, 805-808. 
Johnston D.G., Troyer I.E. \& Whitsett S.T. (1988)

Clomipramine treatment of agoraphobic women: An eight-week controlled trial. Archives of General Psychiatry, vol. 45, 453-459.

Kahn R.S. \& Westenberg H.G.M. (1985)

L-5-hydroxytryptophan in the treatment of anxiety disorders. Journal of Affective Disorders, vol. 8, 197-200.

Kaplan C.D. (1992)

Drug craving and drug use in the daily life of heroin addicts. In: deVries (ed.) The

Experience of Psychopathology. Cambridge University Press, New York, 193-218.

Katon W. (1986)

Panic Disorder: Epidemiology, diagnosis, and treatment in primary care. Journal of Clinical Psychiatry, vol. 47, no. 10, 21-27.

Katon W., Vitaliano, P.P., Russo J. et al. (1986)

Panic Disorder: Epidemiology in primary care. The Journal of Family Practice, vol. 23, no. 3, 233-239.

Katon W., Vitaliano P.P., Russo J., et al. (1987)

Panic disorder. Spectrum of severity and somatization. Journal of Nervous and Mental Disease, vol. 175, no. 1, 12-19.

Kenardy J., Evans L. \& Oei T.P.S. (1988)

The importance of cognitions in panic attacks. Behavior Therapy, vol. 19, 471-483.

Kenardy J., Evans L. \& Oei T.P.S. (1989)

Cognitions and heart rate in panic disorders during everyday activity. Journal of Anxiety Disorders, vol. 3, 33-43.

King R., Margraf J., Ehlers A. \& Maddock R. (1986)

Panic disorder: Overlap with symptoms of somatization disorder. In: Hand I. \& Wittchen H.U. (Eds.) Panic and Phobias I. Empirical Evidence of Theoretical Models and Longterm Effects of Behavioral Treatments. Springer-Verlag, Berlin New York, 72 77.

Klein D.F. (1964)

Delineation of two drug responsive anxiety syndromes. Psychopharmacologia, vol. 5, 397-408.

Klein D.F. (1980)

Anxiety reconceptualized. Comprehensive Psychiatry, vol. 21, no. 6, 411-427:

Klein D.F. \& Gorham J.M. (1987)

A model of panic and agoraphobic development. Acta Psychiatrica Scandinavia, vol. 76, suppl. 335, 87-95.

Klein D.F., Ross D.C. \& Cohen P. (1987)

Panic and avoidance in agoraphobia: Application of PATH analysis to treatment studies. Archives of General Psychiatry, vol. 44, 377-385.

Kleiner L. \& Marshall W.L. (1987)

The role of interpersonal problems in the development of agoraphobia with panic attacks. Journal of Anxiety Disorders, vol. 1, 313-323.

Kolk A.M.M. (1989)

Ontwikkelingsantecedenten van psychisch dysfunctioneren, in het bijzonder de fobie. Dissertation. University of Amsterdam. 
Kraan H.F., Meertens H., Hilwig M. et al. (1992)

Selecting measures, diagnostic validity and scaling in the study of depression. In: deVries M.W. (Ed.) The Experience of Psychopathology. Cambridge University Press, New York, 324-338.

Krieg J.C., Bronisch T., Wittchen H.U. \& von Zerssen D. (1987)

Anxiety disorders: A long term prospective and retrospective follow-up study of former inpatients suffering from an anxiety neurosis or phobia. Acta Psychiatrica Scandinavia, vol. 76, 36-47.

Kuczmierczyk A.R. \& Adams H.E. (1986)

Autonomic arousal and pain sensitivity in women with premenstrual syndrome at different phases of the menstrual cycle. Journal of Psychosomatic Research, vol. 30, no. 4, 421-428.

Larson R.W. (1990)

The solitary side of life: An examination of the time people spend alone from childhood to old age. Developmental Review, vol. 10, 155-183.

Larson R.W. \& Delespaul P.A.E.G. (1992)

Analyzing experience sampling data: A guidebook for the perplexed. In: de Vries M.W. (Ed.) The Experience of Psychopathology. Cambridge University Press, New York, 58-78.

Last C.G., Barlow D.H. \& O'Brien G.T. (1984a)

Precipitants of agoraphobia: Role of stressful life events. Psychological Reports, vol. 54, 567-570.

Last C.G., Barlow D.H. \& O'Brien G.T. (1984b)

Cognitive change during treatment of agoraphobia: Behavioral and cognitive-behavioral approaches. Behavior Modification, vol. 8, no. 2, 181-210.

Last C.G.. O'Brien G.T. \& Barlow D.H. (1985a)

The relationship between cognitions and anxiety: A preliminary report. Behavior Modification, vol. 9, no. 2, 235-241.

Last C.G., Barlow D.H. \& O'Brien G.T. (1985b)

Assessing cognitive aspects of anxiety: Stability over time and agreement between several methods. Behavior Modification, vol. 9, no. 1, 72-93.

Last C.G. \& Strauss C.C. (1989)

panic disorder in children and adolescents. Journal of Anxiety Disorders, vol. 3, 8795.

Leckmann J.F., Merikangas K.R., Pauls D.L. et al. (1983a)

Anxiety disorders and depression: Contradiction between family study data and DSM III conventions. American Journal of Psychiatry, vol. 140, no. 7, 880-882.

Leckmann J.F., Weissman M.M., Merikangas K.R. (1983b)

Panic Disorder and major depression: Increased risk of depression, alcoholism, panic and phobic disorders in families of depressed probands with panic disorder. Archives of General Psychiatry, vol. 40, 1055-1060.

Legrand du Saulle H. (1878)

Etude clinique sur la peur des espaces (agoraphobie des allemands) névrose émotive. Adrien Delahaye, Paris; cited in: Boulenger \& Unde, 1987.

Lelliot P. \& Marks I.M. (1988)

The cause and treatment of agoraphobia. Archives of General Psychiatry, vol. 45, 388392. 
Lesser I.M. (1988)

The relationship between panic disorder and depression. Journal of Anxiety Disorders, vol, 2, no. 1, 3-15.

Ley R. (1985)

Agoraphobia, the panic attack and the hyperventilation syndrome. Behavior Research and Therapy, vol. 23, no. 1, 79-81.

Lidz T. (1983)

The person: His and her development throughout the life cycle. Basic books, New York, third (revised) edition.

Liebowitz M.R., Fyer A.J., Gorman J.M. et al. (1984)

Lactate provocation of panic attacks: I. Clinical and behavioral findings. Archive's of General Psychiatry, vol. 41, 764-770.

Liebowilz M.R., Gorman J.M., Feyer A.J. et al. (1985)

Lactate provocation of panic attacks: II. Biochemical and physiological findings. Archives of General Psychiatry, vol. 42, 709-719.

Littlewood R. \& Lipsedge M. (1985)

Culture-bound syndromes. In: Granville-Grossman K., Recent Advances in Clinical Psychiatry, 5th edition, Churchill Livingstone, Edinburgh.

Littlewood R. \& Lipsedge M. (1987)

The butterfly and the serpent: Culture, psychopathology and biomedicine. Culture, Medicine and Psychiatry, vol. 11, no. 3, 289-337.

Loewenstein R.J., Hamilton J. Alagna S. et al. (1987)

Experience Sampling in the study of multiple personality disorder. American Journal of Psychiatry, vol. 144, 19-24.

de Loof C., Zandbergen J., Lousberg H. et al. (1989)

The role of life events in the onset of panic disorder. Behavior Research and Therapy, vol. 27, no. 4, 461-463.

Lydiard R.B. \& Ballenger J.C. (1988)

Panic-related disorders: Evidence for efficacy of the antidepressants, Journal of Anxiety Disorders, vol. 2, no. 1, 77-94.

Macaulay J.L. \& Kleinknecht R.A. (1989)

Panic and panic attacks in adolescents. Journal of Anxiety Disorders, vol. 3, 221-241.

Mannuza S., Fyer A.J., Martin L.Y. et al. (1989)

Reliability of anxiety assessment. I. Diagnostic agreement. Archives of General Psychiatry, vol. 46, 1093-1101.

Marchione K.E., Michelson L., Greenwald M. \& Darcu C. (1987)

Cognitive behavioral treatment of agoraphobia. Behavior Research and Therapy, vol. 25 , no. 5, 319-328.

Margraf J., Ehlers A. \& Roth W.T. (1986)

Sodium lactate infusions and panic attacks: A review and critique. Psychosomatic Medicine, vol. 48 , no. 1-2, 23-51.

Margraf J., Ehlers A. \& Roth W.T. (1987a)

Panic attack associated with perceived heart rate acceleration: A case report. Behavior Therapy, vol. 18, 84-89.

Margraf J., Taylor C.B., Ehlers A. et al. (1987b)

Panic attacks in the natural environment. Joumal of Nervous and Mental Disease. vol. 175 , no. 9, 558-565. 
Margraf J. \& Ehlers A. (1988)

Panic attacks in nonclinical subjects. In: Hand I. \& Wittchen H.U. (Eds.) Panic and

Phobias II. Treatment and Variables Affecting Course and Outcome. Springer-Verlag, Berlin New York, 103-116.

Margraf J. (1990)

Ambulatory psychophysiological monitoring of panic attacks. Joumal of Psychophysiology, vol. 4, 319-330.

Margraf J., Taylor C.B., Ehlers A. et al. (in preparation)

Clinical and psychophysiological characteristics of naturally occurring panic attacks. cited in Margraf (1990)

Markowitz J.S., Weissman M.M., Ouelette R. et al. (1989)

Quality of life in panic disorder. Archives of General Psychiatry, vol. 46, 984-992.

Marks I.M. (1970)

Agoraphobic syndrome (phobic anxiety state). Archives General Psychiatry, vol. 23, 538-553.

Marks I.M. \& Herst E.R. (1970)

A survey of 1200 agoraphobics in Britain. Social Psychiatry, vol. 5, 16-24.

Marks I.M. \& Mathews A.M. (1979)

Brief standard self-rating for phobic patients. Behavior Research and Therapy, vol. 17, 263-267.

Martin M., Ward J.C. \& Clark D.M. (1983)

Neuroticism and the recall of positive and negative personality information. Behavior

Research and Therapy, vol. 21, no. 5, 495-503.

Massimini F., Csikszentmihalyi M. \& Carli M. (1987)

The monitoring of optimal experience. A tool for psychiatric rehabilitation. Journal of Nervous and Mental Disease, vol. 175, no. 9, 545-549.

Mavissakalian M. \& Michelson L. (1983)

Self-directed in vivo exposure practice in behavioral and pharmacological treatments of agoraphobia. Behavior Therapy, vol. 14, 506-519.

Mavissakalian M. (1986)

The Fear Questionnaire: A validity study. Rehavior Research and Therapy, vol. 24, no. $1,83-85$.

Mavissakalian M. \& Hamann M.S. (1986)

Assessment and significance of behavioral avoidance in agoraphobia. Journal of Psychopathology and Behavioral Assessment, vol. 8, no. 4, 317-327.

Mavissakalian M. \& Michelson L. (1986)

Agoraphobia: Relative and combined effectiveness of therapist-assisted in vivo exposure and imipramine. Joumal of Clinical Psychiatry, vol. 47, no. 3, 117-122.

Mavissakalian M. (1987a)

Initial depression and response to imipramine in agoraphobia. The Journal of Nervous and Mental Disease, vol. 175, no. 6, 358-361.

Mavissakalian M. (1987b)

Trimodal assessment in agoraphobia research: Further observations on heart rate and synchrony/desynchrony, Joumal of Psychopathology and Behavioral Assessment, vol. 9, no. 1, 89-98.

Mavissakalian M. \& Hamann M.S. (1987)

DSM III personality disorder in agoraphobia II. Changes with treatment. Comprehensive Psychiatry, vol. 28, no. 4, 356-361. 
Mavissakalian M., Perel J., Bowler K. \& Dealy R. (1987)

Trazodone in the treatment of panic disorder and agoraphobia with panic attacks. American Journal of Psychiatry, vol. 144, no. 6, 785-787.

Mavissakalian M. (1988)

The mutually potentiating effects of imipramine and exposure in agoraphobia. In: Hand

I. \& Wittchen H.U. (Eds.) Panic and Phobias II. Treatment, and Variables Affecting Course and Outcome. Springer-Verlag, Berlin/ New York, 36-4.3.

Mavissakalian M. \& Hamann M.S. (1988)

Correlates of DSM III personality disorder in panic disorder and agoraphobia. Comprehensive Psychiatry, vol. 29, no. 6, 535-544.

McNally R.J. (1987)

Preparedness and phobias: a review. Psychological Bulletin, vol. 101, 283-303.

McNally R.J., Riemann B.C. \& Kim E. (1990)

Selective processing of threat cues in panic disorder. Behavior Research and Therapy, vol. 28 , no. $5,407-412$.

Mellman T.A. \& Uhde T.W. (1987)

Obsessive-compulsive symptoms in panic disorder. American Joumal of Psychiatry, vol. 144 , no. $12,1573-1576$.

Merckelbach H., de Ruiter C., van den Hout M.A. \& Hoekstra R.. (1989a)

Conditioning experiences and phobias. Behavior Research and Therapy, vol. 27, no. 6 , 657-662.

Merckelbach H., van den Hout M.A. \& van der Molen G.M. (1989b)

The phylogenetic origin of phobias: a review of the evidence. In: Emmelkamp P.M.G., Everaerd W.T.A.M., Kraaimaat F. \& Son M.J.M. (Eds.) Fresh Perspectives on Anxiety Disorders. Annual Series of European Research in Behavior Therapy. Swets \& Zeitlinger, Amsterdam/Lisse, 87-100.

van Meter K.M., deVries M.W., Kaplan C.D. \& Dijkman C.I.M. (1987)

States, syndromes and polythetic classes: The operationalization of cross-classification analysis in behavioral science research. Bulletin de Méthodologie Sociologique, vol. $15,22-38$.

Michels R., Frances A.J. \& Shear M.K. (1985)

Psychodynamic models of anxiety. In: Tuma A.H. \& Maser J.D. (Eds.) Anxiety and the Anxiety Disorders, Lawrence Erlbaum Ass. Publ., New Yersey/London, 595-618.

Michelson L. \& Mavissakalian M. (1985)

Psychophysiological outcome of behavioral and pharmacological treatments of agoraphobia. Joumal of Consulting and Clinical Psychology, vol. 53, no. 2, 229-236.

Micheison L., Mavissakalian M. \& Marchione K. (1985)

Cognitive and behavioral treatments of agoraphobia: Clinical, behavioral and psychophysiological outcomes. Journal of Consulting and Clinical Psychology, vol. 53, no. 6, 913-925.

Michelson L. (1986)

Treatment consonance and response profiles in agoraphobia: The role of individual differences in cognitive, behavioral and physiological treatments. Behavior Research and Therapy, vol. 24, no. 3, 263-275.

Michelson L., Mavissakalian M., Marchione K. et al. (1990a)

Psychophysiological outcome of cognitive, behavioral and psychophysiologically-based treatments of agoraphobia. Behavior Research and Therapy, vol. 28, no. 2, 127-139. 
Michelson L., Marchione K., Greenwald M. et al. (1990b)

Panic disorder: cognitive-behavioral treatment. Behavior Research and Therapy, vol. 28 , no. $2,141-151$.

Mineka S. (1985)

Animal models of anxiety based disorders: Their usefulness and limitations. In: Tuma A.H. \& Maser J.D. (Eds.) Anxiety and the Anxiety Disorders, Lawrence Erlbaum Ass. Publ., New Yersey/London, 199-244

Mizes I.S., Landolf-Fritsche B. \& Grossman-McKee D. (1987)

Patterns of distorted cognitions in phobic disorders: an investigation of clinically severe simple phobics, social phobics and agoraphobics. Cognitive Therapy and Research, vol. 11 , no. $5,583-592$.

Modigh K. (1987)

Antidepressant drugs in anxiety disorders. Acta Psychiatrica Scandinavia, vol. 76; suppl. 335, 57-71.

Mokken R.J. (1971)

A Theory and Procedure of Scale Analysis. Mouton, Paris/The Hague.

van der Molen G.M., van den Hout M.A., Vroemen J. et al. (1986)

Cognitive determinants of lactate induced anxiety. Behavior Research and Therapy, vol. 24 , no. $6,677-680$.

van der Molen G.M. \& van den Hout M.A. (1988)

Expectancy effects on respiration during lactate infusion. Psychosomatic Medecine, vol. 50, 439-443.

van der Molen G.M., Merckelbach H. \& van den Hout M.A. (1988)

The possible relation of the menstrual cycle to susceptibility to fear acquisition. Journal

of Behavior Therapy and Experimental Psychiatry, vol. 19, no. 2, 127-133.

van der Molen G.M., van den Hout M.A., van Dieren A.C. \& Ginez E. (1989)

Childhood separation anxiety and adult-onset panic disorders. Joumal of Anxiety Disorders, vol. 3, 97-1.06.

Mowser O.H. (1960)

Leaming Theory and Behavior. Wiley, New York.

Munjack D.J. \& Moss H.B. (1981)

Affective disorder and alcoholism in families of agoraphobics. Archives of General Psychiatry, vol. 38, 869-871.

Neenan P., Fellener J. \& Reich J. (1986)

Schizoid personality traits developing secondary to panic disorder. Joumal of Nervous and Mental Disease, vol. 174, no. 8, 483.

Nelson R.O. (1977)

Methodological issues in assessment via self-monitoring. In: Cone J.D. \& Hawkins R.P. (eds.) Behavioral Assessment: New directions in clinical psychology. Brunner/Mazel, New York, 217-240.

Nesse R.M. (1987)

An evolutionary perspective on panic disorder and agoraphobia. Ethology and Sociobiology, vol. $8,735-835$.

Nicolson N.A. (unpublished data)

Salivary cortisol dynamics in relation to self-reported anxiety and panic in anxiety outpatients. unpublished manuscript, 1988. 
Nicolson N.A. (1992)

Stress, coping and cortisol dynamics in daily life. In: deVries (ed.) The Experience of Psychopathology. Cambridge University Press, New York, 219-232.

Norton G.R., Harrison B., Hauch J. \& Rhodes L. (1985)

Characteristics of people with infrequent panic attacks. Journal of Abnormal Psychology, vol. 94, 216-221.

Norton G. R., Dorward J. \& Cox B.J. (1986)

Factors associated with panic attacks in nonclinical subjects. Behavior Therapy, vol. 17, 239-252.

Noyes R., Crowe R.R., Harris E.L. et al. (1986)

Relationship between panic disorder and agoraphobia: A family study. Archives of General Psychiatry, vol. 43, 227-232.

Noyes R., Clancy J., Garvey M.J. \& Anderson D. (1987)

Is agoraphobia a variant of panic disorder or a separate illness? Journal of Anxiety Disorders, vol. 1, 3-13.

Dei T.P.S., Gross P.R. \& Evans L. (1989)

Phobic disorders and anxiety states: How do they differ? Australian and New Zealand Joumal of Psychiatry, vol. 23, 81-88.

Oei T.P.S., Wanstall K. \& Evans L. (1990)

Sex differences in panic disorder with agoraphobia. Joumal of Anxiety Disorders, vol. 4, 317-324.

Öt L.G. \& Hugdahl K. (1983)

Acquisition of agoraphobia, mode of onset and anxiety response pattems. Behavior Research and Therapy, vol. 21, no. 6, 623-631.

Ottaviani R. \& Beck A.T. (1987)

Cognitive aspects of panic disorders, Joumal of Anxiety disorders, vol. 1, 15-28.

Parker G. (1979)

Reported parental characteristics of agoraphobics and social phobics. British Journal of Psychiatry, vol. 135, 555-560.

Payne C.D. (Ed.) (1986)

The GLIM System, Release 3.77, Generalized Linear Interactive Modelling, Numerical Algorhithms Group, Oxford.

Perugi G., Akiskal H., Deltito J. et al. (1988a)

Beyond DSM III: Re-evaluation of the concepts of panic, agoraphobia and generalized anxiety disorders. In: Roth M., Noyes R. jr and Burrows G.D. (Eds.) Handbook of Anxiety, vol. 1, Biological, Clinical and Cultural Perspectives. Elsevier Science Press, New York.

Perigi G., Deltito J., Soriani A. et al. (1988b)

Relationships between panic disorder and separation anxiety with school phobia. Comprehensive Psychiatry, vol. 29, no. 2, 98-107.

Peter H. \& Hand I. (1988)

Marital quality and treatment outcome in anxiety disorders. In: Hand I. \& Wittchen H.U. (Eds.) Panic and Phobias II. Treatment and Variables Affecting Course and Outcome. Springer-Verlag, Berlin/New York, 233-251.

Pitts F.N. \& Mc Clure J.N. (1967)

Lactate metabolism in anxiety neurosis. New England Joumal of Medicine, vol. 277. 1329-1336. 
van der Ploeg H.M., Defares P.B. \& Spielberger C.D. (1979)

Zelf-beoordelingsvragenlijst STAI versie DY, Swets \& Zeitlinger, Lisse.

Pollack M.H. \& Rosenbaum J.F. (1988)

Benzodiazepines in panic-related disorders. Journal of Anxiety Disorders, vol. 2, no. 1, 95-107.

Pollard C.A. \& Cox (j.L. (1988)

Social evaluative anxiety in panic disorder and agoraphobia. Psychological Reports, vol. $62,323-326$.

Pollard C.A., Pollard H.J. \& Corn K.J. (1989)

Panic onset and major events in the lives of agoraphobics: A test of contiguity. Joumal of Abnormal Psychology, vol. 98, no. 3, 318-321.

van Praag H.M. (1992)

Reconquest of the subjective. Against the waning of psychiatric diagnosing. British Joumal of Psychiatry, vol. 160, 266-271.

Rachman S. (1983)

The modification of agoraphobic avoidance behavior: Some fresh possibilities. Beha-

vior Research and Therapy, vol. 21, 567-574.

Rachman S. (1984a)

Agoraphobia: a safely signal perspective. Behavior Research and Therapy, vol. 22, no. 1, 59-70.

Rachman S. (1984b)

The experimental analysis of agoraphobia. Behavior Research and Therapy, vol. 22, no. $6,631-640$.

Rachman S., Craske M., Tallman K. \& Solyom C. (1986)

Does escape behavior strengthen agoraphobic avoidance? A replication. Behavior Therapy, vol. 17, 366-384.

Rachman S., Levitt K. \& Lopatka C. (1987)

Panic: The links between cognitions and bodily symptoms I. Behavior Research and

Therapy, vol. 25 , no. 5, 411-423.

Rapee R. (1986)

Differential response to hyperventilation in panic disorder and generalized anxiety disorder. Joumal of Abnormal Psychology, vol. 95, no. 1, 24-28.

Rapee R.M., Mattick R. \& Murrell E. (1986)

Cognitive mediation in the affective component of spontaneous panic attacks. Joumal of Behavior Therapy and Experimental Psychiatry, vol. 17, no. 4, 245-253.

Rapee R.M. \& Murrell E. (1988)

Predictors of agoraphobic avoidance. Joumal of Anxiety Disorders, vol, 2, 203-217.

Rapee R.M., Sanderson W.C. \& Barlow D.H. (1988)

Social phobia features across the DSM III (R) anxiety disorders. Joumal of Psychopathology and Behavioral Assessment, vol. 10, no. 3, 287-299.

Rapee R.M., Litwin E.M. \& Barlow D.H. (1990a)

Impact of life events on subjects with panic disorder and on comparison subjects.

American Journal of Psychiatry, vol. 147, no. 5, 640-644.

Rapee R.M., Craske M.G. \& Barlow D.H. (1990b)

Subject-described features of panic attacks using self-monitoring. Joumal of Anxiety

Disorders, vol. 4, 171-181. 
Raskin M., Peeke H.V.S., Dickman W. \& Pinsker H. (1982)

Panic and generalised anxiety disorders: developmental antecedents and precipitants. Archives of General Psychiatry, vol. 39, 687-689.

Reich J., Noyes R. jr. \& Troughton E. (1987)

Dependent personality disorder associated with phobic avoidance in patients with panic disorder. American Joumal of Psychiatry, vol. 144, no. 3, 323-326.

Reis H.T. \& Shaver P. (1988)

Intimacy as an interpersonal process. In: Duck S. W. (Ed.) Handbook of Personal Relationships, Wiley, New York, 367-389.

Reis H.T. (1990)

The role of intimacy in interpersonal relations. Joumal of Social and Clinical Psychology, vol. 9, no. 1, 15-30.

Regier D.A., Myers J.K., Kramer M. et al. (1984)

The NIMH Epidemiological Cátchment Area Program. Historical context, major objec tives and study population characteristics. Archives of General Psychiatry, vol. 41, 934-941.

Richards M.H. \& Larson R. (1989)

The life space and socialization of the self: Sex differences in the young adolescent. Joumal of Youth and adolescence, vol. 18, no. 6, 617-626.

Richters A. (1988)

Psychiatrische classificering en geestelijke gezondheid: een feministisch antropologische kritiek. In: J. Rolies (Ed.), De Gezonde Burger: Gezondheid als norm, SUIN, Nijmegen.

Rijken H., de Ruiter C., Garssen B. \& Kraaimaat F. (1990)

Sexe en agorafobie. Gedragstherapie, vol. 23, no. 3, 155-165.

Roberts A.H. (1964)

Housebound housewives: A follow up of phobic anxiety states. British Joumal of Psychiatry, vol. 110, 191-197.

Robins L.N., Helzer J.E., Croughan J. et al. (1981)

NIMH Diagnostic Interview Schedule. Its history, characteristics and validity. Archives of General Psychiatry, vol. 38, 381-389.

Roy-Byme P.P., Geraci M. \& Uhde T.W. (1986a)

Life events and the onset of panic disorder. American Joumal of Psychiatry, vol. 143, no. 11, 1424-1427.

Roy-Byme P.P., Geraci M. \& Uhde T.W. (1986b)

Life events and course of illness in patients with panic disorder, American Journal of Psychiatry, vol. 1423, no. 8, 1033-1035.

Rubinow D.R. \& Roy-Byme P. (1984)

Premenstrual syndromes: overview from a methodological perspective. American Journal of Psychiatry, vol. 141, no. 2, 163-172.

Rubinow D.R., Roy-Byme P., Hoban C. et al. (1984)

Prospective assessment of menstrually related mood disorders. American Journal of Psychiatry, vol. 141, no. 5, 684-686.

de Ruiter C., Rijken H., Garssen B. et al. (1987)

Paniekstoornis en agorafobie vergeleken. Gedragstherapie, vol. 20, no. 4, 257-269. 
de Ruiter C. \& Garssen B. (1989)

Social anxiety and fear of bodily sensations in panic disorder and agoraphobia: A matched comparison. Journal of Psychopathology and Behavioral Assessment, vol. 11, no. 2, $175-184$.

de Ruiter C., Rijken H., Garssen B. et al. (1989a)

Comorbidity among the anxiety disorders. Joumal of Anxiety Disorders, vol. 3, 5758.

de Ruiter C., Garssen B., Rijken H. \& Kraaimaat F. (1989b)

The hyperventilation syndrome in panic disorder, agoraphobia and generalized anxiety disorder. Behavior Research and Therapy, vol. 27, 447-452.

de Ruiter C., Garssen B., Rijken H. \& Kraaimaat F. (1989c)

Fear of bodily sensations in anxiety disorder patients. In: Emmelkamp P.M.G., Everaerd W.T.A.M., Kraaimaat F. \& Son M.J.M. (Eds.) Fresh Perspectives on Anxiety Disorders. Annual Series of European Research in Behavior Therapy. Swets \& Zeitlinger, Amsterdam/Lisse, 235-241.

Sanderson W.C., Rapee R.M. \& Barlow D.H. (1989)

The influence of an illusion of control on panic attacks induced via inhalation of $5.5 \%$ carbon dioxide enriched air. Archives of General Psychiatry, vol. 46, 157-162.

Schenkler B.R. (1984)

Identities, identifications and relationships. In: Derlega V.J. (Ed.) Communication, Intimacy and Close Relationships. Academic Press Inc., New York, 71-104.

Schneier F.R., Fyer A.J., Martin L.Y. et al. (1991)

A comparison of phobic subtypes within panic disorder. Joumal of Anxiety Disorders, vol. $5,65-75$.

Seligman (1971)

Phobias and preparedness. Behavior Therapy, vol. 2, 307-321.

Shear M.K., Kligfield P., Harshfield G. et al. (1987)

Cardiac rate and rhythm in panic patients. American Joumal of Psychiatry, vol. 144, no. 5, 633-6.37.

Shear M.K., Polan J.J., Harshfield G. et al. (unpublished data)

Ambulatory monitoring of blood pressure and heart rate in panic patients. cited in: Margraf J. (1990)

Sheehan D.V., Ballenger J. \& Jacobsen G. (1980)

Treatment of endogeneous anxiety with phobic, hysterical and hypochondrical symptoms. Archives of General Psychiatry, vol. 37, 51-59.

Sheehan D.V., Sheehan K.E. \& Minichiello W.E. (1981)

Age of onset of phobic disorders: A reevaluation. Comprehensive Psychiatry, vol. 22, no. $6,544-553$.

Sheehan D.V. (1982)

Panic attacks and phobias. New England Journal of Medicine, vol. 307, 156-158.

Siegel L., Jones W.C. \& Wilson J.D. (1990)

Economic and life consequences experienced by a group of individuals with panic disorder. Joumal of Anxiety Disorders, vol. 4, 201-211.

Sijtsma K. \& Molenaar I.W. (1987)

Reliability of test scores in nonparametric item response theory. Psychometrika, vol. 52 , no. $1,79-97$. 
Silove D. (1986)

Perceived parental characteristics and reports of early parental deprivation in agoraphobic patients. Australian and New Zealand Joumal of Psychiatry, vol. 20, 365-369.

Slade P. (1984)

Premenstrual emotional changes in normal women: Fact or fiction? Joumal of Psychosomatic Research, vol. 28, no. 1, 1-7.

Solyom L., Ledwidge B. \& Solyom C. (1986)

Delineating social phobia. British Joumal of Psychiatry, vol. 149, 464-470.

Spence J.T. \& Helmreich R.L. (1978)

Masculinity \& Femininity: Their Psychological dimensions, correlates and antecedents.

University of Texas Press, Austin/London.

Spielberger C.D., Gorsuch R.L. \& Lushene R.E. (1970)

STAI-Manual for the State-Trait Anxiety Inventory. Consulting Psychologist Press, Inc.

Stein M.B., Shea C.A. \& Uhde T.W. (1989a)

Social phobic symptoms in patients with panic disorder: Practical and theoretical implications. American Journal of Psychiatry, vol. 146, no. 2, 235-238.

Stein M.B., Schmidt P.J., Rubinow D.R. \& Uhde T.W. (1989b)

Panic disorder and the menstrual cycle: Panic disorder patients, healthy control subjects, and patients with premenstrual syndrome. American Joumal of Psychiatry, vol. 146 , no. $10,1299-1303$.

Stokman F. \& van Schuur W. (1980)

Basic scaling. Quality and Quantity, vol. 14, 5-30.

Street L.L., Craske M.G. \& Barlow D.H. (1989)

Sensations, cognitions and the perception of cues associated with expected and unexpected panic attacks. Behavior Research and Therapy, vol. 27, no. 2, 189-198.

de Swaan A. (1981)

The politics of agoraphobia: On changes in emotional and relational management. Theory \& Society, vol. 10, 359-385.

Symonds A. (1981)

Phobias after marriage: Women's declaration of dependence. In: Howell E. \& Bayes M. (Eds.) Women and Mental Health. Basic Books, New York, 228-239.

Tan E.S. (1988)

Transcultural aspects of anxiety. In: Roth M., Noyes R. jr and Burrows G.D. (Eds.) Handbook of Anxiety, vol. 1, Biological, Clinical and Cultural Perspectives. Elsevier Science Press, New York.

Taylor C.B., Telch M.J. \& Havvik D. (1983)

Ambulatory heart rate changes during panic attacks. Journal of Psychiatric Research, vol, 17, no. 3, 261-266.

Taylor C.B., Sheikh J., Agras W.S. et al. (1986)

Ambulatory heart rate changes in patients with panic attacks. American Journal of Psychiatry, vol. 143 , no. $4,478-482$.

Taylor C.B., Fried L. \& Kenardy J. (1990)

The use of a real-time computer diary for data acquisition and processing. Behavior Research and Therapy, vol. 28, no. 1, 93-97.

Telch M.J., Agras W.S., Taylor C.B. et al. (1985)

Combined pharmacological and behavioral treatment for agoraphobia. Behavior Research and Therapy, vol. 23 , no. 3, 325-335. 
Teich M.J., Brouillard M, Telch C.F. et al. (1989)

Role of cognitive appraisal in panic related avoidance. Behavior Research and Therapy, vol. 27 , no. $4,373-383$.

Thompson J.W., Bums B.J., Bartko J. et al. (1988)

The use of ambulatory services by persons with and without phobia. Medical Care, voll. 26, no. 2,183-198.

Thompson A.H., Bland R.C. \& Om H.T. (1989)

Relationship and chronology of depression, agoraphobia, and panic disorder in the general population. The Journal of Nervous and Mental Disease, vol. 177, no. 8, 456463.

Thorpe G.L. \& Burns L.E. (1983)

The Agoraphobic Syndrome: Behvioral Approaches to Evaluation and Treatment. Wiley, New York.

Thyer B.A., Himle J., Curtis G.C. et al. (1985)

A comparison of panic disorder and agoraphobia with panic attacks. Comprehensive Psychiatry, vol. 26, no. 2, 208-214.

Thyer B.A. \& Himle J. (1987)

Phobic anxiety and panic anxiety: How do they differ? Journal of Anxiety Disorders, vol. 1, 59-67.

Thyer B.A., Himle J. \& Fischer D. (1988)

Is parental death a selective precursor to either panic disorder or agoraphobia? A test of the separation anxiety hypothesis. Journal of Anxiety Disorders, vol. 2, 333-338.

Torgersen S. (1983)

Genetic factors in anxiety disorders. Archives of General Psychiatry, vol. 40, 10851089.

Torgersen S. (1990)

Comorbidity of major depression and anxiety disorders in twin pairs. American Journal of Psychiatry, vol. 147, no. 9, 1199-1202.

Tumer S.M., Williams S.L., Beidel D.C. \& Mezzich J.E. (1986a)

Panic disorder and agoraphobia with panic attacks: Covariation along the dimensions of panic and agoraphobic fear. Journal of Abnormal Psychology, vol. 95, no. 4, 384388.

Tumer S.M., Mc Cann B.S., Beidel D.C. \& Mezzich J.E. (1986b)

DSM III classification of the anxiety disorders: a psychometric study. Journal of Abnormal Psychology, vol. 95, no. 2, 168-172.

Turpin G. (1985)

Ambulatory psychophysiological monitoring: Techniques and applications. In: Papakostopoulos D., Butler S. \& Martin I. (eds.) Experimental and Clinical Neuropsychophysiology. Croom Helm, London, 695-728.

Tweed J.L., Schoenbach V.J., George L..K. \& Blazer D.G. (1989)

The effects of childhood parental death and divorce on six-month history of anxiety disorders. British Joumal of Psychiatry, 154, 823-828.

Uhde T.W., Boulenger J.Ph., Roy-Byme P.P. et al. (1985a)

Longitudinal course of panic disorder: Clinical and biological considerations. Progress in Neuro-psychopharmacology and Biological Psychiatry, vol. 9, 39-51. 
Uhde T.W., Roy-Byrne P.P., Vittone B.J. et al. (1985b)

Phenomenology and neurobiology of panic disorder. In: Tuma A.H. \& Maser J. (Fds.) Anxiety and the Anxiety Disorders, Lawrence Frlbaum Ass. Publ., New Yer. sey/London, 557-576.

Vermilyea J.A., Boice R. \& Barlow D.H. (1984)

Rachman \& Hodgson (1974) a decade later: How do desynchronous response systems relate to the treatment of agoraphobia? Behavior Research and Therapy, vol. 22, no. $6,615-621$.

de Waal M. (1989)

Meisjes, een wereld apart: een etnografie van meisjes op de middelbare school. Boom Meppel, Amsterdam.

Waddell M.T., Barlow D.H. \& O'Brien G.T. (1984)

A preliminary investigation of cognitive and relaxation treatment of panic disorder: Effects on intense anxiety vs 'background' anxiety. Behavior Research and Therapy, vol. 22 , no. 4, 393-402.

Weissman M.M. \& Merikangas K.R. (1986)

The epidemiology of anxiety and panic disorders: An update. Journal of Clinical Psychiatry, vol. 47, no. 6 (suppl), 11-17.

Weissman M.M., Leaf P.S., Blazer D.G. et al. (1986)

The relationship between panic disorder and agoraphobia: An epidemiological perspec tive. Psychopharmacology Bulletin, vol. 22, no. 3, 787-791.

Weissman M.M., Klerman G.L., Markowitz J.S. \& Ouellette R. (1989)

Suicidal ideation and suicide attempts in panic disorder and attacks. The New England Journal of Medicine, vol. 321, no. 18, 1209-1214.

Westphal C. (1872)

Die Agoraphobie: eine neuropatische Erscheinung. Archiv für Psychiatrie und Nervenkrankheiten, vol. 3, 138-161.

White W.B. \& Baker L.H. (1986)

Episodic hypertension secondary to panic disorder. Archives of Internal Medicine, vol. $146,1129-1130$.

Wilcoxon L.A., Schrader S.L. \& Sherif C.W. (1976)

Daily self-reports on activities, life events, moods and somatic changes during the menstrual cycle. Psychosomatic Medicine, vol. 38, no. 6, 399-417.

Wilkinson, L. (1988)

SYSTAT: The System for Statistics. Evanston, IL SYSTAT, Inc.

Wittchen H.U. (1986)

Epidemiology of panic attacks and panic disorders. In: Hand I. \& Wittchen H.U. (Eds.) Panic and Phobias I. Empirical Evidence of Theoretical Models and Longterm Effects of Behavioral Treatments. Springer-Verlag. Berlin/ New York, 18-28.

Wittchen H.U. (1988)

Natural course and spontaneous remissions of untreated anxiety disorders: Results of the Munich Follow-up Study. In: Hand I. \& Wittchen H.U. (Eds.) Panic and Phobias II. Treatment and Variables Affecting Course and Outcome. Springer Verlag, Berlin/New York, 3-17.

Wittchen H.U. \& von Zerssen D. (1988)

Verläufe behandelter und unbehandelter Depressionen und Angststörungen. Eine klinisch-psychiatrische und epidemiologische Verlaufsuntersuchung. Springer Verlag, Berlin/New York. 
Wolfe B.E. (1984a)

Gender ideology and phobias in women. In: Spatz Widom C. (Ed.) Sex Roles and Psychopathology, Plenum Press, New York/London, 51-72.

Wolfe B.E. (1984b)

Gender imperatives, separation anxiety and agoraphobia in women. Integrative Psychiatry, no. 2, 57-6॥.

Woipe J. (1981)

The dichotomy between classical conditioned and cognitively learned anxiety. Joumal of Behavior Therapy and Experimental Psychiatry, vol. 12, no. 1, 35-42.

Woods S.W., Charney D.S., Loke J. et al. (1986)

Carbon dioxide sensitivity in panic anxiety: Ventilatory and anxiogenic response to carbon dioxide in healthy subjects and patients with panic anxiety before and after alprazolam therapy. Archives of General Psychiatry, vol. 43, 900-909.

Woods S.W., Chamey D.S., McPherson C.A. et al. (1987)

Situational panic attacks: Behavioral, physiological and biochemical characterization. Archives of General Psychiatry, vol. 44, 365-375.

Zitrin C.M., Klein D.F. \& Woemer M.G. (1980)

Treatment of agoraphobia with group exposure in vivo and imipramine. Archives of General Psychiatry, vol. 37, 63-72.

Zitrin C.M., Klein D.F., Woerner M.G. \& Ross D.C. (1980)

Treatment of phobias: I. Comparison of imipramine hydrochloride and placebo. Archives of General Psychiatry, vol. 40, 125-138.

Zung W.W.K. (1965)

A self-rating depression scale. Archives of General Psychiatry, vol. 12, 63-70.

Zung W.W.K., Richards C.B. \& Short M.J. (1965)

Self-rating depression scale in an outpatient clinic. Archives of General Psychiatry, vol. 13, 508-509.

van Zuuren F.J. (1982)

Fobie, Situatie en Identiteit: een studie over de situatievernijding en identiteitsproblematiek van 2 soorten fobici. Dissertation, University of Amsterdam.

van Zuuren F.J. (1983)

De verwevenheid van fobische angsten met maatschappelijke rollen. In: Visser A.P., van de Vliert E., ter Heine E.J.H. \& Winnubst J.A.N. (Eds.) Rollen. Persoonlijke en sociale invloeden op het gedrag. Boom/Meppel.

van Zuuren F.J. (1987)

Personality differences within a diagnostic entity: Types of phobia in men and women.

Personality and Individual Differences, vol. 8, no. 1, 101-111.

van Z.uuren F.J. (1988)

The Fear Questionnaire: Some data on validity, reliability and layout. British Joumal of Psychiatry, vol. 153, 659-662. 
Appendix 1 DSM III(R) diagnostic criteria (APA, 1987, p. 235-241)

\section{Diagnostic criteria for Panic Disorder}

A. At some time during the disturbance, one or more panic attacks (discrete periods of intense fear or discomfort) have occurred that were (1) unexpected, i.e., did not ociur immediately before or on exposure to a situation that almost always caused anxicty, and (2) not triggered by situations in which the person was the focus of others attention.

B. Either four attacks, as defined in criterion A, have occurred within a four-week period, or one or more altacks have been followed by a period of at least a month of persistent fear of having another attack.

C. At least four of the following symptoms developed during at least one of the attacks:

(1) shortness of breath (dyspnea) or smothering sensations

(2) dizziness, unsteady feelings, or faintness

(3) palpitations or accelerated heart rate (tachycardia)

(4) trembling or shaking

(5) sweating

(6) choking

(7) nausea or abdominal distress

(8) depersonalization or derealization

(9) numbness or tingling sensations (paresthesias)

(10) flushes (hot flashes) or chills

(11) chest pain or discomfort

(12) fear of dying

(13) fear of going crazy, or doing something uncontrolled

D. During at least some of the attacks, at least four of the $C$ symptoms developed suddenly and increased in intensity within ten minutes of the beginning of the first $\mathrm{C}$ symptom noticed in the attack.

E. It cannot be established that an organic factor initiated and maintained the disturbance, e.g. Amphetamine or Caffeine Intoxication, hyperthyroidism.

\section{Diagnostic criteria for 300.21 Panic Disorder with Agoraphobia}

A. Meets the criteria for Panic Disorder.

B. Agoraphobia: Fear of being in places or situations from which escape might be difficult (or embarrassing) or in which help might not be available in the event of a panic attack. (Include cases in which persistent avoidance behavior originated during an active phase of Panic Disorder, even if the person does not attribute the avoidance behavior to fear of having a panic attack.) As a result of this fear, the person either restricts travel or needs a companion when away from home, or else endures agoraphobic situations despite intense anxiety. Common agoraphobic situations include being outside the home alone, being in a crowd or standing in a line, being on a bridge, and traveling in a bus, train, or car.

\section{Diagnostic criteria for 300.01 Panic Disorder without Agoraphobia}

A. Meets the criteria for Panic Disorder.

B. Absence of Agoraphobia, as defined above. 


\section{Appendix 2 ESM report}

What do I think?

This thought is

pleasant

clear

agitated

normal

\begin{tabular}{ccccccc} 
not & \multicolumn{2}{c}{ a little } & \multicolumn{3}{c}{ rather } & \multicolumn{1}{r}{ very } \\
1 & 2 & 3 & 4 & 5 & 6 & 7 \\
1 & 2 & 3 & 4 & 5 & 6 & 7 \\
1 & 2 & 3 & 4 & 5 & 6 & 7 \\
1 & 2 & 3 & 4 & 5 & 6 & 7
\end{tabular}

I feel

cheerful

uncertain

lonely

relaxed

anxious

angry

complaint 1 troubles me

complaint 2 troubles me

$\begin{array}{lllllll}1 & 2 & 3 & 4 & 5 & 6 & 7 \\ 1 & 2 & 3 & 4 & 5 & 6 & 7 \\ 1 & 2 & 3 & 4 & 5 & 6 & 7 \\ 1 & 2 & 3 & 4 & 5 & 6 & 7 \\ 1 & 2 & 3 & 4 & 5 & 6 & 7 \\ 1 & 2 & 3 & 4 & 5 & 6 & 7\end{array}$

I feel short of breath, choking

I have palpitations, pain on the chest

I feel weak, dizzy, unsteady

I feel unreal

I am afraid to die, to go crazy

$\begin{array}{lllllll}1 & 2 & 3 & 4 & 5 & 6 & 7\end{array}$

$\begin{array}{lllllll}1 & 2 & 3 & 4 & 5 & 6 & 7\end{array}$

or to lose control

$\begin{array}{lllllll}1 & 2 & 3 & 4 & 5 & 6 & 7\end{array}$

$\begin{array}{lllllll}1 & 2 & 3 & 4 & 5 & 6 & 7\end{array}$

$\begin{array}{lllllll}1 & 2 & 3 & 4 & 5 & 6 & 7\end{array}$

$\begin{array}{lllllll}1 & 2 & 3 & 4 & 5 & 6 & 7\end{array}$

Where am I now?

How far from home is this? ..... km

With whom am I?

How many men? ..... women? ..... children? ...... 
What am I doing?

I'd like to do something else

I'm active

$I ' m$ in control

I can't concentrate

\begin{tabular}{|c|c|c|c|c|c|c|}
\hline not & & little & & rathe & & very \\
\hline 1 & 2 & 3 & 4 & 5 & 6 & \\
\hline 1 & 2 & 3 & 4 & 5 & 6 & \\
\hline 1 & 2 & 3 & 4 & 5 & 6 & \\
\hline 1 & 2 & 3 & 4 & 5 & 6 & \\
\hline 1 & 2 & 3 & 4 & 5 & 6 & \\
\hline 1 & 2 & 3 & 4 & 5 & 6 & \\
\hline , & 2 & 3 & 4 & 5 & 6 & \\
\hline
\end{tabular}

I'm standing / lying down / sitting / walking around (circle your choice)

I used nothing / alcohol / medication / coffee /

This beep was disturbing

$\begin{array}{lllllll}1 & 2 & 3 & 4 & 5 & 6 & 7\end{array}$

It is now ..... $\mathrm{h} \ldots . . \mathrm{min}$

Notes: 


\section{Appendix 3 Coding system}

\section{Types of situations}

solitary situations $\quad 1.0$

alone at home $\quad 1.1$

alone elsewhere, e.g. work, house of friends, ...

intimate siluations $\quad 2.0$

at home with own family, household members 2.1

at home with relatives, friends,... 2.2

visiting relatives, friends, ... 2.3

personal situations (without significant others) $\quad 4.0$

group matters: party, reception, sports club,... 4.1

together with hairdresser, client,...

work/school 4.3

health care setting $\quad 4.4$

personal situations with significant others are coded as 'else'

anonymous situations with significant others (family, friends) $\quad 5.0$

public places (shop, post office, in the streets) 5.1

transport (car, bus, train, ...) $\quad 5.2$

anonymous situations without significant others 0.0

public places 6.1

transport $\quad 6.2$

else $\quad 8.8$

2. transition? yes $=1$

no $=0$

transition from one situation to another, e.g. going away from home with mother $=$ transition from intimate to anonymous situation with significant other

3. acknowledgement?

3.a. by other people - with whom?

low alone/with strangers/an unspecified other $\quad 0$

moderate with relatives/friends/neighbours/acquaintances

with a nameable other with direct contact,

high with own family/household members 
3.b. by the environment - where?

low public places/transport: e.g. in the bus, train, car,...

moderate at work/network (house of friends/family/parental home) health care setting

high at home, also: in the garden, in the garage, ...

3.c. by the activity - what are you doing? goal-orientedness?

low doing nothing/resting/sleeping/sitting, ...

transport: passive, being in a car as a passenger, public transport,...

moderate leisure: sports, needlework, playing with children, tinkering, lingering at table, talking with visitors,...

active transport: riding a bicycle, driving a car,...

high work/care for others or environment/maintenance activitics e.g., cooking, making coffee, reparing, filling in tax form, ... 2 
Appendix 4 Interrater agreement on codings for situations

Cohen's

unweighted

Kappa

type of situation

solitary situations

intimate situations

personal situations

anonymous situations with significant others

anonymous situations without significant others

else

transition

yes

no

acknowledgement by other people

low

moderate

high

acknowledgement by the environment

low

moderate

high

acknowledgement by the activity

low

moderate

high 


\section{Appendix 5 Individualized complaints}

A. Individualized complaints of patients with panic disorder (number of patients $=64$; number of complaints $=128$ )

anxiety/fear/panic

being afraid/frightened/anxious

panic

dominating anxiety, as if I am not myself

fear of having cancer/an illness

fear of having an heart attack

fear of dying

fear of fainting

fear of going out, going on the street

fear of being alone

fear of social contact

nervousness

feeling tense/tension

nervousness/restlessness

physical complaints related to panic/anxiety

pain on the chest/twinges in the chest

constriction in the chest

palpitations

missing heart beats

hyperventilation

tightness

shortness of breath

superficial respiration

dizziness

feeling of fainting

vomitting/nausea

bitter taste

abdominal pain/stomach complaints

shaking/trembling

troubles with seeing/hearing

tingles

being constrained

sweating

other psychological complaints

troubles concentrating, day-dreaming

feeling depressed, miserable, sullen, seeing no way out

feeling homesick

worrying about work/pressure of work

worrying about health

unable to stop harrasing thoughts 
other physical complaints

headache

pressure in the head/a stunned feeling in the head

pain in the legs/back

tiredness

B. Individualized complaints of patients with other diagnoses (neurotic controls) (number of patients $=19$; number of complaints $=38$ )

anxiety/fear/panic

anxiety/being anxious

anxiety on unexpected moments/at unforeseen circumstances 2

fear of being locked up

anxious when alone

fear of dying/having an illness

fear of contamination

fear of shopping

nervousness

feeling tense/nervous

feeling insecure, restless and pull at hair insecurity, uncertainty and imbalance

feeling unreal under tension

hysical complaints related to panic/anxiety

heart palpitations

pressure on the chest

shortness of breath

feeing oppressed and dizzy

stomach complaints/cramps

shaking/trembling

feeling shivery

troubles with eyes

blushing

other psychological complaints

controlling behavior

feeling depressed

ther physical complaints

pressure/pain in neck and head

tensed muscles in neck and upper part of the body

pain in back, arms and legs

tired/exhausted

general physical malaise

having a cold 
the data

To study the dynamic relationship between panic experiences and situational factors the data were considered as arising from $384=64$ (the number of subjects) $\times 6$ (the number of days) independent replications of a discrete time stochastic process observed at 10 time points (ESM signals). Observations collected at the time of each ESM signal were considered to be representative for the total time block of 90 minutes containing the signal. Individual differences are reflected in diagnostic and demographic characteristics of the subject. Given the assumption of independence, the observed data can be represented as:

$(\operatorname{Si}(\mathrm{t}), \mathrm{Yi}(\mathrm{t}), \mathrm{Di}: \mathrm{i}=1,2, \ldots, 384 ; \mathrm{t}=1,2, \ldots, 10)$;

$\mathrm{Si}(\mathrm{t}) \quad$ stands for a number of categorical situational factors in replication $\mathrm{i}$ at time $\mathrm{t}$. Each categorical variable is represented by a relevant number of dummy variables (0-1 coding).

$\mathrm{Yi}(\mathrm{t})$ is an indicator variable indicating with 1 or 0 whether or not a panic experience was observed in replication $i$ at time $t$.

Di stands for diagnostic and demographic characteristics of the subject determining replication $i$, each variable again being represented by the relevant number of dummy $(0-1)$ variables.

Actually, $S$ and $Y$ should depend on a subject index $j$, on a day of the week index $k$ and on an index for the number of the ESM signal t. Given the independence assumption stating that the experiences of a subject on a given day are independent of the experience of the subject on the previous day and on future days, we combined index $\mathrm{j}$ and index $\mathrm{k}$ into index $\mathrm{i}$ (see below for checks of the independence assumption).

\section{the model}

In order to describe evolving sequences of panic experiences in a day, we decided to focus on transition probabilities and to study the dependence of these transition probabilities on a number of 'fixed' factors (diagnostic and demographic characteristics of the subject) and a number of time dependent factors (situational factors).

The dependence of the transition probabilities

$\mathrm{P}_{\mathrm{ab}}(\mathrm{t})=\mathrm{P}(\mathrm{Y}(\mathrm{t})=\mathrm{b} \mid \mathrm{Y}(\mathrm{t}-1)=\mathrm{a})$ with $\mathrm{a}, \mathrm{b}=0$ or 1

on diagnostic, demographic and situational factors was modeled through logistic regression, i.e. the logit transform of the transition probabilities is a linear function of the diagnostic, demographic and situational factors and their possible interactions:

$P_{01}(t)=\exp \left(\beta_{0}+\beta_{1} D+\beta_{2} S(t)\right) / 1+\exp \left(\beta_{0}+\beta_{1} D+\beta_{2} S(t)\right)$

$\mathrm{P}_{11}(\mathrm{t})=\exp \left(\beta_{0}+\delta_{1} \mathrm{D}+\delta_{2} \mathrm{~S}(\mathrm{t})\right) / 1+\exp \left(\beta_{0}+\delta_{1} \mathrm{D}+\delta_{2} \mathrm{~S}(\mathrm{t})\right)$

(we have dropped the index $\mathrm{i}$ to avoid clutter) 
As possibly $\delta_{1} * \beta_{1}$ and/or $\delta_{2} * \beta_{2}$ we can have $\mathrm{P}_{01}(\mathrm{i}, \mathrm{t}) * \mathrm{P}_{11}(\mathrm{i}, \mathrm{t})$ depending on the value of $\mathrm{D}$ or $\mathrm{S}(\mathrm{t})$. The two formulas above can be summarized in one formula, and this was used to fit the model:

$P(Y(t)=1 \mid Y(t-1), D, S(t))=$

$\exp \left(\beta_{0}+\beta_{1} D+\beta_{2} S(t)+\beta_{3} D Y(t-1)+\beta_{4} S(t) Y(t-1)\right)$

$1+\exp \left(\beta_{0}+\beta_{1} D+\beta_{2} S(t)+\beta_{3} D Y(t-1)+\beta_{4} S(t) Y(t-1)\right)$

If $Y(t-1)=0$, we get $P_{01}(t)$ and taking $Y(t-1)=1$ gives $P_{11}(t)$ with $\delta_{1=} \beta_{1}+\beta_{4}$ and $\delta_{2}$ $=\beta_{2}+\beta_{4}$.

We have fitted models with and without interactions. The model with interactions includes interaction terms of factors with the factor diagnosis (panic disorder with or without agoraphobia) and provides more detailed information on the relationship between the diagnosis and the probability of observing a specific transition in panic experiences. Due to the large number of missing values (see below), only interactions with diagnosis were studied. The choice for interactions with diagnosis is self evident. The inclusion of interaction terms in the model was studied using a step-up procedure on all possible relevant interactions after forcing (if necessary) main effects into the model. The analyses were done using BMDP (Dixon, 1990) and GLIM (Payne, 1986).

The assumption of independence mentioned above was partially tested by including a factor weekday and/or interaction terms of weekday with diagnostic and demographic variables in the model. As far as missing data and sparse data permitted, tests for these effects were in general not significant, $p>.05$. This indicates that presumably there are no periodic effects. Also no significant clustering of panic experiences at specific times of the day was observed.

\section{missing values}

Statistical analysis was complicated by the many missing values for time dependent variables (panic experiences and situational factors) and by large individual variations in daily life behavior. The final model reported here was based on 2071 of the $64 \times 6 \times 9=3456$ possible units $(60 \%)$. The data file includes 64 (subjects) $\times 6$ (days) $\times 10$ (ESM signals), i.e. 3840 possible units. Within each day, however, only 9 transitions can be studied. Therefore, the total number of possible transitions is $64 \times 6 \times 9=3456$. All analyses reported here were done using only complete records (listwise deletion).

Because of the large number of missing values, the main model without interaction terms was also analysed using the EM algorithm for dealing with missing values (brahim, 1990). The results were roughly comparable to the results using only complete records so that further (time consuming and costly) analysis using the EM algorithm was not pursued.

Nevertheless, the missing data are clearly not missing at random as missing values cluster at the beginning and end of days (see also section 4.4.2). This means that all statistical analyses reported here are biased and that care must be taken when interpreting results. 
Due to this large number of missing values it was not possible to study the dependence of transition probabilities on panic experiences lagged more than one time unit (i.e. at earlier points in time $t-2, t-3$, etc.) or on situational characteristics at these earlier points in time. This means that the analysis gives only a partial picture of the dynamic interrelationships of a subject's experiences during a day.

A further consequence of the large number of missing values is the large number of cells of the multidimensional contingency table defined by the data matrix with only very few or zero observations. This results in estimates of parameters and standard errors being somewhat inflated. This entails caution in making judgements on absolute sizes of effects. However, this does not invalidate a cautious qualitative interpretation of the results.

results

Both models (with and without interactions) described the data adequately. For the model without interaction terms with diagnosis, the Hosmer-Lemeshow (1989) goodness of tit pvalue was 0.68 and for the model including interaction terms with diagnosis it was 0.30 . However, as judged by residuals and other diagnostics, the model including interaction terms with diagnosis accounted much better for individual differences in subjects behavior.

Estimates of the regression coefficients, standard errors, odds ratios and p-values for the model with interactions are to be found in table A.1. Only the estimates of regression coefficients for interactions with diagnosis having a significant effect on the predictability of panic experiences are given.

Using the estimates in table A.l and a given set of values of $\mathrm{Y}(\mathrm{t}), \mathrm{Y}(\mathrm{t}-1), \mathrm{D}$ and $\mathrm{S}(\mathrm{t})$ for a given ESM signal at time $t$, the transition probabilities $P_{01}(t)$ and $P_{11}(t)$ can be calculated using the formula:

$P(Y(t)=1 \mid Y(t-1), D, S(t))=$

$\exp \left(\beta_{0}+\beta_{1} D+\beta_{2} S(t)+\beta_{3} D Y(t-1)+\beta_{4} S(t) Y(t-1)\right)$

$1+\exp \left(\beta_{0}+\beta_{1} D+\beta_{2} S(t)+\beta_{3} D Y(t-1)+\beta_{4} S(t) Y(t-1)\right)$

These transition probabilities describe the likelihood of observing a panic experience at a specific point in time given the diagnostic and demographic characteristics of a subject, given the characteristics of the situation and given the presence or absence of a panic experience at the preceding ESM signal.

Comparing these probabilities for subjects having different demographic and diagnostic characteristics and/or being in different situations demonstrates the influence of demographic, diagnostic and situational factors on the occurrence of panic experiences. The results of these comparisons have been described in section 7.3 . 
table A.1.

Estimates and standard errors (s.e.) of logistic regression coefficients and odds ratios for situational, demographic and diagnostic factors in the model with interactions

factor

estimate s.e. odds ratio p-value

constant

diagnosis (with agoraphobia)

age 2 ( 32 to 38 years)

age 3 (39 years or older)

sex (female)

marital status (married)

family life (not alone)

employment (employed)

moderate acknowledgement others

high acknowledgement others

moderate acknowledgement environment

high acknowledgement environment

moderate acknowledgement activities

high acknowledgement activities $\begin{array}{lll}-0.34 & 0.84 & 0.71\end{array}$

$\begin{array}{lll}-2.57 & 1.14 & 0.08\end{array}$

.024

$\begin{array}{ll}-2.41 & 0.37\end{array}$

$-1.99 \quad 0.35$

$0.09)<.001$

$-0.99 \quad 0.42$

0.14

$\begin{array}{ll}-1.74 & 0.49\end{array}$

0.37

0.18

5.52

1.71

0.81

0.92

0.42

$-0.96$

$-1.02$

0.63

0.38

0.36

$-1.70$

0.40

0.18

$-0.77$

0.81

$0.46\}$

$-1.16$

0.46

0.27

$-1.33$

0.31

$0.31<.001$

.019

$<.001$

.035

.844

.022

.048

$0.26\}$

$1.49 \quad 0.46$

4.42

.001

$2.43 \quad 0.54$

$Y(t-1) *$ age 2 (32 to 38 years)

1.31

0.52

11.3

$<.001$

$\mathrm{Y}(\mathrm{t}-1) *$ age 3 (39 years or older)

1.58

0.65

$3.69\}$

$\mathrm{Y}(\mathrm{t}-1) *$ moderate acknowl. environment

1.39

0.51

4.86

.005

$\left.\begin{array}{rrrr}2.94 & 0.67 & 19.0 & <.001 \\ 2.67 & 0.59 & 14.4 & <.001 \\ -3.24 & 0.97 & 0.04 & <.001 \\ -1.30 & 0.62 & 0.27 & .035 \\ 0.98 & 0.81 & 2.66 \\ 1.94 & 0.54 & 6.96 \\ 3.05 & 0.98 & .001 \\ 1.64 & 0.61 & 5.15\end{array}\right\}$

diagnosis * sex (female)

diagnosis * marital status (married)

diagnosis * family life (not alone)

diagnosis * employment (employed)

diagnosis * moderate acknowl. others

diagnosis * high acknowledgement others

diagnosis * moderate acknowl. environment

diagnosis * high acknowl. environment 
It is also possible to compute absolute probabilities using estimates of regression coefficients. For example, a subject having a diagnosis of panic disorder without agoraphobia, who is female, unmarried, unemployed, living alone, 40 years old, who is in a situation with low levels of acknowledgement by other people, by the environment as well as by activities, and who had a panic experience at the previous ESM signal has a transition probability $P_{11}(t)$ that can be calculated as follows:

Firstly $x=-1.99-0.99+1.31=-1.67$

then $P_{11}(t)=e^{x} /\left(1+e^{x}\right)=0.19 / 1.19=.16$

The numbers are the estimates of the regression coefficients for the relevant variables and interactions in table A.1 (in this case: age 3, sex, $\mathrm{Y}(\mathrm{t}-1)^{*}$ age 3 ). For all other variables, this person is in the reference category, having code 0 , so that these variables give no contribution to the calculation of $\mathrm{P}_{\mathrm{II}}(\mathrm{t})$.

Computing transition probabilities given all possible combinations of demographic, diagnostic and situational factors and given the presence or absence of a panic experience at time $1-1$ entails a large amount of calculation and produces a long and complex list of probabilities, and therefore has not been attempted. But, based on the estimates of the regression coefficients, one can compute the probability of observing specific sequences of panic experience in any subject having specific demographic and diagnostic characteristics and being in a specific type of siluation. 


\section{Dankwoord}

De Nederlandse Organisatie voor Wetenschappelijk Onderzoek (NWO) en de Rijksuniversiteit Limburg, mijn werkgevers, dank ik voor het creëren van de basisvoorwaarden voor het uitvoeren van het onderzoek. Drs. H. Pommerantz, directeur van de RIAGG Maastricht, Drs. R. Hoekstra, coördinator van de Geacademiseerde Sectie Gedragstherapie van de afdeling Psychotherapie van de RIAGG Maastricht, Dr. E. Griez en Dhr. J. Peeters, respectievelijk hoofd en coördinalor van het Academisch Angstcentrum van het Psychomedisch Streekcentrum Vijverdal Maastricht, dank ik omdat zij het mogelijk maakten om in deze settings de benodigde onderzoeksgegevens te verzamelen. De medewerkers van beide teams dank ik voor de prettige - zij het soms veeleisende - samenwerking. In het bijzonder dank ik Dr. A. Amtz, Drs. O. Sollet, Mw. H. Keijsers en Mw. A. Demmers voor hun bijdrage tijdens de fase van gegevensverzameling. De patiënten van het Academisch Angstcentrum en de Geacademiseerde Sectie Gedragstherapie, evenals de proefpersonen van de controlegroep, ben ik dank verschuldigd, omdat zij meewerkten aan een onderzoek dat een week lang de nodige inspanning vereiste. Zonder de zorgvuldigheid waarmee zij menige vragenlijst invulden, was dit proefschrift niet geschreven.

Prof. Dr. M.W. deVries, deelprojectleider en promotor, en Dr. H.F. Kraan, clusterleider en co-promotor, dank ik voor hun deskundige begeleiding en voor hun medewerking aan publicaties, die voortvloeiden uit dit onderzoek. Een woord van dank past ook de leden van de beoordelingscommissie voor hun positief oordeel over dit proefschrift, en in het bijzonder Prof. Dr. J. Bremer voor de nuttige aanwijzingen om de laatste puntjes op de $i$ te zetten. De medewerkers van het deelproject STEP, en in het bijzonder Drs. Ph. Delespaul en de leden het 'sad' (somatisatie-angst-depressie) cluster, dank ik voor hun constructieve bijdragen tijdens verschillende fasen van dit onderzoek. Verder dank ik hen, die als belangrijke gesprekspartners fungeerden en op die manier mede richting gaven aan het onderzoek: Prof. Dr. F. Massimini, Dr. A. Delle Fava, Prof. Dr. R. Larson, Prof. Dr. C.D. Kaplan, Dr. K. van Meter, Prof. Dr. H. Reis en vele anderen.

$\mathrm{Bij}$ het verwerken van de gegevens is het advies en de hulp van statistici onmisbaar gebleken. Dr. T. Imbos dank ik voor zijn adviezen met betrekking tot de Mokken-analyses. Drs. A. Volovics ben ik dankbaar voor zijn eindeloos geduld en doorzettingsvermogen, die ontegensprekelijk nodig waren om te komen tot een nauwkeurige beschrijving van een complex gegevensbestand. Marcel Theunissen en Diana Riksen dank ik voor hun bijdrage aan het uitvoeren van de analyses. Natasja van de Weg dank ik voor haar medewerking aan de betrouwbaarheidsanalyses van het codeersysteem in het kader van een wetenschapsstage. Technische assistentie kreeg ik van Peter Sieben. Zijn beheer van de apparatuur bij de vakgroep Sociale Psychiatrie heeft het labeur van de tekstverwerking veel aangenamer gemaakt. Hem dank ik tevens voor zijn bijdrage aan het drukwerk van dit proefschrift. Patricia Hermans-Heynen dank ik voor het typen van de concept-literatuurlijst. Trees Soute en Marie-José Duchateaux dank ik omdat ze bereid waren als contactpersonen te blijven fungeren na mijn vertrek bij de vakgroep Sociale Psychiatrie. 
Danken wil ik ook mijn paranimfen Carolien Dijkman en Greet Amauts. Carolien heeft als onderzoeksassistente een niet geringe bijdrage geleverd aan het coderen en archiveren van gegevens en het verzamelen van literatuur. Haar opleiding tot vertaler kwam goed van pas bij het opsporen van taalfouten in de tekst van dit proefschrift. Greet dank ik voor een jarenlange vriendschap (volgens dit proefschrift belangrijke stap in de vrouwelijke socialisatie).

Dit brengt me bij de mensen buiten de werksfeer, die ben belangrijke rol spelen in miln privé-leven, een prettige thuisbasis vormen en een stimulans voor mijn studies en werk betekenen. In het bijzonder dank ik Wim, omdat hij altijd in woord en in daad de stelling heeft onderschreven dat het hebben van een baan, die de nodige inzet vraagt (om nng maar te zwijgen over het schrijven van een proefschrift) niet te verenigen is met een traditionele rolverdeling. Mijn ouders ben ik dankbaar voor het mogelijk maken van mijn studies en meer recentelijk voor hun praktische hulp in drukke tijden. Bovendien dank ik Wim, kleine Gilles, familie en vrienden niet alleen omdat ze de 'werkende mens' in me steunen, maar vooral omdat de 'spelende en liefhebbende mens' in hun bijzijn zo goed tot haar recht komt. 


\section{Curriculum vitae}

Chantal Dijkman-Caes werd op 7 juni 1959 geboren te Etterbeek-Brussel (Belgiē). Hitar middelbare schoolopleiding (Modeme Humaniora, Wetenschappelijke B) volgde zij in het Mariadal Instituut te Hoegaarden. Vanaf 1976 studeerde zij psychologie aan de Katholicke Universiteit Leuven. In 1982 behaalde zij (met onderscheiding) de graad van licenciaat in de kinische psychologie, specialisatie volwassenen. Van 1983 tot 1992 was zij als wetenschappelijk medewerker/universitair docent verbonden aan de vakgroep Sociale Psychiatrie van de Rijksuniversiteit Limburg. In 1990 behaalde zij het 'European Certificate in Anxicty Disorders' (Erasmus-programma Maastricht/Caen). Sinds 1 september 1992 is rij als docent werkzaam bij de Dienst Opleidingen van het Academisch Ziekenhuis Maastricht. 
